NIELS GANZER

ORTHODONTIC ANCHORAGE WITH MINISCREWS

Towards new possibilities

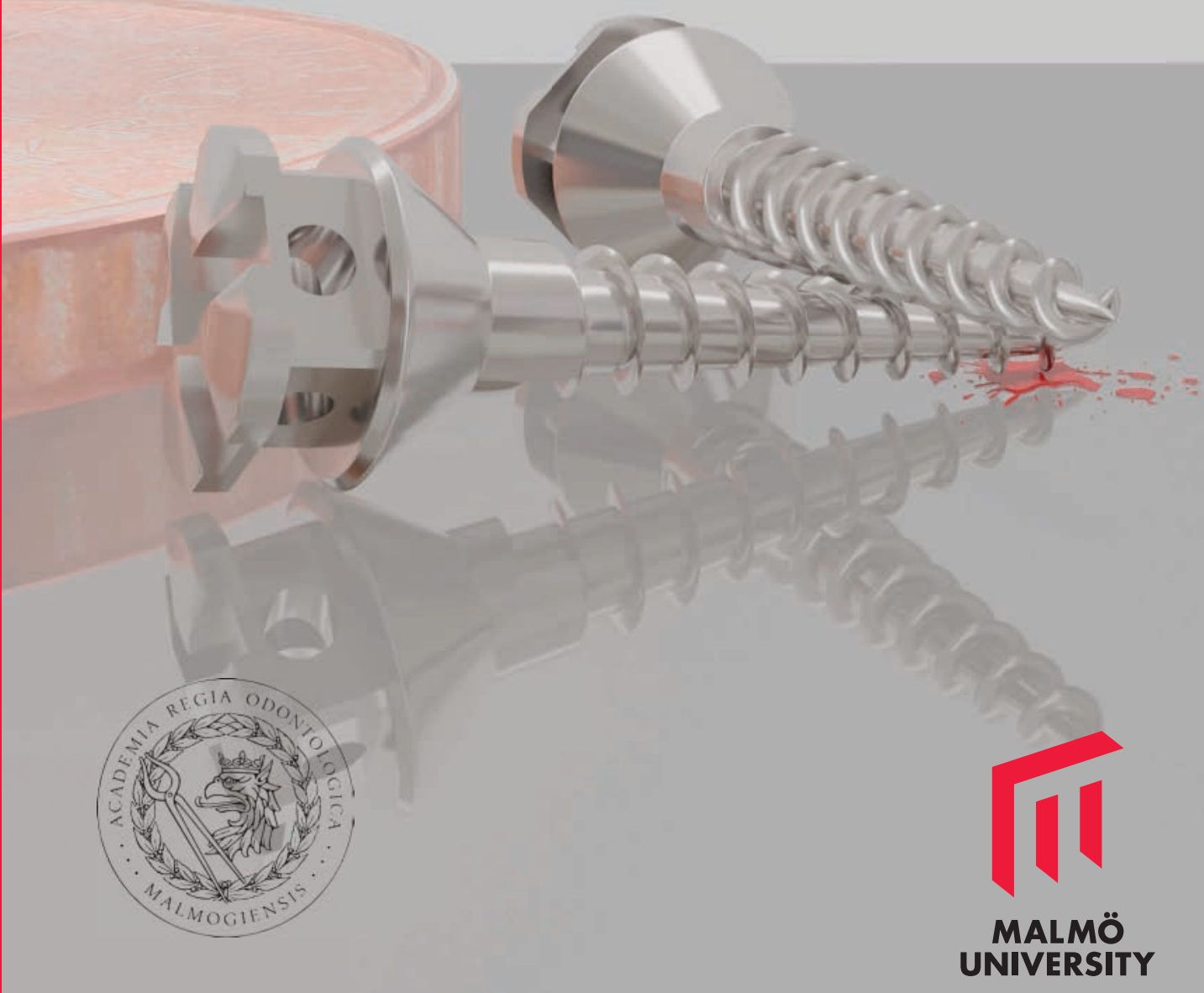





$$
\text { - }
$$


Malmö University, Faculty of Odontology Doctoral Dissertations 2018

(C) Niels Ganzer, 20I 8

Illustrations: Niels Ganzer

ISBN 978-9I-7I04-93 I-5 (print)

ISBN 978-9I-7I04-932-2 (pdf)

Holmbergs, Malmö 2018 


\section{NIELS GANZER \\ ORTHODONTIC ANCHORAGE WITH MINISCREWS}

Towards new possibilities

Department of Orthodontics Faculty of Odontology, Malmö University, Sweden Orthodontic Clinic, Region Gävleborg Gävle, Sweden, 2018 
This publication is also electronically available at: https://muep.mau.se/handle/2043/25610 
To Franziska, Frida \& Max 



\section{PROLOGUE}

Every day I meet young people who receive some kind of orthodontic treatment. Every day these young people impress me with their courage, endurance and motivation. When treatment starts, most of these patients are children. By the time we remove their braces, they have become young adults. My team and I are proud to be a small part of this exciting journey. It is a privilege to meet these adolescents and I am grateful that 80 of these adolescents said "yes" when I asked them to participate in my research project involving inserting screws into their jawbone. Thank you! 



\section{CONTENTS}

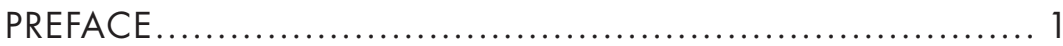

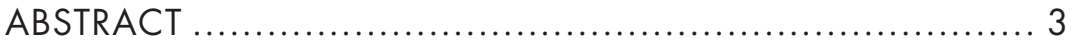

SUMMARY IN SWEDISH .................................. 5

INTRODUCTION ............................................... 7

Skeletal anchorage ..................................................... 12

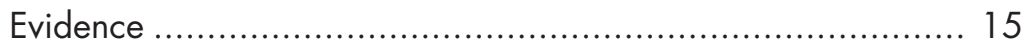

Measurement technique of tooth movements ...................... 17

Clinical implications and importance ............................... 20

AIMS \& HYPOTHESIS ........................................... 21

MATERIALS AND METHODS .............................. 23

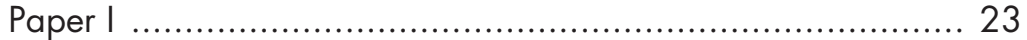

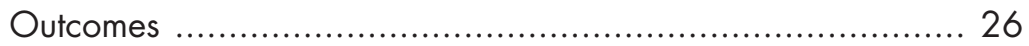

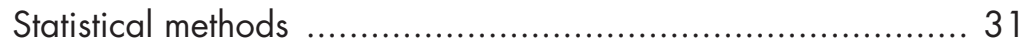

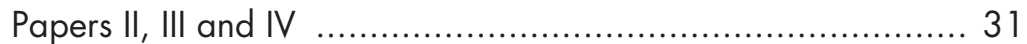

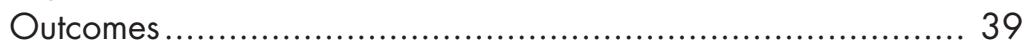

Statistical methods .......................................................... 42

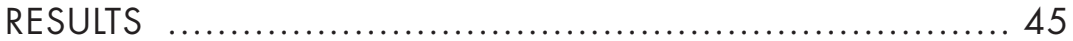

Paper I - Validity and reliability .......................................... 45

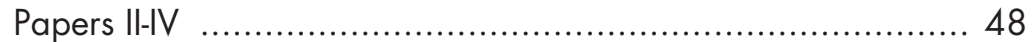

Pain \& discomfort (Paper II) .......................................... 50

Anchorage capacity (Paper III) ............................................ 56

Cost-effectiveness analysis (Paper IV) .................................. 60

Harms and side effects (Paper II-IV) ...................................... 63 


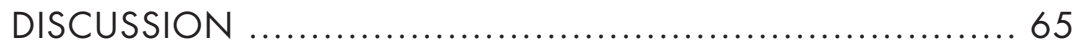

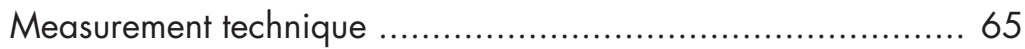

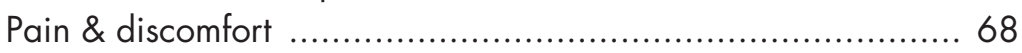

Anchorage capacity \& movement characteristics ................. 70

Cost-effectiveness ............................................................. 72

Overall limitations of this thesis .......................................... 75

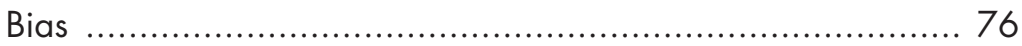

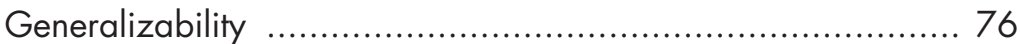

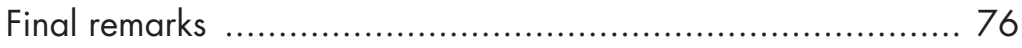

CONCLUSIONS ............................................. 79

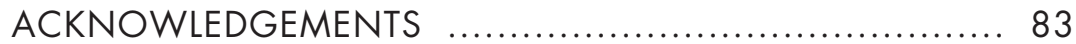

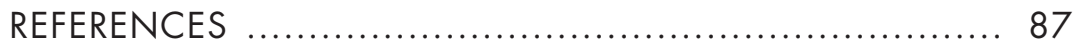

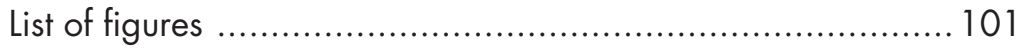

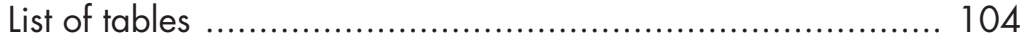

ABBREVIATIONS ............................................. 107

APPENDIX ...................................................... 109 


\section{PREFACE}

This thesis is based upon the following four papers, referred to in the text by their Roman numerals.

I. Ganzer N, Feldmann I, Liv P, Bondemark L. A novel method for superimposition and measurements on maxillary digital 3D models - Studies on validity and reliability. Eur J Orthod. 2018;40(1):45-51.

II. Ganzer N, Feldmann I, Bondemark L. Pain and discomfort following insertion of miniscrews and premolar extractions: A randomized controlled trial. Angle Orthod. 2016;86(6):891-899.

III. Ganzer N, Feldmann I, Bondemark L. Anchorage reinforcement with miniscrews and molar blocks in adolescents: A randomized controlled trial. Accepted for publication in Am J Orthod Dentofacial Orthop.

IV. Ganzer N, Feldmann I, Petrén S, Bondemark L. A cost-effectiveness analysis of anchorage reinforcement with miniscrews and molar blocks in adolescents: A randomized controlled trial. Eur J Orthod. e-published ahead to print 21 June 2018.

All papers are reprinted with the kind permission from the copyright holders and are appended to the end of this thesis. 



\section{ABSTRACT}

An orthodontic appliance functions within a complex system of forces and moments. The challenge in orthodontics is to control these forces and moments in a way that only the target tooth moves. Unwanted tooth movements can be avoided by controlling forces and moments using anchorage reinforcements.

Over the last decade, anchorage reinforcement using small screws (i.e., miniscrews) in the jawbone has become an indispensable part of orthodontic treatment. Several studies have evaluated the functional aspects of these miniscrews, but few studies have evaluated the health economics associated with the treatment and how patients experience the treatment. Systematic reviews suggest that miniscrews provide good anchorage reinforcement. However, miniscrews come in different lengths, diameters and materials. These different miniscrews are used in many insertion sites that have different forces and constructions. This heterogeneity of the data is a limitation in the current reviews, so more research is needed that evaluates specific miniscrews used for specific indications.

To fill this gap in knowledge, this thesis compares buccal miniscrews used as direct anchorage with conventional anchorage reinforcement using molar blocks. In addition to investigating technical details such as anchorage capacity, this thesis investigates the cost-effectiveness of the treatment and how patients experience the treatment.

This thesis is based on four studies. Paper I presents a novel technique for superimposition and measurement of tooth movements in the maxilla. This technique uses digital three-dimensional (3D) models and is based on an algorithm that enables the evaluation of serial models where shape and size of the maxilla have changed due to growth and orthodontic treatment. This technique was 
transferred to the dental field in an interdisciplinary approach. This paper also tested validity, inter-rater reliability and test-retest reliability.

Papers II, III and IV are based on a multi-purpose randomized controlled trial with two parallel arms and a 1:1 allocation ratio. The intervention arm was treated with miniscrews as anchorage reinforcement, and the active comparator was treated with molar blocks. The sample consisted of 80 participants (11 to 19 years old). Paper II evaluated the patients' experiences of pain and discomfort when miniscrews were inserted. These results were compared with the pain associated with premolar extractions. Paper III evaluated the anchorage capacity of miniscrews and molar blocks by analyzing the movement of maxillary first molars. Tooth movements were assessed with the novel measurement technique presented in Paper I. Paper IV analyzed the cost-effectiveness of miniscrews and molar blocks treatments.

The following conclusions were drawn:

- The new method utilizing raw-, fine-matching and deformation analysis, RFD-superimposition, is a valid tool for measuring tooth movements in the maxilla. Both the inter-rater and test-retest reliability were excellent. In addition, RFDsuperimposition can be used to analyze treatment effects in adolescent orthodontic patients.

- Miniscrew insertion caused less pain and discomfort compared to premolar extractions, especially on the evening after and at the one-week follow-up.

- The use of miniscrews in adolescents was well tolerated and can be recommended with accurate anesthetization.

- Miniscrews provided superior anchorage capacity. They can be used in cases where loss of anchorage would jeopardize the treatment results.

- Molar blocks did not provide sufficient anchorage reinforcement.

- The cost-effectiveness analysis showed that miniscrews provided good anchorage reinforcement but also that treatments were significantly more expensive. 


\section{POPULÄRVETENSKAPLIG SAMMANFATTNING}

Vid tandreglering används spiralfjädrar och elastiska drag som skapar krafter för att kunna flytta på tänderna. När en kraft placeras på en tand uppstår enligt fysikens lagar en lika stor motriktad kraft. Den motriktade kraften behövs oftast inte utan ska ledas undan eller förankras. Förankring vid tandreglering kan exempelvis utföras genom att en ståltråd fäster ihop flera kindtänder till ett molarblock. Ett molarblock behöver därför en mycket större kraft innan det flyttar på sig jämfört med en enstaka tand. I vissa situationer är behovet av förankring mycket stort och en lovande teknik är då att sätta in miniskruvar i käkbenet.

Emellertid saknas bevis för hur effektiva miniskruvarna är för förankring och det finns också kunskapsluckor om hur patienterna upplever att få miniskruvar insatta i käkbenet. Dessutom saknas analyser om hur kostnadseffektiva behandlingar med miniskruvar är.

I en unik serie av studier på 80 ungdomar jämförs förankringskapaciteten och kostnadseffektiviteten mellan molarblock och miniskruvar samt undersöks hur ungdomarna upplever behandlingarna. I avhandlingen analyseras också tillförlitligheten av en ny tredimensionell metod för att mäta tandförflyttningar. Den nya mätmetoden utvecklades i en tvärvetenskaplig ansats grundad på en teknik som härstammar från glaciärforskningen. 
Avhandlingens viktigaste slutsatser är att:

- den nya mätmetoden (RFD-superponering) har utmärkt noggrannhet och precision och kan användas för att tredimensionellt beräkna tandförflyttningar vid tandreglering.

- att sätta miniskruvar i käkbenet orsakar låg smärta och litet obehag för patienterna och betydande mindre smärta och obehag jämfört med en tandutdragning som är ett rutiningrepp i tandvården. Ur perspektivet smärta och obehag kan därför miniskruvar rekommenderas som förankring vid tandförflyttning.

- miniskruvar producerar utmärkt förankring och kan rekommenderas vid tandreglering speciellt då förankringsbehovet är stort.

- molarblock skapar ingen acceptabel förankring och kan därför inte rekommenderas vid tandreglering.

- Utvärdering av kostnadseffektiviteten visar att behandling med miniskruvar ger enastående förankring men behandlingarna blir betydligt dyrare. Av kostnadsskäl ska miniskruvar enbart användas då förankringsbehovet är stort. 


\section{INTRODUCTION}

"Of the many improvements in the methods of tooth regulation perhaps none have been greater than the modern devices for securing anchorage" 1

Written by Edward Hartley Angle over a hundred years ago, this statement remains accurate. Securing anchorage to control unwanted tooth movements has been a concern from the very beginning of orthodontics.

Orthodontic appliances use active elements such as coil springs, elastics and steel ligatures to move teeth. These active elements are attached to the teeth to be moved and to an anchor unit. Most often, this anchor unit consists of other teeth. The active elements deliver forces, equal in size but opposite in direction, both to the teeth to be moved and to the anchor unit. Because the force applied on the anchor unit can cause unwanted tooth movements, the challenge with orthodontics is to move only the teeth targeted for movement. For this reason, anchorage reinforcement is an important way to control these unwanted effects. Anchorage can be reinforced in many ways.

Angle described using the larger root surface of the anchor teeth to overcome the resistance of the moving teeth as Simple anchorage. Simple anchorage can be achieved by enlisting the resistance of other teeth in the same arch. ${ }^{1}$ The more teeth that are connected, the less likely unwanted tooth movement will occur. ${ }^{2}$ This technique relies on the assumption that every tooth's anchorage value fairly correlates to its root surface (Figure 1). ${ }^{3} \mathrm{~A}$ larger root surface implies that a larger force or more bone remodeling is required to move teeth. ${ }^{4}$ 


\section{$\begin{array}{lllllll}431 & 433 & 220 & 234 & 273 & 179 & 204\end{array}$}

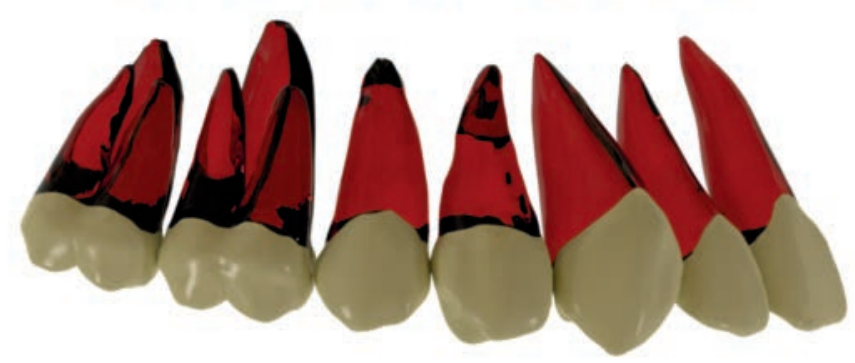

Figure 1: Root surface per tooth in square millimeters as reported by Jepsen $1963 .^{3}$

A very convenient way to reinforce anchorage is to connect teeth in a near location to an anchorage block using a stainless-steel ligature. ${ }^{5}$ This block is called molar block when the second molar is added to the appliance tightly connected to the first molar. In cases where the first premolar is extracted, also to the second premolar is added to the molar block. Due to the larger root surface, this molar block can theoretically withstand much greater forces than single teeth (Figure 2).

The advantages are that a molar block can be inserted in minutes, it does not involve the work of a dental technician and uses inexpensive materials. However, anchorage has three dimensions. A molar block is assumed to maintain anchorage reinforcement in the anteroposterior direction and may have limited effect on the vertical direction. In the transversal direction the molar block has no effect. There is very limited to no evidence about the anchorage capacity of molar blocks.
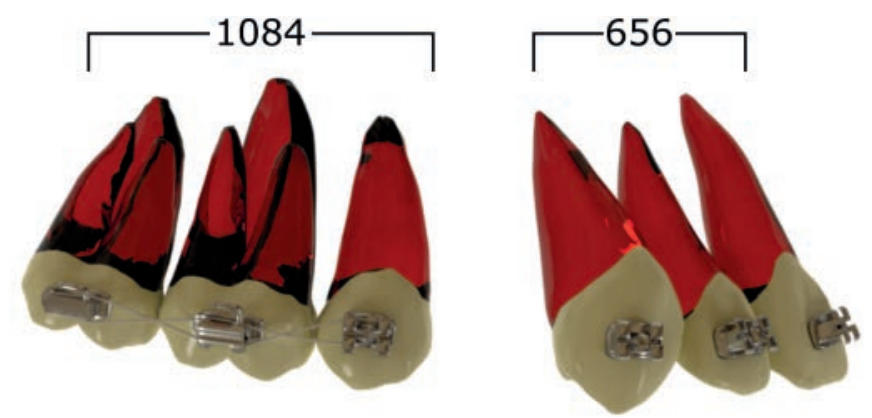

Figure 2: Molar block's root surface compared to the frontal teeth in square millimeters. 
Another approach to create anchorage is to connect teeth with rigid arches. Depending on the design, this can be a transpalatal arch (Figure 3). The rigid fixation locks the transversal distance and can in theory even maintain the molar position in the anteroposterior direction. However, a recently published review reported that anteroposterior anchorage reinforcement with these methods is insufficient. ${ }^{6}$

Additional anchorage reinforcement can be achieved when the palatal arch is combined with a Nance appliance (Figure 4). Characteristic for the Nance appliance is the acrylic button covering the anterior part of the hard palate. However, randomized controlled trials indicate that even with a Nance appliance anchorage loss has to be expected. ${ }^{7,8}$ Furthermore, is the Nance appliance less comfortable for the patient ${ }^{8}$ and it is associated with complications like tissue necrosis under the acrylic button. ${ }^{9}$

Rigid arches are in general manufactured by a dental technician, requiring two or three visits for impressions and cementing of the bar. These techniques are therefore time consuming and costly.

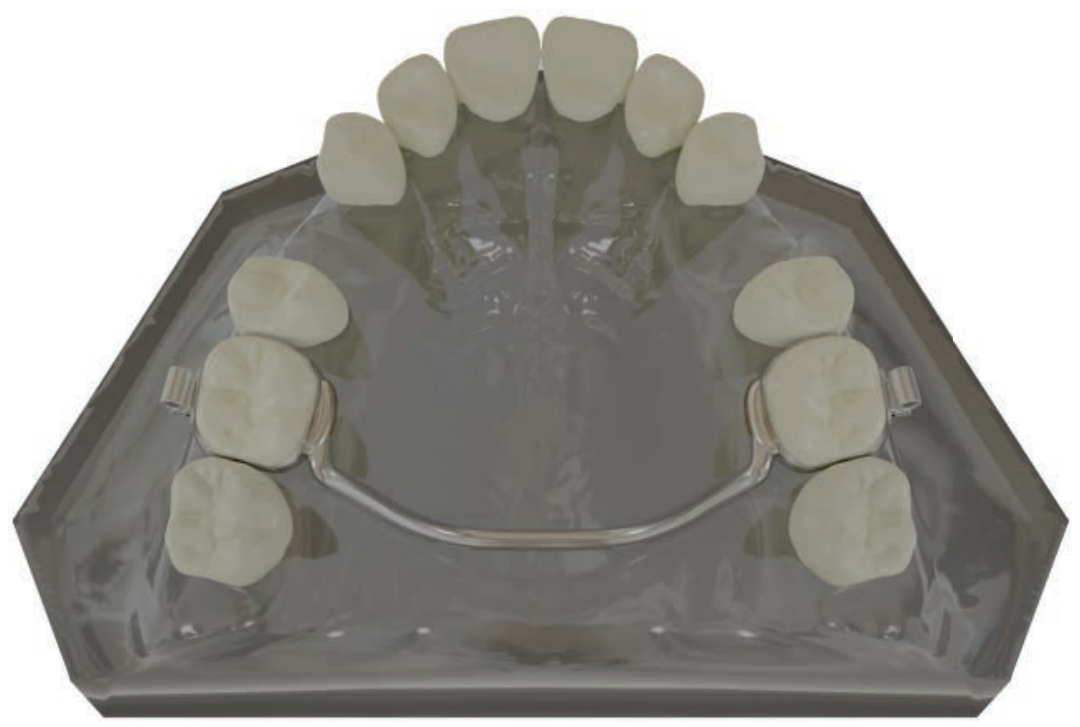

Figure 3: Transpalatal arch connecting the maxillary first molars. 


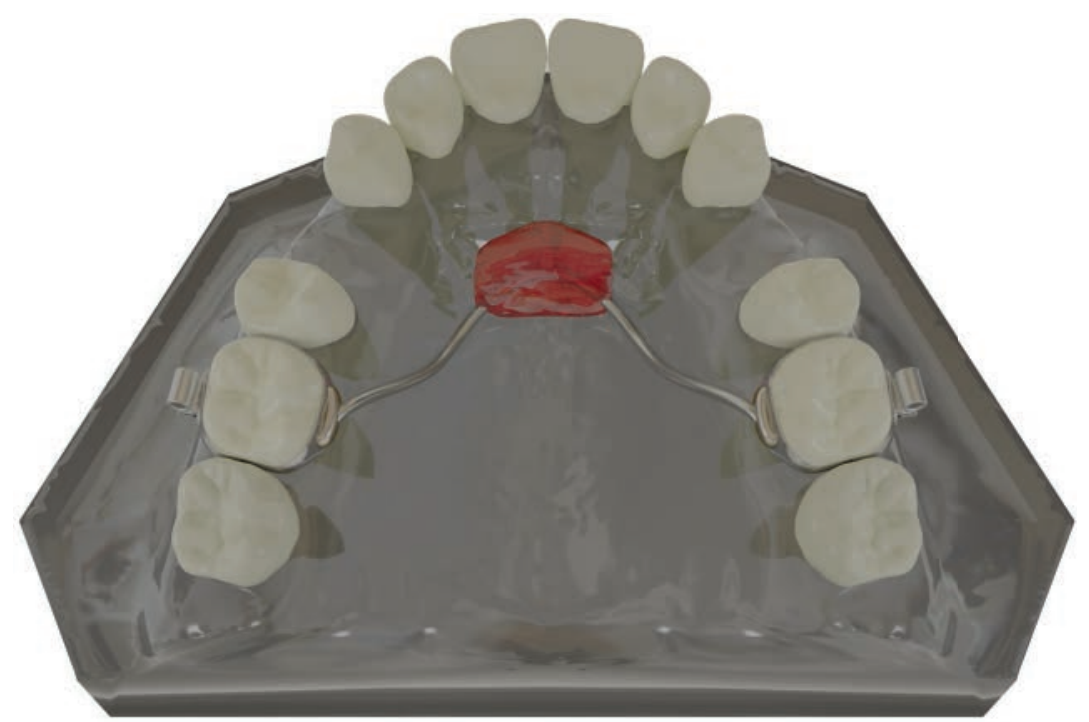

Figure 4: Nance appliance with acrylic button (red) connecting the maxillary first molars.

It can be assumed that as long as the anchorage construction is tooth borne, these teeth will move to some degree. Therefore, headgear is a viable alternative method for anchorage reinforcement. A headgear consists usually of a facebow that attaches to bands on the maxillary first molars (Figure 5). The facebow is anchored with a head cap and a neck strap to the back of the head (Figure 6).

The headgear is an extra dental source of anchorage that can deliver outstanding anchorage reinforcement. Furthermore, can the headgear not only be used to maintain tooth positions but can also be used to move the maxillary molars distally with less risk of anterior anchorage loss. ${ }^{10}$

The only drawback to headgear is that it requires the patient to co-operate consistently (i.e., headgear needs to be worn 10 to 12 hours seven nights a week). ${ }^{11}$ Compliance with these instructions is difficult to predict, ${ }^{12}$ and patients often overestimate duration of wear. ${ }^{13}$ Cole et al. ${ }^{14}$ reported that approximately one-third of their patients did not accurately report how much they used the headgear. A randomized controlled trial found anchorage reinforcement to be insufficient in almost $50 \%$ of the cases treated with the headgear. ${ }^{15}$ 


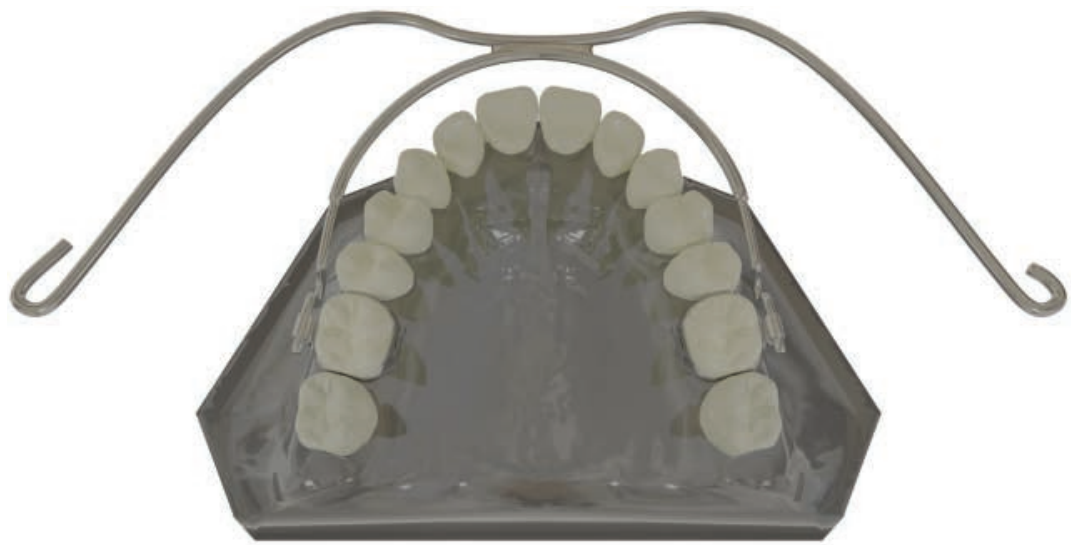

Figure 5: Facebow attached to the maxillary first molars.

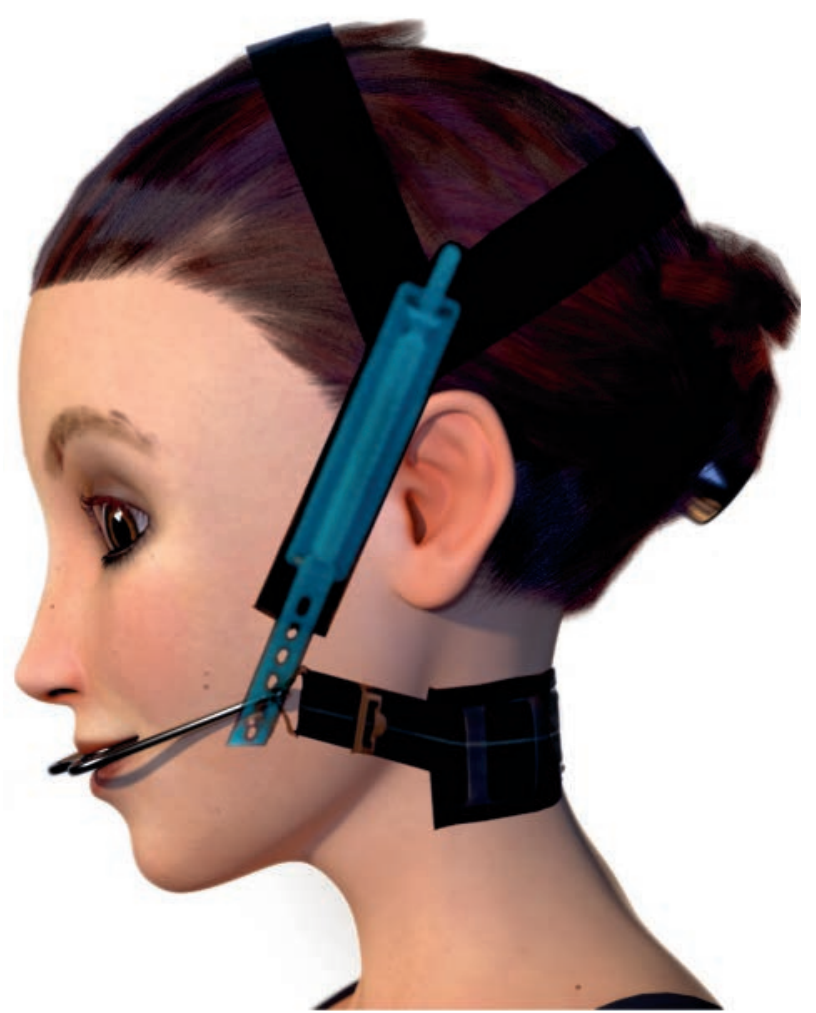

Figure 6: Straight pull headgear with head cap and neck band.

"Own work based on the Sintel lite character, $(1)$ copyright Blender Foundation, www.sintel.org, published under Creative Commons Attribution 3.0 CC-BY. 
Due to the insufficient anchorage capacity of tooth borne constructions and the co-operation dependency of the extra oral anchorage reinforcement, a new method has been developed that uses the jawbone as a source of anchorage. As an anchorage unit now can be inserted in jawbone rather than on moving teeth, and patient co-operation is no longer required. Indeed, skeletal anchorage was nothing less than a revolution in orthodontics.

\section{Skeletal anchorage}

\section{History}

The idea to implant metal objects into the human body is partly derived from research that was done after World War I. One of the researchers, René Le Fort, examined 100 patients with incorporated projectiles in their thorax. He found that a metal foreign body can be integrated into the tissues under certain circumstances. ${ }^{16}$ Even in these early days, the complexity of the healing reaction was known and Le Fort highlighted several factors that could play a role. These factors included the micro-flora, the injury caused by the projectile and the type of tissues surrounding the foreign body. However, even the shape and material of the foreign body could play a minor role. ${ }^{16}$

In the 1940s, bone anchors for orthodontic treatments were tested on animals. ${ }^{17}$ Gainsforth and Higley inserted Vitallium ${ }^{\mathrm{a}}$ screws into the mandibular ramus of six dogs. These screws were similar to the screws that were used for fixation of bone fractures. They had a diameter of $3.4 \mathrm{~mm}$ and were $13 \mathrm{~mm}$ long. The screws were immediately loaded with $160 \mathrm{~g}$ elastics that were attached to an appliance in the upper jaw (Figure 7). The researchers found that tooth movements could be achieved with this type of anchorage. However, all screws were lost within two or three weeks and the conclusion was that this concept could not warrant anchorage for orthodontic tooth movement. They believed that loosening of the screws was mainly caused by contact with the oral micro-flora. The use of intermittent force and the straight direction of the force were not discussed as factors for screw loss.

\footnotetext{
${ }^{a}$ Cobalt-Chromium-Molybdenum
} 


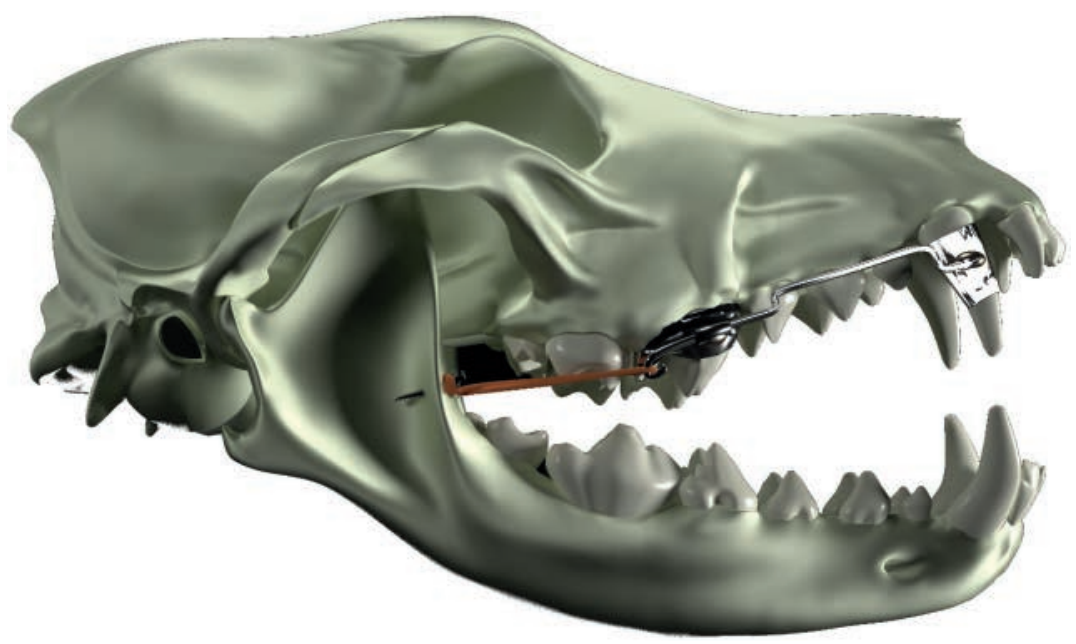

Figure 7: Apparatus used by Gainsforth and Higley in dogs as reported in 1945. ${ }^{17}$

*Own work based on the canis latrans model by Dimus, published under Creative Commons Attribution 3.0 CC-BY.

In the 1980s, a different concept was tested on animals: implants as skeletal anchorage in orthodontics. ${ }^{18,19}$ This concept was based on implants similar to prosthetic implants. In 1990, Roberts et al. ${ }^{20}$ published the first case report of an osseointegrated implant used for space closure in a human.

During this time, orthodontic implants were custom-made items machined from titanium blocks. The insertion protocol included local anesthesia and intravenous sedation. The implant insertion surgery included elevation of a mucoperiosteal flap, pre-drilling of a pilot hole, enlargement of the pilot hole with round burs and finally insertion of a self-tapping screw. This screw was then covered with the flap for a closed healing phase. The surgery was followed by a five-day Penicillin V course. After several months of healing and osseointegration, the implant could be loaded with orthodontic forces. ${ }^{20}$

Since the size of the implant had to be congruent with the available bone, ${ }^{21}$ the use of full-size dental implants was restricted to the retro molar area or to pre-prosthetic treatments. Therefore, shorter and thinner orthodontic implants were developed: The Orthosystem used an implant with a diameter of $3.3 \mathrm{~mm}$ and a length of 4 or $6 \mathrm{~mm}$. Similar to dental implants, the surface was sandblasted and acid-etched to improve osseointegration. ${ }^{22}$ These 


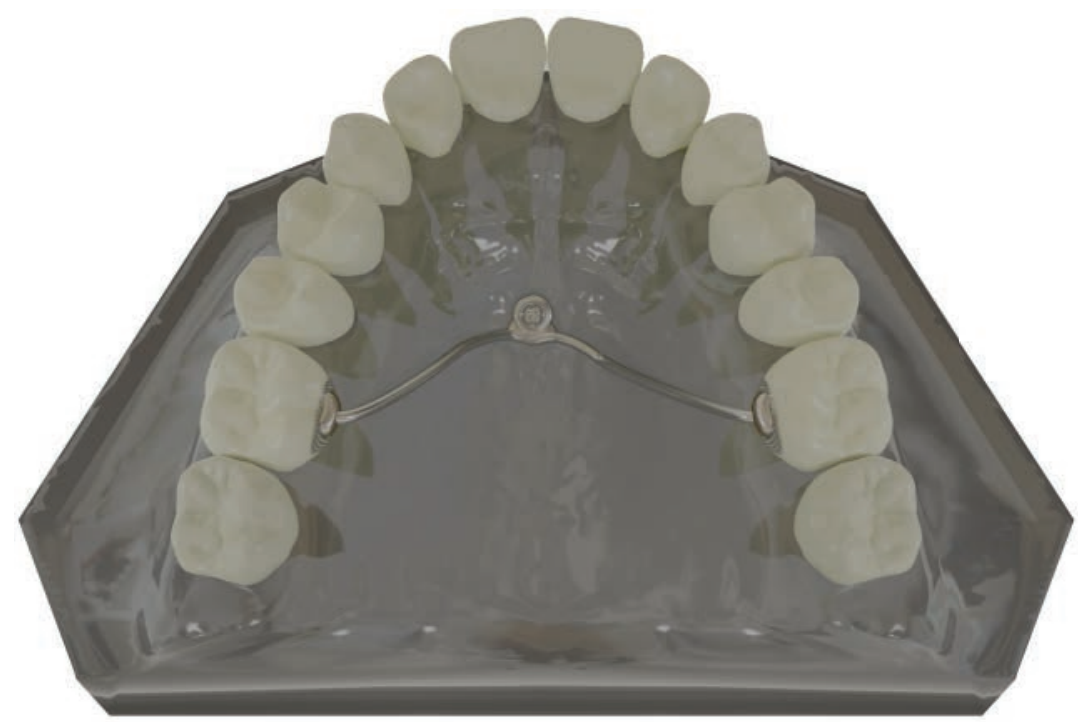

Figure 8: Rigid supra-construction mounted on an Orthosystem implant.

smaller implants could be inserted in the palate providing anchorage reinforcement to the whole maxilla via rigid supra-constructions (Figure 8). Insertion was conducted without flap preparation and using local anesthesia. ${ }^{22}$ The mid-sagittal area of the palate provides sufficient bone height for the Orthosystem implant. ${ }^{23}$

Onplant is another orthodontic skeletal anchorage device. ${ }^{24} \mathrm{An}$ Onplant did not screw into the bone. Instead it was planted between the bone and the periosteum. Thus, there was no need to drill a hole, but a mucoperiosteal tunnel had to be prepared. The Onplant is also used with a rigid supra-construction, anchoring different teeth or groups of teeth. Both the Onplant and Orthosystem implant provide good anchorage capacity. ${ }^{25}$ Experience of pain and discomfort after Onplant insertion is comparable to premolar extractions. However, in comparison to the Onplant, patients reported that pain levels were significantly lower after insertion of the Orthosystem implant. ${ }^{26}$

Osseointegration is one of the characteristics that dental implants, Orthosystem implant and Onplant have in common. Osseointegration means that the skeletal anchorage is meant to grow into the bone, rigidly anchoring in the bone. However, removal of an osseointegrated device requires additional surgery. 


\section{Contemporary skeletal anchorage}

The collective term for bone anchors is Temporary Anchorage Devices (TADs). TADs are temporarily fixed to bone to increase anchorage during tooth movement. ${ }^{27}$ TADs include the subcategories osseointegrated implants, onplants, zygoma wires, miniplates and miniscrews (Figure 9).

Contemporary miniscrews can be regarded as a crossover of surgical screws and dental implants. Thus, miniscrews unite a number of characteristic properties that make them different from surgical screws or osseointegrated implants: Miniscrews are placed transgingivally without need for flap preparation. Miniscrews rely mainly on mechanical stability. They can be immediately loaded with orthodontic forces up to $200 \mathrm{~g} .{ }^{28-31}$ Patients are recommended to use chlorhexidine for a couple of days after the surgery, ${ }^{30}$ but antibiotic administration is usually not indicated in healthy patients.

Contemporary miniscrews have a diameter of 1.2-2.3 $\mathrm{mm}$ and are $5-15 \mathrm{~mm}$ long. The thread design can be self-cutting or selftapping. ${ }^{32}$ Depending on the insertion site and the thread, a pilot hole may be needed, but in most cases it is not necessary. Miniscrews can be made of pure titanium, titanium alloy or stainless steel. ${ }^{32,33}$ Miniscrews are affordable and are easily inserted. Thus, miniscrews are considered an ideal anchorage system. ${ }^{30}$

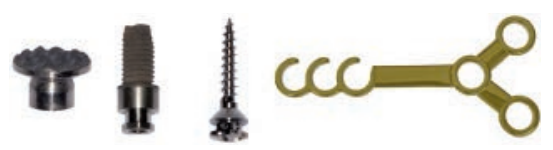

Figure 9: Contemporary TADs: Onplant, Orthosystem implant, Spider Screw ${ }^{\circledR}$ and y-type miniplate.

\section{Evidence}

Despite the fact that the concept to use screws as bone anchors and the concept to unite several teeth to an anchorage block are several decades old, there is little or limited evidence concerning the anchorage capacity, patients' perceptions and cost-effectiveness of these techniques. ${ }^{34,35}$ 


\section{Anchorage capacity}

The literature indicates moderate evidence that miniscrews can provide good anchorage reinforcement. ${ }^{35}$ Recent reviews have reported the success rate for miniscrews to be 83.6 to $86.5 \% .^{36-38}$ At the same time, general conclusions have to be drawn with caution because of the heterogeneity of the data. This heterogeneity is caused by the variety of concepts, including different screw types, insertion sites and loadings. Consequently, more research is needed that investigates miniscrews used for specific indications in specific insertion sites and compares miniscrews to conventional techniques.

\section{Patients' perception}

Fleming et al. ${ }^{39}$ recently published a report that analyzed all randomized controlled trials (RCT) during a three-year period from eight leading international dental journals. They found that patient-centered measures rarely were the primary outcome measure. They concluded that there is an undue emphasis on technical aspects. It is known from the literature that any orthodontic procedure can cause immediate or delayed pain and discomfort. ${ }^{40}$ However, the evidence concerning pain and discomfort related to treatment with miniscrews is very limited.

Based on the few available trials, it can be concluded that patients expect buccal placement of miniscrews to be more painful than it is. ${ }^{41,42}$ Headgear seems to be more troublesome than miniscrews. ${ }^{7}$ Furthermore, there appears to be no difference in patients' acceptance between self-drilling screws and screws that require a pilot hole. ${ }^{43}$ Significantly higher pain levels are reported after flap surgery or soft tissue punching. ${ }^{42,44}$ These findings, however, do not provide any guidance about when to use miniscrews or conventional systems.

Many trials about patients' perceptions lack a control group. Control groups are particularly important when evaluating a reference procedure. The reference procedure can be used to relate survey outcomes to other orthodontic treatments. As premolars are often extracted when there is a lack of space or increased overjet, ${ }^{45}$ this can serve as a reference procedure. ${ }^{46}$ Using data from tooth extractions as a reference has been found to be useful in earlier randomized controlled trials within our research group. ${ }^{26}$ 


\section{Cost-effectiveness}

The evidence concerning health economics of orthodontic interventions is generally insufficient. ${ }^{47}$ Since resources are limited in many governmental funded health service systems, data on costeffectiveness is crucial to prioritize treatments. ${ }^{48}$ These priorities can be determined using many different analyzes. When the interventions to be compared are different in their effect size, a costeffectiveness analysis can be used to determine which treatment provides the best value.

Apart from cost-effectiveness, the most interesting question is opportunity costs. ${ }^{49}$ When resources are limited, the introduction of a new treatment consumes resources that will be cut for other treatments. Consequently, estimating opportunity costs will enable stakeholders to determine which treatments to sacrifice in favor of a new treatment. In this context it is recommended to use relevant comparators to gain cost-effectiveness information about existing treatments. ${ }^{50}$

\section{Measurement technique of tooth movements}

To evaluate the miniscrews anchorage capacity, it is crucial to map how the teeth move during treatment. Tooth movement can be evaluated with measurement techniques using lateral cephalograms. ${ }^{51,52}$ Lateral cephalograms are then taken before and after treatment and a superimposition is performed. Depending on the superimposition technique, different reference structures can be used. Finally, tooth movements are measured by comparing a tooth's position before and after treatment.

Lateral cephalograms are a proven diagnostic tool in orthodontics. However, in addition to radiation exposure, this technique has several other disadvantages. Since the images are two-dimensional, rotations or transversal changes are not measurable. Further more, there are a number of error sources during acquisition of the lateral cephalograms. A trial comparing four different superimposition techniques reported mean differences of up to $0.83 \mathrm{~mm}$ with a standard deviation of $3.70 \mathrm{~mm}$ for measurements on lateral cephalograms. ${ }^{53}$ Thus, the measurement error for these techniques can be regarded high. 
An alternative to lateral cephalograms is to measure tooth movements on study casts. However, even this technique depends on superimposition of reference structures. Already when gypsum study casts were used, the palatal rugae were discussed as reference landmarks (Figure 10). ${ }^{54}$

Today, gypsum study casts are rapidly replaced by digital threedimensional (3D) scans. These scans can be taken directly in the mouth or can be derived from plaster casts. Measurements on single 3D scans have been proven to be valid and reliable. ${ }^{55-61}$ By using 3D scans taken before and after treatment, tooth movements can be analyzed in all three dimensions. Superimposition of 3D scans is usually based on so called matching techniques. Matchings can be differentiated in Raw-matchings giving a coarse alignment manually selected reference points and Fine-matchings based on best-fit procedures. ${ }^{62}$

Different techniques for superimposition of 3D scans have been proposed:

- Best-fit matching of the central-anterior part of the palate (blue mushroom) ${ }^{63}$

- Best-fit matching of the whole palate ${ }^{64}$

- Miniscrew as reference landmarks ${ }^{65}$

- Manual selection of the rugae with weighted factors for different points ${ }^{66}$

- Manual selection of a number of reference points in the palate $^{67}$ 


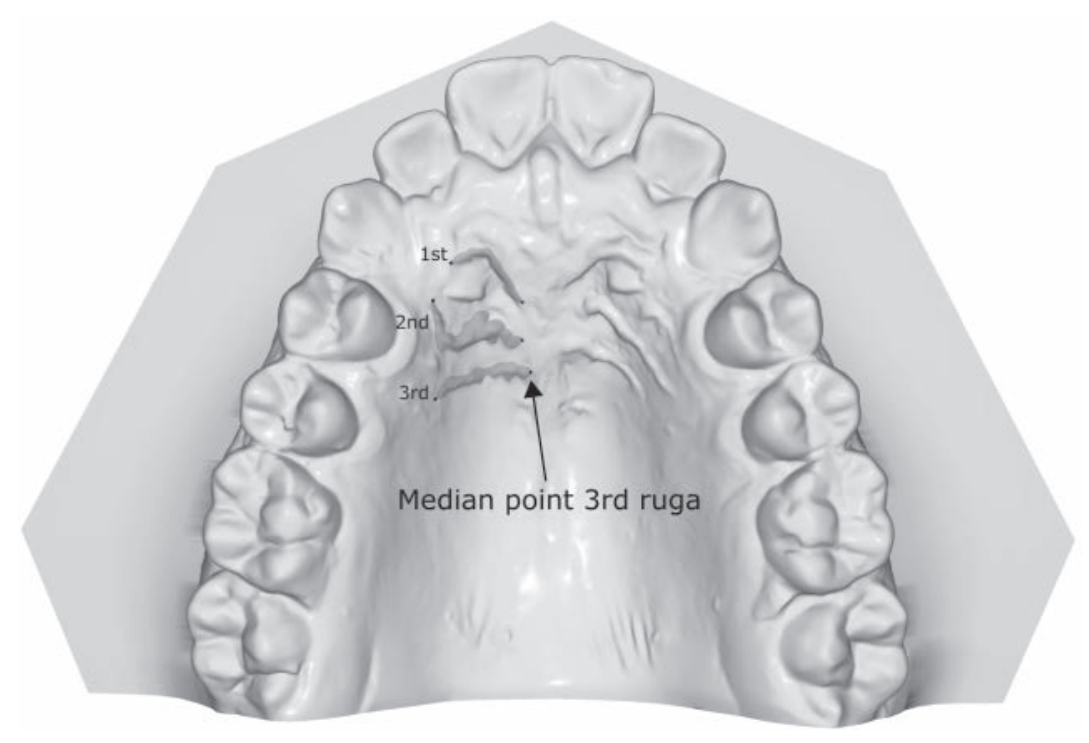

Figure 10: Palatine rugae on maxillary $3 D$ model.

Validations are usually are conducted on 3D scans that are identical in the palate. The typical orthodontic patient, however, is a growing patient (i.e., a teenager). Although not $100 \%$ stable, the palatal rugae and surrounding area (Figure 10) are proposed as reference landmarks. In particular, the median point of the third pair of rugae is reported to be the least unstable. ${ }^{54,65,68,69}$ The palatal height, however, changes several millimeters during the pubertal growth spurt and even in adult patients. ${ }^{70,71}$ Thus, growth or treatment effects can compromise the superimposition. The vertical dimension appears to be especially troublesome in its correct superimposition. ${ }^{69,72}$

A new superimposition approach that possibly can handle morphological changes in the palate is a superimposition technique that was originally developed for long-term monitoring of changes in glaciers. For this purpose, a glacier's surface is regularly scanned with airplane-mounted laser scanners. Superimposition of these scans has the same challenging conditions as superimposition of the palate - no structures are stable. Therefore, an algorithm is used to detect unchanged areas and to use only these areas for superimposition. ${ }^{73,74}$ 
Because this process follows the three steps Raw matching, Fine matching and Deformation analysis, it is named RFD-superimposition. This novel approach assumes that no structure is stable through the whole long-term observation period. Instead, the algorithm detects individual reference structures for each pair of scans.

Furthermore, RFD-superimposition can handle variations in local point resolution, can differentiate morphological changes from outliers and uses multiple techniques for sample size reduction. This superimposition approach and measurement technique were transferred to the dental field and validity and reliability had to be estimated before using it to measure anchorage capacity.

\section{Clinical implications and importance}

In Sweden, every year approximately 100000 children are born. Of these children, approximately $30 \%$ receive some kind of orthodontic treatment. Orthodontic treatment is to two-thirds carried out at specialist clinics.

Among the children who are referred for orthodontic treatment, approximately $50 \%$ have a malocclusion that includes crowding and more than $10 \%$ have an overjet of $6 \mathrm{~mm}$ or more. ${ }^{75}$ This means that every year approximately 10000 Swedish children can potentially be treated with miniscrews or molar blocks.

This thesis will add to the knowledge about orthodontic treatment of these cases. Skeletal anchorage and other anchorage reinforcements can be used when lack of space or increased overjet are treated. In a time when the demand for orthodontic treatment has increased, evidence-based allocation of limited resources is essential. Therefore, we need to know more about treatment effects, patients' perceptions and costs.

In addition, if the RFD-superimposition is applied, lateral cephalograms are not needed for evaluation of tooth movements in the maxilla, a benefit that also limits patient exposure to $\mathrm{X}$-ray radiation. 


\section{AIMS \& HYPOTHESIS}

This doctoral thesis is based on a multi-purpose randomized controlled trial (RCT). The RCT consisted of three sub-studies (Papers II, III, and IV), each with their own aims. In addition, a new measurement technique was introduced and validated (Paper I). This measurement technique was then used to evaluate treatment results. The specific aims and hypothesis for each paper are listed below.

\section{Paper I}

The first paper introduces and validates a new technique to measure tooth movements using digital 3D models. The paper's hypothesis is that this technique can be used for superimposition and measurements in growing patients with minimal measurement error.

\section{Paper II}

The second paper investigates how adolescent patients experience pain and discomfort associated with the insertion of miniscrews. The paper's hypothesis is that the insertion of miniscrews causes less pain than the extraction of premolars.

\section{Paper III}

The third paper evaluates the anchorage capacity of miniscrews compared to molar blocks. The paper's hypothesis is that miniscrews deliver anchorage capacity better than molar blocks although molar blocks are capable of certain anchorage reinforcement. 


\section{Paper IV}

The fourth paper compares the costs of miniscrews and molar blocks as anchorage reinforcement. The further, it was investigated whether the use of miniscrews reduces treatment costs compared to molar blocks. The paper's hypothesis is that miniscrews are more cost-effective than molar blocks. 


\section{MATERIALS AND METHODS}

For this thesis, two samples were used. The first sample, used in the validation study (Paper I) was derived from an earlier trial about anchorage reinforcement. ${ }^{15}$

The second sample was prospectively collected at the Orthodontic clinic in Gävle, Sweden. This sample consisted of 80 participants. All participants received orthodontic treatment and the evaluation of these treatments is presented in Paper II-IV.

\section{Paper I}

The sample consisted of plaster casts prepared for an earlier trial about anchorage reinforcement. ${ }^{15}$ This trial was comparable in its inclusion criteria, age and gender distribution to the sample used for Papers II-IV. From this sample, the required number of pretreatment models was randomly selected. Selection followed a random list generated by an independent person from the Center for Research and Development Uppsala University / Region Gävleborg using the programming language R. ${ }^{76}$

The required sample size was estimated assuming the withincase standard deviation to be between 0.12 and $0.2 \mathrm{~mm}$ as reported by Choi et al. ${ }^{64}$, the between-case standard deviation to be $0.75 \mathrm{~mm}$ and the intra class correlation (ICC) to be between 0.93 and 0.96. The null hypothesis was that the ICC is equal to 0.80 . Calculation using the ICC.Sample.Size package in the programming language $\mathrm{R}^{76}$ revealed that 16 cases were needed to reach $80 \%$ power with an anticipated ICC of 0.95 . 


\section{Ethical considerations}

The trial protocol and informed consent were approved by Uppsala University's Research Committee, Uppsala, Sweden (Dnr. 02192). Written informed consent was retrieved from all patients and their parents.

\section{The Insufficient Gold Standard Dilemma}

The term gold standard describes a method that measures a certain variable with perfect accuracy. In reality, methods considered gold standards often fall short of perfect accuracy. When a gold standard has low accuracy, then this deficiency will limit the validation of a superior method. ${ }^{77}$ Therefore, we decided not to use $T_{0}$ and $T_{1}$ models from real cases to validate the RFD-superimposition against measurements on lateral cephalograms. The measurement error of techniques such as the methods according to Ricketts ${ }^{52}$ or Pancherz ${ }^{51}$ can be of clinically relevant magnitude. Instead, we chose a setup that enabled us to compare measurement results with true values.

\section{Reference models}

The pre-treatment plaster casts from all 16 cases were digitized with a 3D scanner system that had been validated in earlier studies (R700 Desktop Scanner, 3Shape, Copenhagen, Denmark). ${ }^{78,79}$ These pre-treatment scans served as $\mathrm{T}_{0}$ models. Then a $\mathrm{T}_{1}$ model (reference model) was produced by an independent computer engineer who used the $T_{0}$ model as a template for the $T_{1}$ model (Figure 11). Starting from $T_{0}$, teeth were moved to simulate orthodontic treatment. Finally, the palate's width and height were changed to simulate growth. The result of this process was a set of $16 \mathrm{~T}_{1}$ models where the true tooth movement was known to the computer engineer. In this way, the results could be compared to true values. 

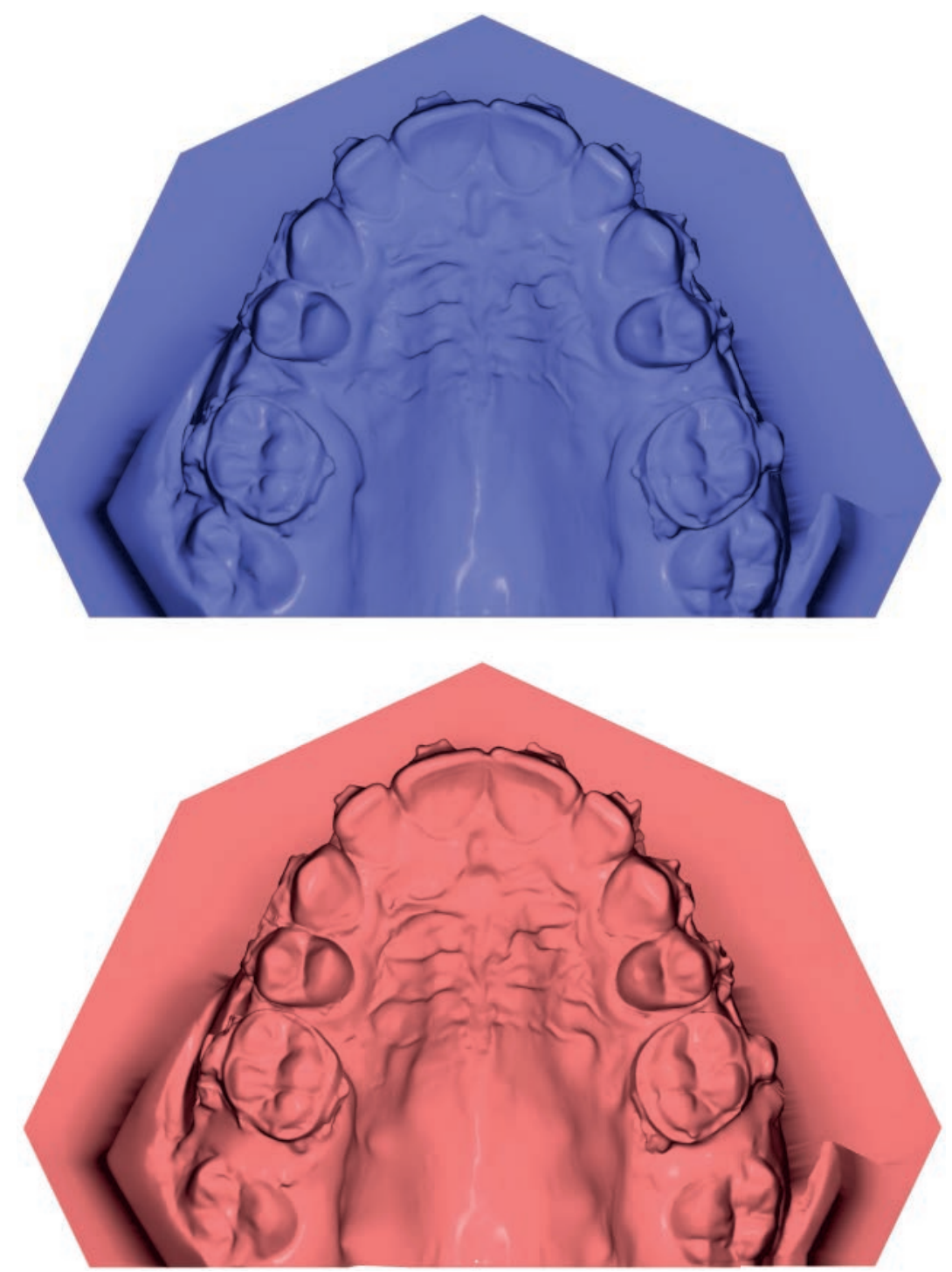

Figure 11: Start model (blue) and reference model (red). 


\section{Outcomes}

The primary outcome was movement of the maxillary first molar defined as translation and rotation according to the axes of the 3D coordinate system. The local coordinate system was aligned so that transversal changes were represented by the $\mathrm{x}$-axis, anteroposterior changes by the $y$-axis and vertical changes by the $\mathrm{z}$-axis. Tooth movement was assessed as the difference in the tooth position in the start model and the reference model. The resulting movement was then calculated as: $d=\sqrt{\left(x^{2}+y^{2}+z^{2}\right)}$

After thorough instructions and an initial training program, four senior consultant orthodontists independently conducted superimpositions and measurements for all 16 cases. Repeated superimpositions and measurements were performed by all four observers on all 16 cases after at least two weeks. Superimposition and measurement took about ten minutes per case.

\section{Blinding}

The assessors were blinded for the true value before and during measurements.

\section{Superimposition}

Superimposition overlays an image of one object over the image of another object, a technique referred to as matching. During a matching process, there is always one object with a fixed position (master) while the other object (slave) is moved to achieve proper object overlay. When the matching uses as many corresponding points as possible from a given reference structure, it is referred to as best-fit matching. Best-fit matching is usually based on an Iterative Closest Point algorithm (ICP). However, there are hundreds of different ICP implementations. ${ }^{80}$ RFD-superimposition uses point-to-surface ICP implementations in the raw matching and fine matching. Basically, RFD-superimposition combines three techniques: Raw matching, Fine matching and Deformation analysis.

Raw matching: Raw matching coarsely aligns the two 3D models in the coordinate system. This step creates optimal conditions for fine matching. Raw matching is conducted by manually choosing six corresponding points on both models. These correspond- 


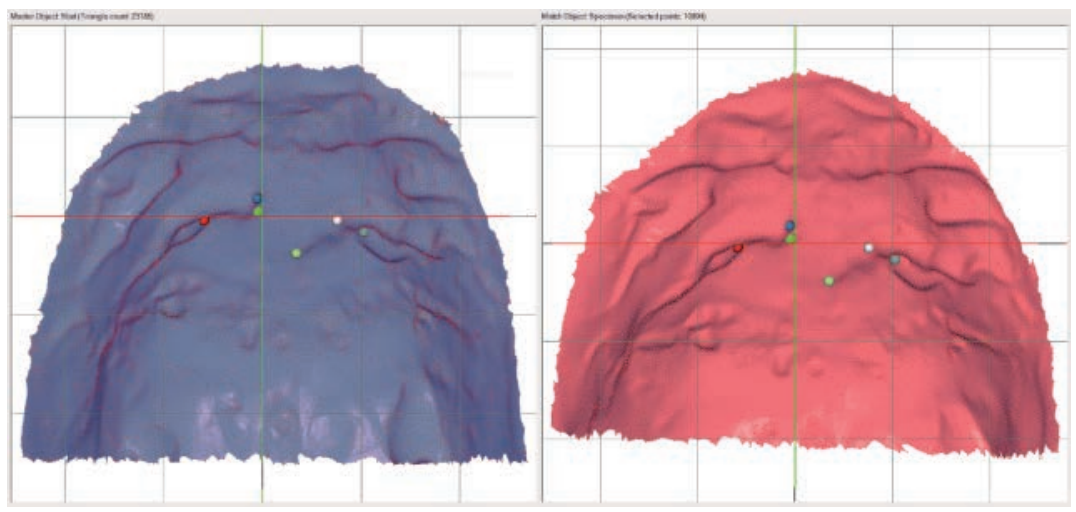

Figure 12: Palatal vault of start (blue, master model) and reference model (red, slave model) with corresponding reference points.

ing points are individually chosen for each case. Since the median point of the third rugae is the most stable area, the corresponding points are preferably found close to this area (Figure 12).

Fine matching: Fine matching puts the models in an optimal position so that the Deformation analysis can be used to filter out morphological changes. In Final Surface ${ }^{\circledR}$, a point to triangle best-fit method is used for fine matching. In contrast to a pointto-point matching, every point from the slave object is matched on a corresponding surface from the master object. Therefore, this technique has some tolerance and is less sensitive to variations in the local point resolution. Furthermore, the number of included points is limited to 1000 and the software automatically uses the best $90 \%$. The number of repetitions is controlled by the convergence method. This method repeats the fine matching until a level of agreement between the matching objects of $0.000001 \mathrm{~mm}$ is reached. Alternatively, if the level of agreement could not be reached, the matching is stopped when 50 repetitions are reached.

Deformation analysis: The purpose of the Deformation analysis is to detect areas that have changed shape. ${ }^{74}$ The Deformation analysis is based on the Iterative Closest Proximity algorithm (ICProx). ${ }^{73}$ The ICProx algorithm filters all areas that have a different shape between the two models. Only the unchanged areas are used as reference for the matching. To do this, the algorithm 
puts a grid of candidate points onto the master model. Then the median distances between the candidate points and their adjacent points are calculated and a surface with a radius of that distance is created around the candidate point. This surface is called the habitat. Another set of candidate points is then created on the slave model. Every candidate point from the slave model is matched to the corresponding habitat on the master model. This point-to-surface technique gives a robust tolerance against variations in point resolution.

When the highest possible resolution is selected, every single point of the model is calculated. However, this method takes a long time and outliers influence results. The resolution of the matching objects is reduced by two mechanisms:

- The collector parameter subdivides the model into small cubes. From every cube, only one candidate point is collected.

- The filter parameter combines several collector cubes into one filter cube. Then, for every candidate point within the filter cube, the distance to the corresponding habitat is calculated. All filter cubes where these distances exceed a certain threshold are interpreted as cubes with morphological changes and are excluded from the matching.

Increasing the number of repetitions (i.e., iterations) is a way to improve accuracy. For every repetition, the result is a little more exact, giving better conditions for the next repetition. In this way, the distances between the corresponding points and the habitats are stepwise minimized. However, when two objects have a different shape, they cannot be matched with $100 \%$ congruence. Then, from a certain point, the matching result is not further improved by additional repetitions. Since every repetition requires time for calculation, it is crucial to choose as many repetitions as necessary although as few as possible. An edge length of $0.5 \mathrm{~mm}$ for the collector cubes and $1.5 \mathrm{~mm}$ for the filter cubes with 15 repetitions were found suitable in the test series (Figure 13).

Figure 14 depicts the distance analysis between the start model and the reference model after RFD-superimposition. The central part of the palatal vault was left unchanged during the production of the reference model. 


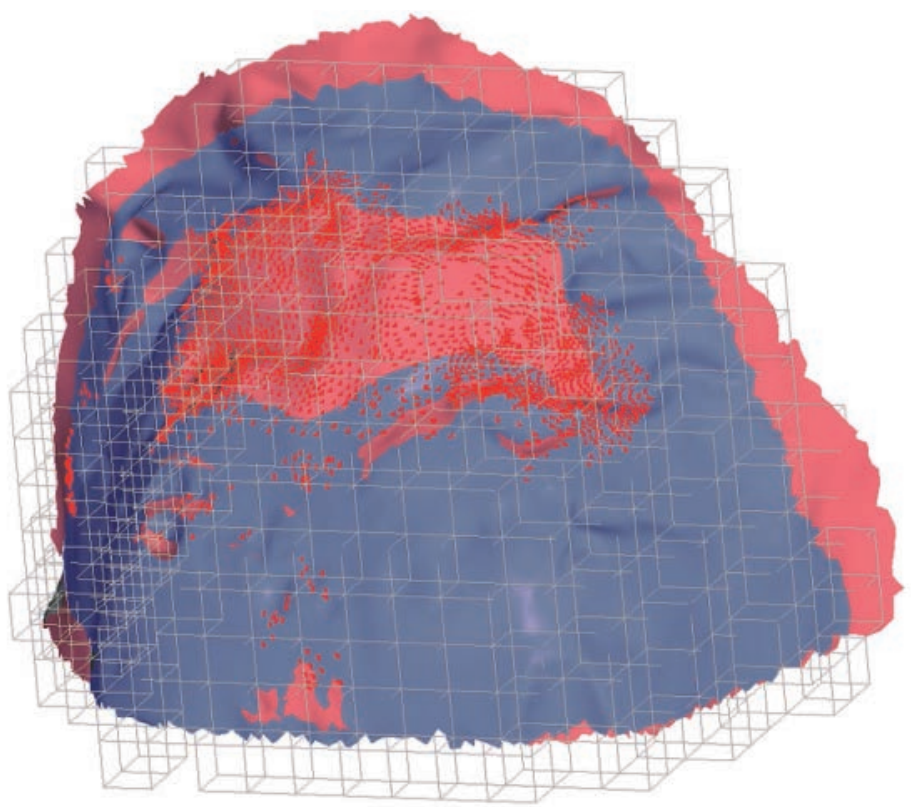

Figure 13: Palatal vault after deformation analysis. The grid of filter cubes is depicted in light grey. Used reference points are marked red.

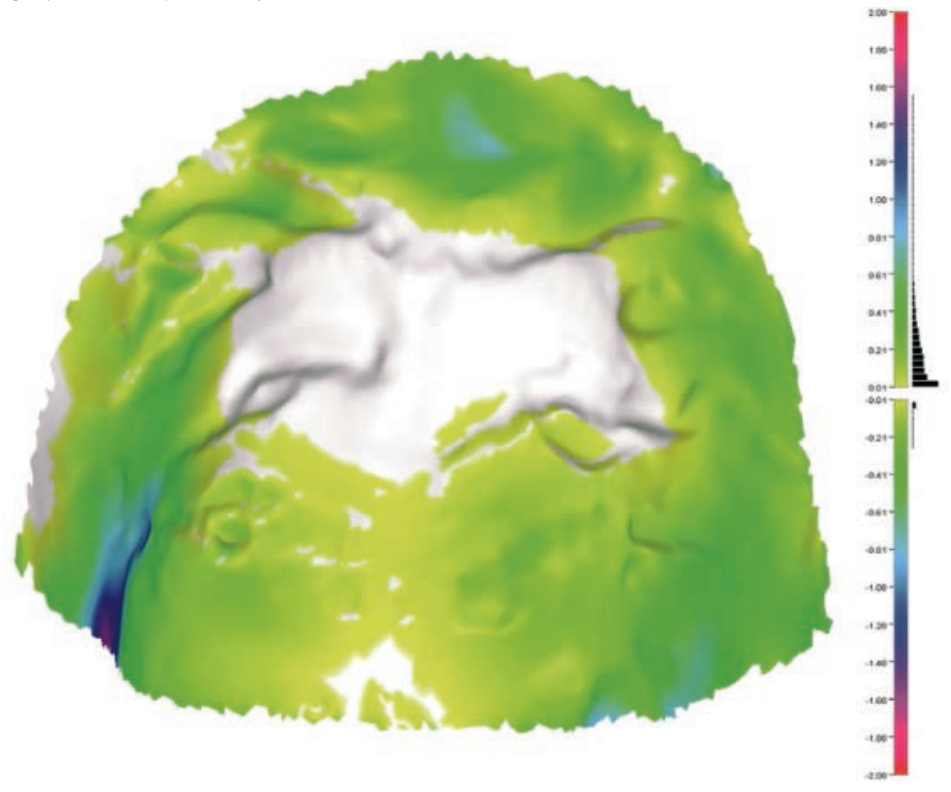

Figure 14: Distance analysis with true values showing an unchanged area (white colored) in the center of the palatal vault. 


\section{D-model analysis}

After import of the .stl-files into the Final Surface ${ }^{\circledR}$ software (v 6.0.2, incl DefoScan ++ Plugin, GFaI, Berlin, Germany), RFD-superimposition was performed as follows (the start model as master, the reference model as slave):

1. In a first step, the start and the specimen model were cloned. These clones were named start palatum and specimen palatum. Then the palatal vault was cropped on both models. The palatal vault was defined as an area between the papilla incisiva and a line distal of the second premolar.

2. Raw matching was performed using six individually chosen corresponding points, ideally near the median point of the third pair of rugae.

3. Fine matching was performed with the convergence method (as many as 50 repetitions).

4. Deformation analysis and superimposition of start palatum and specimen palatum were performed with the DefoScan ++ Plugin. The collector parameter was set to $0.5 \mathrm{~mm}$ edge length and the filter cell parameter to $1.5 \mathrm{~mm}$ edge length, each with 15 repetitions.

5. Superimposition was finished by transferring the result of the RFD-superimposition on the palatal vault onto the original models. This was achieved by copying the transformation matrix from specimen palatum into the specimen model.

Assessment of tooth movement:

1. The superimposed models start and specimen were cloned and the occlusal surfaces of the right first maxillary molar in both models were cropped. The weight centers were then centralized in the occlusal surfaces and the $\mathrm{x}^{-}, \mathrm{y}-\mathrm{z}$ nates were recorded (PreTX position).

2. Another clone of the occlusal surface was created. This new clone was matched onto the occlusal surface of the reference model. Again, the position and rotation angles of the occlusal surface were recorded (PostTX position).

3. Tooth movement was calculated as the difference between PreTX position and PostTX position. 


\section{Statistical methods}

The relationship between measured total movement and true total movement was analyzed with a mixed effects model. The mixed effects model is a simple linear regression model of the relationship between measured and true total movement, which also takes into account dependencies between observations made on the same case and by the same observer. In the mixed effects model, the measured total movement was the dependent variable, the true total movement was a fixed covariate and the cases and observer were random factors. A variance components structure was used in the model.

The intra class correlation coefficients (ICC) estimating the correlation between two repeated measurements on the same case performed by the same observer were calculated for the following variables: total movement; $\mathrm{x}-, \mathrm{y}-, \mathrm{z}$-translations; and $\mathrm{x}-, \mathrm{y}-, \mathrm{z}-$ rotations. The ICCs were estimated according to $\frac{\sigma 2 b s}{(\sigma 2 b s+\sigma 2 b o+\sigma 2 e)}$, where the between case variance component is $\sigma 2 b s$, the inter observer variance component is $\sigma 2 b o$ and the residual variance component is $\sigma 2 e$. Confidence intervals were estimated with $95 \%$ confidence levels for the ICCs with parametric bootstrapping with 2000 iterations.

\section{Papers II, III and IV}

Papers II, III and IV were based on a multi-purpose randomized controlled trial with two parallel arms and a 1:1 allocation ratio. The participants were recruited from the Public Dental Services Orthodontic Clinic in Gävle, Region Gävleborg, Sweden. Treatments were conducted by the principal investigator and one more orthodontist. This trial is completed. The first treatment was started in 2009 and the last treatment was finished in 2017. The trial objectives were as follows:

1. To evaluate pain and discomfort during and after insertion of miniscrews (Paper II);

2. To compare the anchorage capacity between miniscrews and molar blocks in extraction cases treated with en masse retraction of maxillary anterior teeth (Paper III); and

3. To evaluate cost effectiveness of reinforced anchorage using miniscrews and molar blocks (Paper IV). 
The inclusion criteria were as follows:

- Adolescents, 11-19 years of age, referred to the specialist clinic for orthodontic treatment including fixed appliance and extraction of the maxillary first premolars or maxillary first and mandibular first or second premolars;

- Moderate need for anchorage reinforcement;

- Permanent dentition including fully erupted maxillary second molars; and

- Regular dental care in Sweden since the age of three.

Patients who previously received orthodontic treatment, who needed orthognathic surgery, or who needed more than moderate anchorage reinforcement were excluded from the trial.

\section{Estimation of anchorage need}

Need for anchorage reinforcement was estimated in every case. The estimation was based on the available space, molar and canine relation and maxillary incisor position. ${ }^{81}$ When approximately $75 \%$ of the extraction spaces were needed for en masse retraction, anchorage need was considered moderate (Figure 15).

When about $80-100 \%$ of the extraction spaces were needed, this was considered maximum anchorage need. In contrast, $50 \%$ of the extraction spaces needed for space closure implied reciprocal space closure and thus no need for anchorage reinforcement was considered. Patients with maximum need and with no need for anchorage reinforcement were not eligible for this trial.

\section{Sample}

\section{Sample size calculation}

Calculation of the sample size was based on the reported anchorage loss and standard deviation from an earlier trial about anchorage reinforcement. ${ }^{15}$ The Headgear Group was chosen as reference (anchorage loss $1.2 \mathrm{~mm}$, SD $1.96 \mathrm{~mm}$ ) since headgear has shown excellent anchorage capacity when compliance is good, while non-compliant cases showed anchorage loss. This loss was considered comparable to miniscrews where good anchorage capacity was expected for all cases except those with lost screws. The least difference with clinical relevance was set at $1 \mathrm{~mm}$ and $\mathrm{P}$ values of 


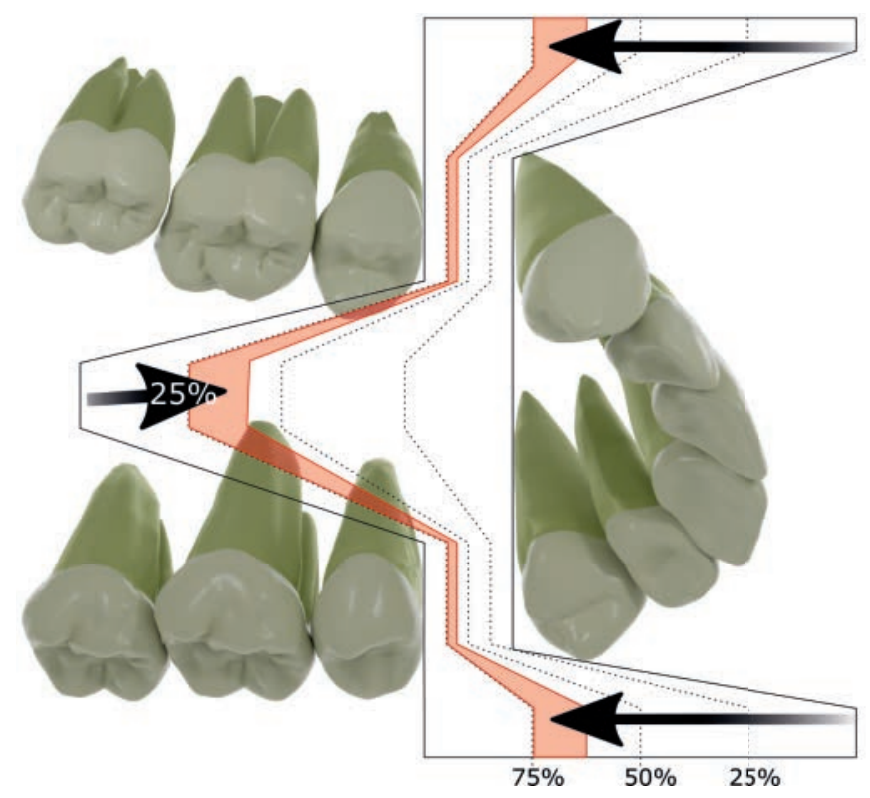

Figure 15: Estimation of anchorage need.

less than $5 \%$ were considered statistically significant. Under these conditions, a sample size of 26 participants per group would give $90 \%$ power.

Some dropouts were expected since the failure rate for miniscrews was reported to be approximately $15 \%{ }^{36,38}$. Furthermore, a few cases with discontinued intervention or participants moving from the area had to be expected. Thus, the planned sample size was 40 participants per group.

\section{Randomization}

An individual from the Center for Research and Development Uppsala University / Region Gävleborg who was not involved in this trial generated a random list with Statistical Package for Social Sciences (SPSS Inc. Released 2009. PASW Statistics for Windows Version 18.0. Chicago, Illinois, USA). The list was based on a simple randomization stratified for gender. Using this list, this independent person produced two series (female / male) of sealed opaque envelopes containing the allocation notes for either miniscrews ("A") or molar blocks ("B"). After oral and written information about the trial, informed consent was retrieved from the 
patients and their parents. Then the patients were enrolled in the trial. These preliminaries concluded, the participants opened the envelope to reveal the intervention they were assigned to.

\section{Blinding}

In this trial, the intervention was obvious to the participant and the caregiver. Therefore, only assessments of the data was blinded. Blinding was provided by assigning internal ID numbers to every participant. Furthermore, all details that could reveal the treatment group were removed from the plaster casts before 3D scanning. Thus, the assessor was unaware of the participant's treatment group, age and sex when making measurements.

\section{Ethical considerations}

The trial protocol and informed consent were approved by the Regional Ethical Review Board, Uppsala University, Uppsala, Sweden following the Declaration of Helsinki (Dnr. 2009/188). In addition to the standard records, two extra plaster casts and lateral cephalograms were taken after leveling and alignment and after space closure. All patients who declined to participate were offered orthodontic treatment with fixed appliance and molar blocks according to the standard treatment concept.

\section{Data monitoring}

Due to the relative small sample size, non-mortal risks and the blinded design (analysis of data), no data monitoring committee was assigned. Data monitoring was provided by the principal investigator. An interim analysis of anchorage loss was performed after the first 20 cases had finished the leveling and alignment phase. There were no stopping guidelines.

\section{Interventions}

\section{Premolar extractions}

The participants' general practitioner conducted the premolar extractions under local anesthesia with 5\% Lidocaine gel (APL, Sweden) and buccal and palatal infiltration of Xylocaine ${ }^{\circledR}$ Dental Adrenalin (Lidocaine hydrochloride $20 \mathrm{mg} / \mathrm{ml}+$ adrenaline 12.5 $\mu \mathrm{g} / \mathrm{ml}$, Dentsply Pharmaceutical, Weybridge, Surrey, UK). 


\section{Orthodontic treatment}

Following the premolar extractions, all participants were treated with fixed appliance following a straight wire concept (MBT ${ }^{\mathrm{TM}}$ prescription, .022" slot size, Victory Series ${ }^{\mathrm{TM}}$ stainless steel brackets, 3M Unitek, Monrovia, CA, USA). ${ }^{82}$ The recommended archwire sequence was .016" Heat-Activated Nickel Titanium (HANT), $.019 " \mathrm{x} .025$ " HANT and .019" x .025" Stainless steel (3M Unitek, Monrovia, CA, USA). Anchorage reinforcement was provided in two ways:

- The intervention arm (Group A) had no anchorage reinforcement during the leveling and alignment phase. During space closure, anchorage was reinforced with buccal miniscrews (Spider Screw ${ }^{\circledR}$ K1, short neck, $1.5 \mathrm{~mm}$ diameter, 8-10 mm length, Health Development Company, Sarcedo, Italy)(Figure 16). All miniscrews were inserted under local anesthesia by the principal investigator with a hand screw driver. Pre- and postoperative apical radiographs were taken to estimate available space and to control the position of the miniscrews. When the position of the miniscrews was close to a root, the miniscrew was adjusted. Miniscrews were used as direct anchorage and immediately loaded with 150 g closed coil springs (Ortho Technology, Tampa, USA) for en masse retraction of the six maxillary frontal teeth.

- The active comparator arm (Group B) used molar blocks as anchorage reinforcement during leveling \& alignment and space closure. The use of molar blocks implied that, in contrast to Group A, the second maxillary molar was added to the appliance. The second molar was then tightly connected to the first molar and second premolar using a stainless steel ligature (Figure 17). En masse retraction of the six maxillary frontal teeth was done with $150 \mathrm{~g}$ active tiebacks.

Once the canines were in Class I relation or space closure was achieved, anchorage reinforcement was discontinued and the finishing phase started. In the finishing phase, individual treatment strategies were used for every single case. According to the circumstances, anchorage had to be "burned" to close the remaining spaces or, when appropriate, Class II elastics were used to establish Class I canine relation. In some cases, inter-maxillary elastics were 


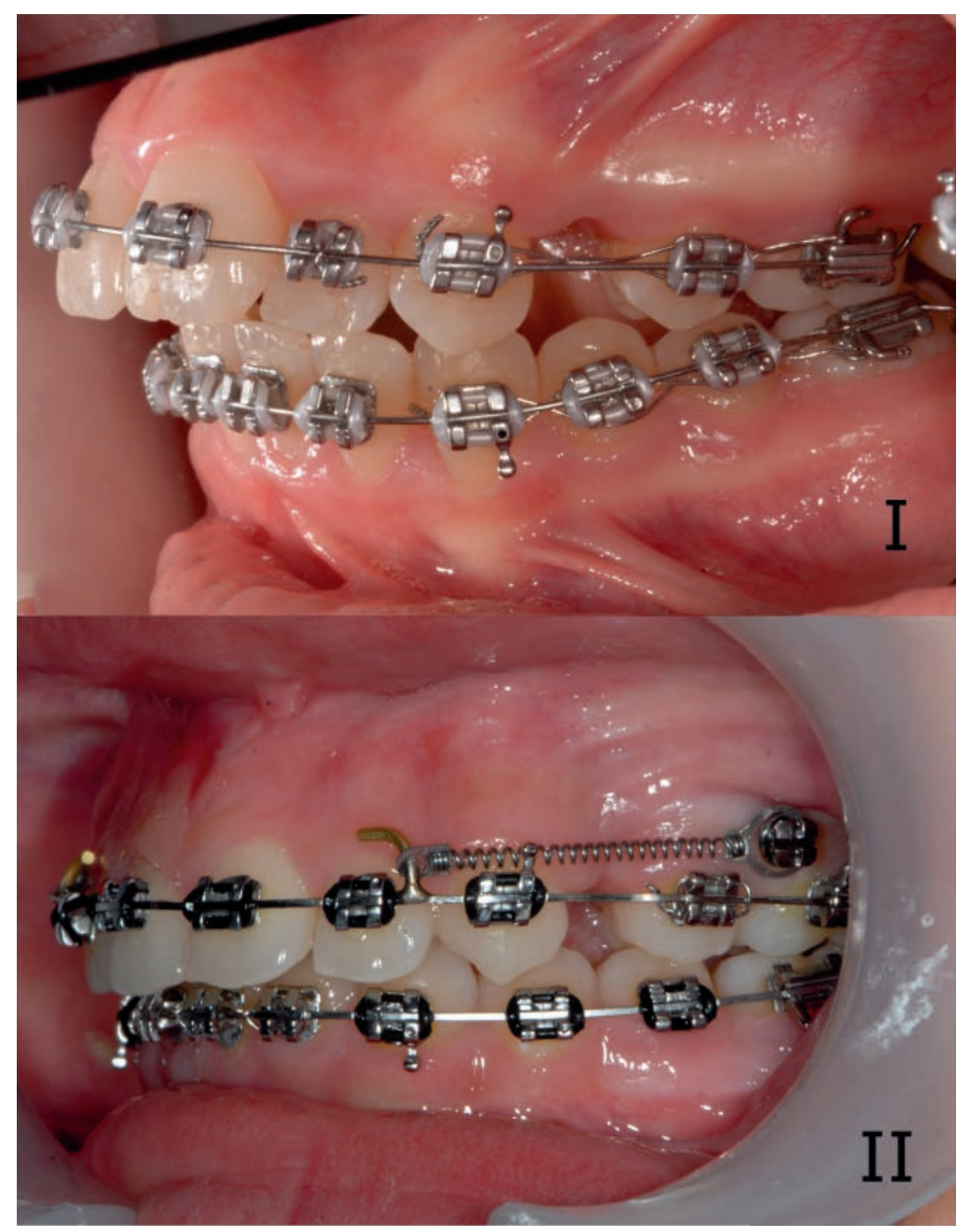

Figure 16: Orthodontic treatment Group A: I leveling \& alignment, II space closure 


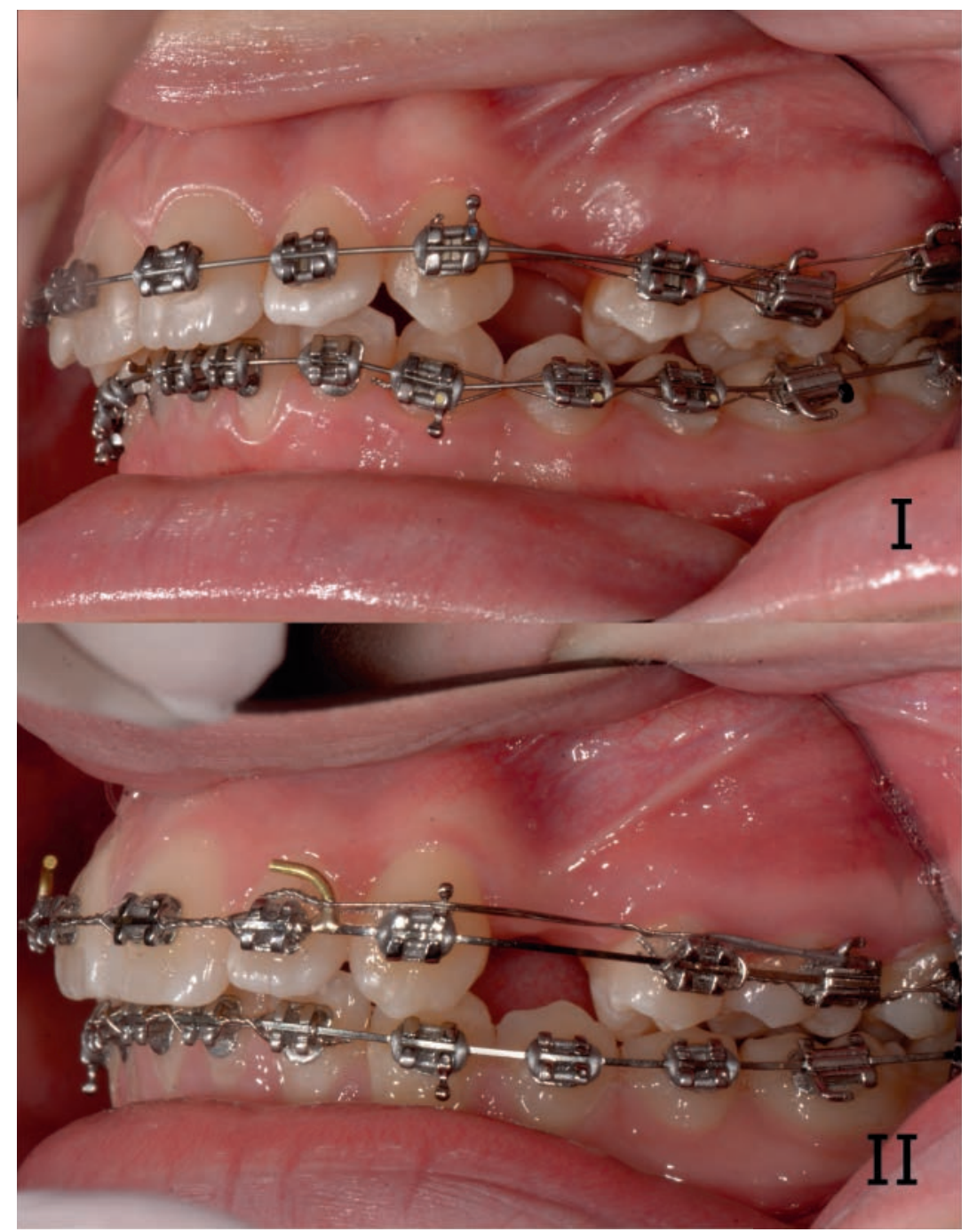

Figure 17: Orthodontic treatment Group B: I leveling \& alignment, II space closure 
used to settle the occlusion. The treatment goals were reached in all cases and no re-treatment was necessary.

\section{Miniscrew insertion characteristics}

To use buccal miniscrews between the second premolar and first molar is one of the safe locations for miniscrew insertion. ${ }^{83}$ For this insertionsite, placement in the keratinized gingiva is favorable and sufficient interradicular space is necessary. ${ }^{84}$ Miniscrew diameters less than $1.6 \mathrm{~mm}$ and length of approximately $6-7 \mathrm{~mm}$ are recommended. ${ }^{83}$

Watanabe et al. ${ }^{85}$ compared CBCT images with apical radiographs. They found a four-grade classification for root proximity (A-D, Figure 18) suitable. Further, only class D was reported to be associated with a higher failure rate for maxillary miniscrew. The insertion-angle of the miniscrew to the long axis of the teeth was recommended to be 40-45 degrees to increase contact to the cortical bone and to maintain an acceptable distance to the neighboring roots. ${ }^{85}$

In this trial we used miniscrews with a diameter of $1.5 \mathrm{~mm}$ and 8-10 mm length that were buccally placed between the maxillary first molar and second premolar. The miniscrews were inserted into the keratinized gingiva with approximately 40 degrees insertion angle. Insertion was conducted with a manual torque screw driver set to $15 \mathrm{Ncm}$. Miniscrews were adjusted when the apical radiograph was classified as $\mathrm{D}$ or $\mathrm{B}$ when judged as in contact with root.

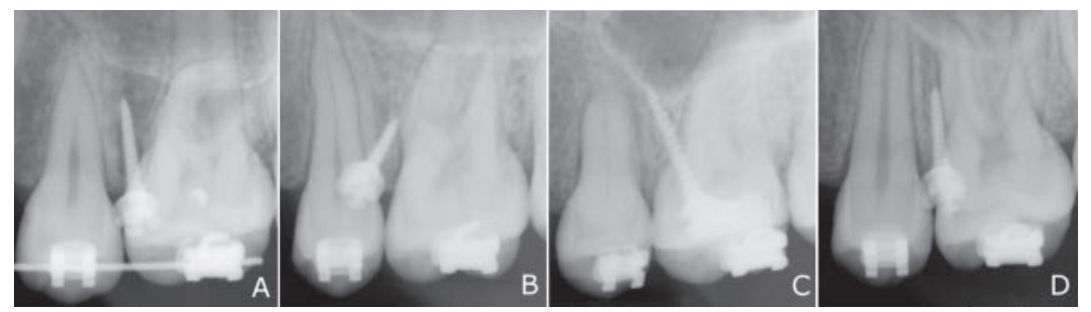

Figure 18: Root proximity classification according to Watanabe ${ }^{85}$ : A - Miniscrew separated from root surface; $B$ - Only the apex of the miniscrew is in contact with root surface; C-Neck or middlepart of miniscrew in contact but with apex separated from the root surface; D - Entire body of the miniscrew in contact with the root. 


\section{Outcomes}

\section{Patient perception outcome - Paper II}

The primary outcome for Paper II was experience of pain and discomfort. Pain and discomfort were assessed on 100-mm horizontal Visual Analogue Scales (VAS) with the end points "not at all" and "worst imaginable". The secondary outcome measures, impact on daily activities and functional jaw impairment, were assessed using the following five-level verbal rating scales (VRS): "not at all", "slightly difficult", "difficult", "much difficult" and "extremely difficult". Furthermore, participants were asked whether they had taken any analgesics, whether any part of the procedure was especially painful/uncomfortable, whether they stayed home from school and whether they had refrained from leisure activities. These questions could be answered with yes/no answers and/or using free text.

The self-report questionnaires we used have been found to be reliable and with sufficient internal consistency. ${ }^{86,87}$ Participants were instructed to complete the paper-and-pencil questionnaires on their own. They were asked to bring the completed questionnaire to their next follow-up visit. A questionnaire could be completed within ten minutes.

A baseline questionnaire, completed by all participants after enrollment, provided information about the participants' preconditions concerning pain and discomfort. Furthermore, these data were then evaluated concerning possible predictors for patients experiencing more pain and discomfort. The other questionnaires were answered in the evening after tooth extractions and one week after tooth extractions. Participants from Group A (miniscrews) also answered the questionnaire in the evening and one week after miniscrew insertions. All questionnaires can be found in the Appendix (A1, A2, A3 and A4 on page 110ff).

\section{Orthodontic outcome - Paper III}

Anchorage capacity was defined as resistance against tooth movement. Tooth movement was estimated as changes in position of the maxillary first molars during the different treatment phases. To assess changes in tooth position, alginate impressions were taken after tooth extractions, i.e. before treatment start $\left(\mathrm{T}_{1}\right)$, after leveling 
and alignment $\left(\mathrm{T}_{2}\right)$ and after space closure $\left(\mathrm{T}_{3}\right)$. Plaster casts were produced within 24 hours at the in-clinic laboratory. These plaster casts were digitized with a 3D desktop scanner (R700, 3Shape, Copenhagen, Denmark). Superimposition and measurements were then conducted using the RFD-superimposition technique, which was validated in Paper I.

\section{Economic outcome - Paper IV}

The primary outcome measure was societal or total costs. Societal costs were defined as the sum of direct and indirect costs. For every visit, the following variables were recorded: the booked chair time, presence of an adult companion and mode of travel to the clinic. Traveling was differentiated into three categories: motor vehicle, public transportation and bicycle/walk. All costs were calculated in Swedish Crowns (SEK) and then converted into Euros $(€)$ according to an exchange rate of $€ 1.00=$ SEK 9.47 (Source: www.riksbank.se, mean exchange rate year 2016).

\section{Direct costs}

Direct costs were defined as the sum of material costs for the appliance and costs for chair time. Material costs were calculated according to the template presented in Table 1. Material costs were calculated using Swedish market prices. Chair time costs were calculated according to a reversed approach: The orthodontic clinic's annual expenses for 2016 were divided by the total number of booked chair time minutes for 2016. Since material costs were calculated separately, this calculation excluded costs for dental work, brackets, archwires and miniscrews. Thus, chair time costs were not based on assumptions but on the real costs including all other materials, hires, equipment, cleaning, IT services, overhead costs, insurances, the staff salary and payroll taxes. Chair time costs were estimated to $€ 197.25$ per hour.

For each visit, the chair time was recorded in minutes and categorized as scheduled, emergency or missed. Canceled visits were not recorded as chair time. However, if the cancellation resulted in an unused chair, this affected the per hour chair time costs. 
Table 1: Direct costs template - material per patient for Group A and B.

\begin{tabular}{lrrrrrrr}
\hline Product & \multicolumn{2}{c}{ List } & & \multicolumn{2}{c}{ Group A } & & \multicolumn{2}{c}{ Group B } \\
\cline { 7 - 8 } & Price [€] & Qty & Price [€] & & Qty & Price [€] \\
\hline Pair of plaster casts & 41.71 & 1 & 41.71 & & 1 & 41.71 \\
Bracket, 3M Victory & 4.75 & 12 & 57.00 & & 12 & 57.00 \\
Bracket with hook, 3M Victory & 5.15 & 4 & 20.60 & & 4 & 20.60 \\
Molar tube, 3M Victory & 6.60 & 4 & 26.40 & & 4 & 26.40 \\
NiTi closed coil spring & 7.87 & 2 & 19.66 & & 0 & 0.00 \\
Stainless steel ligature & 0.13 & 0 & 0.00 & & 2 & 0.26 \\
.016" HANT & 4.30 & 2 & 8.60 & & 2 & 8.60 \\
.019"x.025" HANT & 4.30 & 2 & 8.60 & & 2 & 8.60 \\
.019"x.025" Resilient posted & 5.68 & 2 & 11.36 & & 2 & 11.36 \\
Spider Screw K1 SCR-1508 & 73.26 & 2 & 146.52 & & 0 & 0.00 \\
Apical radiographs & 39.60 & 2 & 79.20 & & 0 & 0.00 \\
SOPIRA Carpule 30G & 0.64 & 1 & 0.64 & & 0 & 0.00 \\
Xylocaine adrenaline 1.8 ml & 0.21 & 1 & 0.21 & & 0 & 0.00 \\
Essix splint C & 58.08 & 2 & 116.16 & & 2 & 116.16 \\
\hline Sum & & & 536.66 & & 303.89 \\
\hline
\end{tabular}

\section{Indirect costs}

Indirect costs were defined as the sum of loss of income and transportation costs. Transportation costs were estimated according to the distance between the patient's registered address and the orthodontic clinic. Distances and travel times for motor vehicles were estimated according to Google Maps' proposal for fastest way. Distances were then multiplied with the per-kilometer-cost (€ 0.20/km) according to the Swedish Tax Agency. Calculation of travel times and costs for public transportation followed the official timetable and price list 2016 (www.xtrafik.se). When participants walked or biked, costs and time were set to zero because this usually applied to patients who went to school near the orthodontic clinic and calculation according to the registered address would have falsified the results. After travel time and time for the visit had been estimated, loss of income for the accompanying adults was calculated. It was assumed that these adults took time off from work. In addition, it was assumed that 15 - and 16-year-old participants typically have parents aged between 40 and 49 years. The mean per hour income for 40- to 49-year olds living in Sweden was derived from the National Bureau of Statistics (SCB). For the fiscal year 2016, the per hour income was $€ 26.65$. 


\section{Cost analysis}

Depending on the results from Paper III, the proper method for cost analysis was selected. If miniscrews and molar blocks were equal in their anchorage capacity, a cost minimization analysis would be chosen. The cost minimization analysis reveals the least expensive treatment. However, if anchorage capacity differs in magnitude, a cost effectiveness analysis would be performed. Cost effectiveness analysis calculates costs $(\mathrm{C})$ and effects (E) to determine anchorage reinforcement per cost (value for money).

\section{Statistical methods}

The statistical analysis was carried out in SPSS (IBM SPSS ${ }^{\circledR}$ Statistics for Windows, Version 22.0. IBM Corp., Armonk, USA) (Paper II) and in the programming language $\mathrm{R}$ (version $3.10-3.42)^{76}$ (Papers II, III and IV). Means, medians and standard deviations were calculated for numerical variables. Normal distribution was analyzed using Shapiro Wilk tests and histograms. A P value of less than $5 \%(\mathrm{P}<0.05)$ was considered statistically significant.

\section{Missing values, per protocol and intention-to-treat}

During a clinical trial, participants occasionally do not finish their treatment. Adolescents, for example, may change their minds and decline to participate or decline to get braces at all. Furthermore, participants might move from the area and sometimes orthodontic treatment needs to be discontinued due to insufficient oral hygiene. Beyond these patient-related factors, there are also technical failures such as fractured archwires, loose miniscrews or allergic reactions. When reverse effects or harms occur, treatment sometimes has to be discontinued. Cases with discontinued treatment are called dropouts.

Traditionally, dropouts have been excluded from statistical analysis. This approach is called per protocol analysis. However, this introduces a risk for bias. One cannot be sure whether there is a correlation between the treatment and a patient declining to participate. Furthermore, technical failures always occur to a certain extent, so the caregiver has to be aware of failure rates.

When all dropouts are excluded, the results might give a false 
positive picture since the "bad cases" have been excluded. Therefore, Fisher introduced the concept of Intention-to-treat analysis (ITT). ${ }^{88} \mathrm{~A}$ recently published review revealed that ITT analyzes are seldom performed in the orthodontic literature. ${ }^{89}$ The basic idea of ITT is that all participants, irrespective of treatment outcome, should be included in the analysis. In cases with discontinued treatment, the researcher has to define how the missing data are to be handled. Depending on the variable, there are different strategies for handling missing data:

\section{Missing value $=$ Failure}

One of the primary outcomes in this trial was anchorage capacity. Since we know that space closure without anchorage reinforcement results in reciprocal space closure, this was the definition of failed anchorage reinforcement. In other words, we assumed a $3.75 \mathrm{~mm}$ mesial movement of the maxillary first molars during leveling and alignment and space closure $\left(\mathrm{T}_{1}-\mathrm{T}_{3}\right)$.

\section{Missing value $=$ Mean}

Some variables lack a definition of successful or failure values. For these variables, the mean value can be imputed from the per protocol subsample. This strategy was applied for transversal, vertical and rotational measurements.

3. Missing value $=$ Last observation carried forward $(\mathrm{LOCF})$ In a series of repeated measurements, one or multiple measurements might be missing. Here, the missing observation is understood as the individual's previous observation. Then the data are analyzed as if no missing values existed.

4. Accept missing values $=$ Per protocol analysis

For some variables it can be difficult to define a value for failure or imputation of the variable's mean could falsify the results. When measurements additionally are not conducted in a continuous series so that LOCF is not applicable, a per protocol analysis can be the only method that is left. However, a per protocol analysis requires a number of dropouts small enough to maintain statistical power. This method was applied for the survey about experience of pain and discomfort since VAS estimates show a huge individual variation. ${ }^{90}$ 


\section{Paper II}

A per protocol analysis of the data was performed. The MannWhitney-Wilcoxon test was used to test ordinal data for differences between groups. Nominal data were tested using the Fisher's exact test. The Wilcoxon signed-rank test was used for within group analysis of differences between tooth extractions and insertion of the miniscrews in Group A. Associations between baseline ratings and experience of pain and discomfort was analyzed with Spearman correlation coefficients. P values were then adjusted using the Holm-Bonferroni method. ${ }^{91}$

\section{Paper III}

The ITT analysis included two dependent observations for each treatment phase $\left(\mathrm{m}_{\mathrm{i}}=2\right)$ from every participant's first right and left maxillary molars. The used linear mixed effect model was adjusted for left and right side. ${ }^{92}$ Linear mixed effect models contain fixed and random factors, which make this a suitable analysis for repeated measurements and dependent data. Treatment group and left and right side were assigned as fixed factors. The subject was assigned as a random factor. Data analysis was conducted for the total observation period and separately for each treatment phase. Measurement error analysis was performed after at least two weeks by repeated RFD-superimposition and measurement on 15 randomly selected cases.

\section{Paper IV}

The distributions were analyzed with histograms and Shapiro-Wilk tests. Homogeneity of variance for all variables was tested using Levene's modified test. Differences between the groups and 95\% confidence intervals were calculated using the Mann-Whitney-Wilcoxon test. To conduct an ITT analysis, missing values were treated as follows: when visits lacked information about how the participant traveled to the clinic or whether the participant was accompanied by an adult, the LOCF method was used; and when the whole case was missing, the values for the summarized variables were set to the mean calculated from the per-protocol subsample. 


\section{RESULTS}

\section{Paper I - Validity and reliability}

Four senior consultant orthodontists superimposed and measured the 16 cases within two weeks after they received training. Each case consisted of a real case start model and a virtually modified reference model.

Figure 19 depicts the difference between true values, measurements and repeated measurements for total movements. The $\mathrm{x}-$ axis represents the total millimeters a tooth moved and the y-axis represents the difference between the true value and the measured value. The closer a measured value is to the dotted line, the closer this measurement is to the true value. The range of the differences was between $-0.07 \mathrm{~mm}$ and $0.08 \mathrm{~mm}$. The mean absolute error was $0.0225 \mathrm{~mm}$ (SD $0.03 \mathrm{~mm}$ ) and the arithmetic mean error was $-0.0017 \mathrm{~mm}$. The ICC for total movement was 0.9996 (95\% CI: $0.9990-0.9998)$. The results of translational and rotational measurements are depicted in Figure 20 and are presented in detail in Table 2.

Table 2: Absolute mean errors, arithmetic mean errors and ICC with estimated 95\% CI.

\begin{tabular}{lrrr}
\hline & Abs. Error & Arit. Error & ICC $(95 \%$ CI $)$ \\
\hline Translation [mm] & & & \\
- Total movement & 0.0225 & -0.0017 & $0.9996(0.9991,0.9998)$ \\
- Ateroposterior & 0.0152 & -0.0049 & $0.9994(0.9985,0.9997)$ \\
- Vertical & 0.0240 & 0.0020 & $0.9902(0.9756,0.9952)$ \\
- Transversal & 0.0208 & -0.0033 & $0.9996(0.9991,0.9998)$ \\
\hline Rotation [degree] & & & \\
- Disto-mesial tipping & 0.0291 & -0.0241 & $0.9999(0.9999,1.0000)$ \\
- Bucco-palatal tilting & 0.0134 & 0.0021 & $0.9999(0.9999,1.0000)$ \\
- Around tooth axis & 0.0215 & 0.0098 & $0.9999(0.9998,1.0000)$ \\
\hline
\end{tabular}




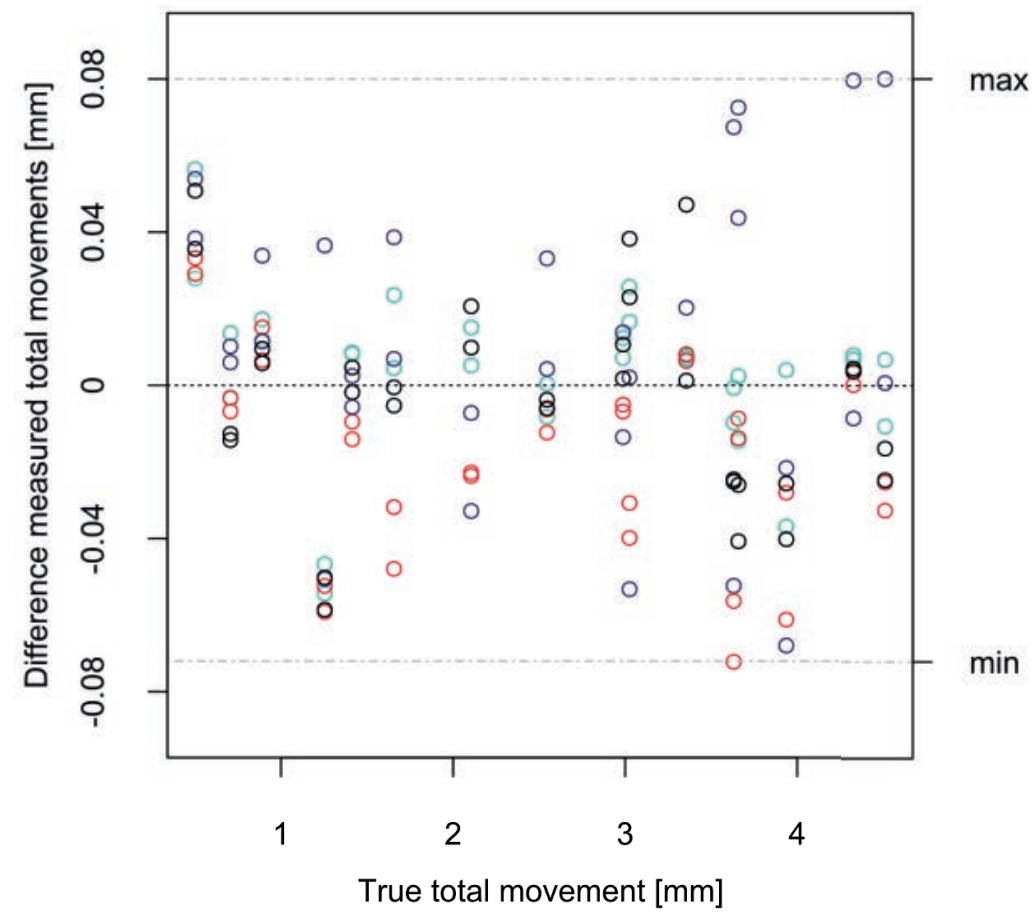

Figure 19: Differences between measured and true total movements. Each of the four observers is represented by a unique color.
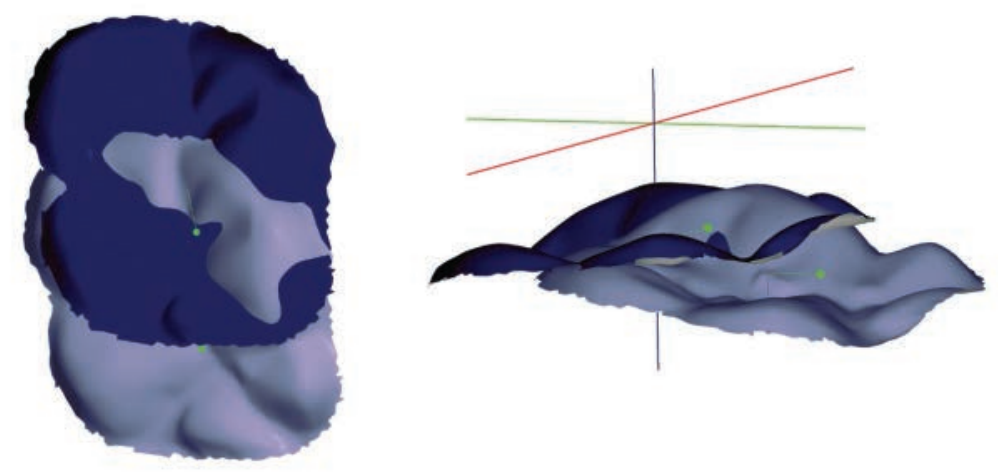

Figure 20: Measurement result showing a tooth's occlusal surface before and after treatment. 


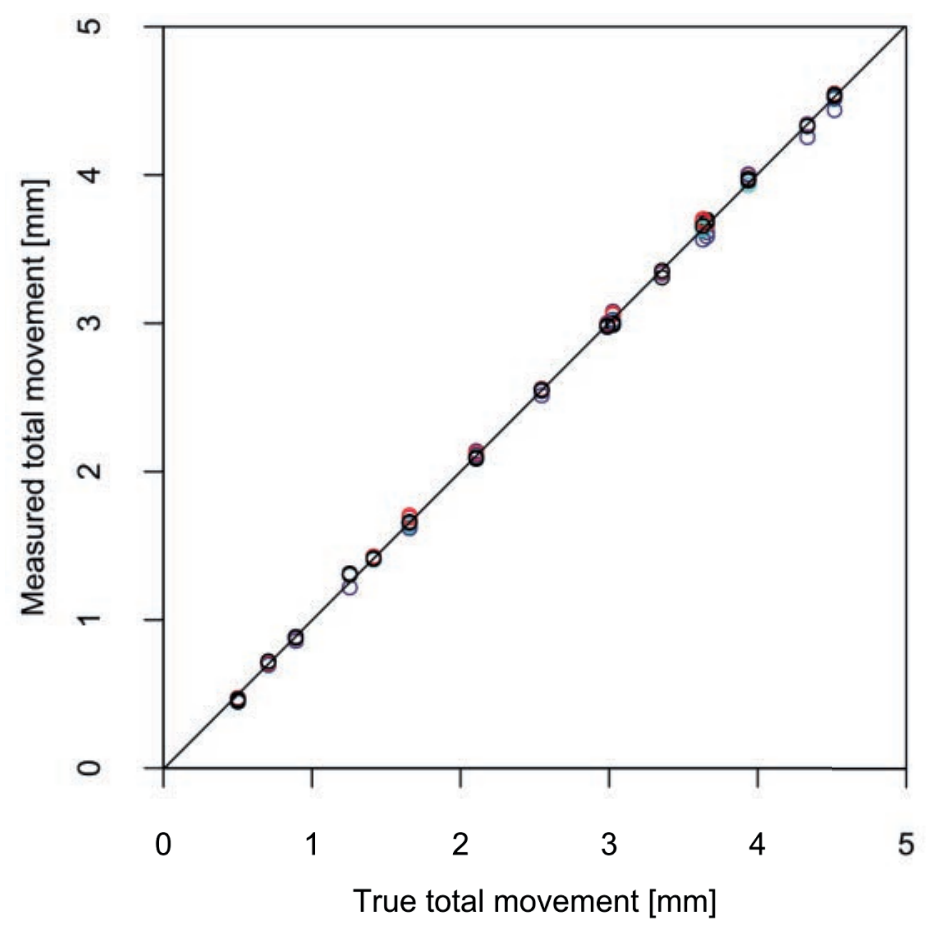

Figure 21: Measured total movement plotted against true total movement.

Figure 21 shows the measured total movements and the corresponding true values. This figure indicates that the accuracy is independent of the measured distance. Small distances close to zero are as accurate as distances greater than $4 \mathrm{~mm}$. The intercept $(-0.007)$ and slope for the total movement (1.003) are very close to the line of identity. Therefore, these measurements have very little systematic error. 
The estimated parameters are presented in Table 3. The Variability of the random effects is dominated by the residual error ( $56.9 \%$ of total variance), followed by the variability due to cases $(32.4 \%)$ and the variability due to observer $(13.7 \%)$.

Table 3: Estimated parameters for total tooth movement of the mixed model.

\begin{tabular}{lcr}
\hline Fixed effect & Estimate & \multicolumn{1}{c}{ Std error } \\
\hline - Intercept & -0.007 & 0.01 \\
- True value (slope) & 1.003 & $<0.01$ \\
\hline Random effect & Variance & Std deviation \\
\hline - Cases & 0.0003142 & 0.017 \\
- Observer & 0.0001327 & 0.011 \\
- Residual error & 0.0005228 & 0.023 \\
- Total variability & 0.0009697 & 0.031 \\
\hline
\end{tabular}

The random measurement errors are also generally small; the standard deviations of the random effects due to residuals, cases and observer are $0.0229 \mathrm{~mm}, 0.0177 \mathrm{~mm}$ and $0.0115 \mathrm{~mm}$, respectively. Model diagnostics calculated with various graphs of residuals and fitted values show somewhat heavy tails in some models' QQ-plots of the residuals. However, these are considered to be within an acceptable limit.

\section{Papers II-IV}

For Papers II-IV, 98 patients fulfilled the inclusion criteria and were invited to participate in this trial, but 18 patients declined to participate so 80 participants were enrolled in the trial. In Groups $\mathrm{A}$ and $\mathrm{B}$, recruitment stopped when the sample size reached 40 participants. Informed consent was collected from all participants and their parents before random group assignment. The patients who declined were offered treatment with fixed appliance, premolar extractions and anchorage reinforcement with molar blocks. These patients were not significantly different with regard to age or gender compared with the participants entering the trial.

Tooth extractions were conducted by the patients' general practitioner. In total 35 dentists from 14 different clinics were involved in extracting premolars in this sample. 


\section{Dropouts}

Two participants from Group A refused orthodontic treatment after random group assignment. Further two participants had no need for anchorage reinforcement or space closure after leveling and alignment. In both cases, the canines had advantageously moved into the extraction sites without causing an increased overjet. In these two cases, no miniscrews were inserted. Anchorage capacity could not be evaluated in two cases due to poor impression quality in the palate. Another participant from Group A was excluded during the space closure phase because one of the miniscrews became loose. Because this participant was pregnant, treatment was finished without reinstalling the miniscrew to avoid further radiation exposure via radiographs.

In Group B, the treatment plan in one case had to be changed because of a pathological finding revealed in preoperative radiographs. In another case, no impressions were taken at $\mathrm{T}_{2}$.

All the cases named above were excluded from the trial and their data were treated as anchorage failure in the intention-to-treat analysis. Further, one participant in each Group A and B failed to return questionnaires. The analysis of pain and discomfort was conducted on a per protocol basis. The RCT was ended after the last participant was de-bonded. The baseline demographic data are presented in Table 4 and the CONSORT Flow-chart is presented in Figure 22.

Table 4: Baseline demographic data.

\begin{tabular}{llllll}
\hline Group / Paper & Total & Female & Male & Mean Age [Yrs] \\
\hline A & ITT & $\mathrm{N}=40$ & $\mathrm{~N}=26$ & $\mathrm{~N}=14$ & 16.4 , SD 1.7 \\
& Paper II & $\mathrm{N}=35$ & $\mathrm{~N}=24$ & $\mathrm{~N}=11$ & 16.3 , SD 1.7 \\
& Paper III & $\mathrm{N}=33$ & $\mathrm{~N}=21$ & $\mathrm{~N}=12$ & 16.3 , SD 1.7 \\
& Paper IV & $\mathrm{N}=35$ & $\mathrm{~N}=24$ & $\mathrm{~N}=11$ & 16.4, SD 1.7 \\
\hline B & ITT & $\mathrm{N}=40$ & $\mathrm{~N}=26$ & $\mathrm{~N}=14$ & 15.0, SD 1.8 \\
& Paper II & $\mathrm{N}=38$ & $\mathrm{~N}=26$ & $\mathrm{~N}=12$ & 14.9, SD 1.8 \\
& Paper III & $\mathrm{N}=38$ & $\mathrm{~N}=25$ & $\mathrm{~N}=13$ & 15.1, SD 1.8 \\
& Paper IV & $\mathrm{N}=39$ & $\mathrm{~N}=26$ & $\mathrm{~N}=13$ & 15.0, SD 1.9 \\
\hline
\end{tabular}




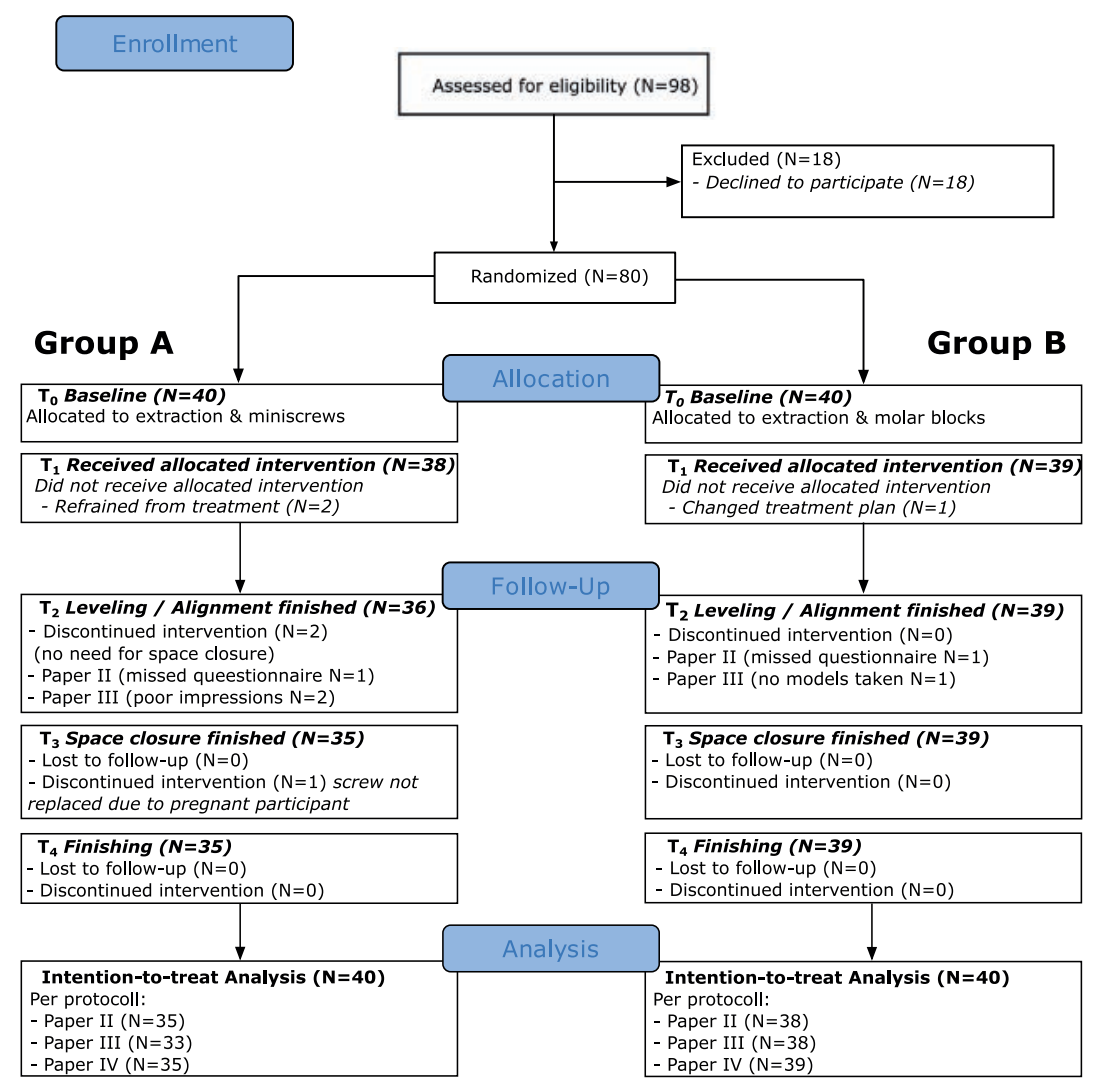

Figure 22: CONSORT Flow Chart

\section{Pain \& discomfort (Paper II)}

Tooth extractions were carried out by the patients' general practitioner. Thus, 35 different dentists were involved in tooth extractions. All miniscrews were inserted by the principal investigator at the specialist clinic in Gävle, Sweden. The overall response rate was $87.8 \%$. At baseline, there were no significant differences between groups concerning experience of pain and discomfort and limitations in daily activities.

However, to a significantly greater extent participants in Group A (miniscrews) answered that it was their own decision to undergo orthodontic treatment $(\mathrm{P}=0.028)$. In addition, they expected the treatment to be more difficult $(\mathrm{P}=0.047)$. 


\section{Experience of pain and discomfort}

Patient-reported experience of pain (Figure 23) and discomfort (Figure 24) are presented in Table 5. There were no significant differences in the reported intensity of pain and discomfort between groups during tooth extractions.

In comparison to tooth extractions, participants reported significantly lower levels for pain and discomfort on the evening and one week after miniscrew insertion. The reported levels for pain and discomfort during the miniscrew insertion procedure were not significantly different from tooth extractions.

Patient-reported pain and discomfort during miniscrew removal was comparable to the insertion procedure. At the evening after miniscrew removal the reported pain intensity and discomfort was close to zero. However, some participants experienced miniscrew removal as painful and discomfortable.

Concerning the question whether there was a part in the miniscrew removal that was particularly unpleasant, the free-text answers can give some guidance: Participants described miniscrew removal as a "strange feeling" and "difficult to describe". In particular the "screwing" was mentioned as unpleasant.

\section{Gender differences}

There were no significant differences between boys and girls concerning experience of pain and discomfort during and after tooth extractions and miniscrew insertions.

However, the other domains revealed few significant differences between genders: At baseline, girls reported higher summary estimates for daily activities $(\mathrm{P}=0.037)$ and complained more often about tension in jaws $(\mathrm{P}=0.018)$ and headaches $(\mathrm{P}=0.027)$.

On the other hand, boys stayed home from school more often on the day of tooth extractions $(\mathrm{P}=0.011)$ and more frequently avoided leisure activities $(\mathrm{P}=0.046)$ on the day of the tooth extractions. 


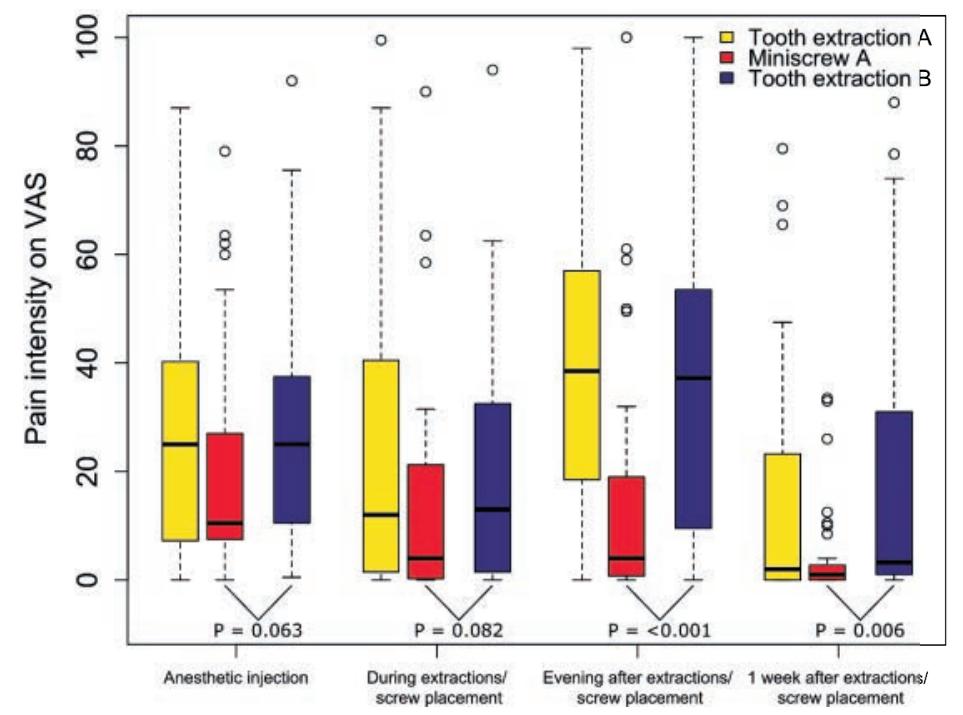

Figure 23: Pain intensity on VAS presented as Tukey boxplot with median values and interquartile range.

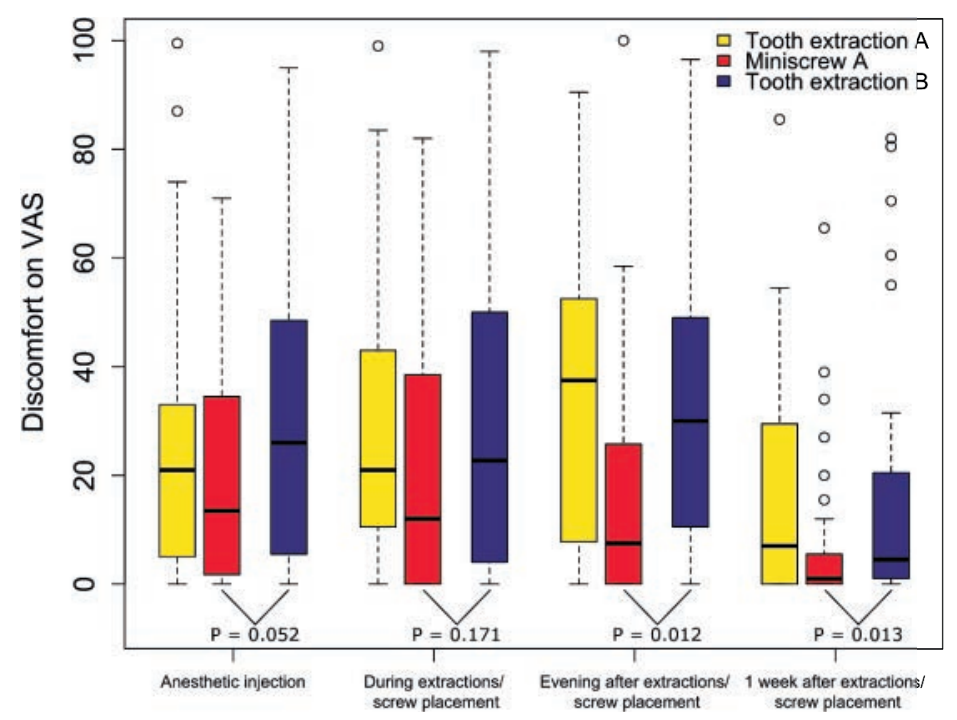

Figure 24: Discomfort on VAS presented as Tukey boxplot with median values and interquartile range. 


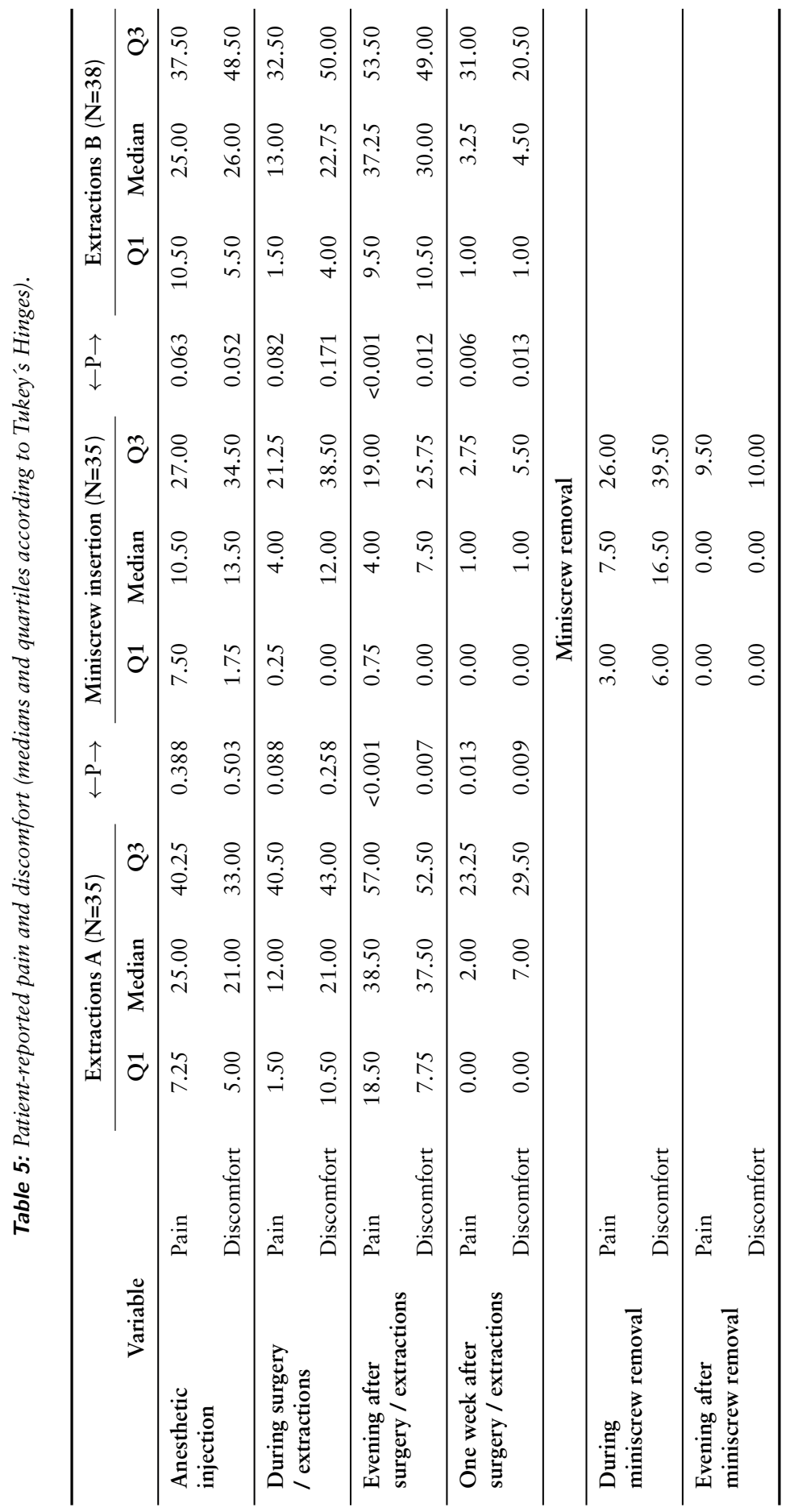




\section{Individual differences}

One drawback with VAS ratings is that every individual has its own level of reference: An acceptable level for pain or discomfort may be zero for some while others would regard 25 as normal. Therefore, the individual differences between the VAS ratings were calculated for every participant.

The medians of the differences for reported pain ratings (Figure 25 ) were close to zero in Group A for all procedures and the differences between procedures were non-significant. Both the pain ratings and the spreading decreased from miniscrew insertion to the week after the procedure. The reported pain ratings in Group $\mathrm{B}$ were significantly higher at the first evening compared to ratings for tooth extraction and to ratings after one week.

The reported discomfort ratings (Figure 26) showed significant more discomfort in Group A at the first evening compared to miniscrew insertions. Further, the ratings in Group B showed significant less discomfort between the first evening after tooth extractions and one week after tooth extractions. No other significant differences between procedures were found.

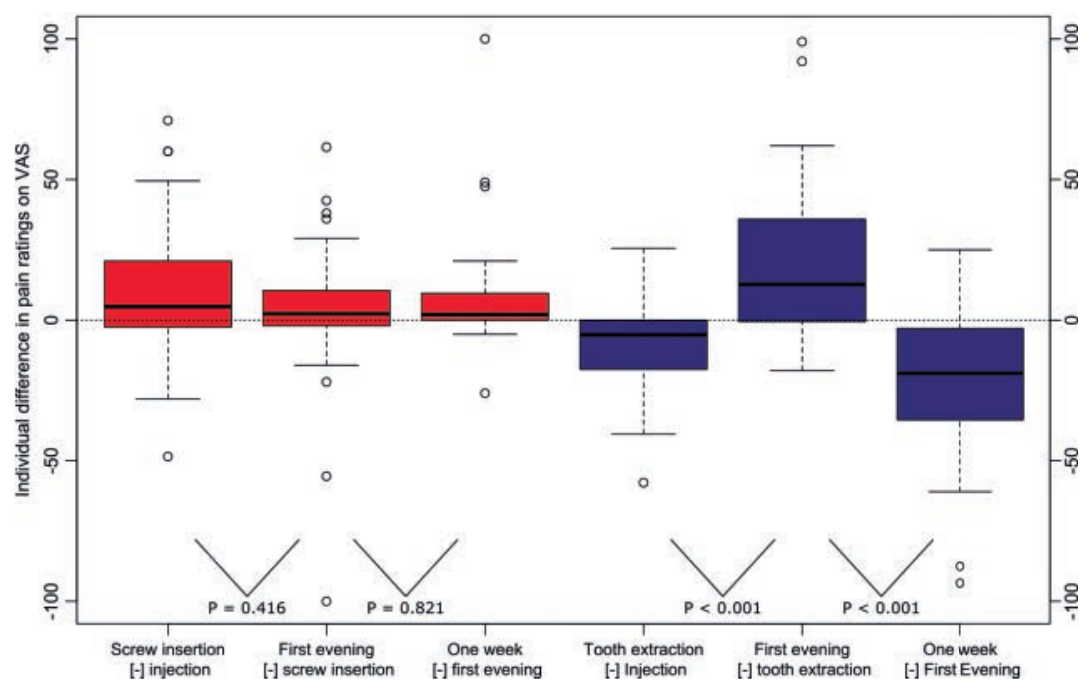

Figure 25: Individual differences in pain ratings on VAS presented as Tukey boxplot with median values and interquartile range. 


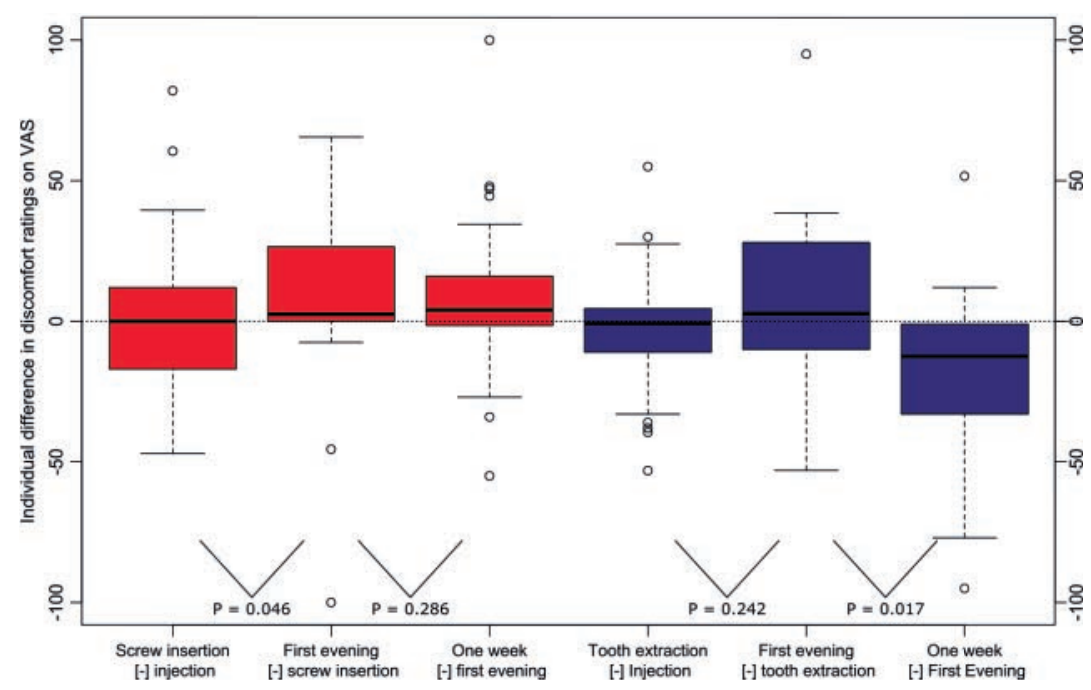

Figure 26: Individual differences in discomfort ratings on VAS presented as Tukey boxplot with median values and interquartile range.

\section{Analgesics}

More than half of the participants $(57.4 \%)$ used analgesics during the first day after premolar extractions and/or miniscrew insertions. Approximately one-third of all participants (29.6\%) continued to use analgesic for one or more days during the first week. The analgesic consumption was not significantly different between groups or between tooth extractions and miniscrew insertions.

The most commonly used analgesics were nonprescription oral analgesics (NPA) such as paracetamol and ibuprofen.

\section{Daily activities and functional jaw impairment}

There were only a few significant differences between groups: Participants reported significantly more difficulties when drinking $(\mathrm{P}$ $=0.035)$ and taking a large bite $(\mathrm{P}<0.001)$ the first evening after tooth extractions. During the first week, even leisure activities were more frequently disturbed after tooth extractions compared to miniscrew insertions $(\mathrm{P}=0.015)$.

Notably, irrespective of treatment group, $19.4 \%$ of the participants stayed home from school the day their teeth were extracted or miniscrews were inserted and $13.0 \%$ stayed home at least one more day during the first week. 


\section{Anchorage capacity (Paper III) \\ Sagittal plane}

When anchorage was reinforced with miniscrews (Group A), the maxillary first molars moved $1.2 \mathrm{~mm}$ mesially during the leveling and alignment phase (i.e., before miniscrews were inserted). When miniscrews were in place during the space closure, no significant mesial movement could be found. During the total observation period (before the finishing phase), the maxillary first molars moved $1.5 \mathrm{~mm}$ mesially.

In contrast, when anchorage was reinforced with molar blocks (Group B), the maxillary first molars comprised $1.4 \mathrm{~mm}$ mesial movement during leveling and alignment and $2.4 \mathrm{~mm}$ during space closure. The mesial movement was $3.8 \mathrm{~mm}$ during the total observation period until finishing started. All differences between groups were statistically significant, except anteroposterior movement during leveling and alignment.

Thus, anchorage reinforcement with molar blocks showed the same results as no additional anchorage reinforcement.

All differences within groups between the different treatment phases were statistically significant except mesial movement during space closure when miniscrews were used. Detailed descriptions about the different tooth movements are presented in Table 6 on page 59 . Figure 27 depicts the anteroposterior movement in detail.

\section{Vertical plane}

When treated with molar blocks, the maxillary first molars revealed a significant eruption of $0.6 \mathrm{~mm}$ until the finishing phase started. In contrast, when miniscrews were used, no significant change was found. This statistical significant difference occurred during the space closure phase.

\section{Transversal plane}

There were no statistically significant differences in transversal movement between or within groups. 


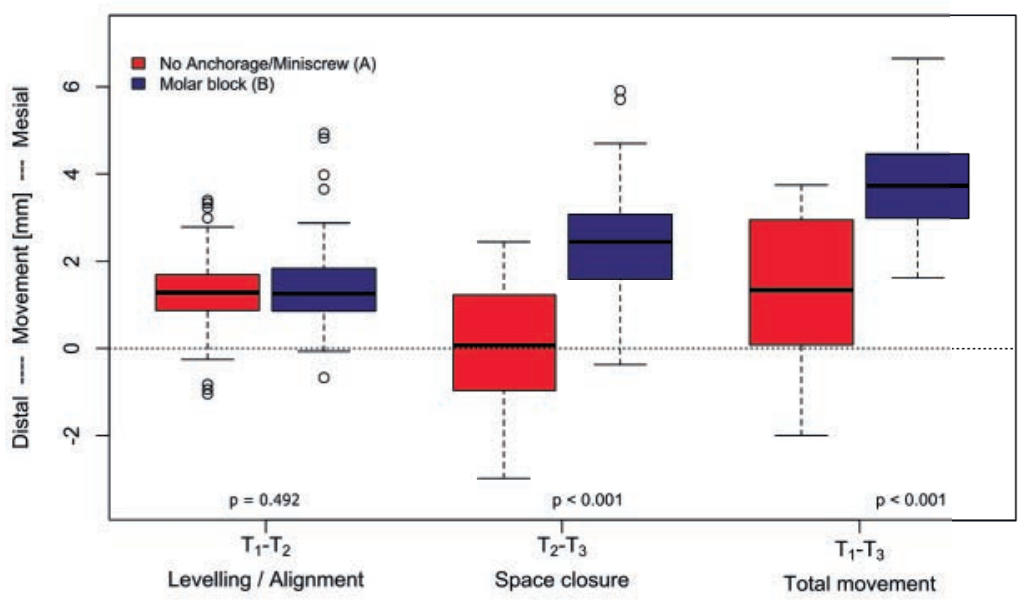

Figure 27: Boxplots with Tukey's Hinges showing the intention-to-treat analysis of the mesial movement of maxillary first molars.

\section{Rotations}

In the cases treated with miniscrews, the maxillary first molars comprised a distal-buccal rotation of 2.3 degrees until the finishing phase started. In contrast, cases treated with molar blocks showed a mesial-palatal rotation of 2.6 degrees. In total, there was a statistical significant difference of 4.9 degrees between groups. It is noteworthy that the rotation characteristics during leveling and alignment were similar in both groups with approximately two degrees distal-buccal rotation. During space closure, rotation did not change when miniscrews were used; when molar blocks were used, there was a 6.4 degrees mesial-palatal rotation.

\section{Tipping}

Compared to miniscrew treatment, molar blocks resulted in 3.3 degrees more mesial tipping of the maxillary first molars before the finishing started. This difference between groups was statistically significant. Even tipping showed similar characteristics with approximately two degrees of mesial tipping in both groups during leveling and alignment. The differences occurred during space closure where the molars were up-righted when miniscrews were 
used, whereas an additional one degree of mesial tipping occurred when molar blocks were used.

\section{Crown torque}

Compared to molar block treatments, miniscrews resulted in 2.0 degrees more buccal crown torque of the maxillary first molars. This statistical significant difference occurred, similar to the differences in rotation and tipping, during space closure.

Figure 28 depicts a simulation of the summarized mean changes in the position of the maxillary first molars.

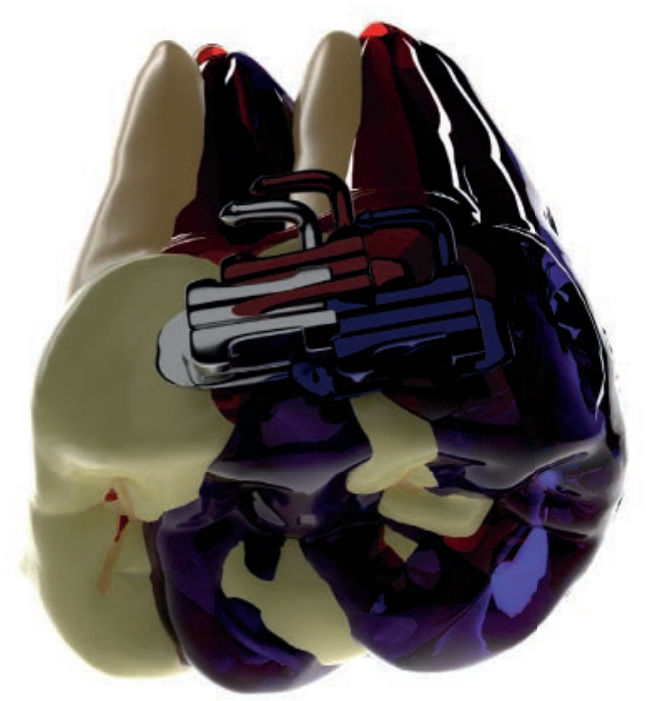

Figure 28: Maxillary first molars mean movement, Group A (red) and B (blue).

\section{Finishing phase $\left(T_{3}-T_{4}\right)$}

The finishing phase followed individual strategies for each case depending on how much space was left. There were some cases that comprised space when the canines had reached a Class I position while the canines in some other cases still had a slight Class II position and no spaces were left. Thus, when no spaces were left, Class II elastics were used to establish a Class I position of the canines. In contrast, in cases with spaces left, anchorage was "burned" to close spaces. The treatment goals were reached in all cases and no re-treatment was needed. 


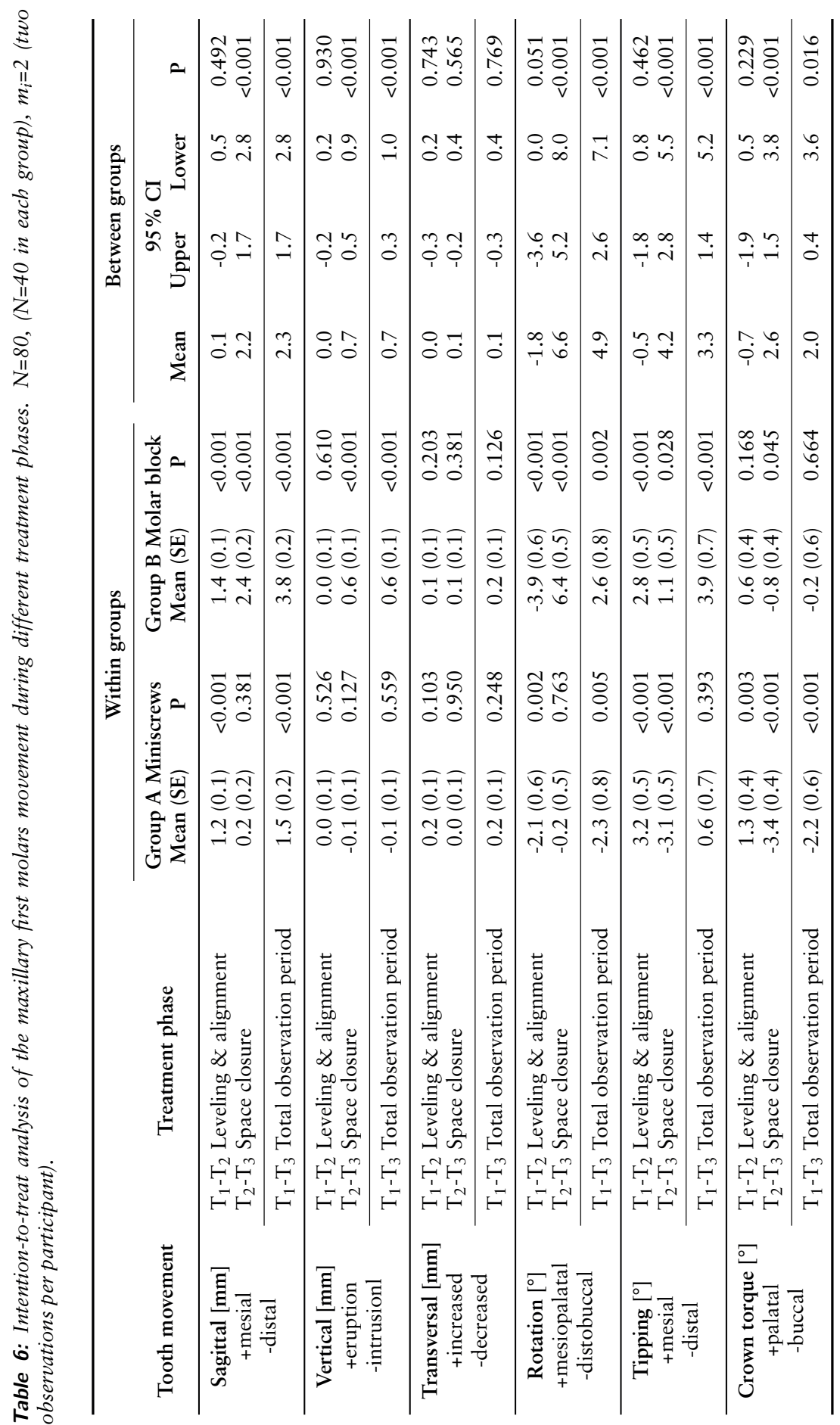




\section{Cost-effectiveness analysis (Paper IV)}

Societal costs - direct and indirect costs

Results concerning treatment costs are presented in Table 7. The median of the difference between groups was $€ 824.96$ (95\% CI $€ 430.80-1267.28$ ), indicating statistical significantly higher societal/total costs for treatment with miniscrews in comparison to molar blocks. This difference was mainly related to significant differences in direct costs. The median of the difference for material costs was $€ 232.77$ and the median of the difference for chair time costs was $€ 460.26$. On the contrary, no statistically significant differences were found for indirect costs (i.e., costs for transportation or for accompanying adults).

\section{Number of visits, summarized visit time and treatment duration}

Results concerning the treatment duration, number of visits and summarized visit time are presented in Table 7 . The analysis revealed that treatment with miniscrews lasted 5.8 months longer. This statistically significant difference in treatment duration resulted in four additional visits - i.e., 140 minutes more of summarized chair time.

Analysis of the different visit categories showed no significant differences in emergency or missed visits. Thus, the difference in the number of visits was largely related to scheduled visits. These scheduled visits mainly occurred during the finishing phase, which was found to be 5.1 months longer in the miniscrew group. Further we found a statistical significant difference between groups in travel-time. At the same time there was no difference in transportation costs. This is an effect of the economic model where transportation within Gävle is calculated with a certain travel-time but zero transportation cost.

\section{Cost-effectiveness}

Since analysis of anchorage capacity in Paper III revealed a difference in treatment effect, a cost-effectiveness analysis was conducted. This cost-effectiveness analysis related the amount of anchorage capacity to increased consumption of resources. Table 8 presents the increased use of resources as per millimeter avoided 


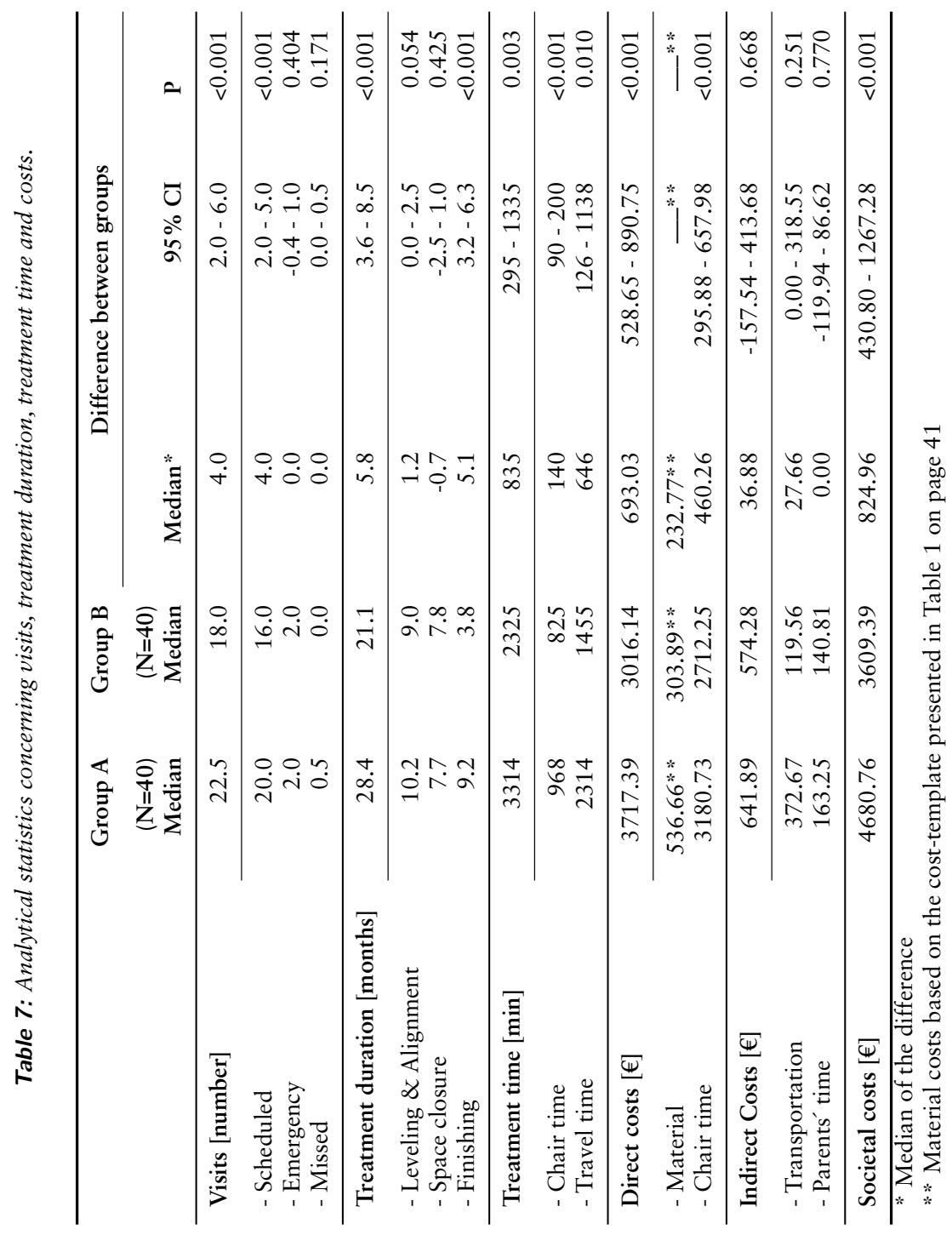


anchorage loss: treatment duration increased by 2.5 months, the summarized visit time increased by 61 minutes and the societal costs increased by $€ 358.68$.

The incremental cost-effectiveness ratio (ICER) and the top right quadrant of the cost-effectiveness plane are depicted in Figure 29. The ICER is based on the median of the difference in costs and the difference in means for anchorage loss.

The magnitude of the difference can be visualized by combining the $95 \%$ confidence intervals in the confidence-box a-b-c-d. ${ }^{93,94}$ However, this approach assumes that cost and effect do not correlate. Since there is a positive correlation between cost and effect, the confidence ellipse is more appropriate. The confidence ellipse reflects covariance in cost and effect differences. The upper and lower limits are an approximation of the $95 \%$ confidence intervals of the ICER. ${ }^{49}$

Table 8: Cost-effectiveness analysis of intention-to-treat data.

\begin{tabular}{llll}
\hline & Group A & Group B & Difference A-B \\
\hline $\mathrm{N}$ & 40 & 40 & - \\
Mean anchorage capacity & $-1.5 \mathrm{~mm}$ & $-3.8 \mathrm{~mm}$ & $2.3 \mathrm{~mm}$ \\
Median treatment duration & $28.4 \mathrm{months}$ & $21.2 \mathrm{months}$ & $5.8 \mathrm{months}$ \\
Median summarized chair time & $968 \mathrm{~min}$ & $825 \mathrm{~min}$ & $140 \mathrm{~min} *$ \\
Median societal costs & $€ 4680.76$ & $€ 3609.39$ & $€ 824.96 *$ \\
\hline Treatment time per millimeter avoided anchorage loss & +2.5 months \\
Visit duration per millimeter avoided anchorage loss & +61 min \\
Costs per millimeter avoided anchorage loss & $€+358.68$ \\
\hline * Median of the difference
\end{tabular}




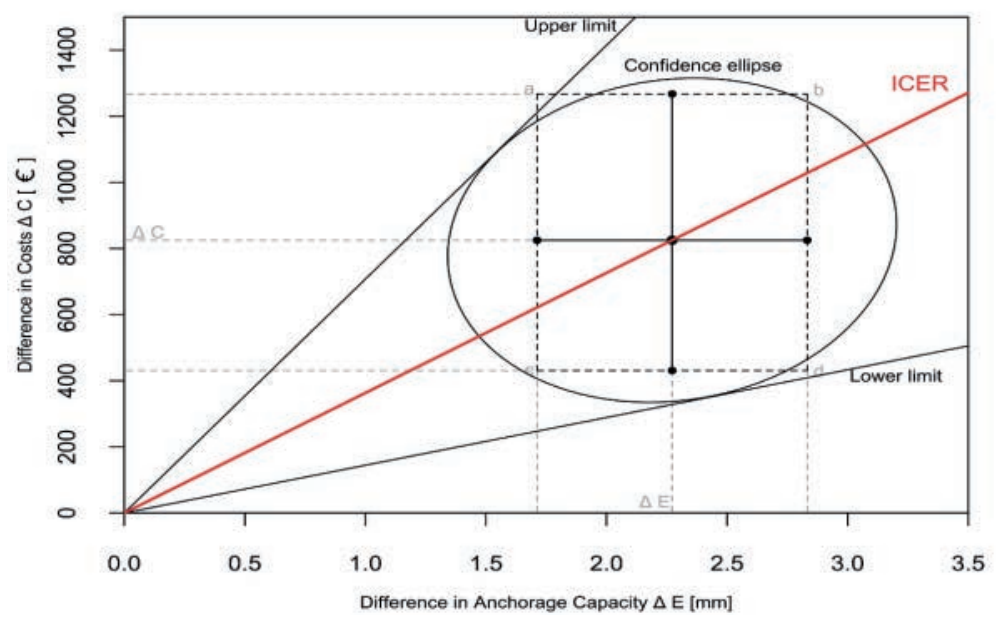

Figure 29: Incremental cost-effectiveness ratio (ICER), cost-effectiveness plane and confidence ellipse.

\section{Harms and side effects (Paper II-IV)}

During this trial, 72 miniscrews were inserted in 36 participants. None of the neighboring roots was damaged during the insertion procedures. The mean wearing duration for miniscrews was 8.5 months (SD 5.5). During this time, three miniscrews became loose. Only one of these miniscrews had to be replaced because additional anchorage reinforcement was necessary. Furthermore, despite the use of a torque screw driver, one miniscrew fractured during insertion. Initially, the fragment was left in the bone and was removed later.

As part of the standard documentation, pre-treatment and posttreatment apical radiographs of the incisors were taken. On these radiographs, root resorption was assessed according to Levander and Malmgren. ${ }^{95}$ The majority of patients showed no or minor root resorptions up to two millimeters (grade 1-2). No statistically significant differences were found in root resorptions between the treatment groups. 



\section{DISCUSSION}

This thesis evaluated patients' perceptions, anchorage capacity and cost-effectiveness of buccal miniscrews. In addition, this thesis compared the results with a conventional system that is used in daily practice.

The most important findings were that miniscrews provided excellent anchorage reinforcement and that miniscrew insertion was well tolerated by adolescent participants. The reported levels of pain and discomfort for the insertion procedure were significantly lower than the levels reported for premolar extractions at the first evening and one week after the procedure. However, when miniscrews were used, treatment duration was prolonged, which in turn caused higher societal/total costs. In contrast, participants treated with molar blocks showed anchorage loss comparable to reciprocal space closure, a finding that suggests molar blocks have little or no anchorage capacity.

\section{Measurement technique}

The RFD-superimposition method presented in Paper I had excellent accuracy and precision. Furthermore, RFD-superimposition is capable of measuring translation in the anteroposterior, transversal and vertical direction and reveals tooth rotation, tipping and torque. Therefore, tooth movements can be mapped over time with RFD-superimposition in a way that gives detailed information about biomechanics.

RFD-superimposition has several advantages compared to other techniques. In most other techniques, measurements are made by manually selecting measurement points; however, manual point selection has been reported as a source of error. ${ }^{96,97}$ RFD-superimposition estimates tooth movement by matching the pre-treatment 
tooth position to the post-treatment tooth position, eliminating an important source of error.

The standard deviations for successive measurements and plaster casts or lateral cephalograms were up to 1.3 and $2.1 \mathrm{~mm} .{ }^{54}$ For lateral cephalograms even higher standard deviations of up to $3.7 \mathrm{~mm}$ have been reported. ${ }^{53}$ Earlier investigations have reported high accuracy and precision for different superimposition techniques on 3D models. However, these studies usually compared their results with the results derived from another technique considered the gold standard. ${ }^{64,72,98}$ Regardless of whether the gold standard was based on plaster casts or lateral cephalograms, it has to be assumed that the measurement error is higher than in modern computerized 3D techniques. Therefore, measurements on plaster casts and lateral cephalograms cannot serve as a gold standard in a validation context (see Insufficient Gold Standard Dilemma on page 24).

In a validation study, Thiruvenkatachari et al. ${ }^{63}$ used a unique setup where the true values for translation were used as references. Their study inspired the validation study in this thesis because this setup was an elegant way to avoid the insufficient gold standard dilemma. In their study, however, both master and slave models were identical in the palate, so the matching technique was not challenged by matching different models. Moreover, no rotational measurements were assessed.

Yet, the question is whether the use of an algorithm-based deformation analysis really is necessary. One has to keep in mind that the purpose of the algorithm is to compensate for the changes between the serial models. If models are taken with a short interval in adult patients, a simple matching might be sufficient. However, even adult patients comprise vertical changes in the palatal vault. ${ }^{71}$ When changes occur, the only alternative would be to use a stable landmark. An interesting approach was to use miniscrews as reference landmarks in the superimposition process. ${ }^{65}$ Following Björk's research ${ }^{99}$, it was assumed that titanium screws maintain their position. Although these miniscrews were unloaded, the authors reported changes in the miniscrews positions up to 0.5 $\mathrm{mm}$. Therefore, miniscrews fail to serve as a stable reference at least as long as they are not osseointegrated. 
The validation study presented in Paper I is unique in its setup. Reference models were used to conduct a validation with known true values. These reference models were modified in the palatal vault in order to challenge the superimposition process by stimulating growth and treatment effects. Furthermore, superimposition and measurements were conducted by four senior consultant orthodontists with different computer skills. After instruction and training, measuring a case took approximately ten minutes, which was comparable to the time needed for tracing and superimposition of lateral cephalograms.

\section{Prerequisites of the RFD-superimposition}

Despite the impressive accuracy and precision of the assessed RFDsuperimposition found in this in vitro validation, there are three compulsory requirements.

- First, there has to be at least some unchanged structure. Because changes correlate with the time passed, the interval between the two registrations is crucial. In adolescents, an interval of one to two years appears to be feasible.

- Second, one basic assumption in the work flow is that the median point of the third rugae is somehow stable. ${ }^{68,72}$ Therefore, this area has to be depicted correctly in the impressions/scans. Some appliances can cause local swelling of the gingiva in this area. This can be the case in particular after treatment with a Nance-appliance, Onplant, Orthosystem implant or palatal miniscrews. To secure correct RFDsuperimposition, areas that obviously changed should be removed before the superimposition process.

- Third, sometimes growth or treatments follow an asymmetric pattern. This asymmetry needs to be considered when corresponding points are picked during raw matching, for example, when a rapid maxillary expansion affects only one side. In these cases, one would only use the median point of the third ruga on the non-effected side in the raw matching.

With this said, it becomes clear that RFD-superimposition is not a one-click solution. 
Consequently, for correct RFD-superimposition in adolescents, serial models can be used with a moderate interval of one to two years. The superimposition outcome can be improved when areas containing obvious changes in the palate are cropped from the model. The superimposition outcome needs to be checked for plausibility, especially in cases with asymmetric growth or treatment effects. With this technique, lateral cephalograms are not needed to evaluate tooth movements, reducing the exposure to $\mathrm{X}$ ray radiation.

\section{Pain \& discomfort}

The reported intensity of pain and discomfort was generally moderate for both premolar extractions and miniscrew insertions. During premolar extractions and miniscrew insertions, differences between groups were not significant. This implies that there was sufficient anesthesia during the procedures. However, after the procedures, participants experienced significant less pain and discomfort after placement of miniscrews compared with tooth extractions. Therefore, the initial hypothesis was accepted.

Compared to findings from earlier trials within our research group, the median values for pain intensity found in this trial were comparable to the values reported for the Orthosystem Implant and lower than pain intensity after Onplant insertion. ${ }^{26}$ When comparing miniscrew insertions with tooth extractions or results from earlier studies one has to be aware that patients with miniscrews also have a fixed appliance that is activated the day of the miniscrew insertion. We know that patients report significant pain even after simple procedures. Bergius et al. ${ }^{100}$ reported mean VAS scores of up to 43.7 one day after the application of elastic separators. This was confirmed in another trial reporting mean VAS scores of 21.4 one day after and 10.4 one week after insertion of fixed appliance. ${ }^{46}$ It can be assumed that at least a part of the experienced pain and discomfort following miniscrew insertions is related to the fixed appliance.

Notably, individual experiences ranged from no pain/discomfort at all to worst imaginable. This wide range of VAS scores can be explained by the fact that in particular adolescents tend to report higher pain scores due to more frequent disturbances in psycho- 
logical well-being. ${ }^{101}$ The general intensity of a painful sensation is the result of a complex modulation. This pain modulation is influenced by factors such as preconditioning experience, attention, attitude and temperament of the patient. ${ }^{102}$ In this context, it is important to recognize that all participants had good to excellent dental health. In many cases, the participant's first experience with an injection in the gums was the injection they received before premolar extractions. Thus, most of the participants had no prior experience of potentially painful dental treatments. This homogeneity of the sample might explain why no significant correlations were found between the baseline questionnaire and reported levels of pain and discomfort. A baseline questionnaire derived from a larger sample or an adult cohort or a sample with poor dental health might have resulted in greater inter-individual differences.

Evaluation of the anesthetic injection revealed that the injection was as painful and as uncomfortable as the procedure itself. Two possible conclusions could be drawn:

First, if the injection is as uncomfortable as the miniscrew installation, miniscrews could be installed with only topical anesthesia, reducing the number of uncomfortable events. Many topical anesthetics can achieve sufficient numbness of the gingiva and to some degree even of the periosteum. ${ }^{103}$ However, when placing miniscrews inter-radicularly, it is important that the patient does not move. To this end, complete numbness of the gingiva, periosteum and cortical bone is necessary and miniscrew insertion with only topical anesthetics is not recommended.

Second, experience of pain and discomfort during anesthetic injection needs to be reduced. This reduction can be achieved with a combination of oral analgesics, topical anesthetics and computerized injection with a system such as The Wand. ${ }^{104}$ This is the recommended approach to provide good pain relief during the injection and the procedure.

One of the disadvantages of the setup was that participants who were treated with miniscrews (Group A) first had to have their premolars extracted and this was followed by approximately six months of orthodontic treatment before miniscrews were inserted. The literature discusses whether a previous intervention can in- 
crease or decrease reported pain values. ${ }^{105,106}$ Therefore, it would have been desirable to insert screws in a group of patients that had no prior experience of tooth extractions or orthodontic treatment. However, Baxmann et al. ${ }^{42}$ reported that prior extractions had no impact on patient perceptions after miniscrew insertion. Since immediate loading improves mechanical stability, this was the concept of choice. ${ }^{30}$ In the end, the results showed a robust difference in experience of pain and discomfort after the intervention.

The questionnaires were analyzed per protocol. The seven patients who were excluded (Group A = 5, Group B $=2$, see CONSORT flow chart, page 50) from the analysis showed no significant differences in the baseline questionnaire, although they reported lower values concerning how well informed they felt about the treatment $(\mathrm{P}=0.039)$. Furthermore, some patients did not answer all the questions in the questionnaires. Nevertheless, the overall response rate was high $(87.8 \%)$.

\section{Anchorage capacity \& movement characteristics}

The results in Paper III showed that miniscrews significantly increased the anchorage capacity from the moment of their insertion. When miniscrews were used, there was no statistically significant mesial movement during space closure. This finding confirms findings from earlier investigations on different skeletal anchorage systems. ${ }^{7,35}$ Consequently, the hypothesis concerning miniscrews anchorage capacity was confirmed. In addition, the results showed that molar blocks did not increase the anchorage capacity. So, the hypothesis that molar blocks were capable of certain anchorage reinforcement had to be rejected. Since no previous randomized controlled trials have evaluated molar blocks' anchorage capacity, these findings are difficult to compare with other trials.

Only a few screws were lost and the overall success rate of miniscrews was $96 \%$. This was higher than reported in recent reviews $(83.6 \%-86.5 \%) .{ }^{36,38}$ This difference in success rate between this trial and the systematic reviews can be explained by the heterogeneity of the data and studies included in the reviews. Typically, systematic reviews report data from trials with different screw types, insertion sites and force applications. Recently, a systematic review revealed that a diameter $>1.4 \mathrm{~mm}$, a length $\geq 8 \mathrm{~mm}$ 
and insertion in the maxilla were three of four factors for higher success rates. ${ }^{107}$ In the current research project we used one brand of miniscrews with $1.5 \mathrm{~mm}$ diameter and $8-10 \mathrm{~mm}$ length. All miniscrews were buccally placed in the maxillary keratinized gingiva and were immediately loaded with $150 \mathrm{~g}$ continuous force. Furthermore, miniscrew insertion was always followed up with apical radiographs to visualize eventual root proximity which is considered an important factor for success rate. ${ }^{85,108}$

Due to the use of RFD-superimposition, ${ }^{109}$ the movement of maxillary first molars could be mapped in a unique way. Treatment effects were described in terms of translation, rotation, tipping and torque. This information was valuable to understand the biomechanics of both treatment concepts. However, the size of movement in some directions might lack clinical importance. When a difference of one millimeter or more is the limit for clinical relevance, only the anteroposterior movement has a considerable effect size. Concerning rotation, tipping and torque, the difference between groups was less than five degrees. Nevertheless, knowledge of the biomechanics is important when tooth positions are already deviant before treatments begin.

When analyzing the space closure phase, it was found that the maxillary first molars in approximately half of the cases treated with miniscrews moved distally. Beyond distalization, the molars tipped distally and showed buccal crown torque. Two factors can explain this kind of movement:

First, the friction, which occurs in the molar tube when the archwire is pressed distally, causes distalization in combination with distal tipping and a slight distobuccal rotation.

Second, the vertical component of the applied force can intrude the maxillary teeth. ${ }^{110,111}$ This might even cause the buccal crown torque.

When molar blocks were used, the maxillary first molars tipped mesially and moved in a contrary rotation because the tiebacks pulled the molars into mesiopalatal rotation.

However, not all cases treated with miniscrews showed a maintained position or distalization of the molars. There were even cases with 1-2 mm mesial movement. One would expect this only to happen when the miniscrew was lost. With only three lost mini- 
screws, this cannot be the main explanation. One other explanation could be displacement of the miniscrews. ${ }^{65,112}$ Furthermore, teeth are exposed to occlusal forces. ${ }^{113}$ The anterior component of the occlusal force is a result of the inclination of the posterior teeth and may be responsible for the mesial movement. ${ }^{113-115}$ Moreover, anchorage loss for dropouts was set to $3.75 \mathrm{~mm}$ in the intention-to-treat analysis. This means that some of the anchorage loss occurred virtually during data analysis and not during treatment.

\section{Cost-effectiveness}

The cost-effectiveness analysis revealed that miniscrews delivered better anchorage reinforcement but treatment was approximately $€ 825$ more expensive. Therefore, the initial hypothesis was rejected.

This paradox needs to be addressed to draw correct conclusions. When anchorage need is only moderate, many anchorage techniques are available. To use miniscrews is one option. This option gives distinct control over the mesial movement of the maxillary molars and does not rely on good compliance. This grade of control has its price as this thesis revealed: If all patients with moderate anchorage need were treated with miniscrews, the number of treatments conducted with existing resources would be reduced by $16 \%$. In other words, the opportunity $\operatorname{cost}^{49}$ is that one out of six treatments would lack resources.

There are several possible reasons for the increased costs:

1. Material costs have direct impact on the treatment costs and the choice of miniscrew-type is the most important factor. The Spider Screw ${ }^{\circledR}$ is mid-price segment. There are cheaper miniscrews and there are miniscrews that are more expensive. Irrespective miniscrew-type there is always a material cost associated with miniscrew insertion for anesthesia, radiographs and instruments.

2. Treatment time related to insertion and removal of the miniscrews has impact on the treatment costs. One could argue that miniscrew insertion and removal is done within minutes. However, the time needed for pretreatment information, topical anesthesia and injection and pre-/post-insertion 


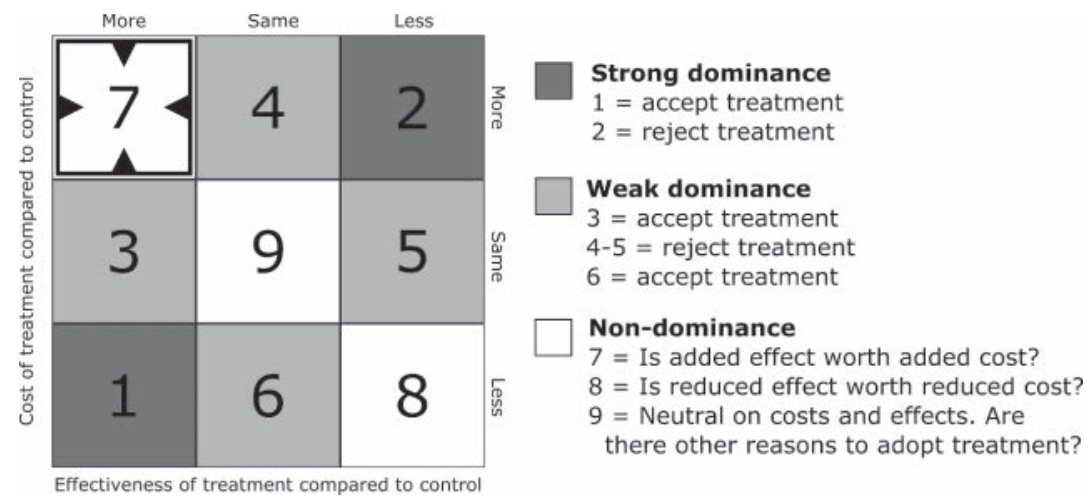

Figure 30: Incremental costs and effects compared between treatment and control. ${ }^{49}$

radiographs is not negligible.

3. Space closure follows a unilateral pattern when miniscrews are used. First, the maxillary six frontal teeth were moved using en masse retraction. Second, as soon as the canines had reached a Class I position, anchorage reinforcement was removed and the lateral teeth were moved mesially to close the spaces. This second step was unnecessary when molar blocks were used because several millimeters anchorage were lost during space closure.

Figure 30 depicts the nine possible outcomes of a cost-effectiveness analysis. The results of this trial show a non-dominance with more effect to a higher price according to stage 7 (Is added effect worth added cost?). Economic analyzes usually discuss the willingness-to-pay as a cost below which a treatment definitely will be paid for. In the context of anchorage reinforcement, one has rather to define the willingness-to-accept-anchorage-loss for the treated cases. When loss of anchorage would jeopardize the treatment result, the extra costs for skeletal anchorage are justified.

One could argue that the miniscrews could have been removed earlier to avoid a two-step space closure. However, in the setup of the trial, treatment phases needed to be defined properly with a standardized treatment protocol.

The literature indicates that the use of miniscrews can result in shorter treatment duration $110,116,117$, although we found the op- 
posite as treatment duration was prolonged. However, even with a longer treatment duration, cost-effectiveness could have been improved by assigning longer intervals between the visits. In this trial, the interval was standardized in both groups to six weeks. With all facts in hand, intervals during space closure could have been set between eight and ten weeks when miniscrews were used. Longer intervals can be reasonable because there is not the same need to check whether anchorage fails and miniscrews are used in combination with NiTi coils. These coils do not need to be reactivated in the same way as tiebacks do.

Another aspect of the paradox was that further anchorage reinforcements were used during the finishing phase. To obtain the whole picture, one has to be aware that the majority of participants used Class II elastics in the finishing phase. Therefore, molar blocks were ineffective in reinforcing anchorage, but the concept to use molar blocks and Class II elastics was more cost effective in treatment of standard cases than treatment with miniscrews. Thus, it could be argued that molar blocks generally are not needed.

In the context of anchorage techniques for moderate anchorage cases, one has to be aware that some anchorage reinforcement will be necessary. To rely on Class II elastics only has the drawback that this technique again is co-operation dependent. Furthermore, are Class II elastics applied in the end of the treatment. Thus, Class II elastics are a compromise solution. Instead, it would be favorable to use an anchorage technique already in the beginning of the treatment. Whatever technique this might be (Nance appliance, lingual arch and so on), it probably will include some dental work which in turn has a cost as well.

The median number of visits and treatment duration in the miniscrew group (22.5 visits, 28.4 months) was similar to the results recently reported in an RCT about maximum anchorage cases (19.84 visits, 27.42 months treatment duration). ${ }^{7}$ Therefore, it can be assumed that treatment duration will be prolonged when anchorage reinforcement is used to achieve unilateral space closure.

It is important to note that differences between the groups in costs were mainly related to increased direct costs. The differences 
in direct costs were related to material costs (€ 232.77) and chair time costs ( $€ 460.26$, see Table 7 , page 61 ). There was no statistically significant difference in indirect costs. This lack of difference could be due to two factors: teenagers, except for the initial appointments, were often not accompanied by an adult and transportation costs were low at the end of the treatment because most participants went to secondary schools within walking distance to the orthodontic clinic.

Thus, additional visits due to prolonged treatment duration had only limited influence on the indirect costs. Indirect costs represent less than $25 \%$ of the societal costs. Studies on younger participants being more frequently accompanied by their parents reported indirect costs of about $40 \%$ of the societal costs. ${ }^{118}$

\section{Overall limitations of this thesis}

This thesis is based on a single center randomized controlled trial. Orthodontic treatments were conducted by two clinicians and all miniscrews were inserted by one. Therefore, operator-related errors might have influenced the results. Furthermore, there are no data concerning the reasons why a number of patients declined to participate. Anxiety may have played a role, so this can be considered a source of selection bias.

The groups comprised a mean difference in age of approximately one year. The difference between 15 and 16 years of age was regarded negligible concerning growth or tooth movement. The age difference may play a role concerning experience of pain and discomfort but the outcomes during and after premolar extractions showed no significant differences between the groups and the groups were regarded comparable. In any case, the age distribution could have been improved by using block randomization.

Concerning health economics, this thesis was based on a number of variables largely impacted by regional factors. Thus, travel times and costs and chair time costs cannot be transferred to other clinics or caregivers. However, non-monetary variables such as number of visits or treatment duration were deemed universal. 


\section{Bias}

By using the design of a randomized controlled trial (RCT), elimination of bias in treatment assignment was assured. ${ }^{119}$ Further, were potentially confounding variables, hidden or out of control, equally distributed in the groups. The use of intention-to-treat (ITT) analysis avoids overoptimistic estimates of the efficacy of an intervention resulting from the removal of dropout. ${ }^{89}$ Since the number of dropouts was lower than assumed in the sample size calculation all investigations had good statistical power.

The measurement technique for tooth movements showed only little bias in the validation and the reversed approach to calculate the chair time costs was based on the real expenses collected from accounting data. Furthermore, assessment and data analysis were conducted blindly. In summary, the overall risk for bias in this thesis was regarded as low.

\section{Generalizability}

In contrast to many other trials that use adult cohorts, this thesis was based on a sample consisting of adolescents with mean age of $15-16$ years and a distribution of $65 \%$ girls and $35 \%$ boys. The gender stratified randomization maintained proportional sampling between groups. Since this gender distribution is comparable to the population found in orthodontic clinics, this thesis is based on a relevant and realistic adolescent sample.

Moreover, the number of dropouts was less than assumed in the sample size calculation and the overall response rate from the questionnaires was high implying maintained statistical power. Overall, the conclusions drawn from this thesis were regarded with sufficient generalizability and also generalizable to other industrial countries.

\section{Final remarks}

This thesis evaluated a treatment concept with buccal miniscrews. Recently, palatal miniscrews with different kinds of supra-constructions have become more popular. One could wonder whether palatal miniscrews are superior to buccal miniscrews. In fact, these two concepts are different in their approach. Typically, palatal miniscrews are used as indirect anchorage with a supra-construction 
of rigid arches. This supra-construction is often manufactured by a dental technician, which implies several visits for taking impressions and inserting the supra-construction. This concept is always a planned measure in cases where the anchorage need already in the planning stage is estimated to be high. Unfortunately, anchorage need is sometimes difficult to assess. Often, estimations done during the planning stage have to be revised during the treatment phase. When the anchorage need unexpectedly becomes problematic during a regular visit, buccal miniscrews as direct anchorage can be immediately inserted and used. Palatal miniscrews used as indirect anchorage requires further investigation because even here the evidence is still weak.

The RFD-superimposition might need further improvements, including increasing the grade of automation in the process to reduce the time needed for measurements and to reduce the risk for operator error. Further improvement could be implemented in the algorithm. Although matching serial scans of glaciers and maxillae have much in common, there is one crucial difference: A maxilla has a mid-line and certain symmetry around this mid-line. Different weightings and plausibility checks could therefore improve the algorithm.

Further research is also needed for superimposition approaches in the mandible. Since the keratinized part of the gingiva only covers areas close to the teeth, these areas are not stable enough when teeth are moved.

For the mandible, a new approach might be necessary. 



\section{CONCLUSIONS}

In the validation study concerning the novel raw-, fine-matching and deformation analysis (RFD-superimposition) (Paper I), the following conclusions were made:

- RFD-superimposition was a valid method for measuring tooth movements in the maxilla. Furthermore, this method had excellent inter-rater and test-retest reliability.

- RFD-superimposition was robust for variances in the local point resolution and outliers. In addition, it tolerated palatal deformations as they typically occur during growth and orthodontic treatment.

- RFD-superimposition may be used to analyze treatment effects in adolescent orthodontic patients.

In the survey comparing experience of pain and discomfort between miniscrew insertions and premolar extractions (Paper II), the following conclusions were made:

- Insertion of miniscrews caused lower levels for pain intensity and discomfort in comparison to premolar extractions. These differences were statistically significant at the followup the evening of the procedure and one week after the procedure.

- The use of miniscrews in adolescents was well tolerated and can be recommended with accurate anesthetization. 
In the trial evaluating and comparing the anchorage capacity of miniscrews and molar blocks (Paper III), the following conclusions were made:

- With buccal miniscrews, no significant mesial movement of the maxillary molars occurred during space closure. Furthermore, the maxillary first molars showed distal rotation, buccal crown torque and no change in vertical position.

- With molar blocks, the mesial movement of the maxillary first molars was comparable to reciprocal space closure. Furthermore, the maxillary first molars showed mesial rotation, mesial tipping and slight eruption.

- Miniscrews provided superior anchorage capacity and molar blocks appeared not to reinforce anchorage. Thus, molar blocks cannot be recommended as anchorage reinforcement.

In the cost-effectiveness analysis comparing the use of miniscrews and molar blocks as anchorage reinforcement (Paper IV), the following conclusions were made:

- The use of miniscrews increased treatment costs.

- With miniscrews, space closure was mainly conducted from one side at a time. This caused a prolonged treatment duration.

- Miniscrews did not reduce treatment costs in a standard treatment, but miniscrews could be used to conduct treatments that were not possible without superior anchorage reinforcement. 


\section{Clinical implications}

1. The use of miniscrews in adolescents can be recommended.

2. Miniscrews provide superior anchorage reinforcement.

3. When miniscrews are used, prolonged treatment duration and higher treatment costs have to be expected. 



\section{ACKNOWLEDGEMENTS}

\section{Supervisors, Co-Workers, and Colleagues}

To combine clinical work with research has always been my dream. With the help of my supervisors, co-workers, and colleagues, this dream came true and I deeply thank everyone who was involved in this work for their support. In particular, I would like to thank the following people:

Professor Lars Bondemark, my main supervisor and co-author. Thank you, Lars, for all your guidance during this work. Your proofreading comments really helped me to get back on track sometimes. Your quick answers came always without any delay. Whenever I sent you a manuscript and thought it would take a couple of days for you to read it, a commented version of the manuscript returned within 24 hours. Your valuable advice during discussions always added another perspective to my work.

Doctor Ingalill Feldmann, my mentor, supervisor, co-author, colleague, and friend. Thank you for your enthusiasm, energy, and time. You introduced me to the world of orthodontics, one of the most exciting professions in the world! I am honored that I got the opportunity to continue the research you started. This project would not exist without your work and you guided me through this journey. You gave me the chance to develop my own ideas and to find out if they were worth pursuing. You opened your research network for me and never gave up on me even when things got ready at the eleventh hour. I hope there will be lots of future publications with our names on.

Doctor Sofia Petrén, my co-author and supervisor. Thank you for all your advice, in particular during the conduct of the health eco- 
nomic analysis. Your experience in this field helped me to retrieve population economic data from different sources and to find an appropriate concept for Paper IV. Your comments when discussing the article added yet another dimension to this work. Thanks to you, I do my best to maintain even the unusual letters such as öåä and of course é in the reference list.

Senior consultant orthodontist Karin Apel Eriksson, my colleague and head of the Orthodontic Clinic in Gävle. Thank you for giving me the opportunity to conduct this research project. Whenever you heard a heavy sigh from my office you stepped by and found some encouraging words.

Daniel Krueger from GFaI - Society for the Advancement of Applied Computer Science, Berlin, Germany. Thank you for your commitment when working with the superimposition technique and the reference models. With 3D techniques, the devil is in the details. Thanks to your support I could solve many problems that I was not even aware existed before we met.

The senior consultant orthodontists Anke Krämer and odont lic Lena Zettergren-Wijk for their support during the validation study. You conducted the measurements with great enthusiasm and spent hours and hours of your valuable time in front of your computers doing measurements and re-measurements.

Senior consultant orthodontist Camilla Hedlund for sharing the office with two PhD students and ALL our models! Thank you for taking care of my patients when I was not at the clinic, in particular the ones with Forsus appliance.

Hossein Ordoubadian from Accent Språkservice for all help with the language review.

Everyone who worked with me in my team, in particular Susanne Skog, Annika Rudolfsson, Eva Granström, Eva Lucchesi, Helga Särkimäki. Without your help it would have been hard to collect the questionnaires. And it would have been even harder to manage all the other patients not participating in the trial. Sometimes it seemed that the every-day-challenge was not to move teeth, it was booking the next appointment! 


\section{My Family}

I deeply thank my wife Franziska for all the love and support. You kept our family running while I was busy doing other "important" things. You remembered the birthdays and managed our social contacts so that we, despite my research, still have friends! I thank my two children Frida and Max for standing out with a periodically unavailable dad.

I thank my sister Kirsten and her husband Christian for all spontaneous help and discussions about english grammar. Especially when urgent questions occurred late at night!

\section{Employer \& Research Funds}

This work would not have been possible without the support from my employer the Public Dental Service Region Gävleborg. I am grateful for the opportunity to conduct this research project. I appreciate all the time and resources that I could use for this work.

The Center for Research and Development Uppsala University/Region Gävleborg and its staff for giving discussions, interesting seminars and brain-storming-coffee-breaks. And for providing essential financial support to my project, year after year, from the very beginning to the end.

Malmö University and the National Odontologic Research School gave me access to their resources and the fantastic scientific training program.

The Thuréus Foundation for the promotion of Dental Science and the Swedish Dental Associations scientific funds supported this project so we were able to use the latest techniques for our research.

\section{Open Source Community}

Special thanks go to all the idealists developing and working with open source software. You provide the world with extraordinary computer programs, free to use for everyone and supported by countless forums giving expert support to newbies. During the conduct of this thesis, the following open source programs were 
used and I want to direct my deep thanks to the people behind this work:

\section{Typesetting in LaTeX}

This dissertation was written in $\mathrm{ATE}_{\mathrm{E}} \mathrm{X}$, the best ever program for typesetting long documents. $\mathrm{AT}_{\mathrm{E}} \mathrm{X}$ uses uncountable scripts and packages. One of the most important scripts was the KOMA script written by Markus Kohm. Without KOMA it would have been impossible to typeset the dissertation according to the template provided by Malmö University.

\section{Statistics in $\mathrm{R}$}

I thank statistician Hans Högberg for his assistance when planning and preparing this research project. Most of the statistical analysis in this thesis was performed using the programming language $\mathrm{R}$. I learned about $\mathrm{R}$ during the statistic classes provided by the $\mathrm{Na}$ tional Odontologic Research School. Dr. Maria Altman from the Karolinska Institute, Stockholm, provided me with great instructions for beginners. Later, I was supported by the statisticians of the Center for Research and Development Uppsala University/Region Gävleborg, Drs Per Liv, and Sara Gustavsson. Without your support I would have never continued using R. You taught me so much that now I can use R on my own, almost.

\section{Artwork in Gimp \& Inkscape}

All graphic work was done using Gimp and Inkscape. There is simply nothing that cannot be done with these two programs. Since I could not afford to buy Photoshop when I was a student, I have been using these programs from the very beginning of my academic career. They should be installed on every computer.

\section{D illustrations in Blender}

All 3D animations that were used during the presentations were done in Blender. Blender is a 3D graphics software used for animations, 3D printing, video games, and more. Blender is developed by the Blender Foundation, a non-profit organization that is chaired by Ton Roosendaal, the original developer of the Blender Software. 


\section{REFERENCES}

1. Angle EH. Chapter X, Anchorage. In: Treatment of Malocclusion of the Teeth: Angle's System.. 6th ed. S.S. White Dental Manufacturing Company; 1900. p. 111-112. Available at: archive.org/details/treatmentofmaloc00angliala. (page 7)

2. Roberts-Harry D, Sandy J. Orthodontics. Part 9: anchorage control and distal movement. Br Dent J. 2004;196(5):255-263. PMID:15017408. (page 7)

3. Jepsen A. Root surface measurement and a method for xray determination of root surface area. Acta Odontol Scand. 1963;21:35-46. PMID:13961805. (page 7, 8)

4. Graber TM, Vanarsdall RL, Vig KW, Huang GJ. Bone Physiology, Metabolism, and Biomechanics in Orthodontic Practice. In: Orthodontics - Current Principles \& Techniques. 6th ed. St. Louis, Missouri, USA: Elsevier Mosby; 2017. p. 131. (page 7)

5. Proffit WR, Fields HW, Sarver DM. Chapter 8 - The Biologic Basis of Orthodontic Therapy. In: Contemporary Orthodontics. 5th ed. Elsevier Mosby; 2013. p. 297. (page 8)

6. Diar-Bakirly S, Feres MF, Saltaji H, Flores-Mir C, El-Bialy T. Effectiveness of the transpalatal arch in controlling orthodontic anchorage in maxillary premolar extraction cases: A systematic review and meta-analysis. Angle Orthod. 2017;87(1):147-158. PMID:27504820. (page 9)

7. Sandler J, Murray A, Thiruvenkatachari B, Gutierrez R, Speight P, O'Brien K. Effectiveness of 3 methods of anchor- 
age reinforcement for maximum anchorage in adolescents: A 3-arm multicenter randomized clinical trial. Am J Orthod Dentofacial Orthop. 2014;146(1):10-20. PMID:24974994. (page $9,16,70,74$ )

8. Stivaros N, Lowe C, Dandy N, Doherty B, Mandall NA. A randomized clinical trial to compare the Goshgarian and Nance palatal arch. Eur J Orthod. 2010;32(2):171-176. PMID:19959609. (page 9)

9. Sullivan ZC, Harrison JE. Tissue necrosis under a Nance palatal arch: a case report. J Orthod. 2017;44(4):302-306. PMID:28602154. (page 9)

10. Jambi S, Thiruvenkatachari B, O’Brien KD, Walsh T. Orthodontic treatment for distalising upper first molars in children and adolescents. Cochrane Database Syst Rev. 2013;10(10):CD008375. PMID:24155018. (page 10)

11. Kloehn SJ. Orthodontics-force or persuasion. Angle Orthod. 1953;23(1):55-65. (page 10)

12. Nanda RS, Kierl MJ. Prediction of cooperation in orthodontic treatment. Am J Orthod Dentofacial Orthop. 1992;102(1):15-21. PMID:1626525. (page 10)

13. Al-Moghrabi D, Salazar FC, Pandis N, Fleming PS. Compliance with removable orthodontic appliances and adjuncts: A systematic review and meta-analysis. Am J Orthod Dentofacial Orthop. 2017;152(1):17-32. PMID:28651764. (page 10)

14. Cole WA. Accuracy of patient reporting as an indication of headgear compliance. Am J Orthod Dentofacial Orthop. 2002;121(4):419-423. PMID:11997767. (page 10)

15. Feldmann I, Bondemark L. Anchorage capacity of osseointegrated and conventional anchorage systems: A randomized controlled trial. Am J Orthod Dentofacial Orthop. 2008;133(3):339.e28. PMID:18331927. (page 10, 23, 32) 
16. LeFort $\mathrm{R}$. Les modes des réaction des tissues et les moyens de défense de l'organisme vis-à-vis des projectiles inclus dans les tissus et en particulier dans le thorax. Bull Mem Soc Chir Paris. 1918;44:733-739. (page 12)

17. Gainsforth BL, Higley LB. A study of orthodontic anchorage possibilities in basal bone. Am J Orthod Oral Surg. 1945;31(8):406-417. (page 12, 13)

18. Turley PK, Kean C, Schur J, Stefanac J, Gray J, Hennes $\mathrm{J}$, et al. Orthodontic force application to titanium endosseous implants. Angle Orthod. 1988;58(2):151-162. PMID:3164593. (page 13)

19. Roberts WE, Helm FR, Marshall KJ, Gongloff RK. Rigid endosseous implants for orthodontic and orthopedic anchorage. Angle Orthod. 1989;59(4):247-256. PMID:2688486. (page 13)

20. Roberts WE, Marshall KJ, Mozsary PG. Rigid endosseous implant utilized as anchorage to protract molars and close an atrophic extraction site. Angle Orthod. 1990;60(2):135-152. PMID:2344070. (page 13)

21. Huang LH, Shotwell JL, Wang HL. Dental implants for orthodontic anchorage. Am J Orthod Dentofacial Orthop. 2005;127(6):713-722. 15953897. (page 13)

22. Wehrbein H, Glatzmaier J, Mundwiller U, Diedrich P. The Orthosystem-a new implant system for orthodontic anchorage in the palate. J Orofac Orthop. 1996;57(3):142-153. PMID:8655109. (page 13, 14)

23. Wehrbein H, Merz BR, Diedrich P. Palatal bone support for orthodontic implant anchorage-a clinical and radiological study. Eur J Orthod. 1999;21(1):65-70. PMID:10191579. (page 14)

24. Block MS, Hoffman DR. A new device for absolute anchorage for orthodontics. Am J Orthod Dentofacial Orthop. 1995;107(3):251-258. PMID:7879757. (page 14) 
25. Li F, Hu HK, Chen JW, Liu ZP, Li GF, He SS, et al. Comparison of anchorage capacity between implant and headgear during anterior segment retraction. Angle Orthod. 2011;81(5):915-922. PMID:21299412. (page 14)

26. Feldmann I, List T, Feldmann H, Bondemark L. Pain intensity and discomfort following surgical placement of orthodontic anchoring units and premolar extraction: a randomized controlled trial. Angle Orthod. 2007;77(4):578-585. PMID:17605489. (page 14, 16, 68)

27. Cope JB. ORTHOTADs The Clinical Guide and Atlas $<$ br $>$. 1st ed. Dallas, Texas, USA: Under Dog Media; 2007. (page 15)

28. Melsen B, Costa A. Immediate loading of implants used for orthodontic anchorage. Clin Orthod Res. 2000;3(1):23-28. PMID:11168281. (page 15)

29. Migliorati M, Drago S, Gallo F, Amorfini L, Dalessandri $\mathrm{D}$, Calzolari C, et al. Immediate versus delayed loading: comparison of primary stability loss after miniscrew placement in orthodontic patients-a single-centre blinded randomized clinical trial. Eur J Orthod. 2016;38(6):652-659. PMID:26728036. (page )

30. Maino BG, Maino G, Mura P. Spider Screw: skeletal anchorage system. Prog Orthod. 2005;6(1):70-81. PMID:15891786. (page 15, 70)

31. Miyawaki S, Koyama I, Inoue M, Mishima K, Sugahara T, Takano-Yamamoto T. Factors associated with the stability of titanium screws placed in the posterior region for orthodontic anchorage. Am J Orthod Dentofacial Orthop. 2003;124(4):373-378. PMID:14560266. (page 15)

32. Alkadhimi A, Al-Awadhi EA. Miniscrews for orthodontic anchorage: a review of available systems. J Orthod. 2018;45(2):102-114. PMID:29542406. Available from: https://www.ncbi.nlm.nih.gov/pubmed/29542406. (page 15) 
33. Brown RN, Sexton BE, Chu TMG, Katona TR, Stewart KT, Kyung HM, et al. Comparison of stainless steel and titanium alloy orthodontic miniscrew implants: a mechanical and histologic analysis. Am J Orthod Dentofacial Orthop. 2014;145(4):496-504. PMID:24703288. (page 15)

34. Feldmann I, Bondemark L. Orthodontic anchorage: a systematic review. Angle Orthod. 2006;76(3):493-501. PMID:16637733. (page 15)

35. Jambi S, Walsh T, Sandler J, Benson PE, Skeggs RM, O'Brien KD. Reinforcement of anchorage during orthodontic brace treatment with implants or other surgical methods. Cochrane Database Syst Rev. 2014;8:CD005098. PMID:25135678. (page 15, 16, 70)

36. Schätzle M, Männchen R, Zwahlen M, Lang NP. Survival and failure rates of orthodontic temporary anchorage devices: a systematic review. Clin Oral Implants Res. 2009;20(12):1351-1359. PMID:19793320. (page 16, 33, 70)

37. Papageorgiou SN, Zogakis IP, Papadopoulos MA. Failure rates and associated risk factors of orthodontic miniscrew implants: a meta-analysis. Am J Orthod Dentofacial Orthop. 2012;142(5):595.e7. PMID:23116500. (page )

38. Alharbi F, Almuzian M, Bearn D. Miniscrews failure rate in orthodontics: systematic review and meta-analysis. Eur J Orthod. 2018;PMID:29315365. (page 16, 33, 70)

39. Fleming PS, Koletsi D, O’Brien K, Tsichlaki A, Pandis N. Are dental researchers asking patient-important questions? A scoping review. J Dent. 2016;49:9-13. PMID:27068159. (page 16)

40. Krishnan V. Orthodontic pain: from causes to management-a review. Eur J Orthod. 2007;29(2):170-179. PMID:17488999. (page 16) 
41. Lee TC, McGrath CP, Wong RW, Rabie AB. Patients' perceptions regarding microimplant as anchorage in orthodontics. Angle Orthod. 2008;78(2):228-233. PMID:18251610. (page 16)

42. Baxmann M, McDonald F, Bourauel C, Jager A. Expectations, acceptance, and preferences regarding microimplant treatment in orthodontic patients: A randomized controlled trial. Am J Orthod Dentofacial Orthop. 2010;138(3):250.e1-250.e10; discussion 250-1. PMID:20816284. (page 16, 70)

43. Lehnen S, McDonald F, Bourauel C, Baxmann M. Patient expectations, acceptance and preferences in treatment with orthodontic mini-implants. A randomly controlled study. Part I: insertion techniques. J Orofac Orthop. 2011;72(2):93-102. PMID:21503849. (page 16)

44. Kuroda S, Sugawara Y, Deguchi T, Kyung HM, TakanoYamamoto T. Clinical use of miniscrew implants as orthodontic anchorage: success rates and postoperative discomfort. Am J Orthod Dentofacial Orthop. 2007;131(1):9-15. PMID:17208101. (page 16)

45. Narendar R, Balakrishnan G, Kavin T, Venkataraman S, Altaf SK, Gokulanathan S. Incidence of Risk and Complications Associated with Orthodontic Therapeutic Extraction. J Pharm Bioallied Sci. 2017;9(Suppl 1):S204. PMID:29284964. (page 16)

46. Chen CM, Chang CS, Tseng YC, Hsu KR, Lee KT, Lee HE. The perception of pain following interdental microimplant treatment for skeletal anchorage: a retrospective study. Odontology. 2011;99(1):88-91. PMID:21271332. (page 16, 68)

47. Sollenius O, Petrén S, Björnsson L, Norlund A, Bondemark L. Health economic evaluations in orthodontics: a systematic review. Eur J Orthod. 2016;38(3):259-265. PMID:26070925. (page 17) 
48. Price J, Whittaker W, Birch S, Brocklehurst P, Tickle M. Socioeconomic disparities in orthodontic treatment outcomes and expenditure on orthodontics in England's state-funded National Health Service: a retrospective observational study. BMC oral health. 2017;17(1):1. PMID:28927396. (page 17)

49. Drummond MF, Sculpher MJ, Claxton K, Stoddart GL, Torrance GW. Methods for the Economic Evaluation of Health Care Programmes. 4th ed. Oxford: Oxford University Press; 2015. (page $17,62,72,73$ )

50. Tordrup D, Chouaid C, Cuijpers P, Dab W, van Dongen JM, Espin J, et al. Priorities for Health Economic Methodological Research: Results of an Expert Consultation. Int J Technol Assess Health Care. 2017;p. 1-11. PMID:29081308. (page 17)

51. Pancherz H. The mechanism of Class II correction in Herbst appliance treatment. A cephalometric investigation. American J Orthod. 1982;82(2):104-113. PMID:6961781. (page 17, 24)

52. Ricketts RM. A four-step method to distinguish orthodontic changes from natural growth. J Clin Orthod. 1975;9(4):28. PMID:1056343. (page 17, 24)

53. Lenza MA, Carvalho AA, Lenza EB, Lenza MG, Torres HM, Souza JB. Radiographic evaluation of orthodontic treatment by means of four different cephalometric superimposition methods. Dental press J Orthod. 2015;20(3):29-36. PMID:26154453. (page 17, 66)

54. Hoggan BR, Sadowsky C. The use of palatal rugae for the assessment of anteroposterior tooth movements. Am J Orthod Dentofacial Orthop. 2001;119(5):482-488. PMID:11343019. (page 18, 19, 66)

55. Bootvong K, Liu Z, McGrath C, Hagg U, Wong RW, Bendeus $\mathrm{M}$, et al. Virtual model analysis as an alternative approach to plaster model analysis: reliability and validity. Eur J Orthod. 2010;32(5):589-595. PMID:20164126. (page 18) 
56. Akyalcin S, Dyer DJ, English JD, Sar C. Comparison of 3-dimensional dental models from different sources: diagnostic accuracy and surface registration analysis. Am J Orthod Dentofacial Orthop. 2013;144(6):831-837. PMID:24286906. (page )

57. Wiranto MG, Engelbrecht WP, Nolthenius HET, van der Meer WJ, Ren Y. Validity, reliability, and reproducibility of linear measurements on digital models obtained from intraoral and cone-beam computed tomography scans of alginate impressions. Am J Orthod Dentofacial Orthop. 2013;143(1):140-147. PMID:23273370. (page )

58. Nalcaci R, Kocoglu-Altan AB, Bicakci AA, Ozturk F, Babacan $\mathrm{H}$. A reliable method for evaluating upper molar distalization: Superimposition of three-dimensional digital models. Korean J Orthod. 2015;45(2):82-88. PMID:25798414. (page )

59. Grewal B, Lee RT, Zou L, Johal A. Royal London space analysis: plaster versus digital model assessment. Eur J Orthod. 2016;PMID:27511915. (page )

60. Reuschl RP, Heuer W, Stiesch M, Wenzel D, Dittmer MP. Reliability and validity of measurements on digital study models and plaster models. Eur J Orthod. 2016;38(1):22-26. PMID:25724574. (page )

61. Aragon ML, Pontes LF, Bichara LM, Flores-Mir C, Normando D. Validity and reliability of intraoral scanners compared to conventional gypsum models measurements: a systematic review. Eur J Orthod. 2016;38(4):429-434. PMID:27266879. (page 18)

62. Diez Y, Ferran R, Llado X, Salvi J. A Qualitative Review on 3D Coarse Registration Methods. ACM Computing Surveys. 2015;47(3):45:1-45:36. (page 18)

63. Thiruvenkatachari B, Al-Abdallah M, Akram NC, Sandler J, O'Brien K. Measuring 3-dimensional tooth movement with 
a 3-dimensional surface laser scanner. Am J Orthod Dentofacial Orthop. 2009;135(4):480-485. PMID:19361734. (page 18, 66)

64. Choi DS, Jeong YM, Jang I, Jost-Brinkmann PG, Cha BK. Accuracy and reliability of palatal superimposition of three-dimensional digital models. Angle Orthod. 2010;80(4):497-503. PMID:20482354. (page 18, 23, 66)

65. Chen G, Chen S, Zhang XY, Jiang RP, Liu Y, Shi FH, et al. Stable region for maxillary dental cast superimposition in adults, studied with the aid of stable miniscrews. Orthod Craniofac Res. 2011;14(2):70-79. PMID:21457456. (page $18,19,66,72$ )

66. Abdi AH, Nouri M. Registration of serial maxillary models via the weighted rugae superimposition method. Orthod Craniofac Res. 2017;20(2):79-84. PMID:28150411. (page 18)

67. Becker K, Wilmes B, Grandjean C, Drescher D. Impact of manual control point selection accuracy on automated surface matching of digital dental models. Clin Oral Investig. 2018;22(2):801-810. PMID:28681247. (page 18)

68. Bailey LT, Esmailnejad A, Almeida MA. Stability of the palatal rugae as landmarks for analysis of dental casts in extraction and nonextraction cases. Angle Orthod. 1996;66(1):73-78. PMID:8678349. (page 19,67)

69. Christou P, Kiliaridis S. Vertical growth-related changes in the positions of palatal rugae and maxillary incisors. Am J Orthod Dentofacial Orthop. 2008;133(1):81-86. PMID:18174076. (page 19)

70. Yang ST, Kim HK, Lim YS, Chang MS, Lee SP, Park YS. A three dimensional observation of palatal vault growth in children using mixed effect analysis: a 9 year longitudinal study. Eur J Orthod. 2013;35(6):832-840. PMID:23314328. (page 19) 
71. Thilander B. Dentoalveolar development in subjects with normal occlusion. A longitudinal study between the ages of 5 and 31 years. Eur J Orthod. 2009;31(2):109-120. PMID:19304760. (page 19,66)

72. Choi JI, Cha BK, Jost-Brinkmann PG, Choi DS, Jang IS. Validity of palatal superimposition of 3-dimensional digital models in cases treated with rapid maxillary expansion and maxillary protraction headgear. Korean J Orthod. 2012;42(5):235-241. PMID:23173116. (page 19, 66, 67)

73. Wujanz D, Krueger D, Neitzel F. Der ICProx-Algorithmus: Oberflächenbasierte Registrierung terrestrischer Laserscans für die Deformationsanalyse. In: Beiträge zum 17. Internationalen Ingenieursvermessungskurs, Zurich, Switzerland; 2014. p. 36-45. (page 19, 27)

74. Wujanz D, Krueger D, Neitzel F. Identification of Stable Areas in Unreferenced Laser Scans for Deformation Measurement. The Photogrammetric Record. 2016;31. (page 19,27)

75. Thilander B, Myrberg N. The prevalence of malocclusion in Swedish schoolchildren. Scand J Dent Res. 1973;81(1):12-21. PMID:4510864. (page 20)

76. Team RC. Team RC, editor. R: A Language and Environment for Statistical Computing. Vienna, Austria: R Foundation for Statistical Computing; 2018. Available at: www.Rproject.org. (page 23, 42)

77. Gold R, Reichman M, Greenberg E, Ivanidze J, Elias E, Tsiouris AJ, et al. Developing a new reference standard: is validation necessary? Acad Radiol. 2010;17(9):1079-1082. PMID:20692619. (page 24)

78. Sousa MV, Vasconcelos EC, Janson G, Garib D, Pinzan A. Accuracy and reproducibility of 3-dimensional digital model measurements. Am J Orthod Dentofacial Orthop. 2012;142(2):269-273. PMID:22858338. (page 24)

79. Hayashi K, Sachdeva AU, Saitoh S, Lee SP, Kubota T, Mizoguchi I. Assessment of the accuracy and reliability of new 
3-dimensional scanning devices. Am J Orthod Dentofacial Orthop. 2013;144(4):619-625. PMID:24075671. (page 24)

80. Pomerleau F, Colas F, Siegwart R, Magnenat S. Comparing ICP variants on real-world data sets. Autonomous Robots. 2013;34:133-148. (page 26)

81. McLaughlin RP, Bennett JC. The dental VTO: an analysis of orthodontic tooth movement. J Clin Orthod. 1999;33(7):394-403. PMID:10535022. (page 32)

82. McLaughlin RP, Bennett JC, Trevisi H. Systemized Orthodontic Treatment Mechanics. 1st ed. Mosby; 2001. (page 35)

83. Park J, Cho HJ. Three-dimensional evaluation of interradicular spaces and cortical bone thickness for the placement and initial stability of microimplants in adults. Am J Orthod Dentofacial Orthop. 2009;136(3):5. PMID:19732658. (page 38)

84. Baumgaertel S, Razavi MR, Hans MG. Mini-implant anchorage for the orthodontic practitioner. Am J Orthod Dentofacial Orthop. 2008;133(4):621-627. PMID:18405827. (page 38)

85. Watanabe H, Deguchi T, Hasegawa M, Ito M, Kim S, Takano-Yamamoto T. Orthodontic miniscrew failure rate and root proximity, insertion angle, bone contact length, and bone density. Orthod Craniofac Res. 2013;16(1):44-55. PMID:23311659. (page 38, 71)

86. Stegenga B, de Bont LG, de Leeuw R, Boering G. Assessment of mandibular function impairment associated with temporomandibular joint osteoarthrosis and internal derangement. J Orofac Pain. 1993;7(2):183-195. PMID:8358365. (page 39)

87. Feldmann I, List T, John MT, Bondemark L. Reliability of a questionnaire assessing experiences of adolescents in orthodontic treatment. Angle Orthod. 2007;77(2):311-7. PMID:17319767. (page 39) 
88. Fisher LD, Dixon DO, Herson J, Frankowski RK, Hearron MS, Peace KE. Intention to treat in clinical trials. In: Statistical issues in drug research and development. New York: Marcel Dekker; 1990. p. 331-350. (page 43)

89. Bondemark L, Abdulraheem S. Intention to treat (ITT) analysis as reported in orthodontic randomized controlled trialsevaluations of methodology and recommendations for the accurate use of ITT analysis and handling dropouts. Eur J Orthod. 2018;40(4):409-413. PMID:29069355. (page 43, 76)

90. Gehling J, Mainka T, Vollert J, Pogatzki-Zahn EM, Maier C, Enax-Krumova EK. Short-term test-retest-reliability of conditioned pain modulation using the cold-heat-pain method in healthy subjects and its correlation to parameters of standardized quantitative sensory testing. BMC neurology. 2016 August 05;16:z. PMID:27495743. (page 43)

91. Holm S. A Simple Sequentially Rejective Multiple Test Procedure. Scandinavian Journal of Statistics. 1979;6(2):65-70. Available from: http://www.jstor.org/stable/4615733. (page 44)

92. Pinheiro J, Bates D, DebRoy S, Sarkar D, Team RC. nlme: Linear and Nonlinear Mixed Effects Models. CRAN. 2018;Available at: http://CRAN.Rproject.org/package=nlme. (page 44$)$

93. O'Brien BJ, Drummond MF. Statistical versus quantitative significance in the socioeconomic evaluation of medicines. Pharmacoeconomics. 1994;5(5):389-398. PMID:10147230. (page 62)

94. O’Brien BJ, Drummond MF, Labelle RJ, Willan A. In search of power and significance: issues in the design and analysis of stochastic cost-effectiveness studies in health care. Med Care. 1994;32(2):150-163. PMID:8302107. (page 62)

95. Levander E, Malmgren O. Evaluation of the risk of root resorption during orthodontic treatment: a study of upper 
incisors. Eur J Orthod. 1988;10(1):30-38. PMID:3162877. (page 63)

96. Asquith J, Gillgrass T, Mossey P. Three-dimensional imaging of orthodontic models: a pilot study. Eur J Orthod. 2007;29(5):517-522. PMID:17974542. (page 65)

97. Sjögren AP, Lindgren JE, Huggare JA. Orthodontic study cast analysis-reproducibility of recordings and agreement between conventional and 3D virtual measurements. J Digit Imaging. 2010;23(4):482-492. PMID:19526268. (page 65)

98. Cha BK, Lee JY, Jost-Brinkmann PG, Yoshida N. Analysis of tooth movement in extraction cases using threedimensional reverse engineering technology. Eur J Orthod. 2007;29(4):325-331. PMID:17513876. (page 66)

99. Björk A. The use of metallic implants in the study of facial growth in children: method and application. Am J Phys Anthropol. 1968;29(2):243-254. PMID:5700620. (page 66)

100. Bergius M, Berggren U, Kiliaridis S. Experience of pain during an orthodontic procedure. Eur J Oral Sci. 2002;110(2):92-98. PMID:12013568. (page 68)

101. Brown DF, Moerenhout RG. The pain experience and psychological adjustment to orthodontic treatment of preadolescents, adolescents, and adults. Am J Orthod Dentofacial Orthop. 1991;100(4):349-356. PMID:1927986. (page 69)

102. Bergius M, Kiliaridis S, Berggren U. Pain in orthodontics. A review and discussion of the literature. J Orofac Orthop. 2000;61(2):125-137. PMID:10783564. (page 69)

103. Kwong TS, Kusnoto B, Viana G, Evans CA, Watanabe K. The effectiveness of Oraqix versus TAC(a) for placement of orthodontic temporary anchorage devices. Angle Orthod. 2011;81(5):754-759. PMID:21563954. (page 69)

104. Mittal M, Kumar A, Srivastava D, Sharma P, Sharma S. Pain Perception: Computerized versus Traditional Local Anesthesia in Pediatric Patients. J Clin Pediatr Dent. 2015;39(5):470-474. PMID:26551372. (page 69) 
105. Gedney JJ, Logan H. Memory for stress-associated acute pain. J Pain. 2004;5(2):83-91. PMID:15042516. (page 70)

106. Babel P. The Influence of State and Trait Anxiety on the Memory of Pain. Pain Med. 2017;18(12):2340-2349. PMID:28340064. (page 70)

107. Hong SB, Kusnoto B, Kim EJ, BeGole EA, Hwang HS, Lim HJ. Prognostic factors associated with the success rates of posterior orthodontic miniscrew implants: A subgroup meta-analysis. Korean J Orthod. 2016;46(2):111-126. PMID:27019826. (page 71)

108. Janson G, Gigliotti MP, Estelita S, Chiqueto K. Influence of miniscrew dental root proximity on its degree of late stability. Int J Oral Maxillofac Surg. 2013;42(4):527-534. PMID:23062958. (page 71)

109. Ganzer N, Feldmann I, Liv P, Bondemark L. A novel method for superimposition and measurements on maxillary digital 3D models-studies on validity and reliability. Eur J Orthod. 2018;40(1):45-51. PMID:28444179. (page 71)

110. Upadhyay M, Yadav S, Nagaraj K, Patil S. Treatment effects of mini-implants for en-masse retraction of anterior teeth in bialveolar dental protrusion patients: a randomized controlled trial. Am J Orthod Dentofacial Orthop. 2008;134(1):29.e1. PMID:18617099. (page 71, 73)

111. Lee KJ, Park YC, Hwang CJ, Kim YJ, Choi TH, Yoo $\mathrm{HM}$, et al. Displacement pattern of the maxillary arch depending on miniscrew position in sliding mechanics. Am J Orthod Dentofacial Orthop. 2011;140(2):224-232. PMID:21803260. (page 71)

112. Lee J, Jeong YH, Pittman J, Deguchi T, Johnston WM, Fields HW, et al. Primary stability and viscoelastic displacement of mini-implant system under loading. Clin Biomech (Bristol, Avon). 2017;41:28-33. PMID:27915135. (page 72)

113. Stallard H. The anterior component of the force of mastication and its significance to the dental apparatus. Dent Cosmos. 1923;65(5):457-474. (page 72) 
114. Southard TE, Behrents RG, Tolley EA. The anterior component of occlusal force. Part 2. Relationship with dental malalignment. Am J Orthod Dentofacial Orthop. 1990;97(1):41-44. PMID:2296942. (page )

115. Qassar SSA, Mavragani M, Psarras V, Halazonetis DJ. The anterior component of occlusal force revisited: direct measurement and theoretical considerations. Eur J Orthod. 2016;38(2):190-196. PMID:25888533. (page 72)

116. Yao CC, Lai EH, Chang JZ, Chen I, Chen YJ. Comparison of treatment outcomes between skeletal anchorage and extraoral anchorage in adults with maxillary dentoalveolar protrusion. Am J Orthod Dentofacial Orthop. 2008;134(5):615-624. PMID:18984393. (page 73)

117. Al-Sibaie S, Hajeer MY. Assessment of changes following en-masse retraction with mini-implants anchorage compared to two-step retraction with conventional anchorage in patients with class II division 1 malocclusion: a randomized controlled trial. Eur J Orthod. 2014;36(3):275-283. PMID:23787192. (page 73)

118. Wiedel AP, Norlund A, Petrén S, Bondemark L. A cost minimization analysis of early correction of anterior crossbite-a randomized controlled trial. Eur J Orthod. 2016;38(2):140-145. PMID:25940585. (page 75)

119. Viera AJ, Bangdiwala SI. Eliminating bias in randomized controlled trials: importance of allocation concealment and masking. Fam Med. 2007;39(2):132-137. PMID:17273956. (page 76) 



\section{List of Figures}

1 Root surface per tooth in square millimeters. . . . 8

2 Molar block's root surface compared to the frontal teeth in square millimeters. . . . . . . . . . . 8

3 Transpalatal arch connecting the maxillary first molars. .................. 9

4 Nance appliance with acrylic button connecting the maxillary first molars. . . . . . . . . . . . . 10

5 Facebow attached to the maxillary first molars. . . 11

6 Straight pull headgear with head cap and neck band. 11

7 Apparatus used by Gainsforth and Higley in dogs. . 13

8 Rigid supra-construction mounted on an Orthosystem implant. . . . . . . . . . . . . . . . 14

9 Contemporary TADs: Onplant, Orthosystem implant, Spider Screw ${ }^{\circledR}$ and y-type miniplate. . . . . . 15

10 Palatine rugae on maxillary 3D model. . . . . . . 19

11 Start model (blue) and reference model (red). . . . . 25

12 Palatal vault of start and reference model with corresponding reference points. . . . . . . . . . 27

13 Palatal vault after deformation analysis. The grid of filter cubes is depicted in light grey. Used reference points are marked red. . . . . . . . . . . . . 29

14 Distance analysis with true values showing an unchanged area (white colored) in the center of the palatal vault. . . . . . . . . . . . . 29 29

15 Estimation of anchorage need. . . . . . . . . . 33

16 Orthodontic treatment Group A: I leveling \& alignment, II space closure . . . . . . . . . . . . . . 36

17 Orthodontic treatment Group B: I leveling \& alignment, II space closure . . . . . . . . . . . . . 37 
18 Root proximity classification according to Watanabe. 38

19 Differences between measured and true total movements. Each of the four observers is represented by a unique color. . . . . . . . . . . . . 46

20 Measurement result showing a tooth's occlusal surface before and after treatment. . . . . . . . . . . 46

21 Measured total movement plotted against true total movement. . . . . . . . . . . . . . 47

22 CONSORT Flow Chart . . . . . . . . . . . 50

23 Pain intensity on VAS presented as Tukey boxplot with median values and interquartile range. . . . . 52

24 Discomfort on VAS presented as Tukey boxplot with median values and interquartile range. . . . . . 52

25 Individual differences in pain ratings on VAS presented as Tukey boxplot with median values and interquartile range. . . . . . . . . . . 54

26 Individual differences in discomfort ratings on VAS presented as Tukey boxplot with median values and interquartile range. . . . . . . . . . 55

27 Boxplots with Tukey's Hinges showing the intention-to-treat analysis of the mesial movement of maxillary first molars. . . . . . . . . . . . 57

28 Maxillary first molars mean movement, Group A (red) and B (blue). . . . . . . . . . . . . . 58

29 Incremental cost-effectiveness ratio, cost-effectiveness plane and confidence ellipse. . . . . . . . . . . 63

30 Incremental costs and effects compared between treatment and control. . . . . . . . . . . . . . 73 


\section{List of Tables}

1 Direct costs template - material per patient . . . . 41

2 Absolute mean errors, arithmetic mean errors and ICC with estimated $95 \%$ CI. . . . . . . . . . . 45

3 Estimated parameters for total tooth movement of the mixed model. . . . . . . . . . . . . . 48

4 Baseline demographic data. . . . . . . . . . 49

5 Patient-reported pain and discomfort (medians and quartiles according to Tukey's Hinges). . . . . . . 53

6 Intention-to-treat analysis of the maxillary first molars movement during different treatment phases. . 59

7 Analytical statistics concerning visits, treatment duration, treatment time and costs. . . . . . . . . 61

8 Cost-effectiveness analysis of intention-to-treat data. 62

A1 Baseline questionnaire . . . . . . . . . . . . 109

A2 Questionnaire administered the first evening after premolar extractions / miniscrew insertions. . . . 111

A3 Questionnaire administered one week after premolar extractions / miniscrew insertions. . . . . . . . 112

A4 Questionnaire administered at the first evening after miniscrew removal. . . . . . . . . . . 113 



\section{ABBREVIATIONS}

$3 D \quad$ Three Dimensional

HANT Heat-Activated Nickel Titanium

ICC Intra Class Correlation

$I C E R$ Incremental cost-effectiveness ratio

ICP Iterative Closest Point algorithm

ICProx Iterative Closest Proximity algorithm

ITT Intention to treat

$L O C F$ Last observation carried forward

NPA Nonprescription oral analgesics

RCT Randomized Controlled Trial

$R F D$ Raw-matching, Fine-matching, Deformation analysis

$T A D$ Temporary Anchorage Device

$V A S$ Visual Analogue Scale

$V R S$ Verbal Rating Scale 



\section{APPENDIX}

Table A1: Baseline questionnaire about treatment motivation, treatment expectations, pain and discomfort, and functional jaw impairment.

\begin{tabular}{|c|c|}
\hline Treatment motivation \& expectations & Scale \\
\hline $\begin{array}{l}\text { 1. Do your teeth bother you? } \\
\text { Är Du störd av ditt bett? }\end{array}$ & VAS \\
\hline $\begin{array}{l}\text { 2. If it was possible, how much would you like to change the appearance } \\
\text { of your teeth? } \\
\text { Om det vore möjligt, hur gärna skulle Du vilja förändra dina tänders } \\
\text { utseende? }\end{array}$ & VAS \\
\hline $\begin{array}{l}\text { 3. Have you ever been teased about the appearance of your teeth? } \\
\text { Har Du blivit retad för dina tänders utseende? }\end{array}$ & VAS \\
\hline $\begin{array}{l}\text { 4. Do you think your teeth need straightening? } \\
\text { Tycker } D u \text { att } D u \text { behöver tandställning? }\end{array}$ & VAS \\
\hline $\begin{array}{l}\text { 5. How motivated are you to have orthodontic treatment with braces? } \\
\text { Hur motiverad är Du för att fä tandställning? }\end{array}$ & VAS \\
\hline $\begin{array}{l}\text { 6. Do you think orthodontic treatment is good for your teeth? } \\
\text { Hur bra tror Du att tandställningen är för dina tänder? }\end{array}$ & VAS \\
\hline $\begin{array}{l}\text { 7. Was it your own decision to undergo orthodontic treatment? } \\
\text { Har du själv fått bestämma att Du skall ha tandställning? }\end{array}$ & VAS \\
\hline $\begin{array}{l}\text { 8. Do you think it is going to be difficult to wear braces? } \\
\text { Tror Du att tandställningsbehandlingen kommer att bli besvärlig? }\end{array}$ & VAS \\
\hline $\begin{array}{l}\text { 9. Are you worried about having orthodontic treatment? } \\
\ddot{A} r d u \text { orolig för att få tandställning? }\end{array}$ & VAS \\
\hline $\begin{array}{l}\text { 10. Are you worried about how you are going to look with braces on? } \\
\ddot{A} r d u \text { orolig för hur Du kommer att se ut med tandställning? }\end{array}$ & VAS \\
\hline $\begin{array}{l}\text { 11. Have you been properly informed about the orthodontic treatment? } \\
\text { Har du fàtt information om behandlingen? }\end{array}$ & VAS \\
\hline Pain and discomfort from teeth, jaws and face & Scale \\
\hline $\begin{array}{l}\text { 12. Do you have pain in your jaws? } \\
\text { Har du smärta från käken? }\end{array}$ & VAS \\
\hline $\begin{array}{l}\text { 13. Do you have pain in your incisors when they are in contact? } \\
\text { Har Du smärta frä framtänderna när Du biter ihop? }\end{array}$ & VAS \\
\hline $\begin{array}{l}\text { 14. Do you have pain in your incisors when they are not in contact? } \\
\text { Har Du smärta frän framtänderna när Du inte biter uhop? }\end{array}$ & VAS \\
\hline $\begin{array}{l}\text { 15. Do you have pain from your molars when they are in contact? } \\
\text { Har Du smärta frän kindtänderna när Du biter ihop? }\end{array}$ & VAS \\
\hline $\begin{array}{l}\text { 16. Do you have pain from your molars when they are not in contact? } \\
\text { Har Du smärta från kindtänderna när Du inte biter ihop? }\end{array}$ & VAS \\
\hline 17. Do you have pain in your neck? & VAS \\
\hline
\end{tabular}


Baseline questionnaire (continued).

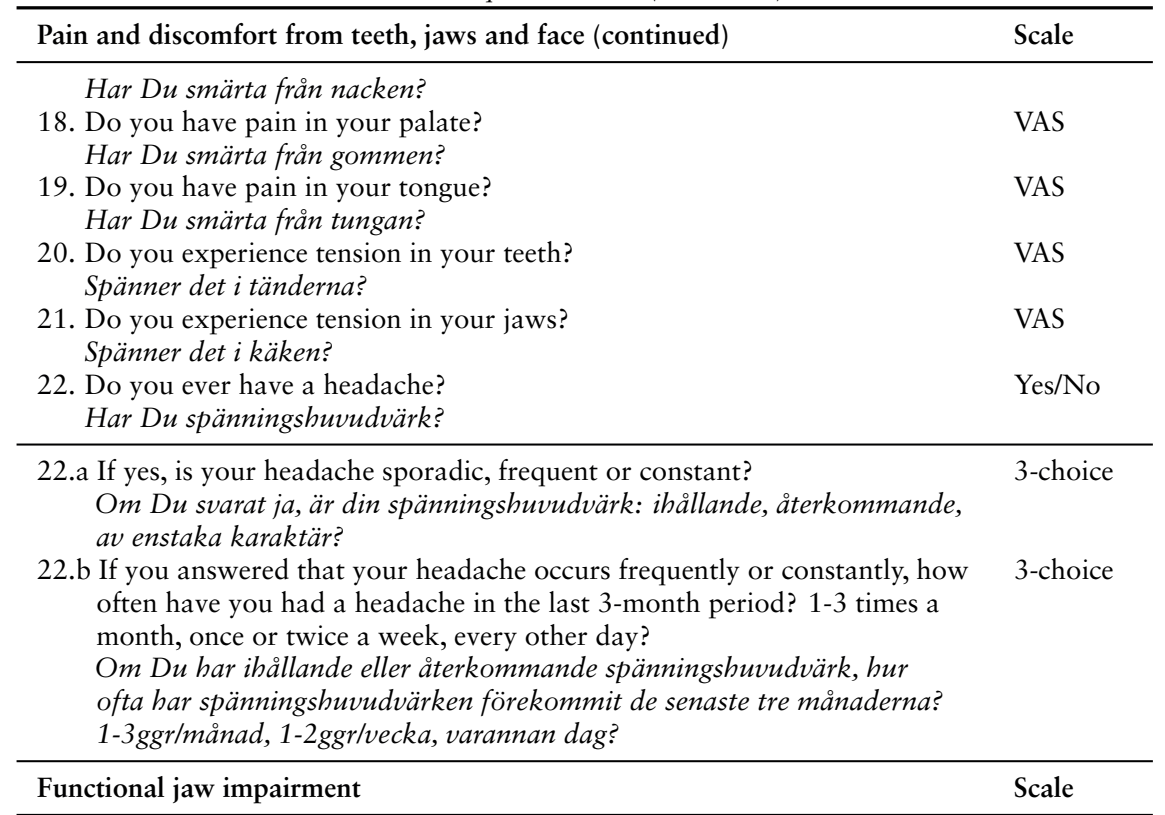

If you have pain or discomfort in your teeth and jaws, how much does that effect:

$\mathrm{O} m \mathrm{Du}$ har besvär från tänder och käkar, hur mycket påverkar det:

\begin{tabular}{lll}
\hline 23. Your leisure time & Dina fritidsaktiviteter & VRS \\
24. Your speech & Talet & VRS \\
25. Your ability to take a big bite & Att ta ett stort bett & VRS \\
26. Your ability to chew hard food & Att tugga här föda & VRS \\
27. Your ability to chew soft food & Att tugga mjuk föda & VRS \\
28. Your schoolwork & Skolarbetet & VRS \\
29. Drinking & Att dricka & VRS \\
30. Laughing & Att skratta & VRS \\
31. Your ability to chew against resistence & Att tugga mot motständ & VRS \\
32. Yawning & Att gäspa & VRS \\
33. Kissing & Att kyssas & VRS \\
\hline
\end{tabular}

Eating means taking a bite, chewing and swallowing, how difficult is it for you to eat: Att äta innebär att ta ett bett, tugga och svälja. Hur svårt är det för dig att äta:

\begin{tabular}{llc}
\hline 34. Crispbread & En hård smörgås & VRS \\
35. Meat & Kött & VRS \\
36. Raw carrots & En rå morot & VRS \\
37. Roll & En fralla & VRS \\
38. Peanuts & Jordnötter & VRS \\
39. Apples & Ett äpple & VRS \\
40. Cake & En miuk kaka & VRS \\
& & \\
\hline
\end{tabular}


Table A2: Questionnaire administered the first evening after premolar extractions and after miniscrew insertions.

\begin{tabular}{ll}
\hline Questions & Scale \\
\hline 1. Did you have pain during the injection of the anesthetic? & VAS \\
Upplevde du smärta när du fick injektion/bedövning? & VAS \\
2. Did you have pain during tooth extraction / miniscrew insertion? & Yes / No \\
Upplevde du smärta under tandutdragningen / skruvinsättningen? & Plain text \\
3. Have you taken analgesic today? & VAS \\
Har du tagit värktabletter/medicin mot smärtan idag? & VAS \\
- If YES, what kind and which dose of analgesic did you use? & \\
4. Did you have discomfort during the injection of the anesthetic? & \\
Upplevde Du obehag när du fick injektion/bedövning? & VAS \\
5. Did you have discomfort during tooth extraction / insertion of the & \\
miniscrews? & \\
Upplevde Du obehag under tandutdragningen / när skrvarna sattes & Scale \\
6. Did you experience any part of the tooth extraction/insertion of the & \\
miniscrews as particularly unpleasant? & Upplevde Du någon del av tandutdragningen / insättningen av skruvar \\
som obehaglig? & \\
- If YES, which part did you experience as particularly unpleasant? \\
- I så fall vad?
\end{tabular}

If you have pain or discomfort in your teeth and jaws, how much does that effect: $\mathrm{Om} \mathrm{Du}$ har besvär efter tandutdragningen / insättning av skruvar, hur mycket påverkar det:

\begin{tabular}{lll}
\hline 9. Your leisure time & Dina fritidsaktiviteter & VRS \\
10. Your speech & Talet & VRS \\
11. Your ability to take a big bite & Att ta ett stort bett & VRS \\
12. Your ability to chew hard food & Att tugga här föda & VRS \\
13. Your ability to chew soft food & Att tugga mjuk föda & VRS \\
14. Your schoolwork & Skolarbetet & VRS \\
15. Drinking & Att dricka & VRS \\
16. Laughing & Att skratta & VRS \\
17. Your ability to chew against resistence & Att tugga mot motstånd & VRS \\
18. Yawning & Att gäspa & VRS \\
19. Kissing & Att kyssas & VRS \\
\hline
\end{tabular}

Eating means taking a bite, chewing and swallowing, how difficult is it for you to eat: Att äta innebär att ta ett bett, tugga och svälja. Hur svårt är det för dig att äta:

\begin{tabular}{llc}
\hline 20. Crispbread & En hård smörgås & VRS \\
21. Meat & Kött & VRS \\
22. Raw carrots & En rå morot & VRS \\
23. Roll & En fralla & VRS \\
24. Peanuts & Jordnötter & VRS \\
25. Apples & Ett äpple & VRS \\
26. Cake & En mjuk kaka & VRS \\
\hline \hline
\end{tabular}


Questionnaire administered at the first evening (continued).

\begin{tabular}{|c|c|}
\hline Questions & Scale \\
\hline $\begin{array}{l}\text { 27. Did you stay at home from school today because of pain from } \\
\text { the extraction / insertion site? } \\
\text { Har Du stannat hemma från skolan idag på grund av smärta } \\
\text { efter tandutdragningen / insättning av skruvarna? }\end{array}$ & Yes / No \\
\hline $\begin{array}{l}\text { 28. Did you refrain from leisure activities today because of pain } \\
\text { from the extraction / insertion site? } \\
\text { Har Du avstått från fritidsaktiviteter idag på grund av smärta } \\
\text { efter tandutdragningen / insättning av skruvarna? }\end{array}$ & Yes / No \\
\hline $\begin{array}{l}\text { - If YES, what activity did you refrain from? } \\
\text { - I så fall vad? }\end{array}$ & Plain text \\
\hline
\end{tabular}

Table A3: Questionnaire administered one week after premolar extractions and after miniscrew insertions.

\begin{tabular}{ll}
\hline Pain \& discomfort & Scale \\
\hline 1. Do you have pain from the extraction site / insertion site right now? & VAS \\
Har du smärta efter tandutdragningen / frän området där skruvarna & \\
sattes in? & \\
2. Do you have discomfort from the extraction site / insertion site right now? & VAS \\
& Har du obehag efter tandutdragningen / från området där skruvarna \\
&
\end{tabular}

\begin{tabular}{lll}
\hline \multicolumn{2}{l}{ Functional jaw impairment } & Scale \\
\hline If you have pain or discomfort in your teeth and jaws, how much does that effect: \\
Om Du har besvär efter tandutdragningen / insättning av skruvar, hur mycket påverkar \\
det: & Dina fritidsaktiviteter \\
\hline 3. Your leisure time & Talet & VRS \\
4. Your speech & Att ta ett stort bett & VRS \\
5. Your ability to take a big bite & Att tugga härd föda & VRS \\
6. Your ability to chew hard food & Att tugga mjuk föda & VRS \\
7. Your ability to chew soft food & Skolarbetet & VRS \\
8. Your schoolwork & Att dricka & VRS \\
9. Drinking & Att skratta & VRS \\
10. Laughing & Att tugga mot motständ & VRS \\
11. Your ability to chew against resistence & Att gäspa & VRS \\
12. Yawning & Att kyssas & VRS \\
13. Kissing &
\end{tabular}

Eating means taking a bite, chewing and swallowing, how difficult is it for you to eat: Att äta innebär att ta ett bett, tugga och svälja. Hur svärt är det för dig att äta:

\begin{tabular}{llc}
\hline 14. Crispbread & En hård smörgås & VRS \\
15. Meat & Kött & VRS \\
16. Raw carrots & En rå morot & VRS \\
17. Roll & En fralla & VRS \\
18. Peanuts & Jordnötter & VRS \\
19. Apples & Ett äpple & VRS \\
20. Cake & En miuk kaka & VRS \\
\hline \hline
\end{tabular}


Questionnaire administered after one week (continued).

\begin{tabular}{ll}
\hline Questions & Scale \\
\hline 21. Did you stay at home from school this week because of pain from & Yes / No \\
the extraction / insertion site? & \\
Har Du stannat hemma från skolan denna vecka på grund av smärta & \\
efter tandutdragningen / insättning av skruvarna? & Yes / No \\
22. Did you refrain from leisure activities this week because of pain & \\
from the extraction / insertion site? & \\
Har Du avstått från fritidsaktiviteter denna vecka på grund av smärta & \\
efter tandutdragningen / insättning av skruvarna? & Plain text \\
- If YES, what activity did you refrain from? & Yes / No \\
- I så fall vad? & \\
23. Has your sleep been disturbed in the last week because of pain & \\
from the extraction site/insertion site? & Yes / No \\
Har Du vaknat på natten denna vecka pågrund av smärta efter & \\
insättning av skruvarna? & Plain text \\
24. Have you taken analgesic because of pain during the last week? & \\
Har Du tagit värktabletter/medicin på grund av smärta efter & \\
insättning av skruvarna den sista veckan? \\
- If YES, what kind and which dose of analgesic did you use? \\
- Om JA, vilken? Hur mycket och vilken dos? \\
\hline
\end{tabular}

Table A4: Questionnaire administered at the first evening after miniscrew removal.

\begin{tabular}{|c|c|c|}
\hline \multicolumn{2}{|l|}{ Pain \& discomfort } & Scale \\
\hline \multicolumn{2}{|c|}{$\begin{array}{l}\text { 1. Did you have pain during miniscrew removal? } \\
\text { Upplevde du smärta när skruvarna togs bort? }\end{array}$} & VAS \\
\hline Har du tagit värktabletter/medicin mot smärtan idag? & 2. Have you taken analgesic today? & Yes / No \\
\hline $\begin{array}{l}\text { - If YES, what kind and which } \\
\text { - Om du svarat Ja, vilken sort }\end{array}$ & $\begin{array}{l}\text { nalgesic did you use? } \\
\text { dos värktabletter tog } d u \text { ? }\end{array}$ & Plain text \\
\hline \multicolumn{2}{|c|}{ 3. Did you have discomfort during miniscrew removal? } & VAS \\
\hline \multicolumn{2}{|c|}{$\begin{array}{l}\text { 4. Did you experience any part of the miniscrews remov } \\
\text { particularly unpleasant? } \\
\text { Upplevde Du någon del av skruvborttagningen som } \\
\text { obehaglig? }\end{array}$} & VAS \\
\hline \multicolumn{2}{|c|}{$\begin{array}{l}\text { - If YES, which part did you experience as particularly unpleasant? } \\
\text { - I så fall vad? }\end{array}$} & Plain text \\
\hline \multicolumn{2}{|c|}{$\begin{array}{l}\text { 5. Do you have pain from the removal site right now? } \\
\text { Har Du smärta frän området där skruvarna har suttit? }\end{array}$} & VAS \\
\hline \multicolumn{2}{|c|}{$\begin{array}{l}\text { 6. Do you have discomfort from the removal site right now? } \\
\text { Har Du obehag frän området där skruvarna har suttit? }\end{array}$} & VAS \\
\hline \multicolumn{2}{|l|}{ Functional jaw impairment } & Scale \\
\hline \multicolumn{3}{|c|}{$\begin{array}{l}\text { If you have pain or discomfort after miniscrew removal, how much does that effect: } \\
\text { Om Du har besvär efter borttagning av skruvarna, skruvar, hur mycket påverkar det: }\end{array}$} \\
\hline 7. Your leisure time & Dina fritidsaktiviteter & VRS \\
\hline 8. Your speech & Talet & VRS \\
\hline 9. Your ability to take a big bite & Att ta ett stort bett & VRS \\
\hline
\end{tabular}


Questionnaire administered at the first evening after miniscrew removal (continued).

\begin{tabular}{|c|c|c|}
\hline \multicolumn{2}{|l|}{ Questions } & \multirow{2}{*}{$\frac{\text { Scale }}{\text { VRS }}$} \\
\hline 10. Your ability to chew hard food & Att tugga hård föda & \\
\hline 11. Your ability to chew soft food & Att tugga mjuk föda & VRS \\
\hline 12. Your schoolwork & Skolarbetet & VRS \\
\hline 13. Drinking & Att dricka & VRS \\
\hline 14. Laughing & Att skratta & VRS \\
\hline 15. Your ability to chew against resistence & Att tugga mot motstånd & VRS \\
\hline 16. Yawning & Att gäspa & VRS \\
\hline 17. Kissing & Att kyssas & VRS \\
\hline \multicolumn{3}{|c|}{$\begin{array}{l}\text { Eating means taking a bite, chewing and swallowing, how difficult is it for you to eat: } \\
\text { Att äta innebär att ta ett bett, tugga och svälja. Hur svårt är det för dig att äta: }\end{array}$} \\
\hline 18. Crispbread & En hård smörgås & VRS \\
\hline 19. Meat & Kött & VRS \\
\hline 20. Raw carrots & En rå morot & VRS \\
\hline 21. Roll & En fralla & VRS \\
\hline 22. Peanuts & Jordnötter & VRS \\
\hline 23. Apples & Ett äpple & VRS \\
\hline 24. Cake & En mjuk kaka & VRS \\
\hline \multirow{3}{*}{\multicolumn{2}{|c|}{$\begin{array}{l}\text { 25. Did you stay at home from school today because of pain from the } \\
\text { removal site? } \\
\text { Har Du stannat hemma från skolan idag på grund av smärta efter } \\
\text { borttagning av skruvarna? } \\
\text { 26. Did you refrain from leisure activities today because of pain from } \\
\text { the removal site? } \\
\text { Har Du avstått från fritidsaktiviteter idag på grund av smärta } \\
\text { efter borttagning av skruvarna? } \\
\text { - If YES, what activity did you refrain from? } \\
\text { - I så fall vad? }\end{array}$}} & Yes / No \\
\hline & & Yes / No \\
\hline & & Plain text \\
\hline
\end{tabular}


PAPER I

115 



\title{
A novel method for superimposition and measurements on maxillary digital 3D models: Studies on validity and reliability
}

\author{
Niels Ganzer, Ingalill Feldmann ${ }^{\dagger}$, Per Liv ${ }^{\ddagger}$, Lars Bondemark ${ }^{\S}$
}

April 22, 2017

\begin{abstract}
This is a pre-copyedited, author-produced version of an article accepted for publication in the European Journal of Orthodontics following peer review. The version of record of article cjx029 is: Eur J Orthod, Volume 40, Issue 1, 23 January 2018, Pages 45-51, ePub ahead to print 22 April 2017. The version of record is available online at:

https://doi.org/10.1093/ejo/cjx029.
\end{abstract}

\footnotetext{
*DDS, PhD Student at Malmö University and Center for Research and Development Uppsala University / Region Gävleborg, Senior Consultant Orthodontist at Public Dental Service Region Gävleborg, Gävle, Sweden. Corresponding author.

Contact: niels.ganzer@regiongavleborg.se

${ }^{\dagger}$ DDS, PhD, Senior Consultant Orthodontist at Public Dental Service Region Gävleborg, Senior Researcher at Center for Research and Development Uppsala University / Region Gävleborg, Gävle, Sweden

${ }^{\ddagger} \mathrm{PhD}$, Statistician at Center for Research and Development Uppsala University / Region Gävleborg, Gävle, Sweden

${ }^{\S} \mathrm{DDS}, \mathrm{PhD}$, Senior Consultant Orthodontist, Professor and Head of Department of Orthodontics, Malmö University, Malmö, Sweden
} 


\begin{abstract}

\section{Background}

Serial 3D models can be used to analyze changes, but correct superimposition is crucial before measurements can be assessed. Earlier studies show that every palatal structure changes due to growth or treatment. Here, we describe a new method that uses an algorithm-based analysis to perform superimpositions and measurements in maxillary $3 \mathrm{D}$ models. This method can be used to identify deformations. In a second step, only unchanged areas are used for superimposition.
\end{abstract}

Objectives

This study investigates the validity and reliability of this novel method.

\title{
Methods
}

Digital 3D models from 16 cases were modified by an independent 3D engineer to simulate space closure and growth. True values for tooth movements were available as reference. Measurements and repeated measurements were performed by four observers.

\section{Results}

The total tooth movement had an absolute mean error of $0.0225 \mathrm{~mm}$ (SD 0.03). The intraclass correlation coefficient (ICC) was 0.9996. Rotational measurements had an absolute mean error of 0.0291 degrees (SD 0.04 degrees) and an ICC of 0.9999.

\section{Limitations}

Serial models need to be taken with a moderate interval (1 to 2 years). Obvious changed areas in the palate need to be cropped before processing the models.

\section{Conclusion}

The tested method is valid and reliable with excellent accuracy and precision even when changes through growth or orthodontic treatment occur. 


\section{Introduction}

Traditionally, orthodontists have used lateral cephalograms and study casts to establish diagnoses and to develop treatment plans. Changes as the result of growth or treatment are commonly evaluated through superimposition in order to describe what changes have taken place between the two registrations. ${ }^{1,2}$

When superimposition is made on study casts, the palatal rugae have been used as references. ${ }^{3}$ Study casts, however, are rapidly being replaced by digital 3D-models, a technique that has proven to be valid and reproducible for linear measurements such as overjet, overbite, arch width, and tooth width. ${ }^{4-8}$ Consequently, measurements on digital $3 \mathrm{D}$ models are generally considered comparable to measurements using study casts, making 3D models a viable replacement for traditional study casts. $^{9}$

As with any superimposition, stable anatomical structures are required as references. Because the medial points of the third palatal rugae were found to be stable enough in untreated patients and in patients treated with premolar extractions and en masse retraction, ${ }^{10}$ the palatal rugae have been used as reference landmarks even for the first attempts to superimpose 3D models. This principle of manually selecting a few corresponding points giving a rough initial alignment is called coarse or raw matching. ${ }^{11}$ Although raw matching is used in most software packages for orthodontic treatment planning and analysis, the manual selection and measurement of matchings can be a source of error.

The next generation of superimposition approaches used the palatal vault or parts of it as a reference by using a best-fit method. ${ }^{12-15}$ This technique of fine matching uses thousands of reference points instead of a few landmarks and is based on iterative closest point algorithms (ICP). ${ }^{16}$ The effect of outliers is reduced while accuracy and reliability markedly improves for superimposition of serial 3D models. A five-year follow-up study found that even the position of the third rugae is changed slightly in the vertical plane, a finding that was true for both adolescents and adults due to growth and remodelling. ${ }^{17}$ Moreover, a trial in patients treated with rapid maxillary expansion and maxillary protraction headgear reported significant changes in the vertical plane due to orthodontic treatment. ${ }^{18}$ In addition, it has been shown that palatal height changes several millimetres due to growth in adolescents. ${ }^{19,20}$ Therefore, it remains unclear whether parts of the palatal vault can be considered stable enough to be used as a reference landmark for superimposition.

There is evidence that in adolescents the palatal vault changes in the sagittal, transversal, and vertical planes, so there is no anatomical structure that in general can be considered stable. However, this instability does not mean that there are no structures at all that can be used for superimposition. Computer programs detect morphological changes in a series of models. By using this deformation analysis, all structures that have changed can be filtered out, leaving only unchanged structures for superimposition.

Through several series of test-measurements, we found that the best results came from a combination of raw matching, fine matching, and deformation analysis. This novel method, that we call RFD-superimposition, can handle variations in local point resolution, can differentiate outliers from morphological changes, and can use several techniques for sample size reduction. We hypothesized that RFD-superimposition introduces minimal measurement error. The aim of this study was to analyse the validity and reliability of measurements on serial 3D models that use the RFDsuperimposition method.

\section{Material and Methods}

\section{Materials}

Sample size requirements were determined based on data from Choi et al. ${ }^{12}$; they reported standard deviations between 0.12 and $0.2 \mathrm{~mm}$ for the mean differences between digital and manual point-topoint measurements. Assuming the within-case standard deviation to be within that range and the between-case standard deviation to be approximately $0.75 \mathrm{~mm}$, based on clinical experiences within the research group, the value of the intraclass correlation coefficient (ICC) lies between 0.93 and 0.96. A power analysis using the programming language $\mathrm{R}^{21}$ and the ICC.Sample.Size package ${ }^{22}$ showed that including 16 cases would give $80 \%$ power with an anticipated ICC of 0.95 when testing the null hypothesis that the ICC is equal to 0.80 .

A list of 16 randomly selected cases was generated using $\mathrm{R}$. These cases were derived from a randomized controlled trial on anchorage. ${ }^{23}$ Eth- 
ical approval was obtained from the Uppsala University ethics committee. All patients and their parents gave written informed consent. Study casts of these 16 cases were fabricated from alginate impressions at the in-clinic laboratory within 24 hours. These casts were then digitalized with a R700 desktop scanner (3Shape, Copenhagen, Denmark). The 3 Shape system has been validated in earlier studies. ${ }^{24,25}$ The 16 digital models served as start models.

\section{Specimen}

To simulate an orthodontic treatment and growth, the 16 start models were modified by an independent $3 \mathrm{D}$ engineer. This modification was used to simulate space closure after extraction of the first premolars. Since tooth movements were performed artificially, the true value for translation and rotation of the right maxillary first molar (tooth 16) could be used as a reference. The palatal vault was then changed morphologically to simulate growth and to challenge the matching process.

\section{Superimposition}

The RFD-superimposition is based on a series of matchings. A matching places one object on top of another object using as many corresponding points as possible from both objects. To improve the accuracy, the matching process is repeated several times. For every repetition, the starting position is improved although matching two different objects cannot result in $100 \%$ congruence. Therefore, the matching result does not improve after a certain number of repetitions. Since every repetition needs time for calculation, it is crucial to choose a balanced number of repetitions: As many times as necessary, as few times as possible.

The same principle applies for the number of points included in the calculation. The part of the palate that was included in the matching process contains about 11000 points. If deformation analysis is performed for each point, the calculation will take hours and the influence of outliers will increase. By reducing the number of points included, calculation times are shortened and outliers are excluded. The number of repetitions and points mentioned in the following description was found suitable in the test series.

When matching two objects, one of the objects has a fixed position and it is called the master object; the other object (the object to be superimposed) is called the slave object. Superimposition of maxillary 3D models was accomplished in three steps: raw matching, fine matching, and deformation analysis.

Raw matching: Since the median point of the third rugae was considered most stable, the superimposition started with a coarse positioning of the models according to six corresponding points in this area (Figure 1). The corresponding points were individually selected for every case. The selection was based on clear and characteristic surfaces that could be found in both models.

Fine matching: The fine matching, performed using Final Surface ${ }^{\circledR}$ software, uses a point to triangle best fit method, a technique that is less sensitive to variations in the local point resolution. To minimize the effect of outliers, the maximum number of reference points was limited to 1000 . From these 1000 reference points, the best 900 were used for the matching. Beyond this, the convergence method was used - i.e., the fine matching was repeated until a certain level of agreement between the matching objects was reached. The level of agreement was defined as $0.000001 \mathrm{~mm}$. The maximum number of repetitions was 50 .

Deformation analysis with the ICProx algorithm: An algorithm is a predefined set of operations. The main task of the Iterative closest proximity algorithm (ICProx) is to detect deformations (26). Deformations can generally be detected by associating corresponding points from master to slave model. The ICProx algorithm puts a grid of regularly distributed points onto the master model. After these so-called candidate points are estimated, the median distances between the candidates and their adjacent points are calculated. Next, a surface with a radius of this distance is created that surrounds every candidate point.

For the slave model, candidate points are estimated in the same way. Every candidate point from the slave model has a corresponding surface on the master model. This point-to-surface approach gives the algorithm a robust tolerance against point resolution variations since the corresponding point is matched somewhere on the surface and not exactly on the corresponding candidate.

Deformations are then detected by applying an octree cell structure onto the model. Octrees are used to subdivide $3 \mathrm{D}$ space into cubes. A grid of cubes with an edge length of $0.5 \mathrm{~mm}$ was put into the model and the algorithm identified one candidate point per cube. The candidate points 


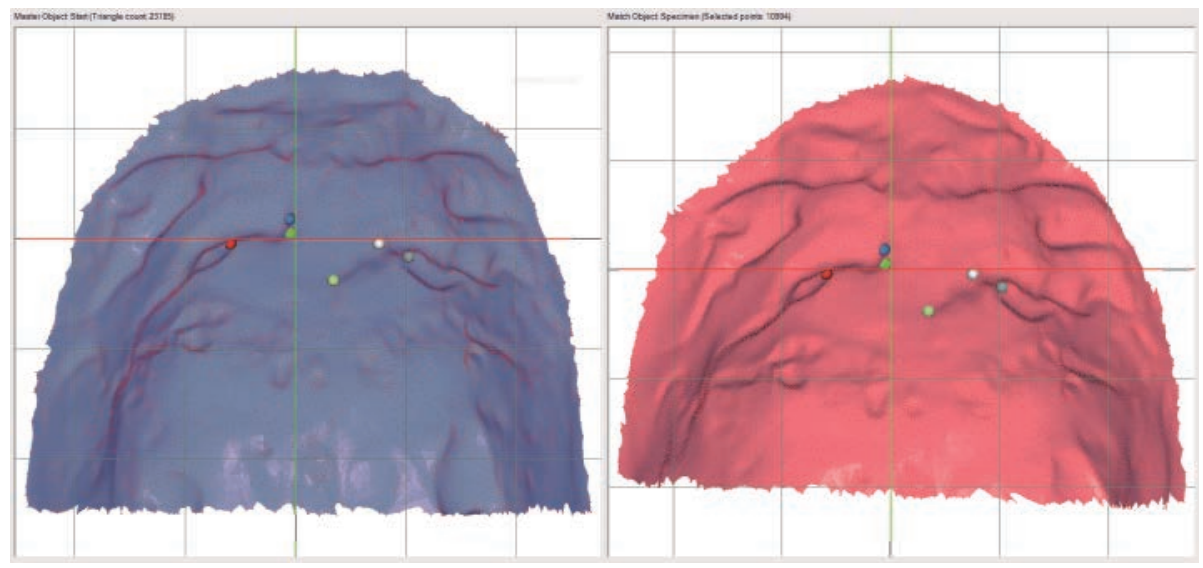

Figure 1: Palatal vault of start (blue, master model) and specimen (red, slave model) with corresponding reference points.

were then filtered by merging cubes into cells with $1.5 \mathrm{~mm}$ edge lengths (Figure 2). Cells where the distances between the candidate surface and the corresponding point exceed a certain threshold are understood as containing morphological changes and are excluded from the following matching.

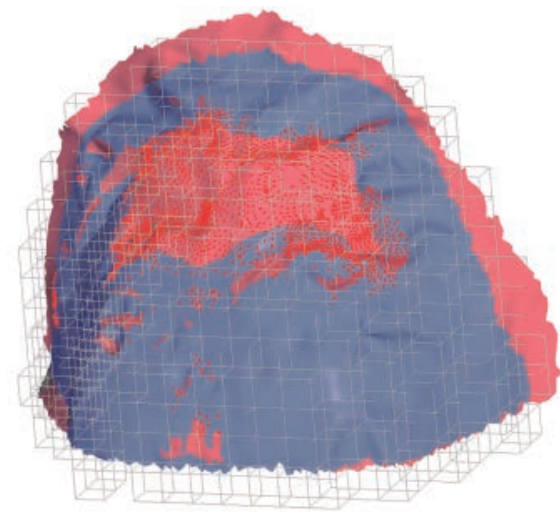

Figure 2: Palatal vault after deformation analysis. Used reference points are marked red. The $3 \mathrm{D}$ grid consisting of filter cubes is shown in light grey.

This three-step process is repeated 15 times to minimize the distance between the corresponding points and surfaces. The final result of the superimposition is shown in Figure 3. The ICProx algorithm was originally developed in order to monitor morphological changes in terrestrial laser scans. ${ }^{26}$ With this algorithm point clouds with large inherent deformation zones can be matched. ${ }^{27}$ RFD-superimposition is the result of an interdisciplinary approach to transfer this knowledge to the dental field. The ICProx (iterative closest proximity) algorithm is not to be confused with ICP (iterative closest point) algorithms. ICP algorithms match corresponding points from two objects. The ICP fails to conduct a correct superimposition as soon as the two objects differ too much in their morphology. Best-fit methods are usually based on ICP algorithms.

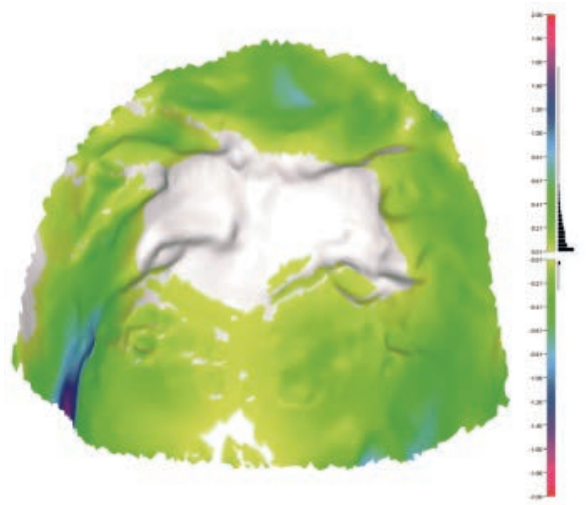

Figure 3: Distance analysis with true values showing an unchanged area (white coloured) in the centre of the palatal vault.

\section{Measurements}

Four senior consultant orthodontists independently conducted the superimpositions followed by 
the measurements. Repeated superimpositions and measurements were performed by all four observers after at least two weeks. The observers were blinded to the true value until the repeated measurements were completed. After the initial exercise program, measurements could be performed within ten minutes per case.

\section{D-model analysis}

All 3D models were imported as .stl-files into the Final Surface ${ }^{\circledR}$ software including the DefoScan++ Plugin (v 6.0.2, Society for the Promotion of Applied Computer Science, Berlin, Germany). Superimposition and measurement are presented in Supp1-InstructionVideo.mov and were performed as follows (the start model is the master and the specimen is the slave):

1. Cropping of the palatal vault: In a first step, both the start and the specimen model were cloned. The clones were named start palatum and specimen palatum. All areas known to be unstable were removed leaving the palatal vault from distal of the second premolar to the papilla incisiva.

2. Raw matching through six individually chosen corresponding points near the median point of the third rugae.

3. Fine matching with up to 50 iterations.

4. Deformation analysis and superimposition with the DefoScan ++ Plugin with 15 iterations. Collector parameter was set to octree cell size $0.5 \mathrm{~mm}$ edge length and filter parameter to octree cell size $1.5 \mathrm{~mm}$ edge length.

5. Superimposition of the uncropped models was performed by loading the transformation matrix of specimen palatum into the specimen model, transferring the result of the RFD-Superimposition of the palatal vault to the original models.

Measurements were then executed as follows:

1. The superimposed models start and specimen were cloned. The clones were named start 16 and specimen 16 . Then the occlusal surfaces of the right maxillary first molar in both models were selected and cropped. The weight centres were centralised and the position of start 16 was measured (PreTX x-, y-, z-coordinates).
2. Start 16 was then cloned again and named start $16 a$. This new clone was moved towards the position of specimen 16 . This was done through an initial raw matching followed by repeated fine matchings until the number of iterations was fewer than ten. The position and rotation angles of the occlusal surface 16 were measured. The position of the two objects start 16 and start $16 a$ are shown in Figure 4.

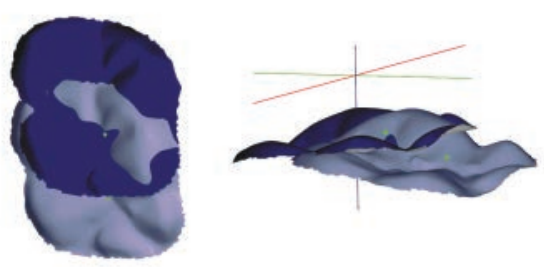

Figure 4: Pre- and post-treatment position of tooth 16 s occlusal surface.

\section{Variables}

Tooth movement was calculated by subtracting the PreTX coordinates from the PostTX coordinates, giving a translation for $\mathrm{x}$ (transversal), $\mathrm{y}$ (mesio-distal), and z (vertical). The total movement, $\mathrm{d}$, was calculated as $d=\sqrt{\left(x^{2}+y^{2}+z^{2}\right)}$. In addition to translation, the rotation was measured. Measurements of tooth 16 were separated into rotations around the three principal axes.

\section{Statistics}

For the purpose of examining the relationship between measured total movement and true total movement, a mixed effects model was fitted with measured total movement as the dependent variable, true total movement as a fixed covariate, and cases and observer as random factors. A variance components structure was used in the model. The mixed model can be explained as a simple linear regression model of the relationship between measured and true total movement, but this also accounts for dependence between observations made on the same case and by the same observer.

As a measure of relative reliability, ICCs were estimated for the following variables: total movement; x-, y-, z-translations; and x-, y-, z-rotations. Random effects models were estimated with each of these as a dependent variable and case and observer as random effects. The ICCs were estimated as follows: $\frac{\sigma 2 b s}{(\sigma 2 b s+\sigma 2 b o+\sigma 2 e)}$, where $\sigma 2 b s$ 
is the between-cases variance component, $\sigma 2 b o$ is the inter-observer variance component, and $\sigma 2 e$ is the residual variance of the model. This ICC estimates the correlation between two repeated measurements on the same case performed by the same observer. Confidence intervals (CI) with $95 \%$ confidence levels for the ICCs were estimated using parametric bootstrapping with 2000 iterations. The R-Code that was used for statistical analysis can be found in Supp2-RCode.R. The raw data is presented in Supp3-RawData.csv.

\section{Results}

The differences between measured total movements and true total movements are presented in Figure 5. The mean absolute error for total movement was $0.0225 \mathrm{~mm}$ (SD $0.03 \mathrm{~mm}$ ). The arithmetic mean error was $-0.0017 \mathrm{~mm}$. The range of total movements was from $-0.07 \mathrm{~mm}$ to $0.08 \mathrm{~mm}$. The ICC for measured total movement was 0.9996 . Figure 6 shows the measured total movements plotted against the corresponding true total movements. Thus, the distribution of the measurements is generally very close to the line of identity. This indicates that this technique is as accurate for measuring small distances as it is for measuring longer distances.

Estimated parameters from the mixed model, describing the relationship between measured and true total movement, are presented in Table 1. The intercept (-0.007) and the slope for the true movement (1.003) were very close to the line of identity (intercept $=0$, slope $=1$ ), indicating that any systematic errors of the measurements were very small. Random measurement errors (i.e., the variability of the random effects) were dominated by the residual error ( $56.9 \%$ of total variance), variability due to cases (32.4\%), and variability due to observer $(13.7 \%)$. However, the random measurement errors were also small; the standard deviation of the random effects due to cases, observer, and residuals were $0.0177 \mathrm{~mm}, 0.0115 \mathrm{~mm}$, and 0.0229 $\mathrm{mm}$, respectively.

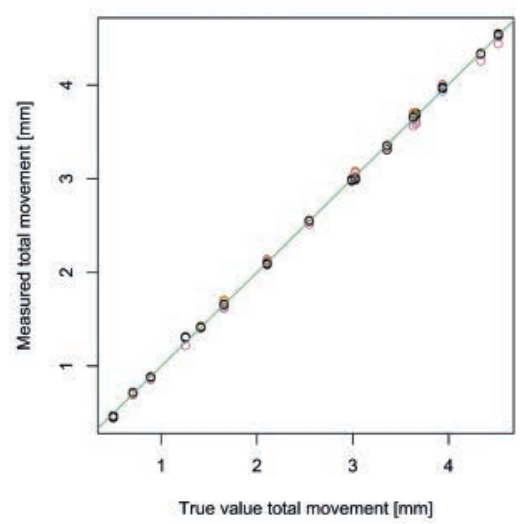

Figure 6: Measured total movement versus True total movement.

The results of translational and rotational measurements are presented in detail in Table 2. Model diagnostics were performed using various graphs of residuals and fitted values. QQ-plots of the residuals showed somewhat heavy tails for some of the mixed effects models but were considered to be within the limit of what could be acceptable. More details can be found in the supplementary material.

Table 1: Estimated parameters for total tooth movement of the mixed model.

\begin{tabular}{lcc}
\hline Fixed effect & Estimate & Std error \\
\hline - Intercept & -0.007 & 0.01 \\
- True value (slope) & 1.003 & $<0.01$ \\
\hline Random effect & Variance & Std deviation \\
\hline - Cases & 0.0003142 & 0.017 \\
- Observer & 0.0001327 & 0.011 \\
- Residual error & 0.0005228 & 0.023 \\
- Total variability & 0.0009697 & 0.031 \\
\hline
\end{tabular}




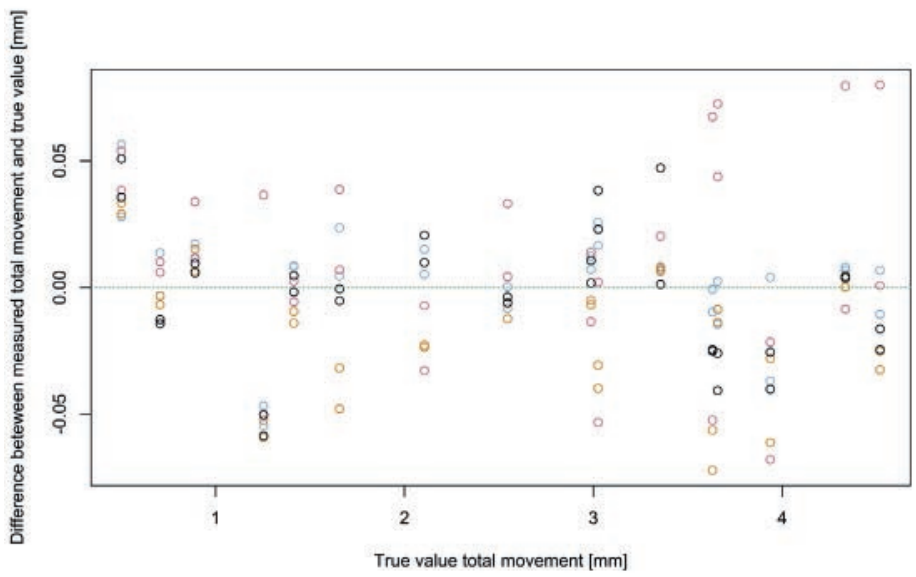

Figure 5: Differences between measured total movements and true total movements. Each of the four observers is represented by a unique colour.

Table 2: Absolute mean errors, arithmetic mean errors and ICC with estimated $95 \%$ CI.

\begin{tabular}{lrrr}
\hline & $\begin{array}{c}\text { Abs. } \\
\text { Error }\end{array}$ & $\begin{array}{c}\text { Arit. } \\
\text { Error }\end{array}$ & ICC (95\% CI) \\
\hline Translation [mm] & & & \\
- Total movement & 0.0225 & -0.0017 & $0.9996(0.9991,0.9998)$ \\
- Ateroposterior & 0.0152 & -0.0049 & $0.9994(0.9985,0.9997)$ \\
- Vertical & 0.0240 & 0.0020 & $0.9902(0.9756,0.9952)$ \\
- Transversal & 0.0208 & -0.0033 & $0.9996(0.9991,0.9998)$ \\
\hline Rotation [degree] & & & \\
- Disto-mesial tipping & 0.0291 & -0.0241 & $0.9999(0.9999,1.0000)$ \\
- Bucco-palatal tilting & 0.0134 & 0.0021 & $0.9999(0.9999,1.0000)$ \\
- Around tooth axis & 0.0215 & 0.0098 & $0.9999(0.9998,1.0000)$ \\
\hline
\end{tabular}

\section{Discussion}

The combination of raw matching, fine matching, and deformation analysis (RFD) superimposition delivers accuracy and precision in a dimension far beyond measurements on cephalometric X-rays, plaster casts, or 3D models with point-to-point measurements. The RFD superimposition delivers results that describe tooth movements not only as translation but also in terms of tipping, tilting, and rotation. This technique takes measurements by matching objects rather than by manually selecting measurement points. The identification of points is difficult and has been reported as a source of error. ${ }^{28,29}$ Nalcaci et al. ${ }^{30}$, comparing manual point measurements of molar distalization on cephalometric X-rays, photographs, and 3D models, found a standard deviation of about $1.3 \mathrm{~mm}$ for all three techniques. No statistical significant difference was found. Therefore, it can be assumed that this new technique can eliminate the error associated with manual selection of measurement points.

Although earlier validation studies have analysed different techniques for superimposition and reported measurements with high accuracy and precision, these studies compared measurements on digital 3D models with measurements on plaster casts or on lateral cephalograms. ${ }^{12,15,18}$ Hoggan et al. ${ }^{3}$, comparing measurements on plaster casts with cephalometric X-rays, found no statistically significant differences in measurements of movement of the maxillary first molar, but they did find that the standard deviation for measurements on plaster casts was between 1.6 and $2.1 \mathrm{~mm}$ and on cephalometric X-rays it was $2.0 \mathrm{~mm}$. Because RFDSuperimposition has a standard deviation of 0.03 
$\mathrm{mm}$, it can be assumed that these techniques, although widely used, suffer from more measurement errors than measurements gathered from digital $3 \mathrm{D}$ models. Therefore, these techniques may no longer be considered the gold standard.

Chen et al. ${ }^{13}$, using unloaded miniscrews as reference points, conducted measurements on 15 adult patients. Although unloaded miniscrews are regarded as stable in this study, they reported changes in miniscrew positions of up to $0.5 \mathrm{~mm}$. This movement indicates that miniscrews might not be suitable as a reference for a technique with minimal measurement errors.

Thiruvenkatachari et al. ${ }^{14}$ actually used a setup where the true values for translation were used as reference. This study was a source of inspiration for our current work. The use of specimen is an elegant way to avoid a situation where measurements assessed with a new technique have to be compared to another technique that obviously has more measurement error. However, in their study both master and slave models were identical in the palate. Technically, this validation matched identical surfaces. It would have been surprising if the matching process had failed. Moreover, their study did not measure rotational movement.

Unlike earlier studies, our study used true values as reference and the master and slave model did not have identical surfaces in the palate. ${ }^{12-14,18,30}$ Consequently, our results showed that our new technique was robust for changes in the palate, implying that this new method can be used in growing patients subjected to orthodontic treatment.

The measurements were performed by senior consultant orthodontists with different computer skills. After thorough instruction, any orthodontist would be capable of performing these measurements. The time needed per case (10 minutes) was comparable or even shorter for the time needed and duration to carry out, for example, tracing and superimposition of cephalometric X-rays. If the RFD superimposition is applied, the lateral head radiographs are not needed for evaluation of tooth movements. That is, an added benefit of the technique is that patients are not exposed to X-ray radiation.

\section{Limitations}

Despite the impressive accuracy and precision of the assessed RFD superimposition found in this study, there are three important circumstances to note:
First, there has to be at least some structure that in fact is unchanged. Since differences correlate with time, it is important to keep the interval between the two registrations short enough. In adolescents, an interval of one to two years is appropriate.

Second, one basic assumption in the workflow of this technique is that the area surrounding the median point of the third rugae is somehow stable. ${ }^{10,18}$ Use of this area during the rawmatching is therefore crucial. Impression or scanning errors could give an inaccurate $3 \mathrm{D}$ model. Local swelling of the gingiva after treatment with, for example, a Nance-appliance or palatal miniscrews could generate an inaccurate $3 \mathrm{D}$ model. Therefore, areas that obviously have been changed need to be cropped before the superimposition process is started.

Third, sometimes growth or treatments like rapid maxillary expansion follow an asymmetric pattern. This asymmetry needs to be taken into account when corresponding points are picked during the raw-matching. Thus, for raw-matching one would only use the median point of the third ruga on the non-effected side.

It is important that this technique has to be used under the conditions discussed above. The algorithm will always process the models that are put in. If there is an asymmetry or other abnormal growth pattern that is visible to the naked eye, one has to check whether the result of the superimposition is feasible or reasonable. The morphological changes caused by growth and treatment are very complex. Therefore, this technique is far from a one-click-solution and it is performed in specialised $3 \mathrm{D}$ software.

Consequently, for correct RFD superimposition it can be advisable to involve serial models taken with a moderate interval (1 to 2 years), to remove obvious changed areas in the palate, and to consider clinical information about asymmetric treatment effects.

We believe that deformation analysis will be a key-element in future superimposition-techniques. There may be several algorithms that could do the trick. However, these algorithms will probably be more complex than a simple best-fit method. 


\section{Conclusions}

The novel RFD-Superimposition method is a valid and reliable tool for measuring tooth movements in the maxilla. This method can tolerate morphological changes in the palate and gives excellent precision and accuracy. In addition, this method is robust for variances in the local point resolution and may also be used in growing subjects who undergo orthodontic treatment.

\section{Acknowledgements}

The authors gratefully acknowledge the senior consulting orthodontists Lena Zettergren Wijk (LZW) and Anke Krämer (AK) for their help with the measurements and computer engineers Daniel Krueger and Lothar Paul for the great support when developing the method of measurements.

All authors have completed the ICMJE Conflict of Interest Disclosure form and declare the following: Niels Ganzer reports grants and nonfinancial support from the Centre for Research and Development, Uppsala University/Region Gävleborg, Sweden, and grants from the Swedish Dental Associations Scientific Funds during the conduct of the study.

Ingalill Feldmann reports grants from the Thuréus Foundation for the Promotion of Dental Science, Uppsala University, Sweden, during the conduct of the study.

The funding sources had no influence on study design, collection, analysis, or interpretation of the data, writing the article, or in the decision to submit the article for publication. There are no financial relationships with any organizations that might have interests in the submitted work in the previous three years. There are no other relationships or activities that could appear to have influenced the submitted work.

\section{References}

1. Ricketts RM. A four-step method to distinguish orthodontic changes from natural growth. J Clin Orthod. 1975;9(4):28.

2. Pancherz H. The mechanism of Class II correction in Herbst appliance treatment. A cephalometric investigation. American J Orthod. 1982;82(2):104-113.
3. Hoggan BR, Sadowsky C. The use of palatal rugae for the assessment of anteroposterior tooth movements. Am J Orthod Dentofacial Orthop. 2001;119(5):482-488.

4. Reuschl RP, Heuer W, Stiesch M, Wenzel D, Dittmer MP. Reliability and validity of measurements on digital study models and plaster models. Eur J Orthod. 2016;38(1):22-26.

5. Wiranto MG, Engelbrecht WP, Nolthenius HET, van der Meer WJ, Ren Y. Validity, reliability, and reproducibility of linear measurements on digital models obtained from intraoral and cone-beam computed tomography scans of alginate impressions. Am J Orthod Dentofacial Orthop. 2013;143(1):140-147.

6. Akyalcin S, Dyer DJ, English JD, Sar C. Comparison of 3-dimensional dental models from different sources: diagnostic accuracy and surface registration analysis. Am J Orthod Dentofacial Orthop. 2013;144(6):831-837.

7. Bootvong K, Liu Z, McGrath C, Hagg U, Wong RW, Bendeus M, et al. Virtual model analysis as an alternative approach to plaster model analysis: reliability and validity. Eur J Orthod. 2010;32(5):589-595.

8. Grewal B, Lee RT, Zou L, Johal A. Royal London space analysis: plaster versus digital model assessment. Eur J Orthod. 2016;.

9. Aragon ML, Pontes LF, Bichara LM, FloresMir C, Normando D. Validity and reliability of intraoral scanners compared to conventional gypsum models measurements: a systematic review. Eur J Orthod. 2016;38(4):429-434.

10. Bailey LT, Esmailnejad A, Almeida MA. Stability of the palatal rugae as landmarks for analysis of dental casts in extraction and nonextraction cases. Angle Orthod. 1996;66(1):73-78.

11. Diez Y, Ferran R, Llado X, Salvi J. A Qualitative Review on 3D Coarse Registration Methods. ACM Computing Surveys. 2015;47(3):45:1-45:36.

12. Choi DS, Jeong YM, Jang I, Jost-Brinkmann PG, Cha BK. Accuracy and reliability of palatal superimposition of threedimensional digital models. Angle Orthod. 2010;80(4):497-503. 
13. Chen G, Chen S, Zhang XY, Jiang RP, Liu $\mathrm{Y}$, Shi FH, et al. Stable region for maxillary dental cast superimposition in adults, studied with the aid of stable miniscrews. Orthod Craniofac Res. 2011;14(2):70-79.

14. Thiruvenkatachari B, Al-Abdallah M, Akram NC, Sandler J, O'Brien K. Measuring 3-dimensional tooth movement with a 3dimensional surface laser scanner. Am J Orthod Dentofacial Orthop. 2009;135(4):480-485.

15. Cha BK, Lee JY, Jost-Brinkmann PG, Yoshida N. Analysis of tooth movement in extraction cases using three-dimensional reverse engineering technology. Eur J Orthod. 2007;29(4):325-331.

16. Pomerleau F, Colas F, Siegwart R, Magnenat S. Comparing ICP variants on real-world data sets. Autonomous Robots. 2013;34:133-148.

17. Christou P, Kiliaridis S. Vertical growthrelated changes in the positions of palatal rugae and maxillary incisors. Am J Orthod Dentofacial Orthop. 2008;133(1):81-86.

18. Choi JI, Cha BK, Jost-Brinkmann PG, Choi DS, Jang IS. Validity of palatal superimposition of 3-dimensional digital models in cases treated with rapid maxillary expansion and maxillary protraction headgear. Korean J Orthod. 2012;42(5):235-241.

19. Thilander B. Dentoalveolar development in subjects with normal occlusion. A longitudinal study between the ages of 5 and 31 years. Eur J Orthod. 2009;31(2):109-120.

20. Yang ST, Kim HK, Lim YS, Chang MS, Lee SP, Park YS. A three dimensional observation of palatal vault growth in children using mixed effect analysis: a 9 year longitudinal study. Eur J Orthod. 2013;35(6):832-840.

21. Team RC. Team RC, editor. R: A Language and Environment for Statistical Computing. Vienna, Austria: R Foundation for Statistical Computing; 2018. Available at: www.Rproject.org.

22. Rathbone A, Shaw S, Kumbhare D. Rathbone A, editor. ICC.Sample.Size: Calculation of Sample Size and Power for ICC. R package version 1.0. https://CRAN.Rproject.org $/$ package $=$ ICC.Sample.Size.

CRAN; 2015. Available from: https://CRAN . R-project. org/package=ICC. Sample. Size.

23. Feldmann I, Bondemark L. Anchorage capacity of osseointegrated and conventional anchorage systems: A randomized controlled trial. Am J Orthod Dentofacial Orthop. 2008;133(3):339.e28.

24. Sousa MV, Vasconcelos EC, Janson G, Garib D, Pinzan A. Accuracy and reproducibility of 3-dimensional digital model measurements. Am J Orthod Dentofacial Orthop. 2012;142(2):269-273.

25. Hayashi K, Sachdeva AU, Saitoh S, Lee SP, Kubota T, Mizoguchi I. Assessment of the accuracy and reliability of new 3-dimensional scanning devices. Am J Orthod Dentofacial Orthop. 2013;144(4):619-625.

26. Wujanz D, Krueger D, Neitzel F. Identification of Stable Areas in Unreferenced Laser Scans for Deformation Measurement. The Photogrammetric Record. 2016;31.

27. Avian M, Wujanz D. Movement of Hinteres Langtalkar rock glacier 2009 - 2013 by using the ICProx-algorithm at very high resolution point clouds from terrestrial laserscanning. In: EGU General Assembly Conference Abstracts. vol. 16 of EGU General Assembly Conference Abstracts; 2014. p. 12152. Provided by the SAO/NASA Astrophysics Data System. Available from: http: //adsabs . harvard.edu/abs/2014EGUGA . .1612152A.

28. Sjögren AP, Lindgren JE, Huggare JA. Orthodontic study cast analysis-reproducibility of recordings and agreement between conventional and 3D virtual measurements. J Digit Imaging. 2010;23(4):482-492.

29. Asquith J, Gillgrass T, Mossey P. Threedimensional imaging of orthodontic models: a pilot study. Eur J Orthod. 2007;29(5):517-522.

30. Nalcaci R, Kocoglu-Altan AB, Bicakci AA, Ozturk F, Babacan H. A reliable method for evaluating upper molar distalization: Superimposition of three-dimensional digital models. Korean J Orthod. 2015;45(2):82-88. 

PAPER II 



\title{
Original Article
}

\section{Pain and discomfort following insertion of miniscrews and premolar extractions: \\ A randomized controlled trial}

\author{
Niels Ganzer ${ }^{\text {; }}$ Ingalill Feldmannº; Lars Bondemark
}

\begin{abstract}
Objective: To investigate and compare the experience of pain and discomfort between insertion of miniscrews and premolar extractions in adolescent patients.

Materials and Methods: $A$ total of 80 adolescents were recruited and randomized into groups $A$ and $B$. Both groups were treated with extraction of the upper first premolars and fixed appliance. Beyond the fixed appliance, patients in group A received anchorage reinforcement with miniscrews. Miniscrews were inserted buccally between the second premolar and first molar when space closure started. Space closure was performed as en masse retraction with immediate loading by 150-g coil springs. Pain, discomfort, impact on daily activities, and functional jaw impairment were assessed with patient-reported questionnaires. Questionnaires were filled in at baseline, the evening after tooth extraction, 1 week after tooth extraction, the evening after screw placement, and 1 week after screw placement.

Results: Patients reported significantly lower levels of pain $(P<.001)$ and discomfort $(P=.012)$ after screw placement compared with premolar extractions. The ability to drink $(P=.035)$ and the ability to take a big bite $(P<.001)$ were also significantly less disturbed in the evening after screw placement. During the first week after screw placement, the impact on leisure time activities was significantly lower $(P=.015)$ compared with premolar extractions.

Conclusion: The use of miniscrews in adolescents can be recommended from a pain and discomfort perspective. (Angle Orthod. 2016;86:891-899)
\end{abstract}

KEY WORDS: Orthodontics; Orthodontic anchorage procedures; Miniscrew; TAD; Temporary anchorage device; MSI

\section{INTRODUCTION}

Orthodontic treatment is often correlated with discomfort and pain. Soreness and aching are certainly

${ }^{a}$ Research Fellow, Senior Consultant Orthodontist, Department of Orthodontics, Public Dental Service Region Gävleborg, Gävle, Sweden, and Centre for Research and Development, Uppsala University/Region Gävleborg, Sweden.

b Senior Consultant Orthodontist, Department of Orthodontics, Public Dental Service Region Gävleborg, Gävle, Sweden, and Centre for Research and Development, Uppsala University/ Region Gävleborg, Sweden

c Professor and Head, Department of Orthodontics, Faculty of Odontology, Malmö University, Malmö, Sweden.

Corresponding author: $\mathrm{Dr}$ Niels Ganzer, Department of Orthodontics, Public Dental Service Region Gavleborg, Box 57, SE-80102 Gävle, Sweden

(e-mail: niels.ganzer@ regiongavleborg.se)

Accepted: February 2016. Submitted: December 2015.

Published Online: March 29, 2016

(c) 2016 by The $\mathrm{EH}$ Angle Education and Research Foundation, Inc.

DOI: $10.2319 / 123115-899.1$ reported after insertion of the initial archwire. ${ }^{1,2}$ Since invasive skeletal anchorage has become a common technique in orthodontics, yet another potentially painful moment has become part of the orthodontic treatment plan.

The use of skeletal anchorage devices is a multifactor scenario in which the type of screw, insertion site, anesthesia, and pre- or postoperative medication make difference. Because of the variety of screw types and their usage, only a few general conclusions can be drawn for the experience of pain and discomfort related to the use of miniscrews. ${ }^{3}$ Lehnen et al. ${ }^{4}$ showed that the drilling of a pilot hole was reported to be as uncomfortable as the pressure that self-drilling screws cause in the bone, and when treatment includes flap surgery or soft tissue punching, patients report even higher pain levels. ${ }^{5,6}$ Lee et al. ${ }^{7}$ showed in a cohort study that patients expect the buccal placement of miniscrews to be more painful than it finally is. 
To evaluate the experience of pain and discomfort under and after insertion of skeletal anchorage devices, a reference procedure is needed. Tooth extractions can serve as a reference since this procedure is commonly used and accepted in orthodontics. ${ }^{8}$ Earlier randomized clinical trials showed that palatal implants, in comparison to tooth extractions, cause pain and discomfort on an acceptable level. ${ }^{9}$ However, individual pain levels range from no pain at all to worst pain imaginable. There are large uncertainties concerning the experience of pain and discomfort since different types of miniscrews, study designs, and statistical methods are used. Consequently, there is a knowledge gap in the management of pain and discomfort when miniscrews are used.

The purpose of this study was to investigate and compare the experience of pain and discomfort between the insertion of miniscrews and premolar extractions in adolescent patients. Our hypothesis was that insertion of miniscrews causes lower pain levels than extraction of premolars.

\section{MATERIALS AND METHODS}

The study protocol, questionnaires, and informed consent were approved by the Regional Ethical Review Board, Uppsala University, Uppsala, Sweden (Dnr.2009/188). After receiving oral and written information about the treatment plan and about the clinical trial, both the patient and the parents signed informed consent. This study is registered at Clinicaltrials.gov, NCT92644811.

\section{Subjects}

Patients were recruited from the Orthodontic Clinic at the Public Dental Service, Gävleborg County Council, Gävle, Sweden.

The inclusion criteria were adolescents in need of orthodontic treatment with a fixed appliance, treatment plan including extraction of the maxillary first premolars, need for anchorage reinforcement, permanent dentition including the maxillary second molars in occlusion, and regular dental care from 3 years of age. Patients with previous orthodontic treatment or need for orthognathic surgery were excluded from the study.

An independent person conducted the randomization as follows: computer-generated randomization list and preparation of numbered and sealed opaque envelopes containing an allocation note (ie, random allocation to either group A or group B). The envelope was then handed to the patient, and the allocation to the study groups was revealed by the patient opening the envelope.
Patients in group A were treated with extraction of the first maxillary premolars (Figure 1a) and fixed appliance in the maxilla or in both jaws. When the space closing phase started, miniscrews were buccally and interradicularily inserted between the maxillary second premolars and first molars (Figure 1b). Space closure was performed as an en masse retraction with closed coil springs.

Group B was also treated with extraction of the first maxillary premolars (Figure 1a) and fixed appliance in the maxilla or in both jaws. Anchorage was reinforced with molar blocks, a stainless steel ligature connecting the second maxillary premolar with the first and second molar. Space closure was performed as an en masse retraction with type 1 active tiebacks.

All patients in both groups were treated by two orthodontists (N.G., I.F.) and in line with a standard straight-wire concept ${ }^{10}$ (Victory, 0.022 slot size, MBT prescription, 3M Unitek, St Paul, Minn). The recommended archwire sequence was 0.016-inch heat-activated nickel-titanium (HANT), $0.019 \times 0.025$-inch HANT, and $0.019 \times 0.025$-inch stainless steel posted.

\section{Tooth Extraction Protocol (Group A and B)}

The patients' general practitioner performed the tooth extractions according to the following protocol:

1. Topical anesthesia with $5 \%$ lidocaine gel (APL, Sweden)

2. Buccal and palatal infiltration of Xylocaine Dental Adrenalin (lidocaine hydrochloride $20 \mathrm{mg} / \mathrm{mL}$, adrenaline $12.5 \mu \mathrm{g} / \mathrm{mL}$, Dentsply Pharmaceutical, Weybridge, Surrey, UK)

3. Tooth extraction after careful mobilization

\section{Miniscrew Insertion Protocol (Group A Only)}

All miniscrews were inserted by one orthodontist (NG) according to the following protocol:

1. Topical anesthesia with $5 \%$ lidocaine gel (APL)

2. Buccal infiltration of $0.3 \mathrm{~mL}$ Xylocaine Dental Adrenalin per site (lidocaine hydrochloride $20 \mathrm{mg} / \mathrm{mL}$, adrenaline $12.5 \mu \mathrm{g} / \mathrm{mL}$, Dentsply Pharmaceutical)

3. Chlorhexidine mouth rinse for 60 seconds (Corsodyl $2 \mathrm{mg} / \mathrm{mL}$, SmithKline Beecham Ltd, Brentford, UK)

4. Insertion of two miniscrews (Spider Screw K1 SCR1510 or SCR-1508, Health Development Company, Sarcedo, Italy), one on the right and one on the left side, buccally and interdentally with $30^{\circ}-40^{\circ}$ of angulation between the maxillary second premolar and first molar

5. Periapical radiographs

6. Immediate loading of the miniscrews as direct anchorage with 150-g closed-coil springs (TAD Coil 


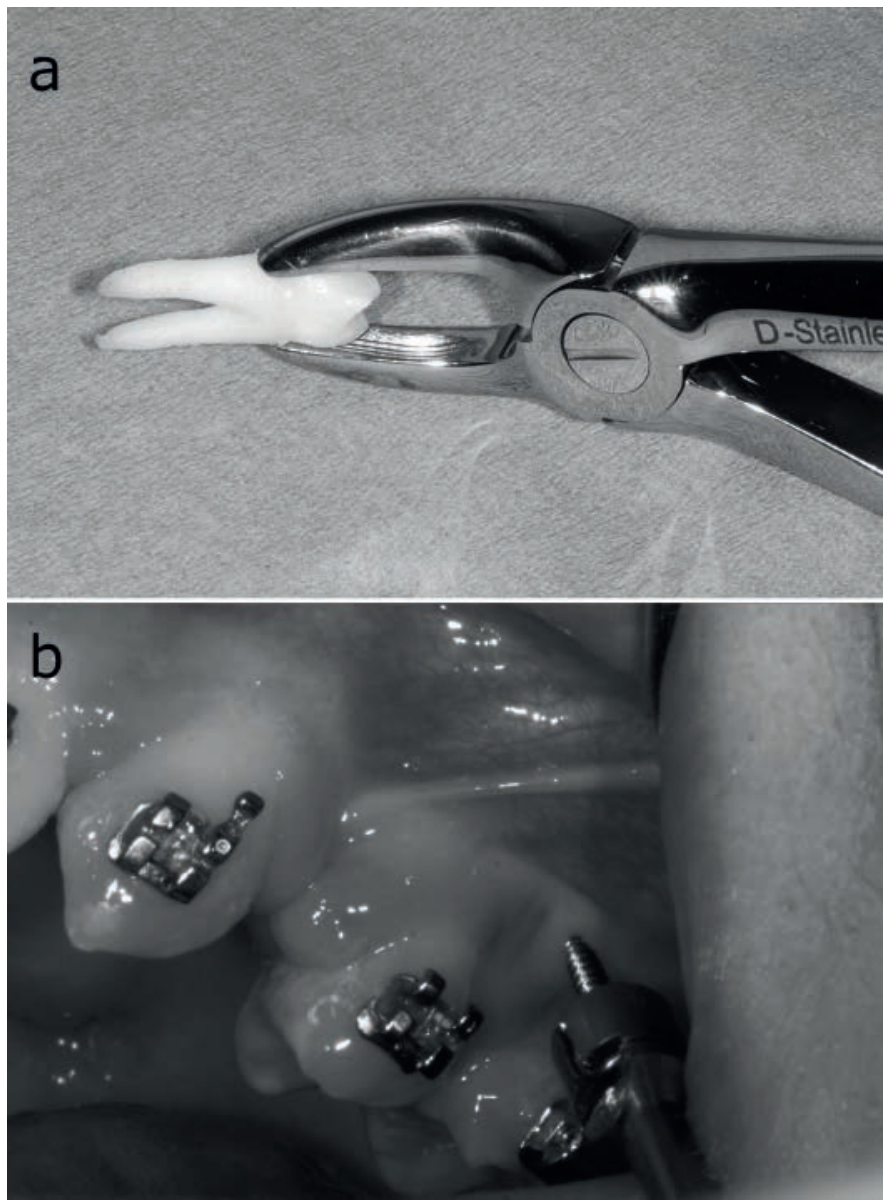

Figure 1. (a) Extracted maxillary premolar. (b) Miniscrew installation.

Spring, medium force $150 \mathrm{~g}$, Ortho Technology, Tampa, Fla)

7. After screw insertion, patients were instructed to apply chlorhexidine gel onto the miniscrews once a day for 2 weeks.

\section{Postoperative Instructions}

When experiencing pain after tooth extractions (group A and B) or installation of the miniscrews (group
A), patients were advised to use over-the-counter analgesics according to their personal judgment.

\section{Questionnaires}

Treatment motivation and expectation, experience of pain and discomfort, analgesic consumption, and the impact on daily activities were assessed using selfreport questionnaires. These questionnaires have

Angle Orthodontist, Vol 86, No 6, 2016 
Table 1. Self-report Questionnaires Concerning Pain and Discomfort, Analgesic Consumption, and Daily Activities Assessed the First Evening after Premolar Extraction and Insertion of the Miniscrews, Respectively

\begin{tabular}{|c|c|}
\hline & Scale \\
\hline \multicolumn{2}{|l|}{ Pain and discomfort, analgesic consumption } \\
\hline \multicolumn{2}{|l|}{ 1. Did you have pain during the injection } \\
\hline \multicolumn{2}{|l|}{ 2. Did you have pain during tooth } \\
\hline extraction/insertion of the miniscrews? & VAS \\
\hline 3. Have you taken analgesic today? & Yes/No \\
\hline \multicolumn{2}{|l|}{ - If YES, what kind and which dose } \\
\hline \multicolumn{2}{|l|}{ 4. Did you have discomfort during the } \\
\hline injection of the anesthetic? & VAS \\
\hline \multicolumn{2}{|l|}{ 5. Did you have discomfort during tooth } \\
\hline $\begin{array}{l}\text { extraction/insertion of the miniscrews? } \\
\text { 6. Did you experience any part of the tooth }\end{array}$ & \\
\hline $\begin{array}{l}\text { 6. Did you experience any part of the tooth } \\
\text { extraction/insertion of the miniscrews as }\end{array}$ & \\
\hline \multicolumn{2}{|l|}{$\begin{array}{l}\text { particularly unpleasant? } \\
\text { - If YES, which part did you experience }\end{array}$} \\
\hline as particularly unpleasant? & Plain text \\
\hline \multicolumn{2}{|l|}{ 7. Do you have pain from the extraction } \\
\hline \multicolumn{2}{|l|}{ 8. Do you have discomfort from the extra } \\
\hline site/insertion site right now? & VAS \\
\hline \multicolumn{2}{|l|}{ Daily activities and functional jaw impairment } \\
\hline \multicolumn{2}{|l|}{$\begin{array}{l}\text { If you have pain or discomfort in your teeth and } \\
\text { jaws, how much does that affect }\end{array}$} \\
\hline 9. Your leisure time & 5-point scal \\
\hline 10. Your & 5-point scal \\
\hline to take a big bite & 5-point sca \\
\hline 12. Your & 5-po \\
\hline 13. $Y$ & $5-\mathrm{po}$ \\
\hline choolwork & 5-point scale \\
\hline 15. Drinking & 5-point scale \\
\hline 16. Lau & 5-point scale \\
\hline 17. Your ability to chew against resistance & 5-point scale \\
\hline 18. Yawning & 5-point scale \\
\hline 19. Kissing & 5-point sca \\
\hline \multicolumn{2}{|l|}{$\begin{array}{l}\text { Eating means taking a bite, chewing, and } \\
\text { swallowing. How difficult is it for you to eat }\end{array}$} \\
\hline 20. Crisp bread & 5-point scal \\
\hline 21. Meat & 5-point scale \\
\hline 22. Raw carrots & 5-point scale \\
\hline 23. Roll & 5-point scale \\
\hline 24. Peanuts & 5-point scale \\
\hline 25. Apples & 5-point scale \\
\hline 26. Cake & 5-point sca \\
\hline \multicolumn{2}{|l|}{$\begin{array}{l}\text { 27. Did you stay at home from school today } \\
\text { because of pain from the extraction }\end{array}$} \\
\hline site/insertion site? & Yes/No \\
\hline \multicolumn{2}{|l|}{$\begin{array}{l}\text { 28. Did you refrain from your leisure activities } \\
\text { today because of pain from the }\end{array}$} \\
\hline extraction site/insertion site? & Yes/No \\
\hline - If YES, what activity did you refrain from? & Plain text \\
\hline
\end{tabular}

been found to be reliable and with sufficient internal consistency in earlier studies..$^{911-13}$

The baseline questionnaire was administrated after the randomization process and comprised questions about treatment motivation and expectation, pain and discomfort, and limitations in daily activities. ${ }^{11}$ Table 1
Table 2. Self-report Questionnaire Concerning Pain and Discomfort, Analgesic Consumption, and Daily Activities Assessed 1 Week After the First Tooth Extraction and Insertion of the Miniscrews, Respectively

\begin{tabular}{|c|c|}
\hline & Scale \\
\hline \multicolumn{2}{|l|}{ Pain and discomfort } \\
\hline \multicolumn{2}{|l|}{ 1. Do you have pain from the extraction } \\
\hline $\begin{array}{l}\text { 2. Do you have discomfort from the extraction } \\
\text { site/insertion site right now? }\end{array}$ & VAS \\
\hline \multicolumn{2}{|l|}{$\begin{array}{l}\text { If you have pain or discomfort in your teeth and } \\
\text { jaws, how much does that affect }\end{array}$} \\
\hline 3. Your leisure time & 5-point sca \\
\hline 4. $Y$ & 5-po \\
\hline to take a big bite & 5-point scale \\
\hline 6. Yo & 5-point scale \\
\hline 7. You & 5-point scale \\
\hline hoolwork & 5-point scale \\
\hline 9. Dri & 5-point scale \\
\hline 10. Lé & scal \\
\hline ity to chew against resistance & cale \\
\hline 12. $Y$ & ca \\
\hline 13. $\mathrm{K}$ & \\
\hline \multicolumn{2}{|l|}{ Eating means taking a bite, chewing, and } \\
\hline swallowing. How difficult is it for you to eat & 5-poin \\
\hline 14. Cris & $5-1$ \\
\hline 15. Meat & 5-point sca \\
\hline 16. $\mathrm{R}$ & 5-poir \\
\hline 17. $\mathrm{R}$ & $5-p$ \\
\hline 18. $\mathrm{P}$ & \\
\hline 19. A & cale \\
\hline 20. Cake & 5-point s \\
\hline \multicolumn{2}{|l|}{$\begin{array}{l}\text { 21. Did you stay at home from school this } \\
\text { week because of pain from the extraction }\end{array}$} \\
\hline site/insertion site? & Yes/No \\
\hline $\begin{array}{l}\text { - If YES, how many days did you stay home } \\
\text { from school? }\end{array}$ & \\
\hline \multicolumn{2}{|l|}{ 22. Did you refrain from your leisure activities } \\
\hline $\begin{array}{l}\text { this week because of pain from the } \\
\text { extraction site/insertion site? }\end{array}$ & Yes/No \\
\hline - If YES, what activity did you refrain from? & Plain text \\
\hline \multicolumn{2}{|l|}{$\begin{array}{l}\text { 23. Has your sleep been disturbed in the last } \\
\text { week because of pain from the extraction }\end{array}$} \\
\hline $\begin{array}{l}\text { week because of pain from the extraction } \\
\text { site/insertion site? }\end{array}$ & Yes/No \\
\hline \multicolumn{2}{|l|}{ Analgesic consumption } \\
\hline \multirow{3}{*}{$\begin{array}{l}\text { 24. Have you taken analgesic because of pain } \\
\text { during the last week? } \\
\text { - If YES, what kind and which dose of } \\
\text { analgesic did you use? }\end{array}$} & \\
\hline & Yes/No \\
\hline & Plain text \\
\hline
\end{tabular}

presents the questions used at the evening after premolar extraction and at the evening after insertion of the miniscrews. The questions displayed in Table 2 were administrated 1 week after premolar extraction and miniscrew insertion, respectively. Consequently, patients in group A were evaluated at baseline, after premolar extractions, and after miniscrew insertion. Patients in group B were evaluated at baseline and after premolar extractions only. 


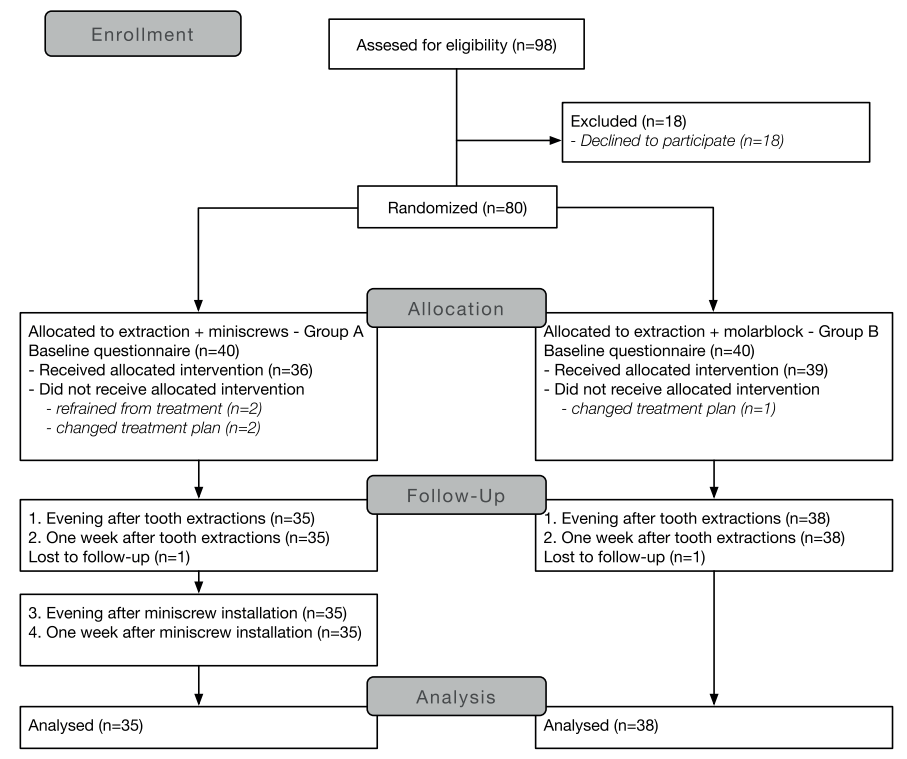

Figure 2. CONSORT flow diagram of the patients.

We used horizontal visual analogue scales (VAS; $100 \mathrm{~mm}$ ) with the end phrases not at all and worst imaginable.

The five-point scale consisted of the alternatives not at all, slightly difficult, difficult, much difficult, and extremely difficult.

The patients in both groups were instructed to complete the questionnaire on their own. They were asked to bring it to the clinic at the follow-up visit. Approximately 10 minutes were needed to fill in the questionnaire.

\section{Measurements}

The VAS was assessed to the nearest $0.5 \mathrm{~mm}$ by using a standard 100-mm metric ruler. For blinding purposes, a new random identification number was assigned to each patient prior to measurements; thus, the investigator was unaware of patient's name, age, sex, or group assignment.

\section{Statistical Analysis}

Differences between groups were tested with the Mann-Whitney $U$-test (ordinal data) and Fisher exact test (nominal data). The Wilcoxon signed rank test was used to analyze differences between tooth extractions and insertion of the miniscrews within group A. To examine associations between the baseline questionnaire and later experience of pain and discomfort, Spearman correlation coefficients were calculated. $P$ values were then adjusted for multiple comparisons with the Holm-Bonferroni correction. $P$ values less than $5 \%$ were considered statistically significant. Statistical analysis was performed with IBM SPSS Statistics version 22 and in $\mathrm{R}$ version 3 (New York, NY).

\section{RESULTS}

Ninety-eight patients matched the inclusion criteria and were invited to participate in this investigation, but 18 patients declined to participate. Thus, informed consent was collected from 80 patients before they were enrolled into the trial. The patients who declined comprised eight boys and 10 girls (mean age, 15.1 years; SD, 1.85) and were not significantly different with regard to age or gender compared with the patients who entered the study.

After randomization and before treatment start, two patients from group A were excluded because of refrainment from orthodontic treatment. Further, two patients from group $A$ were excluded because no spaces were apparent after levelling and alignment, implying no 


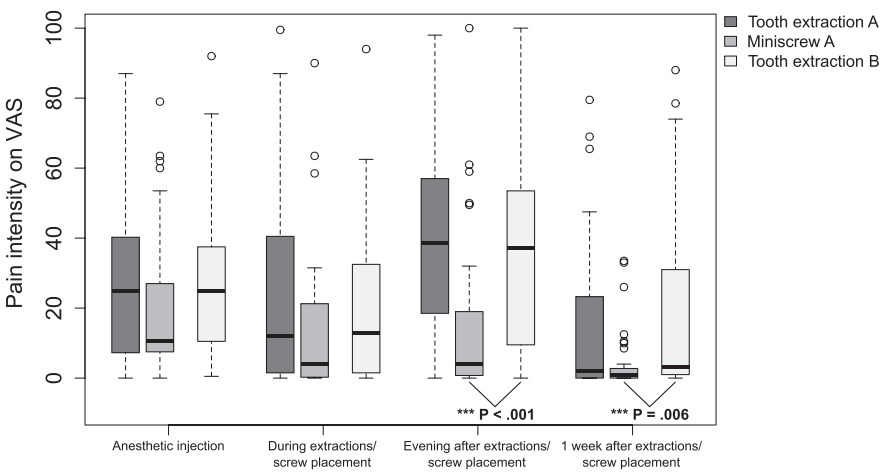

Figure 3. Pain intensity on visual analogue scale presented as Tukey boxplot with median values and interquartile range.

need for space closure. In addition, the extraction procedure had to be changed for one patient in group $B$ because of a pathological finding on preoperative x-rays, and this patient was also excluded from the trial (Figure 2).

One patient in group $A$ and one in group $B$ were lost to follow-up because of questionnaires that were not returned. Consequently, group A consisted of 35 patients (24 girls, 11 boys; mean age, 16.3 years; SD, 0.28 years) and group B of 38 patients ( 26 girls, 12 boys; mean age, 14.9 years; SD, 0.3 years). The overall response rate was $87.8 \%$.

\section{Baseline Questionnaire}

The baseline questionnaire showed no significant differences between groups $\mathrm{A}$ and $\mathrm{B}$ concerning pain and discomfort and limitations in daily activities. However, patients in group A (miniscrews) more often answered that it was their own decision to undergo orthodontic treatment $(P=.028)$ and that they expected it to be more difficult to wear braces $(P=.047)$. There were no correlations between later experience of pain and discomfort and the baseline assessments.

\section{Pain Intensity}

Patient-reported pain intensity is presented in Figure 3 and Table 3. There were no significant differences in experience of pain between tooth extractions in group A or B.

Comparing pain intensity for tooth extractions and miniscrew installation, we found significantly lower pain levels at the evening and 1 week after placement of the miniscrews compared with tooth extractions.

\section{Discomfort}

Patient-reported discomfort is presented in Figure 4 and Table 4. There were no significant differences in experience of discomfort between tooth extractions in groups A and B. Patients experienced significant less discomfort at the evening and 1 week after installation of the miniscrews compared with tooth extractions.

Table 3. Patient-Reported Pain Intensity (Median Values and Tukey's Hinges)

\begin{tabular}{|c|c|c|c|c|c|}
\hline & Extractions A & $\leftarrow P \rightarrow$ & Miniscrews A & $\leftarrow P \rightarrow$ & Extractions B \\
\hline \multirow[t]{3}{*}{ Anesthetic injection } & $\mathrm{Q} 1=7.25$ & \multirow[t]{3}{*}{.388} & $\mathrm{Q} 1=7.50$ & \multirow[t]{3}{*}{.063} & $\mathrm{Q} 1=10.50$ \\
\hline & Median $=25.00$ & & Median $=10.50$ & & Median $=25.00$ \\
\hline & $\mathrm{Q} 3=40.25$ & & $\mathrm{Q} 3=27.00$ & & $\mathrm{Q} 3=37.50$ \\
\hline \multirow[t]{3}{*}{ During screw placement/extractions } & $\mathrm{Q} 1=1.50$ & \multirow[t]{3}{*}{.088} & $\mathrm{Q} 1=0.25$ & \multirow[t]{3}{*}{.082} & $\mathrm{Q} 1=1.50$ \\
\hline & Median $=12.00$ & & Median $=4.00$ & & Median $=13.00$ \\
\hline & $\mathrm{Q} 3=40.50$ & & $\mathrm{Q} 3=21.25$ & & $\mathrm{Q} 3=32.50$ \\
\hline \multirow[t]{3}{*}{ Evening after screw placement/extractions } & $\mathrm{Q} 1=18.50$ & \multirow[t]{3}{*}{$<.001$} & $\mathrm{Q} 1=0.75$ & \multirow[t]{3}{*}{$<.001$} & $\mathrm{Q} 1=9.50$ \\
\hline & Median $=38.50$ & & Median $=4.00$ & & Median $=37.25$ \\
\hline & $\mathrm{Q} 3=57.00$ & & $\mathrm{Q} 3=19.00$ & & $\mathrm{Q} 3=53.50$ \\
\hline \multirow[t]{3}{*}{ One week after screw placement/extractions } & $\mathrm{Q} 1=0.00$ & \multirow[t]{3}{*}{.013} & $\mathrm{Q} 1=0.00$ & \multirow[t]{3}{*}{.006} & $\mathrm{Q} 1=1.00$ \\
\hline & Median $=2.00$ & & Median $=1.00$ & & Median $=3.25$ \\
\hline & $\mathrm{Q} 3=23.25$ & & $\mathrm{Q} 3=2.75$ & & $\mathrm{Q} 3=31.00$ \\
\hline
\end{tabular}




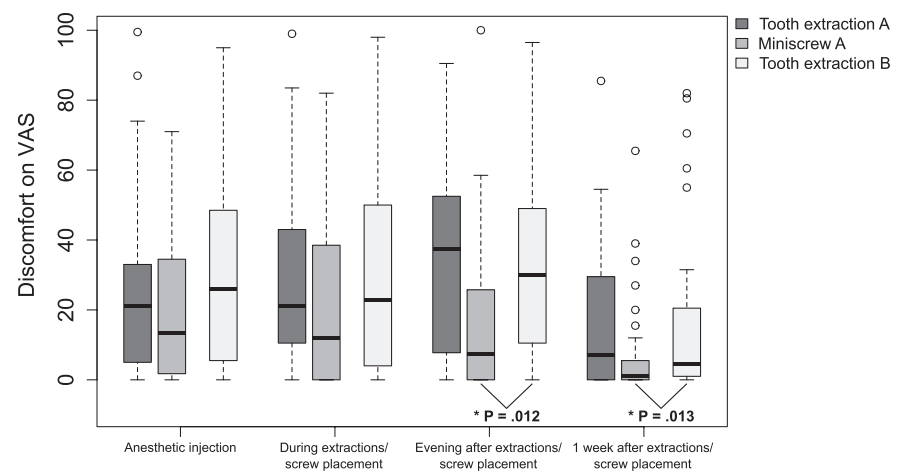

Figure 4. Discomfort on visual analogue scale presented as Tukey boxplot with median values and interquartile range.

\section{Analgesics}

In total, $57.4 \%$ of our patients used analgesics at the evening after premolar extractions and/or placement of the miniscrews, while $29.6 \%$ used analgesics during the first week after the procedures. There were no significant differences between analgesic consumption after miniscrew placement in group $A$ and premolar extractions in group B, although pain levels were significantly lower after miniscrew placement. Prescription-free compositions of paracetamol or ibuprofen were most commonly used.

\section{Daily Activities and Functional Jaw Impairment}

Patients reported significantly more problems taking a big bite $(P<.001)$ and drinking $(P=.035)$ at the evening after the tooth extractions than at the evening after installation of the miniscrews. Leisure time activities were more often reported to be disturbed during the first week after tooth extractions than after installation of the miniscrews $(P=.015)$.
In total, $19.4 \%$ of our patients stayed home from school the day of the tooth extractions or installation of the miniscrews, although $13.0 \%$ stayed home at least 1 day during the first week after tooth extractions or installation of the miniscrews. There were no other significant differences between groups $\mathrm{A}$ and $\mathrm{B}$.

\section{Gender Differences}

Girls complained more frequently about tension in the jaw $(P=.018)$ and headache $(P=.027)$ in the baseline questionnaire. Moreover, girls reported higher summary scores (ie, more disturbances) for daily activities in the baseline questionnaire $(P=.037)$.

Boys stayed home from school more frequently $(P=$ .011) the day of the tooth extraction compared with girls. Boys also refrained more often from leisure time activities $(P=.046)$ on the day of the tooth extractions.

Differences concerning experience of pain and discomfort during and after premolar extractions and/ or miniscrew placement were nonsignificant.

Table 4. Patient-Reported Discomfort (Median Values and Tukey's Hinges)

\begin{tabular}{|c|c|c|c|c|c|}
\hline & Extractions A & $\leftarrow P \rightarrow$ & Miniscrews & $\leftarrow P \rightarrow$ & Extractions B \\
\hline \multirow[t]{3}{*}{ Anesthetic injection } & $\mathrm{Q} 1=5.00$ & .503 & $\mathrm{Q} 1=1.75$ & .052 & $\mathrm{Q} 1=5.50$ \\
\hline & Median $=21.00$ & & Median $=13.50$ & & Median $=26.00$ \\
\hline & $\mathrm{Q} 3=33.00$ & & $\mathrm{Q} 3=34.50$ & & $\mathrm{Q} 3=48.50$ \\
\hline \multirow[t]{3}{*}{ During surgery/extractions } & $\mathrm{Q} 1=10.50$ & .258 & $\mathrm{Q} 1=0.00$ & .171 & $\mathrm{Q} 1=4.00$ \\
\hline & Median $=21.00$ & & Median $=12.00$ & & Median $=22.75$ \\
\hline & Q3 $=43.00$ & & Q3 $=38.50$ & & $\mathrm{Q} 3=50.00$ \\
\hline \multirow[t]{3}{*}{ Evening after surgery/extractions } & $\mathrm{Q} 1=7.75$ & .007 & $\mathrm{Q} 1=0.00$ & .012 & $\mathrm{Q} 1=10.50$ \\
\hline & Median $=37.50$ & & Median $=7.50$ & & Median $=30.00$ \\
\hline & $\mathrm{Q} 3=52.50$ & & $\mathrm{Q} 3=25.75$ & & $\mathrm{Q} 3=49.00$ \\
\hline \multirow{3}{*}{ One week after surgery/extractions } & $\mathrm{Q} 1=0.00$ & .009 & $\mathrm{Q} 1=0.00$ & .013 & $\mathrm{Q} 1=1.00$ \\
\hline & Median $=7.00$ & & Median $=1.00$ & & Median $=4.50$ \\
\hline & $\mathrm{Q} 3=29.50$ & & $\mathrm{Q} 3=5.50$ & & $\mathrm{Q} 3=20.50$ \\
\hline
\end{tabular}




\section{DISCUSSION}

The main finding in this trial was that patients experienced significant less pain and discomfort after placement of miniscrews compared with tooth extractions. Consequently, our hypothesis was confirmed.

The reported pain intensity and discomfort levels were generally moderate. In addition, the median values for pain intensity found in our study were lower than median values reported for the first days for insertion of Onplant, headgear, or transpalatal arch. ${ }^{14}$ However, individual experiences ranged from no pain/ discomfort at all to worst imaginable. It is important to recognize that the study population consisted of adolescents with good to excellent dental health. Thus, most of these patients never experienced painful dental treatments before and therefore had a limited perspective when it comes to pain. This homogeneity of the study population might also explain why we found no significant correlations between the baseline questionnaire and later experiences of pain and discomfort. The assessments from the baseline questionnaire showed very few interindividual differences, which probably would have been different in a population with poorer dental health or in an adult population.

Since our results also showed that anesthetic injection is reported to be as painful and uncomfortable as the procedures itself, it can be discussed whether the use of topical anesthesia only would be sufficient. ${ }^{15}$ Kwong et al. ${ }^{16}$ showed that different types of topical anesthetics can achieve sufficient numbness of the gingiva and to some degree even of the periosteum. However, when placing miniscrews interradiculary, it is important that the patient does not move during the procedure. Therefore, full numbness of the gingiva, periosteum, and cortical plate is necessary. To use the advantages of local infiltration and reduce the experience of pain and discomfort at the same time, a computerized injection system such as The Wand could be used. ${ }^{17}$

An unexpected significant difference in patients' age was found. Nevertheless, all patients had the same dental age because full permanent dentition with the second molar in occlusion was one of the inclusion criteria.

Analysis of perception of pain and discomfort of tooth extractions in group A vs group B revealed no significant differences. Comparison of tooth extractions vs miniscrew placement within group $A$ showed the same results as tooth extractions in group $B$. Therefore, it can be assumed that groups $A$ and $B$ were equal in perception of pain and discomfort. However, miniscrews were placed after tooth extractions and installation of fixed appliance. The preceding interven- tion might cause an increase or decrease in pain values for miniscrew placement through sensitization or habituation. ${ }^{18}$ Nevertheless, the results show a robust difference in experience of pain and discomfort after the intervention. Thus, the conclusions still remain the same (i.e., tooth extractions caused more discomfort and pain than miniscrew placement).

In total, 73 of 80 patients were analyzed. Two patients in group A refrained from treatment after randomization. Whether these patients were anxious about miniscrew placement is not known, and this may be a source of selection bias. The seven patients who were excluded from the analysis showed no significant differences in the baseline questionnaire, except they reported significantly lower values for how well informed they were about the treatment $(P=.039)$. This might be considered a source of survivorship bias. Since the number of nonparticipants was small and both groups were affected, the overall risk for bias was regarded as low. Furthermore, some patients did not answer all questions in the questionnaires. Nevertheless, the overall response rate was high.

In summary, this trial used validated and reliable questionnaires for a study population relevant for orthodontic treatment in industrial countries. We found good internal validity.

\section{CONCLUSIONS}

- Installation of miniscrews causes moderate pain and discomfort.

- Pain intensity and discomfort were significant lower for miniscrew installation than tooth extractions.

- From the perspective of pain and discomfort, the use of miniscrews in adolescents can be recommended.

\section{ACKNOWLEDGMENTS}

We thank Per Liv from the Centre for Research \& Development, Uppsala University/Region Gävleborg, for assistance with statistical procedures. All authors have completed the ICMJE Conflict of Interest Disclosure form and declare the following: Niels Ganzer reports grants and nonfinancial support from the Centre for Research and Development, Uppsala University/Region Gävleborg, Sweden, and grants from Swedish Dental Associations Scientific Funds during the conduct of the study; Ingalill Feldmann reports grants from the Thuréus Foundation for the Promotion of Dental Science, Uppsala University, Sweden, during the conduct of the study; there are no financial relationships with any organizations that might have interests in the submitted work in the previous 3 years; and there are no other relationships or activities that could appear to have influenced the submitted work.

\section{REFERENCES}

1. Sandhu SS, Sandhu J. A randomized clinical trial investigating pain associated with superelastic nickel-titanium and 
multistranded stainless steel archwires during the initial leveling and aligning phase of orthodontic treatment. $J$ Orthod. 2013;4:276-285.

2. Ong $E, H_{0} C$, Miles P. Alignment efficiency and discomfort of three orthodontic archwire sequences: a randomized clinical trial. J Orthod. 2011;1:32-39.

3. Reynders R, Ronchi L, Bipat S. Mini-implants in orthodontics: a systematic review of the literature. Am J Orthod Dentofacial Orthop. 2009;5:564.e1-19.

4. Lehnen S, McDonald F, Bourauel C, Baxmann M. Patient expectations, acceptance and preferences in treatment with orthodontic mini-implants. a randomly controlled study. Part I: insertion techniques. J Orofac Orthop. 2011;2:93-102.

5. Baxmann M, McDonald F, Bourauel C, Jager A. Expectations, acceptance, and preferences regarding microimplant treatment in orthodontic patients: a randomized controlled trial. Am J Orthod Dentofacial Orthop. 2010;3:250.e1250.e10.

6. Kuroda S, Sugawara Y, Deguchi T, Kyung HM, TakanoYamamoto T. Clinical use of miniscrew implants as orthodontic anchorage: success rates and postoperative discomfort. Am J Orthod Dentofacial Orthop. 2007;1:9-15.

7. Lee TC, McGrath CP, Wong RW, Rabie AB. Patients perceptions regarding microimplant as anchorage in orthodontics. Angle Orthod. 2008;2:228-233.

8. Chen CM, Chang CS, Tseng YC, Hsu KR, Lee KT, Lee HE. The perception of pain following interdental microimplant treatment for skeletal anchorage: a retrospective study. Odontology. 2011;1:88-91.

9. Feldmann I, List T, Feldmann H, Bondemark L. Pain intensity and discomfort following surgical placement of orthodontic anchoring units and premolar extraction: a randomized controlled trial. Angle Orthod. 2007;4:578-585.
10. McLaughlin RP, Bennett JC, Trevisi H. Systemized Orthodontic Treatment Mechanics. 2nd ed. St Louis, Mo: Mosby; 2001.

11. Feldmann I, List T, John MT, Bondemark L. Reliability of a questionnaire assessing experiences of adolescents in orthodontic treatment. Angle Orthod. 2007;2:311-317.

12. Stegenga B, de Bont LG, de Leeuw R, Boering G. Assessment of mandibular function impairment associated with temporomandibular joint osteoarthrosis and internal derangement. J Orofac Pain. 1993;2:183-195.

13. Krekmanova L, Bergius M, Robertson A, et al. Everydayand dental-pain experiences in healthy Swedish 8-19 year olds: an epidemiological study. Int $J$ Paediatr Dent. 2009;6:438-447.

14. Feldmann I, List T, Bondemark L. Orthodontic anchoring techniques and its influence on pain, discomfort, and jaw function-a randomized controlled trial. Eur $J$ Orthod. 2012;1:102-108.

15. Reznik DS, Jeske AH, Chen JW, English J. Comparative efficacy of 2 topical anesthetics for the placement of orthodontic temporary anchorage devices. Anesth Prog. 2009;3:81-85

16. Kwong TS, Kusnoto B, Viana G, Evans CA, Watanabe K. The effectiveness of Oraqix versus TAC(a) for placement of orthodontic temporary anchorage devices. Angle Orthod. 2011;5:754-759.

17. Mittal M, Kumar A, Srivastava D, Sharma P, Sharma S. Pain perception: computerized versus traditional local anesthesia in pediatric patients. J Clin Pediatr Dent. 2015:5:470-474.

18. Jepma $M$, Jones $M$, Wager TD. The dynamics of pain: evidence for simultaneous site-specific habituation and sitenonspecific sensitization in thermal pain. J Pain. 2014;7:734-746. 

PAPER III 



\title{
Anchorage reinforcement with miniscrews and molar blocks in adolescents: A randomized controlled trial
}

\author{
Niels Ganzer*, Ingalill Feldmann ${ }^{\dagger}$, Lars Bondemark ${ }^{\ddagger}$ \\ Accepted for publication
}

This is a pre-copyedited, author-produced version of an article accepted for publication in the American Journal of Orthodontics 85 Dentofacial Orthopedics. The version of record of this article can be found at the journals website:

https://www. ajodo.org/.

\footnotetext{
*DDS, PhD Student at Malmö University and Center for Research and Development Uppsala University / Region Gävleborg, Senior Consultant Orthodontist at Public Dental Service Region Gävleborg, Gävle, Sweden.

Corresponding author.

Contact: niels.ganzer@regiongavleborg.se

${ }^{\dagger}$ DDS, PhD, Senior Consultant Orthodontist at Public Dental Service Region Gävleborg, Senior Researcher at Center for Research and Development Uppsala University / Region Gävleborg, Gävle, Sweden

${ }^{\ddagger}$ DDS, PhD, Senior Consultant Orthodontist, Professor and Head of Department of Orthodontics, Malmö University, Malmö, Sweden
} 


\begin{abstract}
Introduction

Anchorage can be reinforced in many ways. Due to the variety of anchorage concepts only few general conclusions can be drawn. Therefore, more research is needed to investigate specific concepts with specific indications. The objective of this trial was to compare the anchorage capacity of miniscrews and molar blocks.
\end{abstract}

\title{
Methods
}

This randomized controlled trial was conducted on two parallel arms. The trial was conducted at the Public Dental Service Orthodontic Clinic in Gävle, Sweden. Participants were adolescents who needed orthodontic treatment with a fixed appliance, extraction of the maxillary first premolars, and anchorage reinforcement. In Group A, miniscrews were used as direct anchorage during space closure. In Group B, molar blocks were used as anchorage reinforcement during leveling / alignment and space closure. The primary outcome was loss of anchorage assessed as the maxillary first molars movement. Random allocation was maintained with a simple randomization stratified for gender. The observer was blinded for the allocation during the conduct of measurements.

\section{Results}

40 participants were randomized to each Group A and B. Results were analyzed on an intention-to-treat basis meaning that all participants successful or not were included in the analysis. Group A showed a mean anchorage loss of $1.2 \mathrm{~mm}$ during leveling/alignment. During space closure with miniscrews, no significant anchorage loss was found. Group B showed a mean anchorage loss of $1.4 \mathrm{~mm}$ during leveling/alignment and $2.4 \mathrm{~mm}$ during space closure. No serious harms were detected. The first molar's rotation, torque, and tipping showed different characteristics during the treatment phases.

\section{Conclusions}

Miniscrews can be recommended for anchorage reinforcement. Depending on the need for anchorage reinforcement, miniscrews can be inserted at the beginning of a treatment or when space closure starts. Molar blocks cannot be recommended for anchorage reinforcement.

\section{Registration}

www.clinicaltrials.gov (NCT02644811).

\section{Protocol}

The protocol was published after trial commencement.

\section{Funding}

This trial received funding from the Center for Research and Development Uppsala University / Region Gävleborg, Thuréus Foundation for the Promotion of Dental Science and the Swedish Dental Associations Scientific Funds. 


\section{Introduction}

In orthodontics, teeth are moved using active elements such as tiebacks, elastomeric chains, or coil springs. Active elements always deliver the same but opposite force on the teeth being moved and on the anchor teeth. This opposite force can cause undesired movement of the anchor teeth. Anchorage, as the ability to resist undesired tooth movements, needs to be reinforced in many cases.

Anchorage reinforcement has traditionally been provided by adding resistant units, such as a headgear or intermaxillary elastics. Anchorage reinforcements basic principle is to distribute the reaction forces and to reduce the pressure on the anchor units. ${ }^{1}$

These traditional methods of anchorage reinforcement have their drawbacks: The headgear can deliver outstanding anchorage reinforcement when used 10-12 hours seven days a week. However, this implies that patients must actually wear the appliance for the suggested period. ${ }^{2}$ Clinical trials showed that in real life approximately one third of the patients is not accurate in reporting their headgear usage. ${ }^{3}$ Further, up to $50 \%$ of the cases treated with headgear comprised unacceptable anchorage loss. ${ }^{4}$

The same applies for Class II elastics: Used fulltime they are as effective as functional appliances in correcting Class II malocclusions, ${ }^{5}$ but even here compliance is an issue. Anchorage, however, can be reinforced in ways that do not rely on compliance. The basic assumption is that every tooth has a certain anchorage value which is correlated to its root surface. ${ }^{6}$ The resistance of moving teeth can be overcome by uniting several teeth to an anchorage block. The more teeth that are used in the anchorage block, the less likely these teeth will move. ${ }^{7}$

Molars from the left and the right side can be united with a trans palatal arch. This construction produced by a dental technician can theoretically reinforce anchorage. However, a systematic review ${ }^{8}$ revealed that this concept was not sufficient in cases with space closure after premolar extractions.

A very convenient way to reinforce anchorage is to undertie adjacent teeth with a stainless steel ligature. When the second molar is added to the appliance and tightly connected to the first molar, this so called molar block has twice as much root surface as a single molar. This technique is espe- cially suitable when the first premolars are extracted because then also the second premolars can be added to the anchorage block further increasing the anchorage value. ${ }^{9}$ In that way, the root surface ratio between the anchor blocks and the frontal teeth is changed. Theoretically, this results in less mesial movement of the anchor teeth.

Molar blocks do not involve the work of a dental technician, are not cooperation based, and can be inserted within minutes. The anchorage capacity of the molar block has not been investigated in clinical studies.

Due to the limited anchorage capacity of dental non-cooperation based techniques, skeletal anchorage with miniscrews has been claimed to be the ideal anchorage reinforcement. ${ }^{10}$ However, the literature indicates only moderate evidence that miniscrews can provide good anchorage. ${ }^{11}$ General conclusions have to be drawn with caution due to the heterogeneity of the published data. ${ }^{12}$ To fill these knowledge gaps about miniscrews, more research is needed about the use of miniscrews for specific indications in specific insertion sites.

\section{Specific objectives}

Anchorage capacity has traditionally mainly been discussed in the sagittal and vertical dimension. ${ }^{11,13}$ Changes in the transversal dimension are rarely reported.

The main objectives of this trial were to evaluate anchorage capacity in its three dimensions: 1) when molar block and buccal miniscrews were used in cases treated with extraction of the maxillary first premolars and en masse retraction and 2) to evaluate the anchorage capacity with and without molar block during the leveling and alignment phase.

It was hypothesized that miniscrews deliver better anchorage capacity than molar block and that the molar block is capable of certain anchorage reinforcement.

\section{Materials and Methods}

The trial was designed as a randomized controlled trial with one intervention arm and one active comparator and a 1:1 allocation ratio.

\section{Participants}

The sample was collected at the Public Dental Service Orthodontic Clinic in Gävle, Region Gävleborg, Sweden. The sample consisted of adolescents, 11 to 19 years of age, who needed orthodontic 
treatment with a fixed appliance, extraction of the maxillary first premolars, and anchorage reinforcement.

Anchorage need was assessed according to the dental visual treatment objective. ${ }^{14}$ Moderate anchorage need corresponded to approximately $75 \%$ retraction of anterior teeth during space closure. ${ }^{15}$ All the adolescents in this study had permanent dentition, including erupted maxillary second molars, and had received regular dental care since the age of three.

Adolescents who previously underwent orthodontic treatment or who were in need for maximum anchorage or orthognathic surgery were excluded from the trial.

\section{Interventions}

All patients were treated with extraction of the maxillary or maxillary and mandibular first premolars and fixed appliance in both jaws. Treatment with fixed appliance (Victory Series ${ }^{\mathrm{TM}}$ Stainless Steel Brackets, .022in slot size, MBT ${ }^{\mathrm{TM}}$ prescription, 3M Unitek Orthodontic Products, Monrovia, CA, USA) followed a straight wire concept. ${ }^{16}$

The recommended archwire sequence was .016 in Nitinol Heat-Activated, .019x.025 in Nitinol Heat-Activated, .019x.025 in Resilient Posted (3M Unitek Orthodontic Products, Monrovia, CA, USA).

Space closure was accomplished as en masse retraction of the anterior six teeth. The treatment was conducted by N.G. and I.F., the staff had several years of experience in different systems for skeletal anchorage.

The two treatment groups were different in their anchorage strategy depending on the treatment phases. During leveling/alignment $\left(\mathrm{T}_{1}-\mathrm{T}_{2}\right)$, the molars in Group A had no anchorage reinforcement. I Group B, anchorage was reinforced with molar blocks. During space closure $\left(\mathrm{T}_{2}-\mathrm{T}_{3}\right)$, anchorage reinforcement was provided by miniscrews in Group A, while Group B continued with molar blocks.

\section{Leveling/alignment phase $\left(\mathrm{T}_{1}-\mathrm{T}_{2}\right)$}

In the maxilla, the appliances were bonded on all teeth from first right to first left maxillary molars. Lacebacks were used in both groups to control canine proclination during the time the $.016 \mathrm{Nitinol}$ Heat-Activated archwire was in use (Figure 1).

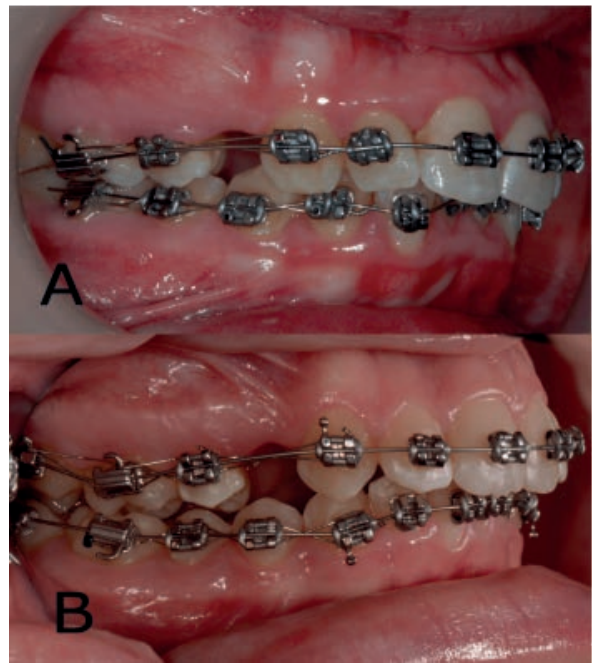

Figure 1: Leveling \& alignment A - without anchorage reinforcement; B - with molar blocks.

In contrast to Group A, anchorage in Group B was reinforced by bonding the maxillary second molars. The second molars were then united with the first molars and second premolars (U7-U6-U5) using a stainless steel ligature. ${ }^{9}$ Leveling and alignment were considered completed when the .019x.025 in stainless steel archwire was in place and space closure started.

\section{Space closure $\left(\mathrm{T}_{2}-\mathrm{T}_{3}\right)$}

In Group A, all patients received one miniscrew on each side in the upper jaw (Spider Screw ${ }^{\circledR}$ K1 SCR-1510 or SCR-1508, diameter $1.5 \mathrm{~mm}$, length 8-10 mm, Health Development Company, Sarcedo, Italy). The miniscrews were placed from the buccal side between the second maxillary premolar and the first maxillary molar under local anesthesia according to the protocol published in the clinical trials register.

The miniscrews were immediately loaded with 150 g closed-coil springs (Ortho Technology, Tampa, Florida, USA) (Figure 2 A).

In Group B, the molar block was loaded with 150 $\mathrm{g}$ active tiebacks (Figure $2 \mathrm{~B}$ ). In order to reduce friction, all archwires were cut distal of the first molars during space closure. 


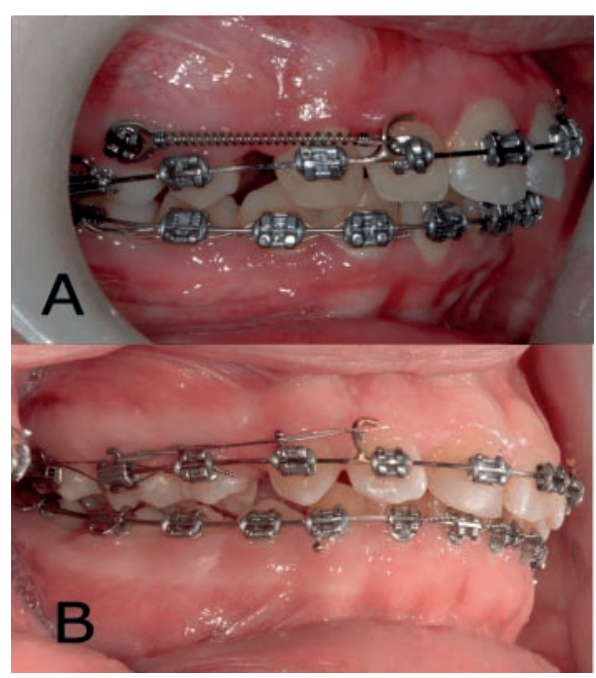

Figure 2: Anchorage reinforcement during space closure A - with miniscrews; B - with molar blocks.

Space closure was considered completed when the canines reached a Class I relationship and/or all spaces were closed.

Alginate impressions for plaster casts were taken at start of treatment $\left(\mathrm{T}_{1}\right)$, after leveling/alignment $\left(\mathrm{T}_{2}\right)$, and after space closure $\left(\mathrm{T}_{3}\right)$. The plaster casts were produced at the in-clinic laboratory within 24 hours and then the casts were digitized with a R700 ${ }^{\mathrm{TM}}$ Desktop scanner (3Shape, Copenhagen, Denmark).

\section{Outcomes}

The primary outcome measures were loss of anchorage during leveling/alignment $\left(\mathrm{T}_{1}-\mathrm{T}_{2}\right)$ defined as changes in tooth position of the first right and left maxillary molars and loss of anchorage during space closure $\left(\mathrm{T}_{2}-\mathrm{T}_{3}\right)$, defined as changes in tooth position of the first right and left maxillary molars.

Superimposition was performed on digital 3D models with the computer program Final Surface ${ }^{\circledR}$ (GFaI, Berlin, Germany) and according to the Raw, Fine matching, and Deformation (RFD) superimposition technique. ${ }^{17}$ This technique calculates individual reference points for every case. Reference points were detected with an algorithm based deformation analysis that identified unchanged areas in the palate. The tooth's movement was assessed in millimeters. Rotations, tipping, and torque were assessed in degrees.

\section{Sample size calculation}

The sample-size calculation was based on values for anchorage loss and standard deviation found in earlier studies within the research group (Headgear, anchorage loss $1.2 \mathrm{~mm}$, SD $1.96 \mathrm{~mm}) .{ }^{4}$ Additionally, it was assumed that the loss of anchorage would be half as much when miniscrews were used. The least clinical difference for the margin of superiority was set at $1 \mathrm{~mm}$. The significance level was set at $5 \%$.

Thus, under these circumstances a sample of 26 subjects in each group would give a $90 \%$ power. In addition, dropouts due to discontinued treatment or patients moving from the area and a $15-20 \%$ failure rate for the miniscrews were expected. ${ }^{12,18}$ Consequently, a sample size of 40 patients was established for both Group A and Group B.

\section{Randomization}

This trial was conducted as a randomized controlled trial with two parallel arms. The protocol was approved by the Regional Ethical Review Board, Uppsala University, Uppsala, Sweden (Dnr.2009/188).

All participants were randomly allocated to either Group A or Group B. The allocation was conducted by an independent person not involved in the trial. Each participant was provided with a sealed opaque envelope that contained a note with either "Group A" or "Group B" and all envelopes were assigned using simple randomization, stratified on gender, with IBM SPSS statistics (SPSS Inc. Released 2009. PASW Statistics for Windows Version 18.0. Chicago, Illinois, USA). After informed consent, allocation was revealed by the participant opening the envelope.

\section{Blinding}

All measurements were performed by one examiner (N.G.) who was blinded during the assessments of the outcomes. All details revealing the groups, such as the maxillary buccal part of the second molar and the buccal portion of the attached gingiva from the first maxillary premolar to the second maxillary molar, were removed from the plaster casts before the scanning.

\section{Statistical analysis}

Statistical analysis was performed using the programming language $\mathrm{R}$ (v 3.42). ${ }^{19}$ Arithmetic means and standard deviations were calculated for numerical variables. For every patient, the first right and left maxillary molars were included in 
the analysis, giving two dependent observations for every treatment phase $\left(\mathrm{m}_{\mathrm{i}}\right)$. The maxillary first molars movements were analyzed with adjustment for left and right side using linear mixed effect models. ${ }^{20}$

Linear mixed effect models is a statistical model containing fixed and random factors, which are particularly suitable for analysis of repeated measurements and dependent data.

The statistical model was built with the following fixed factors: Treatment group and maxillary molar position on left and right side. The subject was assigned as random factor. Data was analyzed separately for the different treatment phases $\left(\mathrm{T}_{1}\right.$ $\left.\mathrm{T}_{2}, \mathrm{~T}_{2}-\mathrm{T}_{3}\right)$ and for the total observation period $\left(\mathrm{T}_{1}-\mathrm{T}_{3}\right)$. Differences with probabilities of less than $5 \%(\mathrm{P}<.05)$ were considered statistically significant.

Data on all patients who were randomly assigned to the two groups were analyzed on an intention-totreat (ITT) basis. ${ }^{21,22}$ This implies that all cases irrespective of success were included in the final analysis. In addition, if drop-outs occured during the trial, those were considered unsuccessful. Unsuccessful anchorage was defined as reciprocal space closure, i.e., mesial movement corresponding to $50 \%$ of a premolar width $(3.75 \mathrm{~mm})$.

All other variables such as transversal and vertical movement, rotation, tipping, and torque were set to the mean value of the variables calculated from the per-protocol subsample.

\section{Method error analysis}

Repeated superimpositions and measurements were performed on 15 randomly selected cases after at least two weeks. No significant mean differences between the two series of records were found with the use of linear mixed effect models. ${ }^{20}$

The mean measurement error was $-0.01 \mathrm{~mm}$ and the absolute mean error was $0.14 \mathrm{~mm}$ (95\% CI: 0.10 ; 0.18 ) for distance measurements or 0.02 degrees mean error and 0.34 degrees absolute mean error (95\% CI: $-0.14 ; 0.12$ ) for rotational measurements.

\section{Results}

\section{Participant flow and baseline data}

Ninety-eight patients matched the inclusion criteria and were invited to participate in this trial.
Eighteen patients declined to participate. Thus, 80 patients were enrolled in the trial. Informed consent was collected from all patients and their parents.

In summary, there were seven drop-outs in Group A and two in Group B. The details can be found in the CONSORT flow diagram (Figure 3). The baseline demographic characteristics are presented in Table 1.

\section{Outcome analyzes}

Details about the maxillary first molars movement, such as means, standard erros and comparisons within and between groups can be found in Table 2.

\section{Sagittal movement}

In the sagittal plane, changes in Group A were characterized by the maxillary first molars moving $1.5 \mathrm{~mm}$ mesially during the total observation period. This mesial movement $(1.2 \mathrm{~mm})$ occurred mainly during the leveling and alignment phase. During the space closure no significant mesial movement could be found. Thus, loss of anchorage in the antero-posterior dimension occurred before the miniscrew insertion.

In Group B, the maxillary first molars comprised a mesial movement of $3.8 \mathrm{~mm}$ during the total observation period. Of these $1.4 \mathrm{~mm}$ mesial movement occurred during leveling / alignment and 2.4 mm during space closure.

The differences between groups were statistically significant during space closure and during the total observation period. However, there was no statistical significant difference between the groups during the leveling and alignment phase.

More details about the movement in the anteroposterior direction are presented in the boxplots in Figure 4.

\section{Transversal movement}

There were no statistically significant differences within or between groups in the transversal plane.

\section{Vertical movement}

During the total observation period, the maxillary first molars showed no significant vertical change in Group A.

In Group B a significant eruption of $0.6 \mathrm{~mm}$ was found. This eruption occurred during the space closure phase. The difference between the groups was statistically significant. 


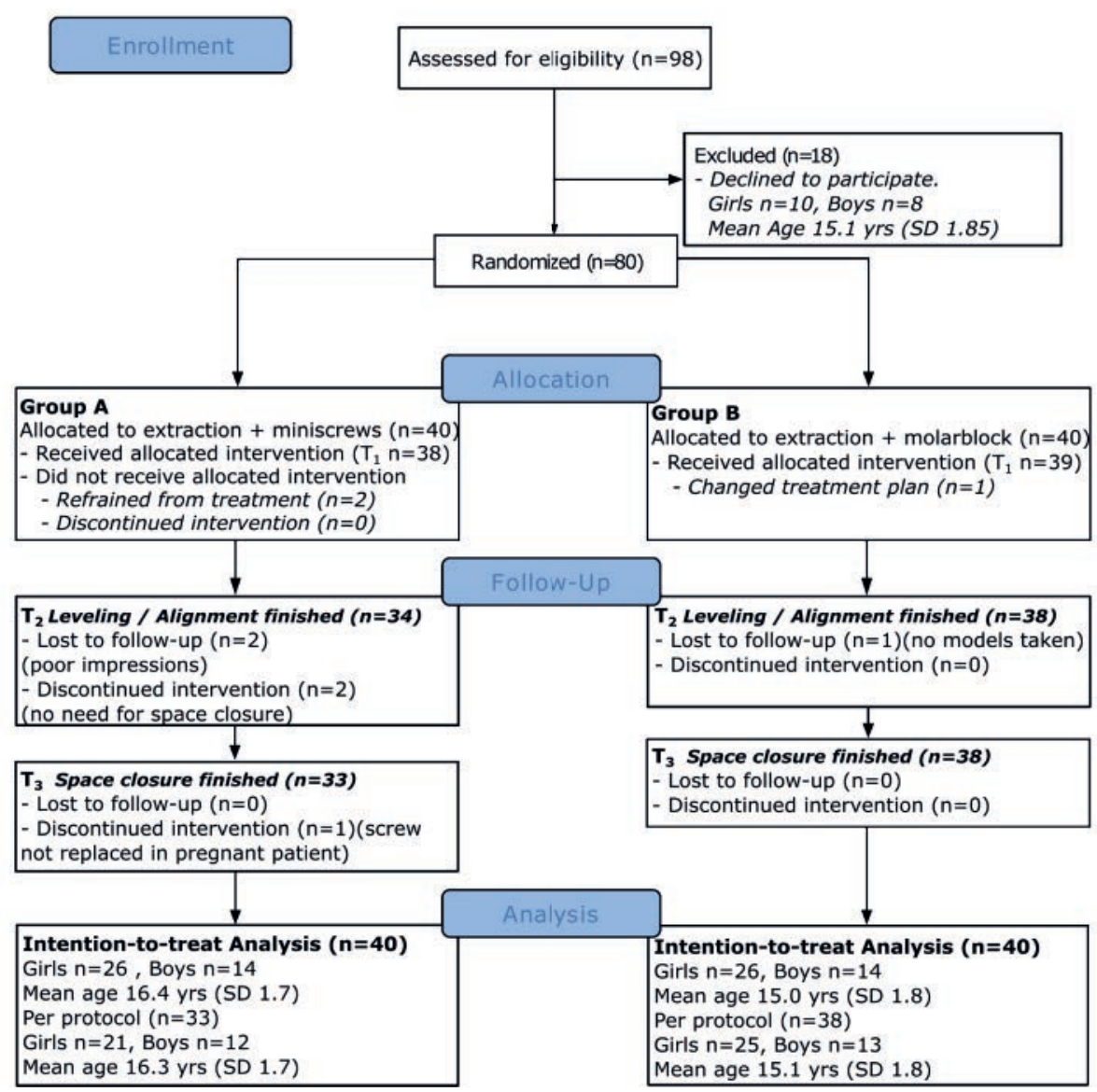

Figure 3: CONSORT flow diagram. 
Table 1: Baseline demographic data.

\begin{tabular}{|c|c|c|c|c|c|c|c|c|c|c|c|c|}
\hline \multirow[b]{3}{*}{ Group } & \multicolumn{6}{|c|}{ Per protocoll } & \multicolumn{6}{|c|}{ Intention-to-treat } \\
\hline & \multicolumn{3}{|c|}{ Number } & \multicolumn{3}{|c|}{ Age [Years] } & \multicolumn{3}{|c|}{ Number } & \multicolumn{3}{|c|}{ Age [Years] } \\
\hline & Total & Girls & Boys & Mean & Range & SD & Total & Girls & Boys & Mean & Range & SD \\
\hline A & $\mathrm{N}=33$ & $\mathrm{~N}=21$ & $\mathrm{~N}=12$ & 16.3 & $12.3-19.3$ & 1.7 & $\mathrm{~N}=40$ & $\mathrm{~N}=26$ & $\mathrm{~N}=14$ & 16.4 & $12.3-19.3$ & 1.7 \\
\hline B & $\mathrm{N}=38$ & $\mathrm{~N}=25$ & $\mathrm{~N}=13$ & 15.1 & $11.1-18.7$ & 1.8 & $\mathrm{~N}=40$ & $\mathrm{~N}=26$ & $\mathrm{~N}=14$ & 15.0 & $11.1-18.7$ & 1.8 \\
\hline
\end{tabular}

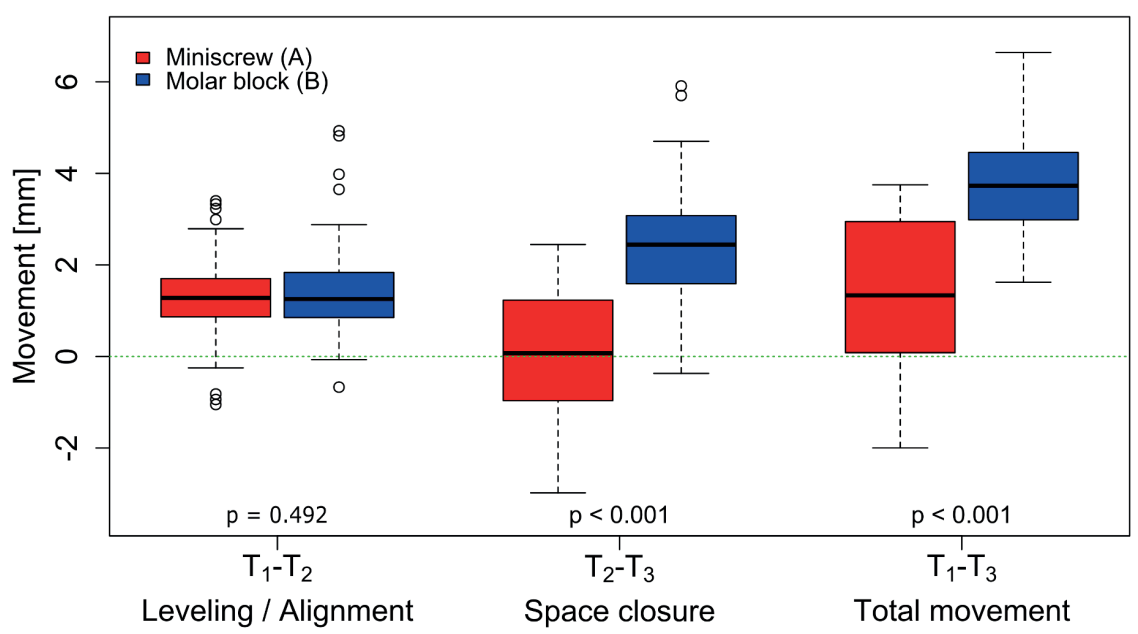

Figure 4: Maxillary first molars mesial movement presented as boxplots with Tukey's hinges.

\section{Rotation}

In Group A, the maxillary first molars showed a distal-buccal rotation of 2.3 degrees during the total observation period. This rotation was mainly established during leveling/alignment. The changes in rotations during space closure were not significant.

In contrast, the maxillary first molars in Group B showed a mesial-palatal rotation of 2.6 degrees during the total observation period. There was a statistical significant difference between the groups of 4.9 degrees in rotation.

An interesting finding was that rotation characteristics were similar during the leveling and alignment phase but significantly different during the space closure where Group B revealed a 6.4 degree mesial-palatal rotation.

\section{Tipping}

Maxillary first molars in both groups showed a mesial tipping of about 3 degrees during leveling/alignment. In Group A, this tipping was reset during space closure. In Group B additional mesial tipping of 1 degree was found during space closure. For the total observation period there was a statistical significant difference between groups of 3.3 degrees.

\section{Crown torque}

There was no statistical significant difference in crown torque between the groups during leveling/alignment. During space closure, Group A revealed a buccal crown torque of 3.4 degrees. During the total observation period there was a statistical significant difference between the groups of 2.0 degrees. 
The summarized simulated mean changes in the maxillary first molars' position and rotations are depicted in Figure 5.

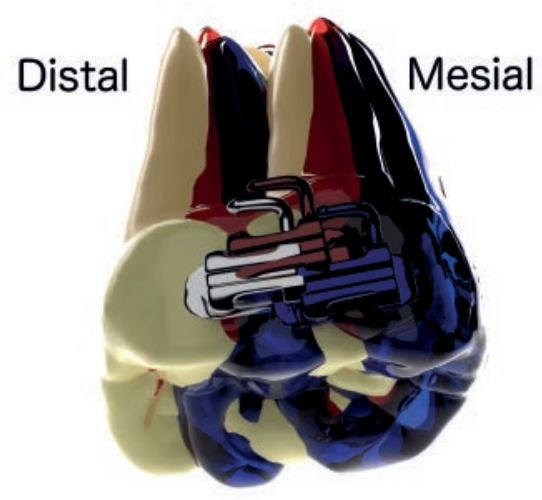

Figure 5: Mean movement of the maxillary first molar in Group A (red) and B (blue).

\section{Treatment time}

There were no statistical significant differences in treatment time between groups. Consequently, the mean time for leveling/alignment phase was 10.5 months in Group A (miniscrews) and 9.3 months in Group B (molar block). The space closure phase took on average 8.9 months in Group A and 9.0 months in Group B.

\section{Finishing phase}

When finishing started, some cases comprised several millimeters anchorage loss while others comprised residual spaces. All cases were finished on an individual basis and the finishing phase was not part of the observation time. During the finishing phase, in both groups, Class II elastics were used when appropriate. If there were residual spaces, the posterior teeth were protracted. All cases reached their treatment goal.

\section{Harms}

In 36 patients, 72 miniscrews were inserted. Of these, three miniscrews were lost during the space closure phase. In one case the participant was pregnant. Since replacement of the miniscrew would have involved taking apical x-rays, this treatment was finished with other anchorage reinforcement. In another case, space closure was already finished when the screw became loose so anchorage reinforcement was not continued. Consequently, of three lost miniscrews only one was replaced.

Furthermore, a Spider Screw ${ }^{\circledR}$ K1 SCR-1510 with $10 \mathrm{~mm}$ length fractured during installation. The fragment was initially left in place but could be removed later on.

Intraoral apical radiographs of the incisors were routinely taken before and after treatment. The majority of patients showed no or minor root resorptions up to two millimeters. ${ }^{23}$ There was no statistical significant difference in root resorptions between groups.

\section{Discussion}

\section{Main findings}

The main findings of this trial were that miniscrews significantly increased the anchorage capacity of the appliance. There was no statistical significant mesial movement in the miniscrew group (Group A) during space closure. This finding is in line with earlier studies on different systems for bone anchorage. ${ }^{4,12}$ Thus, the hypothesis concerning the anchorage capacity of miniscrews was confirmed.

In addition, showed cases treated with molar blocks reciprocal space closure during the observation time. Thus, molar blocks did not increase the anchorage capacity of the appliances. Therefore, the second part of our hypothesis was rejected. To our knowledge, the anchorage capacity of molar blocks has not been described in the literature before, and therefore, no comparisons with other studies can be performed.

The overall success-rate was $96 \%$ which was higher than reported in recent reviews $(83.6 \%$ $86.5 \%) .{ }^{12,24}$ The high success-rate in this trial can be explained by the heterogeneity of the data that the systematic reviews are based on. The systematic reviews reported results with a mixture of different screw types, insertion sites and force applications. In contrast, this trial used miniscrews from one brand. Moreover, all miniscrews in our trial were placed buccally in the attached gingiva and were immediately loaded with $150 \mathrm{~g}$ continuous force.

Because RFD superimposition of digital 3D models ${ }^{17}$ was used, the movement of maxillary molars could be mapped in a unique way. Therefore, treatment effects are described in terms of translational movement, rotation, tipping, and torque. The analysis of tooth movement revealed comprehensive 


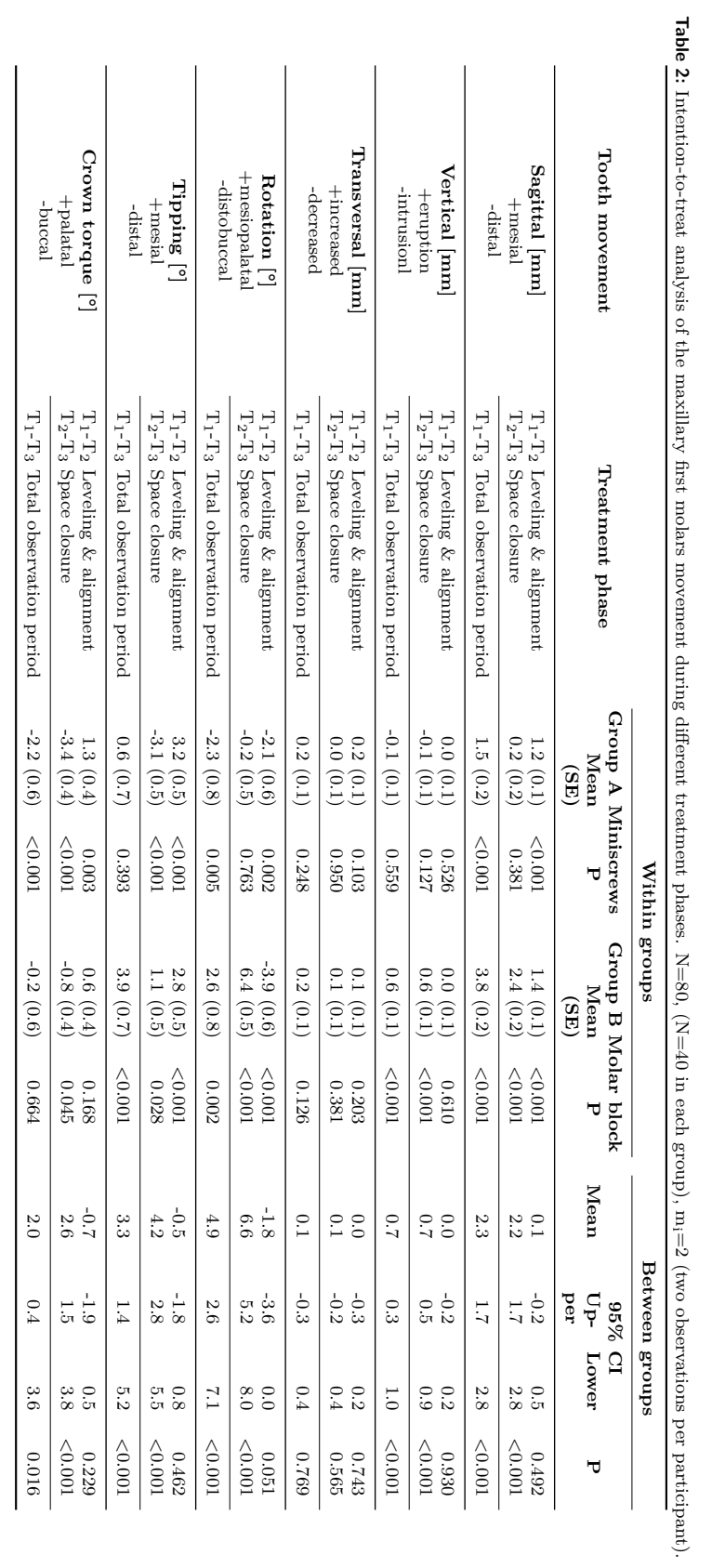


information about the biomechanics of the two concepts that were used in this trial. However, it can be argued whether all statistically significant findings are of clinical importance. Assuming, that a difference of one millimeter or more is clinically relevant, only the antero-posterior movement has a considerable effect size.

Concerning rotation, tipping and tilting the differences between groups were less than 5 degrees. Nevertheless, knowledge of the effects can be important in cases where tooth positions are deviant already from the beginning.

When the space closure phase was analyzed in detail, the boxplots in Figure 4 revealed a distalization of the maxillary first molars in about half of the cases treated with miniscrews. Beyond distalization there was distal tipping, and buccal crown torque. This could be explained by two factors: the vertical component of the applied force ${ }^{25}$ and the friction in the molar tube when the archwire is pressed distally into the tube. Compared to treatment with molar blocks, the same forces and moments occur, but in contrast to miniscrews the active tieback causes a contrary force. This force seems to be larger than the friction caused by the archwire since the first molars in the molar block group rotated mesial-palatally.

At the same time as some cases treated with miniscrews showed molar distalization, the opposite movement was found in other cases. One could argue that this only can happen when the miniscrew is lost; however, since only three miniscrews were lost during the treatment, this cannot be the main explanation. Although it is known that miniscrews show a certain displacement during treatment, the anterior component of occlusal the force is likely the explanation for this effect. ${ }^{26-28}$ Moreover, the intention-to-treat analysis included seven dropout cases that were defined as unsuccessful. For unsuccessful treatment a mesial movement of $3.75 \mathrm{~mm}$ was assumed.

It is important to note that the used concept with miniscrews as direct anchorage during the space closure phase had no anchorage reinforcement during the leveling/alignment phase. Since an average anchorage loss of about $1.5 \mathrm{~mm}$ was found during the total observation period, this should be recognized as acceptable for cases treated with this concept. Therefore, this concept should not be used in maximum anchorage cases where anchorage loss cannot be accepted. Instead, max- imum anchorage can be provided by indirect anchorage with a rigid connection between the anchor teeth and where tooth movement can be controlled as early as in the leveling/alignment phase.

Of course, both concepts described above have suitability: Indirect skeletal anchorage with rigid supra constructions that are mounted on miniscrews are planned measures for cases where anchorage is recognized as problematic already in the planning stage. On the contrary, miniscrews as direct anchorage can be used in cases where anchorage unexpectedly becomes a problem during the treatment. In such cases, miniscrews can be installed and loaded immediately.

\section{Limitations and generalizability}

The evaluated sample comprised $65 \%$ girls and $35 \%$ boys. One could argue that an even gender distribution would have eliminated the risk for bias due to gender differences. Yet, the gender distribution in this sample agrees with the gender distribution that is found in many orthodontic clinics. By the use of a gender stratified randomization proportional sampling between groups could be maintained.

However, the simple randomization could have been done in blocks, and hence improved the age distribution. Though the groups comprised a mean difference in age of about a year, the differences between 15 and 16 years of age concerning growth or tooth movement are regarded negligible.

Due to the trials nature, blinding of the participant or care provider was not possible which might be considered a source of bias. Nonetheless, the assessor was blinded during the conduct of the measurements.

In summary, the risk for bias in this trial is regarded low. This sample is regarded representative for populations that can be found in orthodontic clinics in industrial countries.

\section{Conclusions}

Miniscrews as direct anchorage provided increased anchorage capacity with no statistical significant mesial movement during space closure. Thus, miniscrews can be recommended for anchorage reinforcement. Treatment with miniscrews resulted in movement of the maxillary first molars, which were characterized by distal rotation and buccal crown torque.

Molar blocks did not increase the anchorage 
capacity and can thus not be recommended as anchorage reinforcement. The molar blocks caused a movement of the maxillary first molars, which was characterized by mesial rotation and mesial tipping.

\section{Acknowledgements}

We would like to thank all participants who helped us to conduct this trial. The further, we would like to thank Dr Per Liv and Dr Sara Gustavsson from the Center for Research and Development Uppsala University / Region Gävleborg for assistance with the statistical analysis.

All authors have completed the ICMJE Form for Disclosure of Potential Conflicts of Interest and declare the following: Dr. Ganzer reports grants and non-financial support from the Center for Research and Development, Uppsala University/Region Gävleborg, Sweden and grants from the Swedish Dental Associations Scientific Funds during the conduct of the trial.

Dr. Feldmann reports grants from Thuréus Foundation for the Promotion of Dental Science, Uppsala University, Sweden, during the conduct of the trial.

\section{References}

1. Feldmann I, Bondemark L. Orthodontic anchorage: a systematic review. Angle Orthod. 2006;76(3):493-501.

2. Kloehn SJ. Orthodontics-force or persuasion. Angle Orthod. 1953;23(1):55-65.

3. Cole WA. Accuracy of patient reporting as an indication of headgear compliance. Am J Orthod Dentofacial Orthop. 2002;121(4):419-423.

4. Feldmann I, Bondemark L. Anchorage capacity of osseointegrated and conventional anchorage systems: A randomized controlled trial. Am J Orthod Dentofacial Orthop. 2008;133(3):339.e28.

5. Janson G, Sathler R, Fernandes TM, Branco NC, Freitas MR. Correction of Class II malocclusion with Class II elastics: a systematic review. Am J Orthod Dentofacial Orthop. 2013;143(3):383-392.
6. Jepsen A. Root surface measurement and a method for x-ray determination of root surface area. Acta Odontol Scand. 1963;21:35-46. PMID:13961805.

7. Graber TM, Vanarsdall RL, Vig KW, Huang GJ. Bone Physiology, Metabolism, and Biomechanics in Orthodontic Practice. In: Orthodontics - Current Principles \& Techniques. 6th ed. St. Louis, Missouri, USA: Elsevier Mosby; 2017. p. 131.

8. Diar-Bakirly S, Feres MF, Saltaji H, Flores-Mir C, El-Bialy T. Effectiveness of the transpalatal arch in controlling orthodontic anchorage in maxillary premolar extraction cases: A systematic review and meta-analysis. Angle Orthod. 2017;87(1):147-158.

9. Proffit WR, Fields HW, Sarver DM. Chapter 8 - The Biologic Basis of Orthodontic Therapy. In: Contemporary Orthodontics. 5th ed. Elsevier Mosby; 2013. p. 297.

10. Maino BG, Maino G, Mura P. Spider Screw: skeletal anchorage system. Prog Orthod. 2005;6(1):70-81.

11. Jambi S, Walsh T, Sandler J, Benson PE, Skeggs RM, O'Brien KD. Reinforcement of anchorage during orthodontic brace treatment with implants or other surgical methods. Cochrane Database Syst Rev. 2014;8:CD005098.

12. Schätzle M, Männchen R, Zwahlen M, Lang NP. Survival and failure rates of orthodontic temporary anchorage devices: a systematic review. Clin Oral Implants Res. 2009;20(12):1351-1359.

13. Lai EH, Yao CC, Chang JZ, Chen I, Chen YJ. Three-dimensional dental model analysis of treatment outcomes for protrusive maxillary dentition: comparison of headgear, miniscrew, and miniplate skeletal anchorage. Am J Orthod Dentofacial Orthop. 2008;134(5):636-645.

14. McLaughlin RP, Bennett JC. The dental VTO: an analysis of orthodontic tooth movement. J Clin Orthod. 1999;33(7):394-403.

15. Nanda R. Biomechanic Basis of Extraction Space Closure. In: Biomechanics and Esthetic Strategies in Clinical Orthodontics. 1st ed. Elsevier Saunders; 2005. p. 194-196. 
16. McLaughlin RP, Bennett JC, Trevisi H. Systemized Orthodontic Treatment Mechanics. 1st ed. Mosby; 2001.

17. Ganzer N, Feldmann I, Liv P, Bondemark L. A novel method for superimposition and measurements on maxillary digital 3D modelsstudies on validity and reliability. Eur J Orthod. 2018;40(1):45-51.

18. Rodriguez JC, Suarez F, Chan HL, PadialMolina M, Wang HL. Implants for orthodontic anchorage: success rates and reasons of failures. Implant Dent. 2014;23(2):155-161.

19. Team RC. Team RC, editor. R: A Language and Environment for Statistical Computing. Vienna, Austria: R Foundation for Statistical Computing; 2018. Available at: www.Rproject.org.

20. Pinheiro J, Bates D, DebRoy S, Sarkar D, Team RC. nlme: Linear and Nonlinear Mixed Effects Models. CRAN. 2018;Available at: http://CRAN.R-project.org/package $=$ nlme.

21. Fisher LD, Dixon DO, Herson J, Frankowski RK, Hearron MS, Peace KE. Intention to treat in clinical trials. In: Statistical issues in drug research and development. New York: Marcel Dekker; 1990. p. 331-350.

22. Bondemark L, Abdulraheem S. Intention to treat (ITT) analysis as reported in orthodontic randomized controlled trials-evaluations of methodology and recommendations for the accurate use of ITT analysis and handling dropouts. Eur J Orthod. 2017;First published on Oct $21,2017,10.1093 /$ ejo/cjx084.

23. Levander E, Malmgren O. Evaluation of the risk of root resorption during orthodontic treatment: a study of upper incisors. Eur J Orthod. 1988;10(1):30-38.

24. Alharbi F, Almuzian M, Bearn D. Miniscrews failure rate in orthodontics: systematic review and meta-analysis. Eur J Orthod. 2018;.

25. Lee AY, Kim YH. Comparison of Movement of the Upper Dentition According to Anchorage Method: Orthodontic Mini-Implant versus Conventional Anchorage Reinforcement in Class I Malocclusion. ISRN Dent. 2011;2011:321206.

26. Stallard H. The anterior component of the force of mastication and its significance to the dental apparatus. Dent Cosmos. 1923;65(5):457-474.

27. Southard TE, Behrents RG, Tolley EA. The anterior component of occlusal force. Part 2. Relationship with dental malalignment. Am J Orthod Dentofacial Orthop. 1990;97(1):41-44.

28. Qassar SSA, Mavragani M, Psarras V, Halazonetis DJ. The anterior component of occlusal force revisited: direct measurement and theoretical considerations. Eur J Orthod. 2016;38(2):190-196. 

PAPER IV 



\title{
A cost-effectiveness analysis of anchorage reinforcement with miniscrews and molar blocks in adolescents: A randomized controlled trial
}

\author{
Niels Ganzer, Ingalill Feldmann ${ }^{\dagger}$, Sofia Petrén ${ }^{\ddagger}$, Lars Bondemark ${ }^{\S}$
}

June 21, 2018

This is a pre-copyedited, author-produced version of an article accepted for publication in the European Journal of Orthodontics following peer review. The version of record of article cjy041, Eur J Orthod, ePub ahead to print 21 June 2018, is available online at: https://doi.org/10.1093/ejo/cjy041.

\footnotetext{
*DDS, PhD Student at Malmö University and Center for Research and Development Uppsala University / Region Gävleborg, Senior Consultant Orthodontist at Public Dental Service Region Gävleborg, Gävle, Sweden. Corresponding author.

Contact: niels.ganzer@regiongavleborg.se

${ }^{\dagger}$ DDS, PhD, Senior Consultant Orthodontist at Public Dental Service Region Gävleborg, Senior Researcher at Center for Research and Development Uppsala University / Region Gävleborg, Gävle, Sweden

${ }^{\ddagger}$ DDS, PhD, Senior Consultant Orthodontist and Senior Researcher at Malmö University, Malmö, Sweden

${ }^{\S}$ DDS, PhD, Senior Consultant Orthodontist, Professor and Head of Department of Orthodontics, Malmö University, Malmö, Sweden
} 


\begin{abstract}

\section{Objective}

To analyse cost-effectiveness of anchorage reinforcement with buccal miniscrews and with molar blocks. We hypothesized that anchorage with miniscrews is more cost-effective than anchorage with molar blocks.
\end{abstract}

\title{
Trial design
}

A single-centre, two-arm parallel-group randomized controlled trial.

\section{Methods}

Adolescents (age 11-19 years) in need of treatment with fixed appliance, premolar extractions, and en masse retraction were recruited from one Public Dental Health specialist centre. The intervention arm received anchorage reinforcement with buccal miniscrews during space closure. The active comparator received anchorage reinforcement with molar blocks during levelling/alignment and space closure. The primary outcome measure was societal costs defined as the sum of direct and indirect costs. Randomization was conducted as simple randomization stratified on gender. The patients, caregivers, and outcome assessors were not blinded.

\section{Results}

Eighty patients were randomized into two groups. The trial is completed. All patients were included in the intention-to-treat analysis. The median societal costs for the miniscrew group were $€ 4681$ and for the molar block group were $€ 3609$. The median of the difference was $€ 825$ (95\% confidence interval (CI) 431-1267). This difference was mainly caused by significantly higher direct costs consisting of material and chair time costs. Differences in chair time costs were related to longer treatment duration. No serious harms were detected, one screw fractured during insertion and three screws were lost during treatment.

\section{Generalizability and limitations}

The monetary variables are calculated based on a number of local factors and assumptions and cannot necessarily be transferred to other countries. Variables such as chair time, number of appointments, and treatment duration are generalizable. Owing to the study protocol, the benefit of miniscrews as a stable anchorage has not been fully utilized.

\section{Conclusions}

When only moderate anchorage reinforcement is needed, miniscrews are less cost-effective than molar blocks. The initial hypothesis was rejected. Miniscrews provide better anchorage reinforcement at a higher price. They should be used in cases where anchorage loss cannot be accepted.

Trial registration

NCT02644811 


\section{Introduction}

In many countries, market analysts predict an increasing demand for orthodontic treatments. ${ }^{1}$ These analysts conclude that the reasons are demographic changes such as a growing middle class and the improved availability of orthodontic care. On the individual level, intensified attention on facial imperfections may contribute to the increased desire for orthodontic care. ${ }^{2}$ Being repeatedly reminded of the own malocclusion can impact daily life. ${ }^{3}$ Recently published systematic reviews conclude that malocclusions in the aesthetic zone diminish oral health-related quality of life. ${ }^{4,5}$ In countries with publicly funded health service systems, the increased demand for orthodontic treatment encounters limited resources and the need to reduce overall expenditure. ${ }^{6}$ Evidence based allocation of resources needs to take health economic evaluations into account. These evaluations should therefore include relevant comparators so that cost-effectiveness of both new and established treatments can be compared. ${ }^{7}$

About one third of the children and adolescents in industrial countries have a severe malocclusion where orthodontic treatment is needed. ${ }^{8,9}$ The most common malocclusions in the permanent dentition are crowding $(57.4-59.3 \%)$ and maxillary overjet $(25.9-38.63 \%) .{ }^{10,11}$ In these cases, extraction of the maxillary first premolars followed by en masse retraction of the maxillary anterior teeth is a well-established treatment concept. ${ }^{12}$ However, this concept often requires anchorage reinforcement. Anchorage can be reinforced with different techniques: A very convenient way to reinforce anchorage is to unite several teeth to an anchorage block. ${ }^{13}$ This technique relates on the assumption that every tooth has a certain anchorage value. ${ }^{14}$ In cases where the first premolars are extracted, the use of an anchorage block is particularly suitable because additional teeth such as the second molars can be added to the appliance. The molar block, tightly connects the second molar with the first molar and second premolar using a stainless steel ligature. The molar block is a dental, non-compliance anchorage system. It can be inserted within minutes and does not involve expensive material or dental work.

Besides this convenient way to reinforce anchorage, miniscrews as skeletal, non-compliance anchorage system has been claimed to be the ideal anchorage. ${ }^{15}$ Inserted by orthodontists, miniscrews can be loaded and used immediately. ${ }^{16,17}$ The failure rate is reported to be at acceptable $86.5 \%^{18}$ and the experience of pain and discomfort is reported to be comparable to other orthodontic procedures. ${ }^{19}$

A recent RCT has shown that miniscrews in comparison to molar blocks delivered significantly superior anchorage reinforcement during space closure (N. Ganzer, I. Feldmann and L. Bondemark, manuscript in preparation). However, these treatments should be assessed for both their clinical and economic outcomes with respect to their anchorage capacity.

To our knowledge, cost-effectiveness of these two techniques has not been evaluated before. In general, economic aspects of orthodontic treatments are a knowledge gap. ${ }^{20}$ To this end, this trial compares reinforced anchorage using miniscrews and molar blocks and relates the costs to the effects of the treatments. The aim of this economic evaluation is to answer the following question: Will the use of miniscrews as anchorage reinforcement in adolescents reduce treatment costs compared to molar blocks? We hypothesized that treatment with miniscrews would result in greater cost-effectiveness.

\section{Materials and Methods}

\section{Trial design, participants, eligibility, and setting}

This multi-purpose two-arm parallel group RCT with 1:1 allocation ratio has three objectives: to evaluate pain and discomfort during and after insertion of miniscrews; ${ }^{19}$ to compare the anchorage capacity between miniscrews and molar blocks in extraction cases treated with en masse retraction of maxillary anterior teeth (N. Ganzer, I. Feldmann and L. Bondemark, manuscript in preparation); to evaluate cost-effectiveness of reinforced anchorage using miniscrews and molar blocks.

The trial protocol was approved by the Uppsala University Regional Ethical Review Board (Dnr. 2009/188) following the Declaration of Helsinki. Participant recruitment was ceased when the planned sample size of 40 participants in each Group A and B was reached. All participants and their parents gave written informed consent before being enrolled in the trial.

All patients who declined to participate were offered orthodontic treatment with conventional anchorage using molar blocks. Data monitoring was provided by the principal investigator. No 
interim analyses for cost-effectiveness were done. There were no stopping guidelines.

This trial is completed and was registered at www.clinicaltrials.gov (NCT02644811).

Treatments were conducted at the Orthodontic Clinic in Gävle, Sweden. All treatments were conducted by N.G. and I.F.. The staff had several years of experience in the use of different skeletal anchorage systems. Patients eligible for participation were healthy adolescents, 11-19 years of age, referred to the Orthodontic clinic. Good oral hygiene was a prerequisite for the referral.

The treatment plan included treatment with fixed appliance, and extraction of the maxillary first or maxillary first and mandibular premolars. All participants had a fully erupted permanent dentition including the maxillary second molars. In addition, anchorage need was assessed in every individual case according to lack of space, molar- and canine relation, and maxillary incisor position. ${ }^{21}$ When anchorage need corresponded to approximately $75 \%$ of the extraction spaces needed for en masse retraction, the patient was considered eligible for participation.

The exclusion criteria were: Need for absolute anchorage, any kind of prior orthodontic treatment and need for orthognathic surgery.

\section{Interventions}

After premolar extractions, all patients were treated with a fixed appliance (Victory Series ${ }^{\mathrm{TM}}$ Stainless Steel Brackets, 0.022" slot size, 3M Unitek, Monrovia, CA, USA). The orthodontic treatment followed a straight wire concept according to $\mathrm{MBT}^{\mathrm{TM}}$ prescription. ${ }^{22}$ The recommended archwire sequence was 0.016" Nitinol HeatActivated, $0.019 \times 0.025$ " Nitinol Heat-Activated, and 0.019x0.025" Stainless steel (3M Unitek, Monrovia, CA, USA). The two arms differed in their anchorage reinforcement in the following ways:

- The intervention arm (Group A) had no additional anchorage during the levelling/alignment phase (Figure $1 \mathrm{~A}-1$ ). Anchorage reinforcement with buccal miniscrews (Spider Screw ${ }^{\circledR}$ K1, 1.5 mm diameter, 8-10 mm length, Health Development Company, Sarcedo, Italy) was inserted when the space closure phase was started. Miniscrews were inserted with a hand screw driver under local anaesthesia. Apical radiographs were taken before and after screw insertion. When the apical radiographs revealed root contact or root proximity, the miniscrew position was repositioned. Space closure was then conducted as en masse retraction with $150 \mathrm{~g}$ Nickel-Titanium (NiTi) closed coil springs (Ortho Technology, Tampa, Florida, USA) as immediately loaded direct anchorage (Figure 1 A-2).

- The active comparator arm (Group B) used anchorage reinforcement with molar blocks during the levelling/alignment and the space closure phase (Figure 1 B-1). When molar blocks were used, the second maxillary molar was added to the appliance and tightly connected with a stainless steel ligature to the first molar and second premolar. In theory, this block has a larger root surface providing increased resistance against unwanted tooth movement. Space closure was conducted as en masse retraction with $150 \mathrm{~g}$ active tiebacks (Figure 1 B-2).

Anchorage supplementation was discontinued once the canines were in Class I relation. Some cases still comprised a slight Class II relationship in their canines when spaces were closed. In these cases, miniscrews or molar blocks were removed and Class I relationship was established in the finishing phase.

In the finishing phase individual concepts were used for both groups: Class II elastics were used when appropriate and in some cases the anchorage had to be "burned" to close the remaining spaces and to settle the occlusion. All patients reached their treatment goal and no patient needed retreatment.

\section{Outcome \\ Orthodontic Outcome}

Data regarding anchorage capacity were published in an earlier study (N. Ganzer, I. Feldmann and L. Bondemark, manuscript in preparation). Anchorage capacity was defined as resistance against change in tooth position of the maxillary first molars during the different treatment phases. Change in tooth position was assessed using 3dimensional (3D) scans. Assessments were conducted blindly using the Raw-, Fine matching \& Deformation analysis superimposition (RFD). ${ }^{23}$

The results showed a mean loss of anchorage during levelling/alignment and space closure of about $1.5 \mathrm{~mm}$ for anchorage reinforcement with miniscrews and $3.8 \mathrm{~mm}$ for anchorage reinforcement 


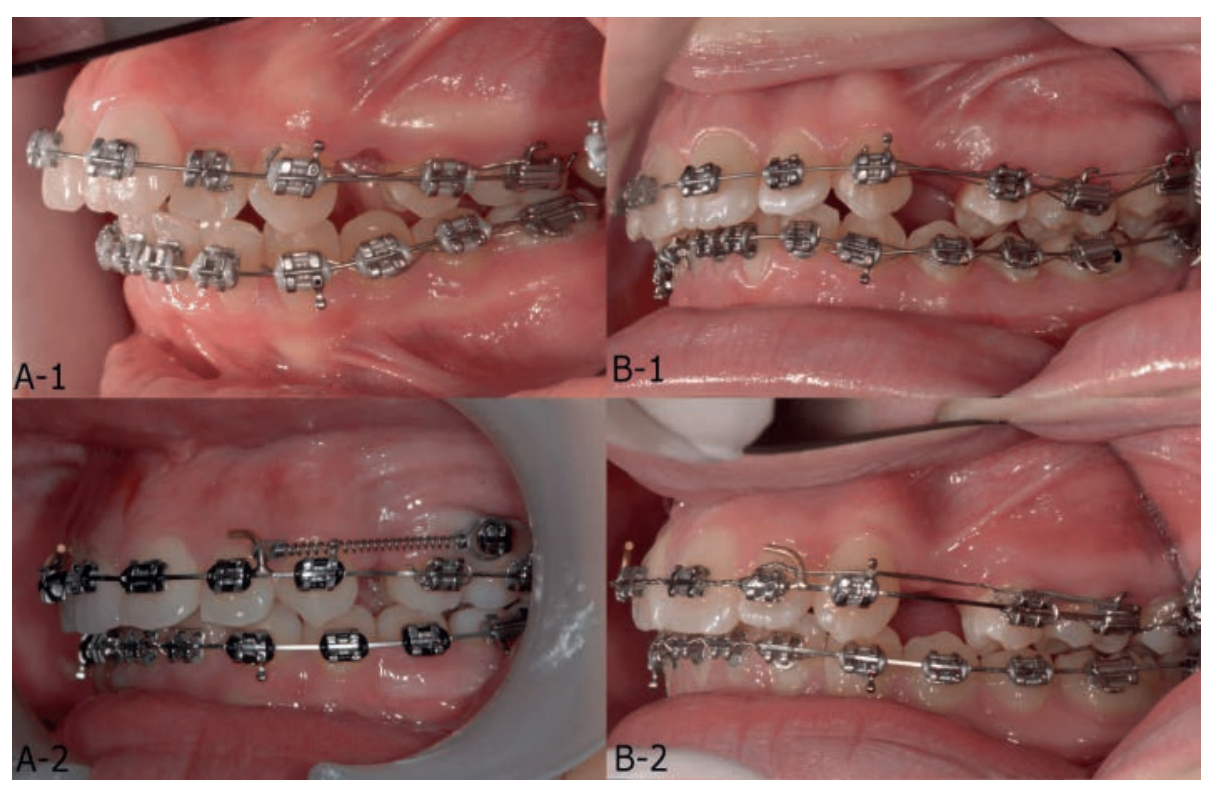

Figure 1: Interventions in groups A and B: 1 - during levelling and alignment, 2 - during space closure.

with molar blocks. The difference in anchorage loss occurred mainly during space closure and was statistically significant.

\section{Economic Outcome Societal costs}

The following variables were assessed for each appointment: the chair time, whether the patient was accompanied by an adult, and how the patient travelled to the orthodontic clinic. Travelling was subdivided as private motor vehicle, public transportation, and bicycle/walk.

The primary outcome measure was societal or total costs, which is the sum of the direct and indirect costs. Costs were calculated in Swedish Crowns (SEK) and then converted into Euros $(€)$. The mean exchange rate in 2016 was $€ 1.00=$ SEK 9.47 (Source: Swedish Riksbank).

\section{Direct costs}

Direct costs were subdivided into material costs for fixed appliance and costs for chair time. Material costs were calculated according to market prices. Costs for fixed appliance, plaster casts, and retention were approximately $€ 304$.
Additional costs for miniscrews, anaesthesia and apical radiographs were approximately $€ 233$. The detailed prices are presented in the supplementary Table 1.

Chair time costs were calculated based on the orthodontic clinic's annual expenses for the year 2016. Costs for dental work, brackets, archwires, and miniscrews were excluded from the annual expenses. Thus, chair time costs included all other materials, consumables, hires, dental equipment, cleaning, IT services, overhead costs, insurances, and the staffs' salary and payroll taxes including the receptionist and other personnel.

The sum of the annual expenses was then divided by the sum of treatment chair minutes that were scheduled in the year 2016. Thus, costs for chair time were estimated to $€ 197.25$ per hour. For each appointment, the chair time was assessed in minutes and was categorised as follows: scheduled appointment, emergency appointment, and missed appointment. Chair time was then summarized for every single patient. 


\section{Indirect costs}

Indirect costs were subdivided into loss of income and transportation costs. Calculation of loss of income and transportation costs was based on the distance between the patient's registered address and the orthodontic clinic. The distances and travel times by private motor vehicle were estimated using Google Maps. Transportation costs for private motor vehicle were based on the distance multiplied with the per-kilometre-cost according to the Swedish Tax Agency ( $€ 0.20$ per kilometres). Travel times and costs for public transportation were derived from the official timetable and price list (www.xtrafik.se). Travel times and costs for bicycle/walk were set to zero because this usually applied to patients who went to school near the orthodontic clinic.

Loss of income was then calculated for the time an adult accompanied a patient. This calculation was based on the assumption that the adults accompanying the patient took time off from work. The amount of time included the appointment and travel time. It was assumed that the parents of 15 and 16-year olds typically are between 40 and 49 years old. In 2016, the mean per hour income for 40 to 49-year olds living in Sweden was $€ 26.65$ (Source: Statistics Sweden, fiscal year 2016).

\section{Sample size calculation}

Because this is a multi-purpose trial, the sample size was calculated to give $90 \%$ power to evaluate anchorage capacity with a least difference of $1 \mathrm{~mm}$. The estimated sample size was 40 patients per group. This sample size included compensation for about $15 \%$ failures in miniscrews and further $10 \%$ dropouts due to patients moving from the area. (N. Ganzer, I. Feldmann and L. Bondemark, manuscript in preparation)

\section{Randomization}

An independent person from the Centre for Research and Development Uppsala University / Region Gävleborg generated a list with SPSS (SPSS inc. Released 2009. PASW Statistics for Windows Version 18.0. Chicago, Illinois, USA) using a simple randomization stratified for gender. Using this list, the independent person produced allocation notes in sealed opaque envelopes.

After researchers (N.G, I.F.) provided oral and written information about the study, informed con- sent was retrieved from the patients and parents and the patients were enrolled in the trial. These preliminaries concluded, the patient opened the envelope to reveal the intervention they were assigned: either miniscrews ("A", 40 participants) or molar blocks ("B", 40 participants).

\section{Blinding}

Due to the nature of the treatment, only assessment of anchorage loss could be blinded.

\section{Cost effectiveness analysis}

Because the anchorage capacity of miniscrews and molar blocks has been evaluated in an earlier study on this sample, societal costs can be related to increased anchorage capacity. In this way, the societal costs of the two treatments can be directly compared. ${ }^{24}$ When the effects of the alternative methods differ in magnitude, differences in both costs $(\Delta \mathrm{C})$ and effects $(\Delta \mathrm{E})$ can be evaluated with a cost-effectiveness analysis.

\section{Statistical methods}

The statistical analysis was conducted using the programming language $\mathrm{R}(\mathrm{v} 3.42) .{ }^{25}$ Arithmetic means, medians and standard deviations were calculated for numerical variables. The variables' distribution was analysed with histograms and Shapiro Wilk tests. Homogeneity of variance for all variables was confirmed with Levene's modified test. Mann-Whitney-Wilcoxon test was used to calculate $95 \%$ confidence intervals and to test differences between groups.

A P-value of less than $5 \%(\mathrm{P}<0.05)$ was regarded as statistically significant. All patients who were randomized to either Group A or Group $B$ were analysed on an intention-to-treat (ITT) basis. ${ }^{26,27}$ The missing values were set to the variables' mean value calculated from the per-protocol subsample.

\section{Results}

\section{Participant flow and baseline data}

In this trial, 98 patients satisfied the inclusion criteria and were invited to participate. Of these, eight boys and ten girls declined to participate (Figure 2). Recruitment was stopped when the RCT had reached its sample size goal. Thus, informed consent was collected from 80 participants 
and their parents before enrolment. Compared to the participants who entered the trial, the patients who declined to participate were not significantly different with respect to age or gender (mean age, 15.1 years; SD, 1.85).

Before treatment started, two participants from Group A were excluded from the trial because they refrained from orthodontic treatment. In addition, two patients from Group A were excluded after levelling and alignment because they did not require anchorage reinforcement or space closure. Another patient from Group A was excluded during space closure because one of the miniscrews was loose. Since this patient was pregnant, we decided not to reinstall the screw to avoid taking additional apical radiographs.

In Group B, one participant was excluded from the trial due to a pathological finding on preoperative radiographs, resulting in a changed treatment plan.

The RCT was ended after the last participant was debonded. The baseline demographic characteristics are presented in Table 1; the participant flow is presented in Figure 2.

Table 1: Baseline demographic data.

\begin{tabular}{lllll}
\hline \multirow{2}{*}{ Group / Sex } & \multicolumn{2}{c}{ Per protocoll } & \multicolumn{2}{c}{ Itention-to-treat } \\
\cline { 2 - 5 } & $\mathbf{N}$ & $\begin{array}{l}\text { Mean } \\
\text { age (SD) }\end{array}$ & N & $\begin{array}{l}\text { Mean } \\
\text { age (SD) }\end{array}$ \\
\hline A Female & 24 & $16.6(1.5)$ & 26 & $16.7(1.5)$ \\
A Male & 11 & $15.7(1.8)$ & 14 & $15.9(2.0)$ \\
A Total & 35 & $16.3(1.7)$ & 40 & $16.4(1.7)$ \\
\hline B Female & 26 & $14.9(1.9)$ & 26 & $14.9(1.9)$ \\
B Male & 13 & $15.1(1.9)$ & 14 & $15.1(1.8)$ \\
B Total & 39 & $15.0(1.9)$ & 40 & $15.0(1.8)$ \\
\hline
\end{tabular}

\section{Societal Costs - Direct and Indirect Costs}

Results concerning treatment costs are presented in Table 2, descriptive statistics are presented in supplementary Table 2 . There were statistical significantly higher Total/Societal costs for treatment with miniscrews compared to treatment with molar blocks (median of the difference between groups $€ 824.96 ; 95 \%$ CI $€ 430.80$ - 1267.28).

Further analysis showed no statistical significant difference in indirect costs for transportation or costs for adults accompanying the patient to the appointments. The differences in costs were largely related to the significant differences in direct costs:
Median of the difference was $€ 232.77$ for material costs and $€ 460.26$ for chair time costs.

\section{Number of Appointments, Duration, and Treatment Time}

Results concerning the number of appointments, appointment time, and treatment duration are presented in Table 2, descriptive statistics are presented in Supplementary Table 2. There was a statistical significant difference in the total number of appointments between the groups: Patients treated with miniscrews (Group A) had four more appointments than patients treated with molar blocks (Group B). There were no significant differences between groups concerning emergency appointments or missed appointments. Thus, the difference was caused by extra scheduled appointments.

Analysis of the different treatment phases' duration revealed that the difference in the number of scheduled appointments was caused by a 5.1 month longer finishing phase in the miniscrew group. In addition, analysis of the total chair time showed that patients in Group A (miniscrews) spent 140 minutes longer at the orthodontic clinic than patients in Group B (molar blocks).

\section{Cost-effectiveness Analysis}

The cost-effectiveness analysis put increased chair time, treatment duration, and societal cost in relation to avoided loss of anchorage in millimetres (Table 3). For every millimetre of avoided anchorage loss, the treatment duration increased by 2.5 months, the total appointment time increased by 61 minutes, and the societal costs increased by $€$ 358.68 .

The cost-effectiveness plane (CE plane, Figure 3) shows the incremental cost-effectiveness ratio (ICER) based on the difference in means for anchorage loss and societal costs. The $95 \%$ confidence intervals are represented by the confidence box a-b-c-d and the confidence ellipse.

\section{Side effects}

During this trial, 72 miniscrews were inserted. Three of these miniscrews became loose during the space closure phase. Only one of these miniscrews was replaced since further anchorage reinforcement was necessary. In addition, one miniscrew fractured during insertion. The fragment was initially left in place but could be removed later on. 


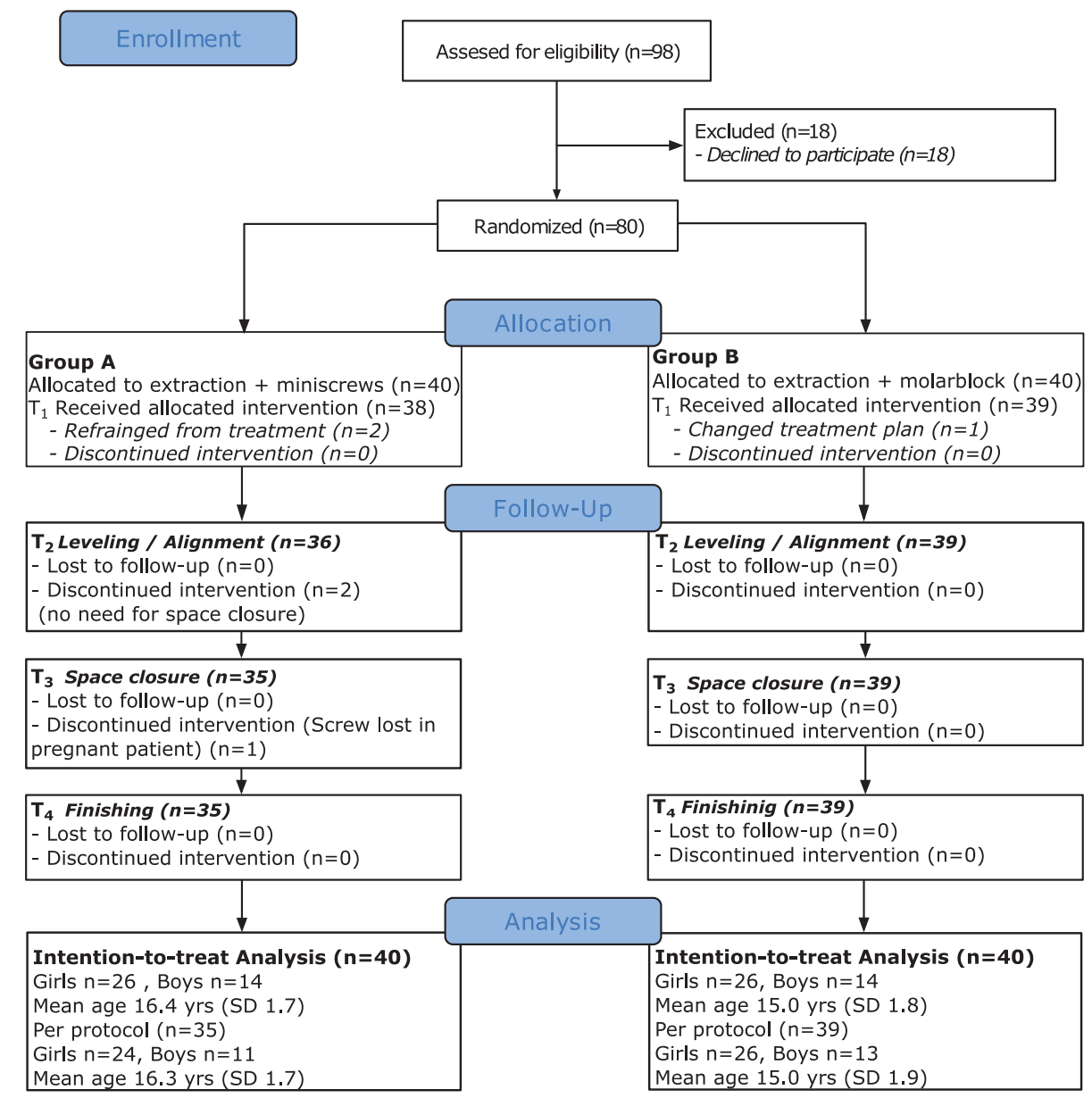

Figure 2: CONSORT flow diagram. 


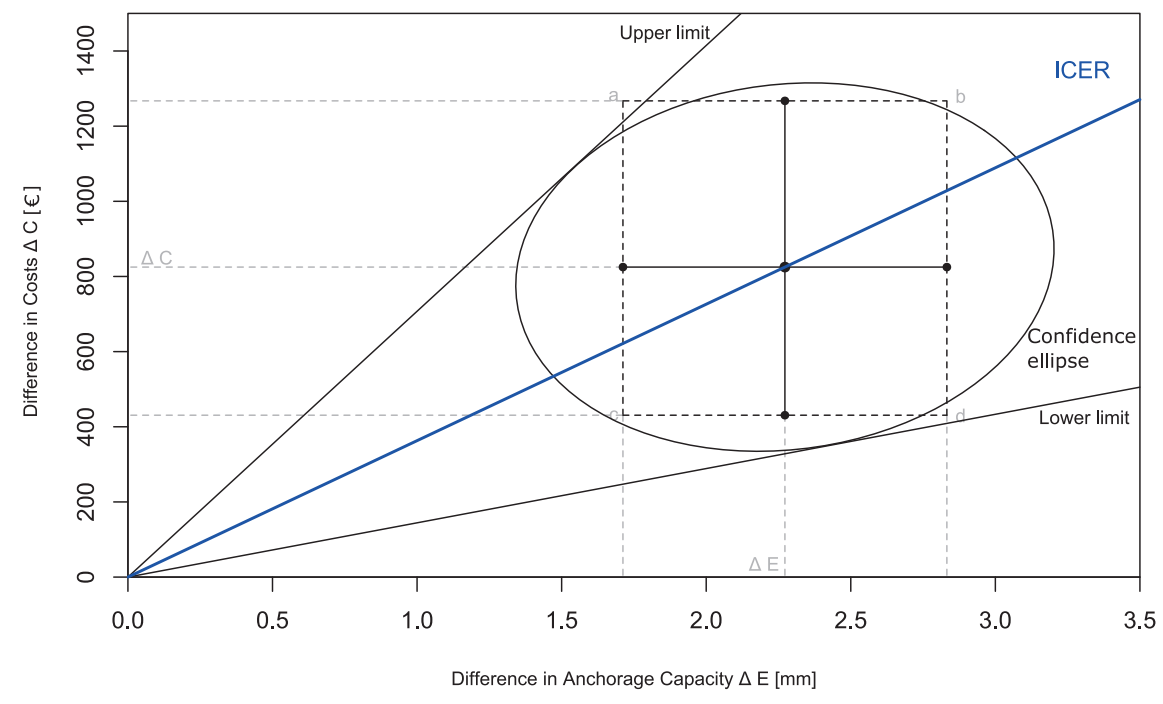

Figure 3: Cost-effectiveness plane showing the incremental cost-effectiveness ratio (ICER).

Table 2: Analytical statistics concerning visits, treatment duration, treatment time and costs.

\begin{tabular}{|c|c|c|c|c|c|}
\hline & \multirow{2}{*}{$\begin{array}{r}\text { Group A } \\
(\mathrm{N}=40) \\
\text { Median }\end{array}$} & \multirow{2}{*}{$\begin{array}{r}\text { Group B } \\
(\mathrm{N}=40) \\
\text { Median }\end{array}$} & \multicolumn{3}{|c|}{ Difference between groups } \\
\hline & & & Median* & $95 \% \mathrm{CI}$ & $\mathbf{P}$ \\
\hline Visits [number] & 22.5 & 18.0 & 4.0 & $2.0-6.0$ & $<0.001$ \\
\hline - Scheduled & 20.0 & 16.0 & 4.0 & $2.0-5.0$ & $<0.001$ \\
\hline - Emergency & 2.0 & 2.0 & 0.0 & $-0.4-1.0$ & 0.404 \\
\hline - Missed & 0.5 & 0.0 & 0.0 & $0.0-0.5$ & 0.171 \\
\hline Treatment duration [months] & 28.4 & 21.1 & 5.8 & $3.6-8.5$ & $<0.001$ \\
\hline - Leveling \& Alignment & 10.2 & 9.0 & 1.2 & $0.0-2.5$ & 0.054 \\
\hline - Space closure & 7.7 & 7.8 & -0.7 & $-2.5-1.0$ & 0.425 \\
\hline - Finishing & 9.2 & 3.8 & 5.1 & $3.2-6.3$ & $<0.001$ \\
\hline Treatment time [min] & 3314 & 2325 & 835 & $295-1335$ & 0.003 \\
\hline - Chair time & 968 & 825 & 140 & $90-200$ & $<0.001$ \\
\hline - Travel time & 2314 & 1455 & 646 & $126-1138$ & 0.010 \\
\hline Direct costs [€] & 3717.39 & 3016.14 & 693.03 & $528.65-890.75$ & $<0.001$ \\
\hline - Material & $536.66^{* *}$ & $303.89^{* *}$ & $232.77^{* *}$ & —** & —** \\
\hline - Chair time & 3180.73 & 2712.25 & 460.26 & $295.88-657.98$ & $<0.001$ \\
\hline Indirect Costs $[€]$ & 641.89 & 574.28 & 36.88 & $-157.54-413.68$ & 0.668 \\
\hline - Transportation & 372.67 & 119.56 & 27.66 & $0.00-318.55$ & 0.251 \\
\hline - Parents' time & 163.25 & 140.81 & 0.00 & $-119.94-86.62$ & 0.770 \\
\hline Societal costs $[€]$ & 4680.76 & 3609.39 & 824.96 & $430.80-1267.28$ & $<0.001$ \\
\hline
\end{tabular}

* Median of the difference

** Material costs based on the cost-template presented in Supplementary Table 1 
Table 3: Cost-effectivness analysis of intention-to-treat data.

\begin{tabular}{llll}
\hline & Group A & Group B & Difference A-B \\
\hline $\mathrm{N}$ & 40 & 40 & - \\
Mean anchorage capacity & $-1.5 \mathrm{~mm}$ & $-3.8 \mathrm{~mm}$ & $2.3 \mathrm{~mm}$ \\
Median treatment duration & $28.4 \mathrm{months}$ & $21.2 \mathrm{months}$ & $5.8 \mathrm{months}$ \\
Median summarized chair time & $968 \mathrm{~min}$ & $825 \mathrm{~min}$ & $140 \mathrm{~min}^{*}$ \\
Median societal costs & $€ 4680.76$ & $€ 3609.39$ & $€ 824.96^{*}$ \\
\hline Treatment time per millimeter avoided anchorage loss & & $+2.5 \mathrm{months}$ \\
Visit duration per millimeter avoided anchorage loss & & $+61 \mathrm{~min} / \mathrm{mm}$ \\
Costs per millimeter avoided anchorage loss & & $€+358.68 / \mathrm{mm}$ \\
\hline * Median of the difference & & &
\end{tabular}

\section{Discussion}

\section{Interpretation}

This trial showed that reinforcement of anchorage with miniscrews resulted in total/societal costs significantly higher than reinforcement of anchorage with molar blocks. The difference was approximately $€ 825$ and the main reason was increased treatment duration that in turn caused an increased number of appointments and accordingly increased chair time. Thus, anchorage reinforcement with miniscrews does not result in more cost-effective treatments in cases with moderate anchorage need, and our initial hypothesis had to be rejected.

Since the capacity of anchorage reinforcements was analysed in an earlier study, we know that cases treated with miniscrews (Group A) had a mean anchorage loss of about $1.5 \mathrm{~mm}$. In contrast, cases treated with molar blocks (Group B) showed a mean anchorage loss of about $3.8 \mathrm{~mm}$, implying reciprocal space closure when molar blocks are used (N. Ganzer, I. Feldmann and L. Bondemark, manuscript in preparation). Consequently, there was no need for additional mesial movement of the molars in Group B during the finishing phase, but most cases in Group A needed additional mesial movement of the maxillary molars during finishing due to the good anchorage capacity provided by the miniscrews. Therefore, space closure in Group A followed a two-step pattern: First retraction of the frontal teeth, then mesialisation of the molars. A prolonged finishing phase in Group A was also the main reason for increased treatment time and higher costs. Thus, our results show that anchorage reinforcement with miniscrews cannot be used to make a standard treatment with moderate need of anchorage reinforcement more cost effective. This is in contrast to findings from an earlier study reporting shorter treatment duration for en masse retraction with skeletal anchorage compared to conventional anchorage. ${ }^{28}$ If our results from the miniscrew group (22.5 appointments, 28.4 months treatment duration) are compared to the treatment of maximum anchorage cases reported in a recent RCT (19.84 appointments, 27.42 months treatment duration), ${ }^{29}$ values for treatment duration and number of appointments are comparable. The cause for this lies in the fact that space closure in both concepts has a unilateral character. This implies that whenever anchorage needs to be reinforced, one has to expect longer treatment duration.

It is noteworthy that differences in costs between the groups are mainly related to increased direct costs. There are no statistical significant differences in indirect costs. This difference is likely related to two factors: Teenagers, except for the initial appointments, usually are not accompanied by an adult. Transportation costs in the end of treatment were generally low because most participants went to secondary schools within walking distance to the orthodontic clinic. Thus, a few more appointments have only little influence on the indirect costs. Indirect costs represent less than $25 \%$ of the societal costs. Studies on younger participants, being more frequently accompanied by their parents, reported indirect costs of about $40 \%$ of the societal costs. ${ }^{30}$

According to Drummond ${ }^{24}$, the most important question is the opportunity cost of a new treatment. Our trial reveals that five patients treated with fixed appliance and miniscrews take as much resources as six patients treated with fixed appliance and conventional anchorage. In publicly funded healthcare systems with a per capita compensation irrespective of type of treatment, chair time is the limiting factor. This means that using miniscrews for standard cases would reduce the total number of conducted treatments by $16 \%$ (one of six cases). 
Societal costs for treatment with miniscrews would have been even higher if the success rate had been $86.5 \%$ as it was recently published in a systematic review. ${ }^{18}$ The difference between the success rate in this trial (96\%) and the systematic review might be a result from the heterogeneity of data since reviews mix data from different screw types, insertion sites and treatment concepts.

In many economic analyses the Willingness-topay (WTP) is introduced as a cost below which a treatment definitely will be paid for. In order to answer the question when the additional costs of miniscrews can be justified, one has to define the willingness-to-accept-anchorage-loss instead. There are cases that cannot be treated without maximum anchorage reinforcement. In these cases, the extra costs are absolutely justified. But still, with maximum anchorage, space closure is mainly conducted in a unilateral manner and will therefore take longer time than reciprocal space closure.

The intention of this trial was to find out whether patients with different need for anchorage would benefit from the use of miniscrews. If we had used a maximum anchorage sample we could not have used molar block as control group. Instead we would have to compare two different types of skeletal anchorage. Results from a trial like that can only show whether screws are equivalent or not. At the same time, one would never know how these findings would relate to treatments with conventional anchorage. Consequently, our findings do not imply that miniscrews should not be used Instead it implies when miniscrews are needed they provide good anchorage reinforcement. This extra feature causes extra costs.

\section{Limitations}

One limitation of this trial is that both groups followed the same study protocol with identical appointment intervals. With all facts in hand, one could argue that the results give a too negative picture of miniscrews cost-effectiveness. Patients treated with miniscrews and NiTi coil springs could have been treated with longer intervals between the appointments or anchorage reinforcement could have been removed earlier. Longer intervals could possibly have compensated for the higher material costs in Group A compared to the cheaper tiebacks in Group B. However, the treatment phases needed to be defined properly in order to standardise the treatments.

The patients who declined to participate were not urged to motivate their decision. However, one could speculate that anxiety played a roll. This can be considered a source of bias since anxiety can have impact on the extent to which patients were accompanied by an adult.

\section{Generalisability}

When the generalisability of this trial is assessed one has to keep in mind that this is a single centre $\mathrm{RCT}$, carried out on a regional scale. In particular monetary variables cannot be completely transferred to other clinics. Because monetary variables are influenced by local factors such as the insurance system, rental costs, and staff salaries, every clinic has its own per hour chair time price.

But then, a number of measures were taken to improve generalisability: In this trial we used a reversed approach to calculate the chair time costs. This reversed approach used the real expenses for the clinic derived from the balancing of the books and it included every item needed to run a clinic. Therefore, this trial is more realistic in calculation of chair time costs.

Furthermore, the participants' mean age of 15-16 years and the gender distribution of $65 \%$ girls and $35 \%$ boys make this sample comparable to populations found in orthodontic clinics in industrial countries.

The design as a randomized controlled trial using an intention-to-treat analysis further reduces risk for bias. Consequently, the non-monetary measures such as chair time, number of appointments and treatment duration are considered generalizable.

\section{Conclusions}

Compared to molar blocks, miniscrews provide better anchorage reinforcement but at a higher price. In cases with moderate need for anchorage reinforcement, the use of anchorage reinforcement with miniscrews is not cost-effective. Consequently, our results show that miniscrews cannot be used to make a standard treatment more cost-effective.

Instead, miniscrews can be recommended for treatments where anchorage loss cannot be accepted.

\section{Funding \& conflict of interest}

All authors have filled in the ICMJE form for Disclosure of potential conflict of interest and declare 
the following: Dr. Ganzer reports grants and nonfinancial support from the Centre for Research and Development, Uppsala University/Region Gävleborg, Sweden and grants from the Swedish Dental Associations Scientific Funds.

Dr. Feldmann reports grants from Thuréus Foundation for the Promotion of Dental Science, Uppsala University, Sweden during the conduct of the trial. We have no other conflicts of interest to declare.

\section{Acknowledgements}

We thank all patients and their parents for participating in this trial. We also thank Dr. Sara Gustavsson from the Centre for Research and Development, Uppsala University/Region Gävleborg for her assistance with the statistical evaluation.

\section{References}

1. Rohan M. Orthodontic Supplies Market worth 4.71 Billion USD by 2021. MarketsandMarkets Research Private Ltd.; 2016. Available from: http: //www . marketsandmarkets . com/ PressReleases/orthodontic-supplies. asp.

2. Newton JT, Minhas G. Exposure to 'ideal' facial images reduces facial satisfaction: an experimental study. Community Dent Oral Epidemiol. 2005;33(6):410-418.

3. Bayat JT, Hallberg U, Lindblad F, Huggare J, Mohlin B. Daily life impact of malocclusion in Swedish adolescents: a grounded theory study. Acta Odontol Scand. 2013;71(3-4):792-798.

4. Dimberg L, Arnrup K, Bondemark L. The impact of malocclusion on the quality of life among children and adolescents: a systematic review of quantitative studies. Eur J Orthod. 2015;37(3):238-247.

5. Kragt L, Dhamo B, Wolvius EB, Ongkosuwito EM. The impact of malocclusions on oral health-related quality of life in children-a systematic review and meta-analysis. Clin Oral Investig. 2016;20(8):1881-1894.

6. Price J, Whittaker W, Birch S, Brocklehurst $\mathrm{P}$, Tickle M. Socioeconomic disparities in or- thodontic treatment outcomes and expenditure on orthodontics in England's state-funded National Health Service: a retrospective observational study. BMC oral health. 2017;17(1):1.

7. Tordrup D, Chouaid C, Cuijpers P, Dab W, van Dongen JM, Espin J, et al. Priorities for Health Economic Methodological Research: Results of an Expert Consultation. Int J Technol Assess Health Care. 2017;p. 1-11.

8. Steinmassl O, Steinmassl PA, Schwarz A, Crismani A. Orthodontic Treatment Need of Austrian Schoolchildren in the Mixed Dentition Stage. Swiss Dent J. 2017;127(2):122-128.

9. Shaw WC, Richmond S, O'Brien KD. The use of occlusal indices: a European perspective. Am J Orthod Dentofacial Orthop. 1995;107(1):1-10.

10. Thilander B, Pena L, Infante C, Parada SS, de Mayorga C. Prevalence of malocclusion and orthodontic treatment need in children and adolescents in Bogota, Colombia. An epidemiological study related to different stages of dental development. Eur J Orthod. 2001;23(2):153-167.

11. Kaur H, Pavithra US, Abraham R. Prevalence of malocclusion among adolescents in South Indian population. J Int Soc Prev Community Dent. 2013;3(2):97-102.

12. Rizk MZ, Mohammed H, Ismael O, Bearn DR. Effectiveness of en masse versus twostep retraction: a systematic review and metaanalysis. Prog Orthod. 2018;18(1):7.

13. Proffit WR, Fields HW, Sarver DM. Chapter $8-\hat{A}$ The Biologic Basis of Orthodontic Therapy. In: Contemporary Orthodontics. 5th ed. Elsevier Mosby; 2013. p. 297.

14. Graber TM, Vanarsdall RL, Vig KW. Bone Physiology, Metabolism, and Biomechanics in Orthodontic Practice. In: Orthodontics - Current Principles \& Techniques. 6th ed. St. Louis, Missouri, USA: Elsevier Mosby; 2017. p. 131.

15. Maino BG, Maino G, Mura P. Spider Screw: skeletal anchorage system. Prog Orthod. 2005;6(1):70-81. 
16. Migliorati M, Drago S, Gallo F, Amorfini L, Dalessandri D, Calzolari C, et al. Immediate versus delayed loading: comparison of primary stability loss after miniscrew placement in orthodontic patients-a single-centre blinded randomized clinical trial. Eur J Orthod. 2016;38(6):652-659.

17. Melsen B, Costa A. Immediate loading of implants used for orthodontic anchorage. Clin Orthod Res. 2000;3(1):23-28.

18. Alharbi F, Almuzian M, Bearn D. Miniscrews failure rate in orthodontics: systematic review and meta-analysis. Eur J Orthod. 2018;.

19. Ganzer N, Feldmann I, Bondemark L. Pain and discomfort following insertion of miniscrews and premolar extractions: A randomized controlled trial. Angle Orthod. 2016;86(6):891-899.

20. Sollenius O, Petrén S, Björnsson L, Norlund A, Bondemark L. Health economic evaluations in orthodontics: a systematic review. Eur J Orthod. 2016;38(3):259-265.

21. McLaughlin RP, Bennett JC. The dental VTO: an analysis of orthodontic tooth movement. J Clin Orthod. 1999;33(7):394-403.

22. McLaughlin RP, Bennett JC, Trevisi H. Systemized Orthodontic Treatment Mechanics. 2nd ed. Mosby; 2001.

23. Ganzer N, Feldmann I, Liv P, Bondemark L. A novel method for superimposition and measurements on maxillary digital 3D modelsstudies on validity and reliability. Eur J Orthod. 2018;40(1):45-51.

24. Drummond MF, Sculpher MJ, Claxton K, Stoddart GL, Torrance GW. Methods for the Economic Evaluation of Health Care Programmes. 4th ed. Oxford: Oxford University Press; 2015.
25. Team RC. Team RC, editor. R: A Language and Environment for Statistical Computing. Vienna, Austria: R Foundation for Statistical Computing; 2018. Available at: www.Rproject.org.

26. Fisher LD, Dixon DO, Herson J, Frankowski RK, Hearron MS, Peace KE. In: Peace KE, editor. Intention to treat in clinical trials. Statistical issues in drug research and development. New York: Marcel Dekker; 1990. p. 331-350.

27. Bondemark L, Abdulraheem S. Intention to treat (ITT) analysis as reported in orthodontic randomized controlled trials-evaluations of methodology and recommendations for the accurate use of ITT analysis and handling dropouts. Eur J Orthod. 2017;First published on Oct 21, 2017, 10.1093/ejo/cjx084.

28. Al-Sibaie S, Hajeer MY. Assessment of changes following en-masse retraction with mini-implants anchorage compared to two-step retraction with conventional anchorage in patients with class II division 1 malocclusion: a randomized controlled trial. Eur J Orthod. 2014;36(3):275-283.

29. Sandler J, Murray A, Thiruvenkatachari B, Gutierrez R, Speight P, O'Brien K. Effectiveness of 3 methods of anchorage reinforcement for maximum anchorage in adolescents: A 3-arm multicenter randomized clinical trial. Am J Orthod Dentofacial Orthop. 2014;146(1):10-20.

30. Wiedel AP, Norlund A, Petrén S, Bondemark L. A cost minimization analysis of early correction of anterior crossbite-a randomized controlled trial. Eur J Orthod. 2016;38(2):140-145. 


\section{Supplementary material}

Supplementary Table 1: Direct costs template - material per patient for Group A and B.

\begin{tabular}{|c|c|c|c|c|c|}
\hline \multirow[t]{2}{*}{ Product } & \multirow{2}{*}{$\begin{array}{r}\text { Net price } \\
{[€]}\end{array}$} & \multicolumn{2}{|c|}{ Group A } & \multicolumn{2}{|c|}{ Group B } \\
\hline & & Qty & Price $[€]$ & Qty & Price $[€]$ \\
\hline Pair of plaster casts & 41.71 & 1 & 41.71 & 1 & 41.71 \\
\hline Bracket, 3M Victory & 4.75 & 12 & 57.00 & 12 & 57.00 \\
\hline Bracket with hook, 3M Victory & 5.15 & 4 & 20.60 & 4 & 20.60 \\
\hline Molar tube, Victory Series & 6.60 & 4 & 26.40 & 4 & 26.40 \\
\hline NiTi closed coil spring & 7.87 & 2 & 19.66 & 0 & 0.00 \\
\hline Stainless steel ligature & 0.13 & 0 & 0.00 & 2 & 0.26 \\
\hline $.016 " \mathrm{HANT}$ & 4.30 & 2 & 8.60 & 2 & 8.60 \\
\hline $.019 " x .025 "$ HANT & 4.30 & 2 & 8.60 & 2 & 8.60 \\
\hline $.019 " \times .025 "$ Resilient posted & 5.68 & 2 & 11.36 & 2 & 11.36 \\
\hline Spider Screw K1 SCR-1508 & 73.26 & 2 & 146.52 & 0 & 0.00 \\
\hline Apical radiographs & 39.60 & 2 & 79.20 & 0 & 0.00 \\
\hline SOPIRA Carpule 30G & 0.64 & 1 & 0.64 & 0 & 0.00 \\
\hline Xylocaine w. adrenaline $1.8 \mathrm{ml}$ & 0.21 & 1 & 0.21 & 0 & 0.00 \\
\hline Essix splint $\mathrm{C}$ & 58.08 & 2 & 116.16 & 2 & 116.16 \\
\hline Sum & & & 536.66 & & 303.89 \\
\hline
\end{tabular}

Supplementary Table 2: Descriptive statistics (ITT) of appointments, treatment duration and -time and treatment costs.

\begin{tabular}{lrrr}
\hline & $\begin{array}{r}\text { Group A } \\
(\mathrm{N}=40) \\
\text { Mean (SD) }\end{array}$ & $\begin{array}{r}\text { Group B } \\
(\mathrm{N}=40) \\
\text { Mean (SD) }\end{array}$ & $\begin{array}{r}\text { Difference } \\
\text { A - B } \\
\text { Mean }\end{array}$ \\
\hline Appointment [number] & $23.4(6.4)$ & $19.2(5.0)$ & 4.2 \\
- Scheduled & $20.2(4.8)$ & $16.3(3.5)$ & 3.9 \\
- Emergency & $2.6(2.5)$ & $2.3(2.4)$ & 0.3 \\
- Missed & $0.7(1.0)$ & $0.5(1.1)$ & 0.2 \\
\hline Treatment duration [months] & $28.4(7.5)$ & $22.3(4.9)$ & 6.1 \\
- Leveling / alignment & $10.5(2.7)$ & $9.3(2.8)$ & -0.4 \\
- Space closure & $8.5(5.2)$ & $8.9(3.8)$ & 5.1 \\
- Finishing & $9.2(5.3)$ & $4.1(3.9)$ & 916 \\
\hline Treatment time [min] & $3429(1574)$ & $2513(1211)$ & 164 \\
- Chair time & $1005(214)$ & $841(140)$ & 752 \\
- Travel time & $2424(214)$ & $1672(149)$ & 752.64 \\
\hline Direct costs [€] & $3841.14(702.28)$ & $3068.83(460.43)$ & 232.77 \\
- Material & $536.66^{*}$ & $303.89^{*}$ & 539.54 \\
- Chair time & $3304.48(702.28)$ & $2764.94(460.43)$ & 138.85 \\
\hline Indirect costs [€] & $839.62(797.25)$ & $700.77(632.53)$ & 134.95 \\
- Transportation & $475.30(579.66)$ & $340.35(441.38)$ & 3.90 \\
- Parent's time & $364.32(504.01)$ & $360.42(403.86)$ & 911.16 \\
\hline Societal costs [€] & $4680.76(1024.11)$ & $3769.60(745.52)$ &
\end{tabular}



isbn 978-91-7104-931-5 (print) isbn 978-91-7104-932-2 (pdf) 